\title{
Assessment of Groundwater Challenges \& Opportunities in Support of Sustainable Development in Sub-Saharan Africa
}

Practice Manager: Task Team Leader:
Steven Schonberger

Marcus Wijnen 


\section{Acronyms / Abbreviations}

\begin{tabular}{|c|c|}
\hline ACE & African Center of Excellence \\
\hline AfDB & African Development Bank \\
\hline ASA & Advisory Services \& Analytics \\
\hline BGR & $\begin{array}{l}\text { German Federal Institute for Geosciences and Natural Resources } \\
\text { (Bundesanstalt für Geowissenschaften und Rohstoffe') }\end{array}$ \\
\hline BGS & British Geological Survey \\
\hline BRGM & $\begin{array}{l}\text { French Geological Survey (Bureau de Recherches Géologiques et } \\
\text { Minières) }\end{array}$ \\
\hline CGIAR & Consultative Group on International Agricultural Research \\
\hline ECA & United Nations Economic Commission on Africa \\
\hline FAO & Food \& Agricultural Organization \\
\hline GDP & Gross Domestic Product \\
\hline GP & Global Practice \\
\hline GWSP & Global Water Security \& Sanitation Partnership \\
\hline IBRD & International Bank for Reconstruction \& Development \\
\hline ICR & Implementation Completion Report \\
\hline IDA & International Development Association \\
\hline IEG & Independent Evaluation Group \\
\hline IFAD & International Fund for Agricultural Development \\
\hline IFPRI & International Food Policy Research Institute \\
\hline IGAD & Intergovernmental Authority on Development \\
\hline IPCC & Intergovernmental Panel on Climate Change \\
\hline IWMI & International Water Management Institute \\
\hline IWRM & Integrated Water Resources Management \\
\hline JMP & Joint Monitoring Program \\
\hline MAR & Managed Aquifer Recharge \\
\hline MDG & Millennium Development Goal \\
\hline mha & million hectares \\
\hline O\&M & Operations \& Maintenance \\
\hline PAD & Project Appraisal Document \\
\hline SADC & Southern Africa Development Community \\
\hline SDG & Sustainable Development Goal \\
\hline SSA & Sub-Saharan Africa \\
\hline STEM & Science, Technology, Engineering \& Mathematics \\
\hline UN & United Nations \\
\hline UNDP & United Nations Development Program \\
\hline UNEP & United Nations Environment Program \\
\hline WASH & Water, Sanitation and Hygiene \\
\hline WSS & Water Supply \& Sanitation \\
\hline WWF & World Wildlife Fund \\
\hline
\end{tabular}


(C) 2018 The World Bank

1818 H Street NW

Washington DC 20433

Telephone: 202-473-1000

Internet: $\underline{\text { www.worldbank.org }}$

\section{Acknowledgements}

This report was prepared by a team coordinated by Marcus Wijnen (Senior Water Resources Management Specialist, Water Global Practice) of the World Bank Group. The team comprised Marcus Wijnen, Shawki Barghouti (Consultant), Jude Cobbing (Consultant), Bradley Hiller (Consultant) and Raphael Torquebiau (Consultant). The team is grateful to Natalia Limones (Consultant) for technical support on hydro-meteorological assessments.

The report was produced under the overall guidance of Jennifer Sara (Director, Water Global Practice) and Steven Schonberger (Practice Manager, Water Global Practice - Western Africa).

The quality of the report greatly benefitted from the comments and suggestions of the peer reviewers Tushar Shah (International Water Management Institute -IWMI), Zablon Adane (World Resources Institute - WRI), Xiaokai Li (Lead Water Resources Management Specialist, GWA01), Kirstin Conti (Natural Resources Specialist, GGOAS) and Matheus Van Ledden (Senior Disaster Risk Management Specialist, GFDRR). The team is grateful for feedback received during the development of the report from Thomas O'Brian (Senior Advisor, AFRVP), Vijay Pillai (Advisor, AFRVP), Richard Damania (Lead Economist, Water Global Practice) and Bill Kingdom (Lead Water \& Sanitation Specialist, Water Global Practice).

This work was made possible by the financial contribution of the Africa Window of the Water Partnership Program (WPP) - http://water.worldbank.org/water/wpp.

\section{Disclaimer}

The experts and peer reviewers participated in their personal capacity and the findings, interpretations, and conclusions expressed in this work do not necessarily reflect the views of the Institutions and Organizations, The World Bank, its Board of Executive Directors or the governments they represent.

The World Bank does not guarantee the accuracy of the data included in this work. The boundaries, colors, denominations, and other information shown on any map in this work do not imply any judgment on the part of The World Bank concerning the legal status of any territory or the endorsement or acceptance of such boundaries. 


\section{Contents}

Executive Summary

Scope

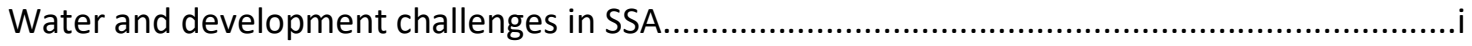

A strategy on groundwater in Sub-Saharan Africa ...................................................................

Priority groundwater actions for the World Bank ................................................................ii

Macroeconomic development through irrigated agriculture ............................................vii

Urban and rural water security .......................................................................................ii

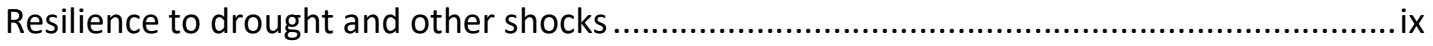

Analytical and operational guidance to identify priority countries .....................................ix

Technical Assistance Activities for Immediate Follow-on from this Study ................................

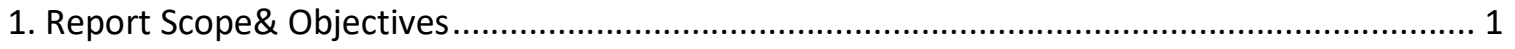

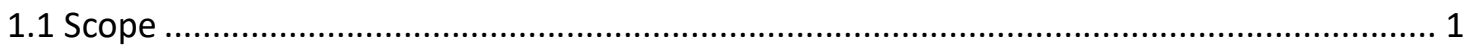

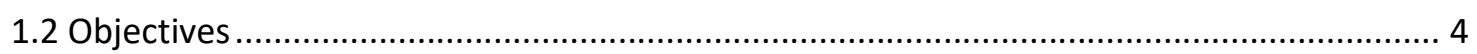

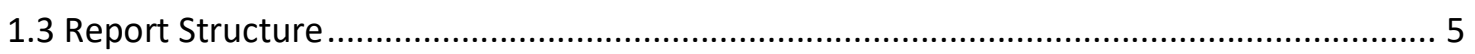

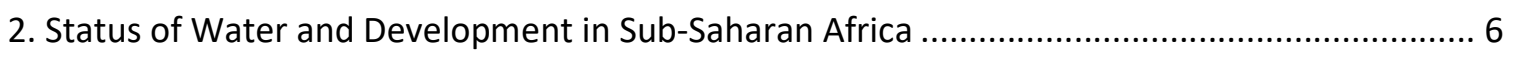

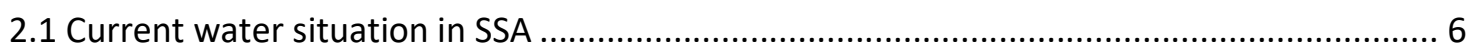

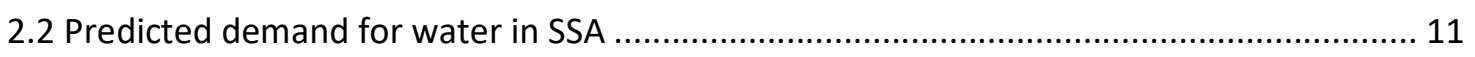

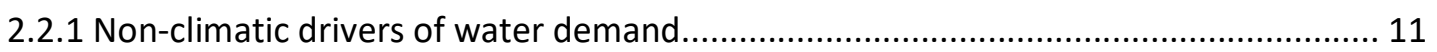

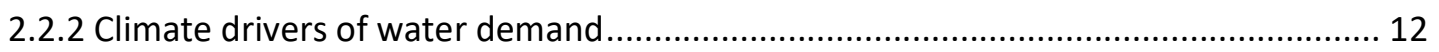

2.2.3 Overarching global agreements to help address water-development challenges ...... 13

2.3 Comparative utilization of surface water and shallow and deep groundwater in SSA ....... 14

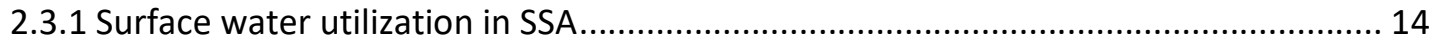

2.3.2 Deep and shallow groundwater: utilization in SSA ................................................ 15

2.3.3 Conjunctive use of surface and groundwater resources in SSA? ............................... 18

2.4 What potential roles for groundwater development? ..................................................... 18

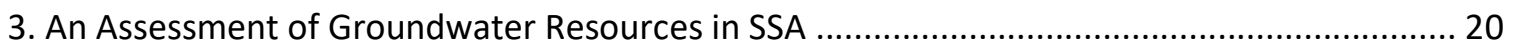

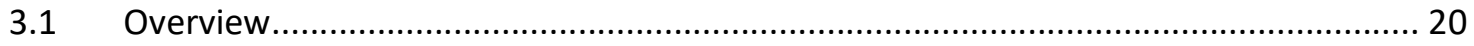

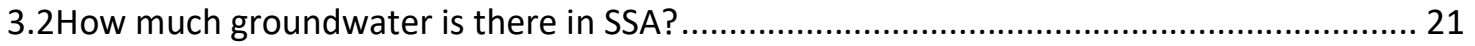

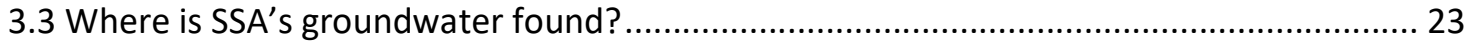

3.4 How much groundwater is available for irrigation and other socioeconomic development

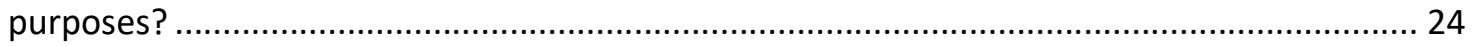

3.5Will groundwater abstraction impact the environment? ................................................ 27

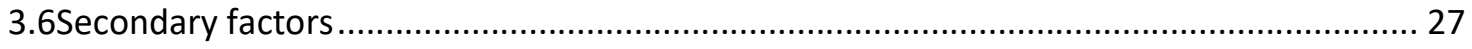

4. Key Benefits and Challenges for Groundwater Investment in SSA ...................................... 29 


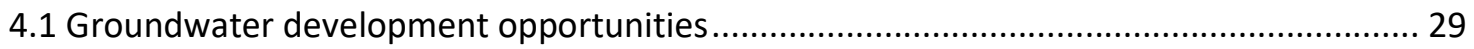

4.1.1 Macroeconomic development through irrigated agriculture .................................... 29

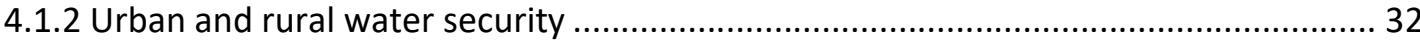

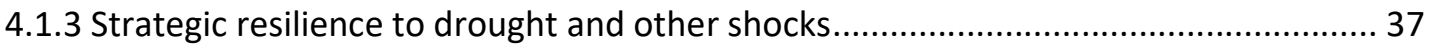

4.2 Support to shallow groundwater development \& integrating non-conventional water

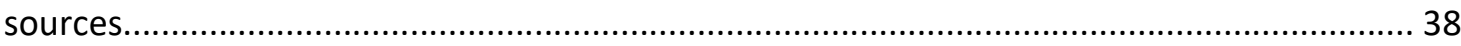

4.2.1 Securing livelihoods of smallholder farmers and pastoralists................................... 38

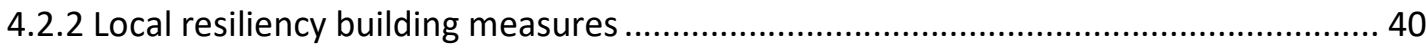

4.3 Challenges and caveats to groundwater development - potential risks and tradeoffs ..... 41

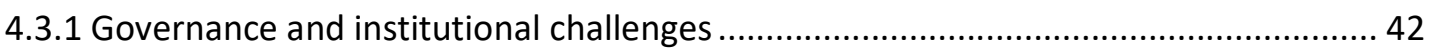

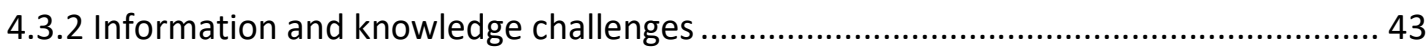

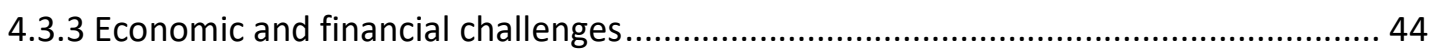

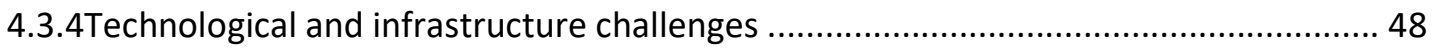

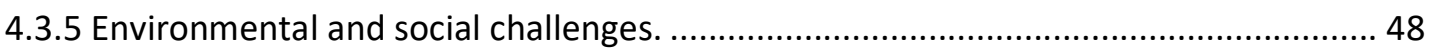

5. A Strategic Framework for Sustainable Groundwater Development in SSA ............................ 50

5.1 A guiding framework built around "four l's" .................................................................... 50

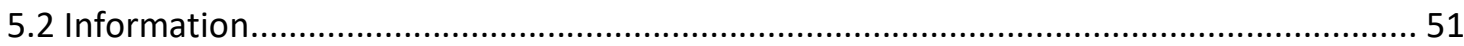

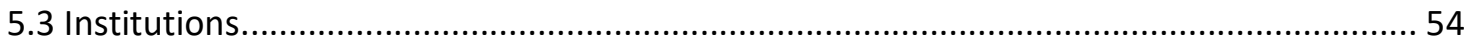

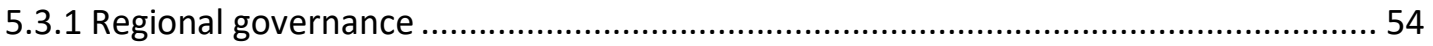

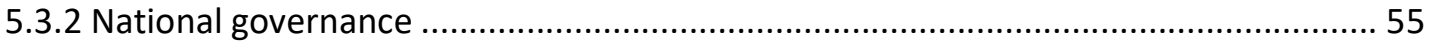

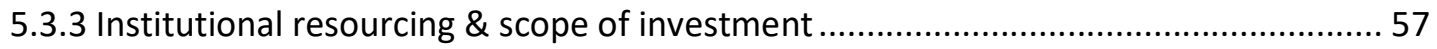

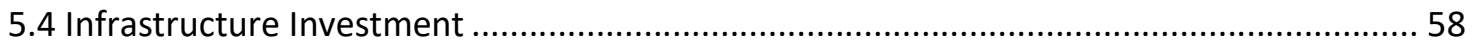

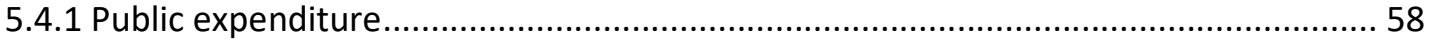

5.4.2Costs and benefits of regional and national groundwater strategy for cooperation ... 60

5.4.3 Costs and benefits of groundwater development at the household level....................62 62

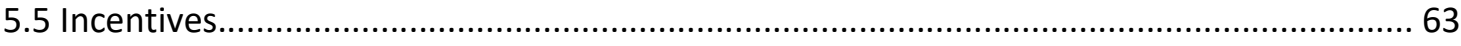

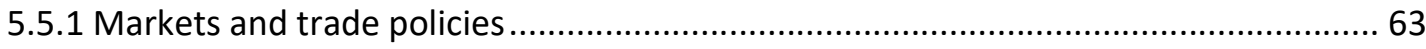

5.5.2 Support and enhance private sector investment in water services............................64

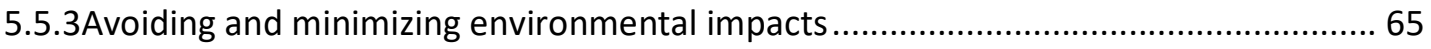

Chapter 6: Implementing the Strategic Framework- Analytical and Operational Guidance........ 67

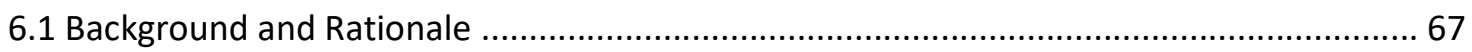

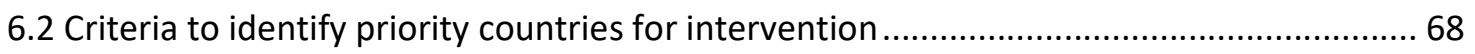

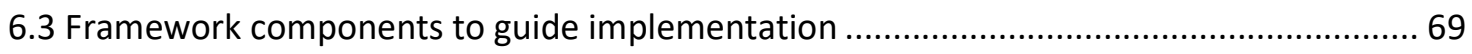

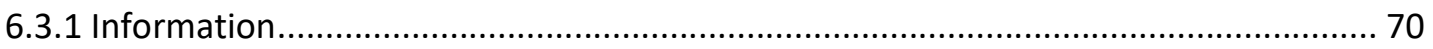

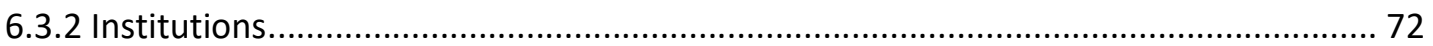




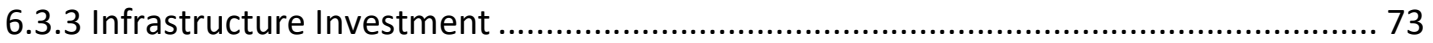

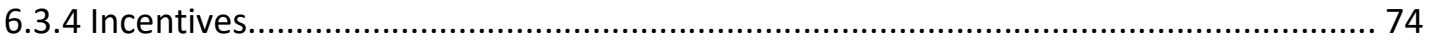

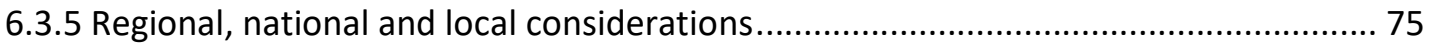

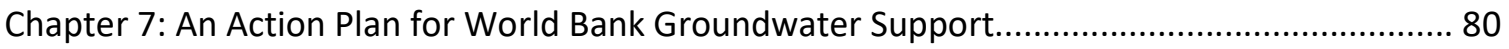

7.1 Examples of Investment Projects in 3 Strategic Areas of Intervention .............................. 80

7.1.1Macroeconomic development through irrigated agriculture .................................... 80

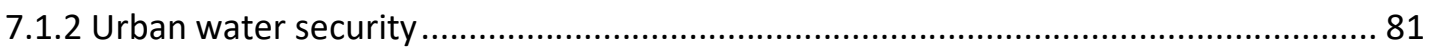

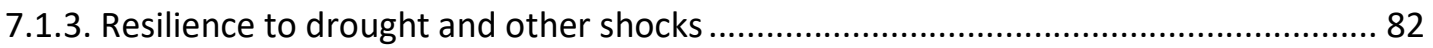

Analytical and operational guidance to identify priority countries .................................... 84

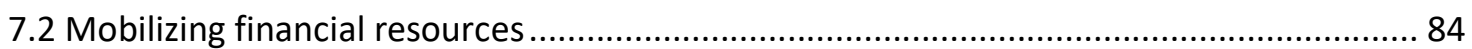

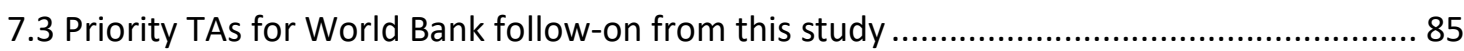

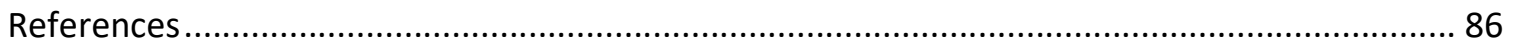

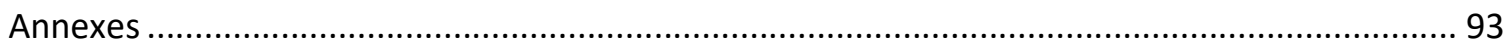

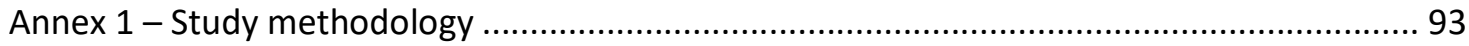

Annex 2 - Country-level groundwater \& irrigation area estimates ...................................... 95

Annex 3 - Case study of Managed Aquifer Recharge (MAR) in Windhoek, Namibia ............... 99

Annex 4 - Economics of groundwater extraction in Sub Saharan Africa ............................... 103

Annex 5- Expanding role for the World Bank in Water Sector Development in SSA ............. 112

Annex 5a- Evaluation of role of groundwater in World Bank water sector portfolio ............. 117

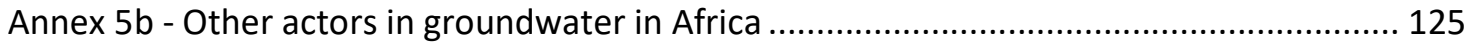

Annex 6 - Matrix of national-level water assessments, with special attention to vulnerability and to potential for sustainable groundwater resource development ............................... 133

Annex 7 -A guide for developing a specialized center for Advanced Water Studies............. 141 


\section{Executive Summary}

Scope

This report confirms that groundwater, if managed sustainably, can be an important development resource across the Sub-Saharan Africa (SSA) region. The report presents data related to groundwater resource characteristics and highlights the opportunities and challenges presented in promoting sustainable and resilient groundwater development in the region. Groundwater has significant potential to support human and economic development in SSA, as it has done in other global regions.

This report recommends investment in expanding groundwater development as an integral component of national water resources strategy for countries in SSA. Investment in groundwater can be financially viable and a wise policy option to support socioeconomic development if safeguards specific to groundwater are incorporated into investment programs. The expansion should be designed within a sustainable framework responsive to the special social and cultural and economic features of groundwater resources, compounded by their special hydrological, environmental and engineering dimensions to guide sustainable development of this important component of water resources.

\section{Water and development challenges in SSA}

SSA suffers from underdevelopment of its water sector, with significant human and economic consequences. Groundwater development could make significant contributions to regional poverty reduction and shared prosperity goals. SSA is constrained by 315 million people remaining without access to improved drinking water (across both rural and urban areas); only 3 percent of total cultivated land is irrigated (compared to 37 percent in Asia); and recurrent water scarcity and drought events impact millions (for example, SSA is currently in the grip of its worst drought in 35 years, with 38 million people at risk across eastern and southern Africa). Such absolute and economic water scarcity contributes to chronic food insecurity, environmental migration and civil instability being endemic in some SSA countries.

Major climate and non-climate drivers are forecast to place further pressure on water resources in SSA, threatening development progress achieved to date. In addition to the chronic challenges experienced today, regional increases in water demand between 2005 and 2030 are projected to reach almost 300 percent - up to three times higher than any other global region. Greatest non-climate demand is expected to come from agriculture and the municipal and domestic sectors. Urban populations are predicted to triple by 2050 and rural populations are expected to continue to grow, by approximately 45 percent by 2050 . While climate drivers will vary across SSA, generally accelerated warming is likely to increase precipitation in wet months and decrease precipitation in dry months, increase desertification, reduce river flow, increase risk of flash flooding, and reduce long-cycle crop production. Water resources development will need to keep pace with climate and non-climate drivers.

As traditional sources of surface water become scarce and expensive, groundwater - an integral component of national water resource base - has the greatest potential for positive development impact in the forty percent of SSA classified as 'drylands'. National water 
resource options include surface waters, groundwater and non-conventional water sources (Figure A). Groundwater is by far the largest water resource in these areas, and could help overcome water scarcity and drought-related shocks, which compound existing poverty and divert scarce humanitarian resources.

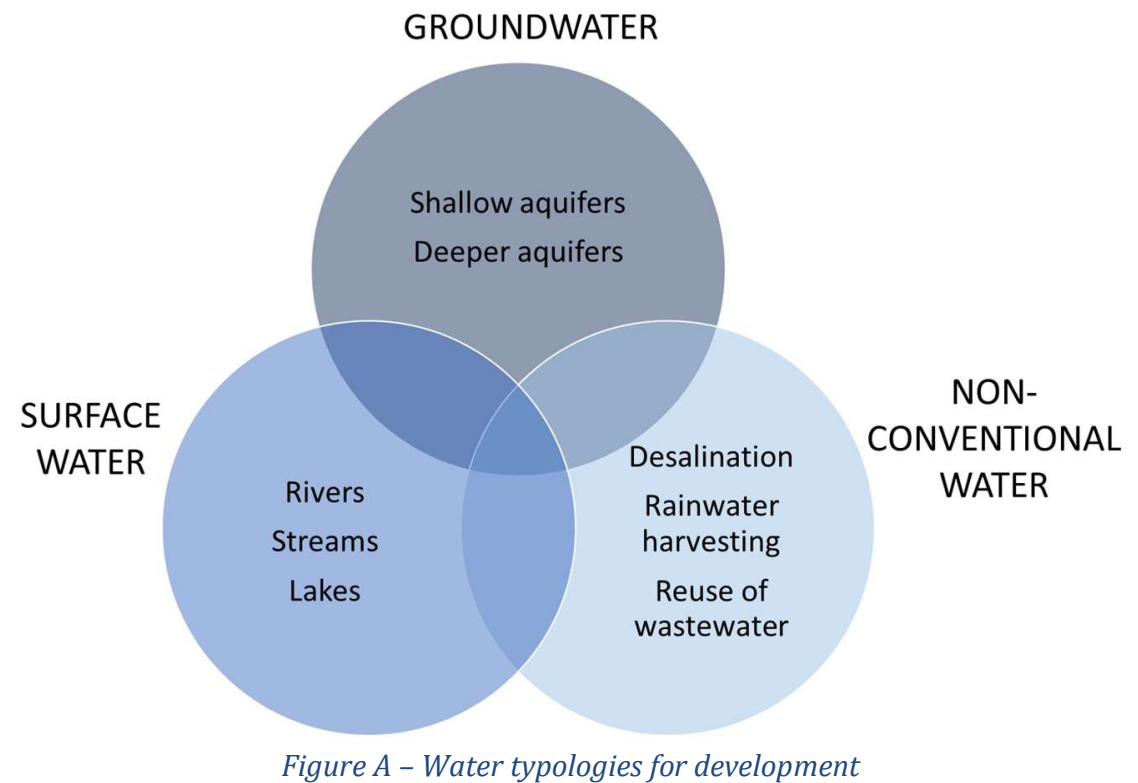

Although groundwater is hidden, both physically and institutionally, when sustainably managed it can yield significant benefits:

- International experience shows that groundwater can underpin impressive development outcomes and increase resilience, as evidenced in regions such as South Asia and China. There is opportunity to build on the successes and learn from the drawbacks of groundwater development in those regions;

- When properly managed, the inherent advantages of groundwater include local availability, protection from pollution and cost effective and incremental development potential; and

- Groundwater's large storage volumes and protection from evaporation make groundwater a strategic asset in adapting to climate change impacts.

To date, the expansion of groundwater development that has occurred in SSA has been largely informal, driven primarily by private well owners exploiting shallow aquifers for drinking water and small-scale irrigation. In contrast, most deeper aquifers in SSA remain essentially unutilized. Given the widespread water scarcity across much of the region, this represents a potentially significant dormant economic and human development opportunity.

This report confirms that, at the regional scale, there are sufficient groundwater resources to support sustainable development in SSA. 
Groundwater is, by far, the largest stock of water in SSA - multiple times more than surface water resources. The total volume of groundwater in storage in SSA is approximately 660,000 $\mathrm{km}^{3}$, comprising both renewable and non-renewable resources. This is equivalent to more than 7,000 years of average total flow of the Nile River.

Regional renewable groundwater resources are significant and there is large capacity to scale up their utilization to support economic development. Renewable groundwater resources in SSA amount to about $1,400 \mathrm{~km}^{3} /$ year (equivalent to 15 years of average total flow of the Nile River). Groundwater is severely underutilized in the region - only Djibouti, Mauritania and South Africa use more than 25 percent of their renewable groundwater resources. Hence, there is significant potential to scale up renewable groundwater utilization across the region, including in dryland areas (Table A).

Table A - Comparison between renewable groundwater available and groundwater abstracted (SSA, SSA drylands, India)

\begin{tabular}{|c|c|c|c|}
\hline Region & $\begin{array}{c}\text { Total renewable } \\
\text { groundwater }\end{array}$ & $\begin{array}{c}\text { Total groundwater } \\
\text { abstracted }\end{array}$ & $\begin{array}{c}\text { Groundwater abstracted } \\
\text { per capita }\end{array}$ \\
\hline SSA & $1400 \mathrm{~km}^{3} / \mathrm{yr}$ & $20 \mathrm{~km}^{3} / \mathrm{yr}$ & $28 \mathrm{~m}^{3} / \mathrm{yr}$ \\
\hline SSA Drylands & $324 \mathrm{~km}^{3} / \mathrm{yr}$ & $15 \mathrm{~km}^{3} / \mathrm{yr}$ & $37 \mathrm{~m}^{3} / \mathrm{yr}$ \\
\hline India & $432 \mathrm{~km}^{3} / \mathrm{yr}$ & $251 \mathrm{~km}^{3} / \mathrm{yr}$ & $208 \mathrm{~m}^{3} / \mathrm{yr}$ \\
\hline
\end{tabular}

Renewable groundwater resource potential is also considerable across SSA's drylands, where its utilization could be scaled up to overcome surface water scarcities for many populations. Drylands compose 43percent of the region and are home to half of the population, three quarters of whom live in poverty. Table i suggests that current groundwater abstractions in drylands countries represent only around 5percent of the renewable groundwater resource. However, the main groundwater used is from shallow local aquifers with limited capacity that are vulnerable to extended periods of drought whereas the deeper aquifers are less utilized. Groundwater is a resource that depends on local geology, topography and climate, and its potential is variable in space. While regional data indicate high groundwater potential overall, physical resource characteristics need to be confirmed at local levels to determine key parameters such as sustainable yields and water quality.

Regional non-renewable groundwater resources are substantial and could be utilized strategically. Non-renewable groundwater cannot be used indefinitely and may be difficult to access, but it could be valuable in the medium term as a strategic asset and as an emergency water supply.

However, multiple factors contribute to low levels of formal investment in groundwater, particularly a lack of information on resource characteristics at regional, national and local scales, which are preventing its development potential being realized.

Overall, groundwater resources in SSA are poorly understood, which remains a barrier to their sustainable development at regional, national and local scales. A few well-monitored aquifers contrast with large areas where little is known apart from regional averages. Many countries have inadequate groundwater monitoring networks. Regional and national datasets provide a 
generalized sense of groundwater potential, but may miss local anomalies. Satellite and other remotely sensed data adds value to existing information, however much more is needed to support sustainable development.

Considering existing groundwater uses for water supply and pastoralism (and their projected growth) and minimum (rather than average) groundwater availability, current projections of groundwater potential for irrigation using shallow groundwater resources are likely to be too optimistic and need to be confirmed at the level of individual aquifers. The potential of deeper aquifers in dryland regions is substantial but the higher construction and operating cost of deeper wells and associated issues such as environmental cost and land tenure policies make them less attractive for small-holder irrigation. It is important to evaluate the groundwater irrigation potential based on economic assumptions in line with the shallow and deep groundwater resource availability.

\section{A strategy on groundwater in Sub-Saharan Africa}

This report is informed by the experiences from the World Bank contribution to the development of the water sector in general and in Sub-Saharan Africa in particular. The proposed strategy is informed by lessons learned from the World Bank lending to the water sector as well as thoughtful recommendations presented in series of studies conducted by several donors and national and international water agencies and research centers

The World Bank has steadily increased lending to the water sector in SSA, prioritizing surface water development. Lending in the water sector is an important component of the Bank's global portfolio of projects, and Bank investment in SSA's water sector has generally increased over the past decade (US\$820m in FY07 to US\$1,780m in FY17). Surface water projects (such as watershed management, dams and hydropower, rivers and lakes) have received the greatest investment focus in the Bank's water portfolio. However, major surface water resources are spatially limited and 85 percent of SSA's population lives at more than $10 \mathrm{~km}$ from a major river or lake. Surface water resources are becoming increasingly costly to develop and are also more vulnerable to the effects of climate change.

Looking forward, integrating groundwater resource development in the national strategy for water resources management will help meet the growing gap in demand in SSA. Investment in the water sector, from irrigated agriculture and WSS to rural development and disaster risk reduction - will become increasingly reliant on groundwater resources, either utilized independently or in conjunction with surface water resources. The current low profile of groundwater investment portfolio in SSA suggests significant opportunity to promote groundwater more explicitly as part of a holistic development approach.

\section{A framework to guide investment in management of groundwater in SSA}

A framework is presented to guide sustainable groundwater development in SSA, highlighting measures to overcome the current knowledge, policy and investment gaps (Figure B). A framework is built around regional, national and local level pillars, where future interventions can provide support where investment can be prioritized around four themes: information, institutions (and policies), infrastructure investment, and incentives (secondary factors). 


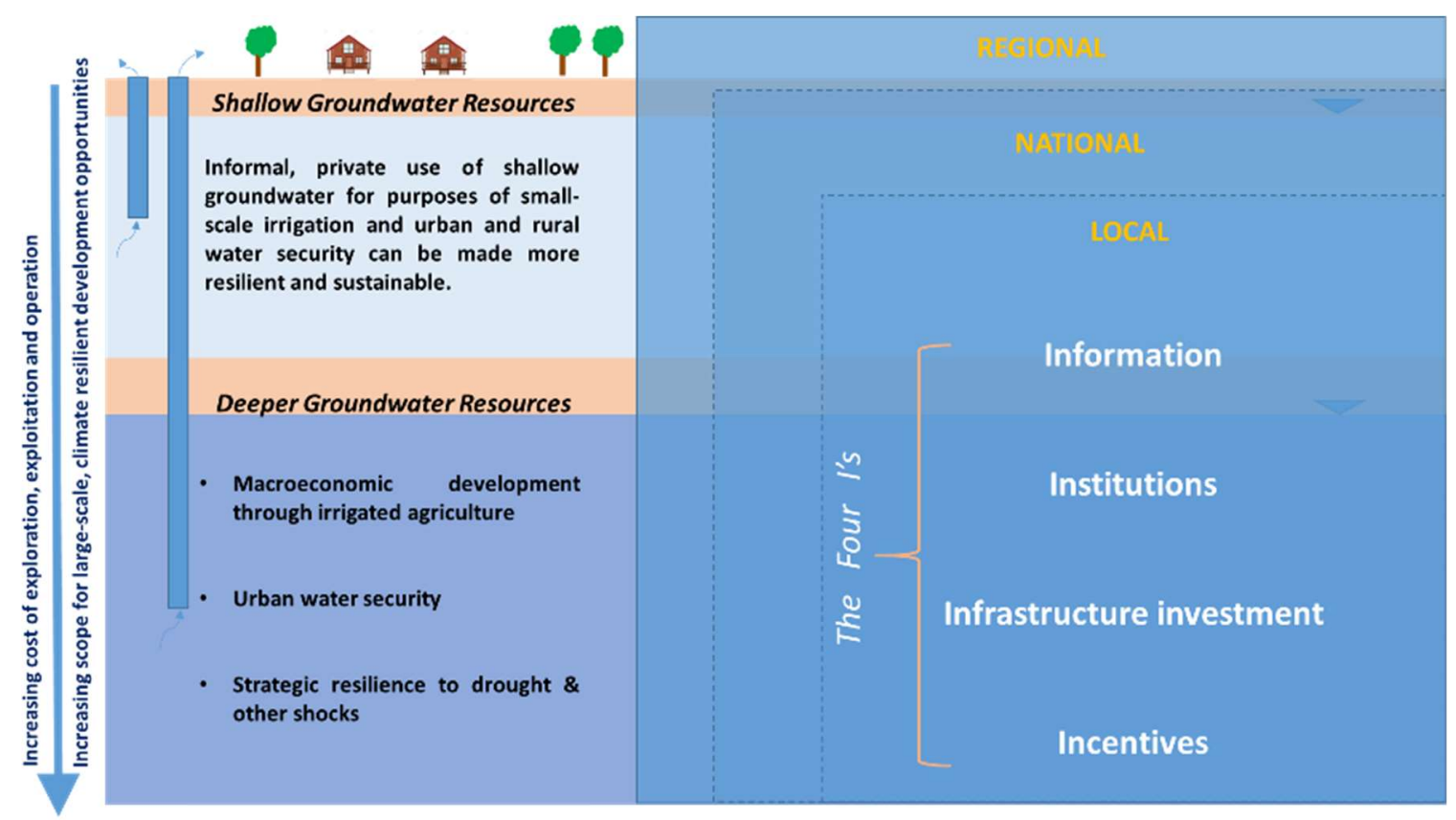

Figure B - A framework to guide a World Bank sustainable development strategy for shallow and deeper groundwater resources in SSA

The main elements of the proposed strategy are to articulate support around the four themes:

- The information element: SSA would benefit from adopting advanced information technologies to expand and update water data and increase the application of remote sensing at national and local levels, to help characterize and monitor groundwater resources and their key parameters. Basic characterization of groundwater resources should become standardized of investment and interventions in SSA water resources, with direct and indirect impacts / reliance on water resources. Environmental safeguards require confirmation of sustainability of water resources used by World Bank investments but in SSA adequate data to evaluate impacts on groundwater resources are often lacking.

- The institutions (and policy) element: Institutional capacity building at regional and national level is required to enhance water development strategies integrating groundwater resources through scientific inquiries to update data collection and knowledge production to guide water policies and investment programs. Also important is to updating water policies in response to the changing dynamics of economic growth, urbanization and industrialization and the impact on the national water balance between supply and demand and advances in water and information technologies. Existing institutions, such as the SADC groundwater institute, can help facilitate this and provide a template for South-South knowledge exchange and collaboration. An important dimension of institutional support is to enhance strong links between research, education and policy development in the water sector. For example, institutional support could aim to support interdisciplinary water center(s) for teaching and research on emerging water development topics (e.g. water resources planning integrating conventional and non-conventional water resources, government water policies including public expenditure and pricing and the performance of water agencies, adaptation to climate change; water scarcity and security for urban and rural communities, and food safety) at selected universities in SSA. These facilities and 
programs could develop and deliver quality innovative, interdisciplinary research, teaching and extension programs, primarily to policy makers and to audiences in their respective communities (farmers, students, agribusiness), and would also serve national constituencies and be models for replication in other countries.

- The infrastructure investment element: the financial requirements need for expanding and modernizing water infrastructure, especially groundwater resources in SSA are significant. A combination of public and private investment will be required to develop groundwater resources, particularly deeper resources. To date, investment has been limited to shallow groundwater private investment. Investment in supporting infrastructure will be required, as well as in end use efficiencies (e.g. irrigation, urban water security). Analysis of public expenditure in groundwater development and the costs and benefits of groundwater investment at regional, national and local levels is required. At local levels, supporting smallholder access to finance and insurance will be key for further investments; and

- The incentives (secondary factors) element: Secondary factors - from markets and trade policies, availability and affordability of technology, private sector engagement and managing adverse environmental impacts - can either be barriers or facilitators of sustainable groundwater development.

Highlights of opportunities at the regional level include consideration of transboundary resource exploration, development and governance models; convening of stakeholders (including interactions between formal and informal institutions); and accounting for environmental baseflows (understanding recharge, avoiding depletion, and managing quality).

Highlights of opportunities at the national level include consideration of public expenditure and budget allocations for water services in general and the groundwater sub-sector with a special focus on responsive water pricing and cost recovery. Also important the role of tenure policies and land titling in attracting the private sector to invest in the water resources within national water security framework; costs and benefits of groundwater investment for both small and large investors and the role of the ministry of finance in setting water pricing and tariff regime to ensure conducive investment by the private sector in the provision of reliable and viable water services; the role of private sector (including public-private partnerships and related policies for water and land rights ); developing markets and trade and related local infrastructure; utilizing technology advancements in information technology, in drilling and well construction, in water delivery networks, and in irrigation and productivity for water supply and agricultural purposes; and accounting for environmental baseflows (understanding recharge, avoiding depletion, and managing quality). Box A captures many of the factors that should be considered at the national level in a comprehensive assessment of water resources. It highlights that traditionally considered factors, such as economic and financial elements, should only be considered in the context of other competing factors contributing to national development objectives.

Highlights of opportunities at the local level include consideration of increasing access to technology for small-scale drilling and pumping of groundwater; piloting models to bolster community water security (through local delivery networks); and promoting community-led local governance and management models, informed by understanding of local resource characteristics. 
Box A - support for national water resource assessments

Investment in the water sector could support SSA countries conduct holistic assessments of their national water resource potential (including groundwater, surface water and non-conventional sources). Such assessments could be presented to national Ministries of Finance to help prioritize public expenditures. As outlined in Figure C, a comprehensive set of measures should be included to produce a holistic assessment for national water resource prioritization: i. Economic and Financial (including returns on investment, cost-benefit analyses); ii. Social and Cultural (including gender and humanitarian considerations, cultural norms); iii. Environmental (including climate resilience, resource quality, ecological baseflows); iv. Political Economy (national security, water as 'social' or 'economic' good, tariffs/subsidies); v. Institutional (formal and informal, state and local, public and private); vi. Informational (resource knowledge status, mapping / quantification of resources); and vii. Technical (resource development, water production and delivery, technological requirements). Such assessments would be bespoke country-by-country and help to raise the profile of groundwater as an important and competitive strategic national resource.

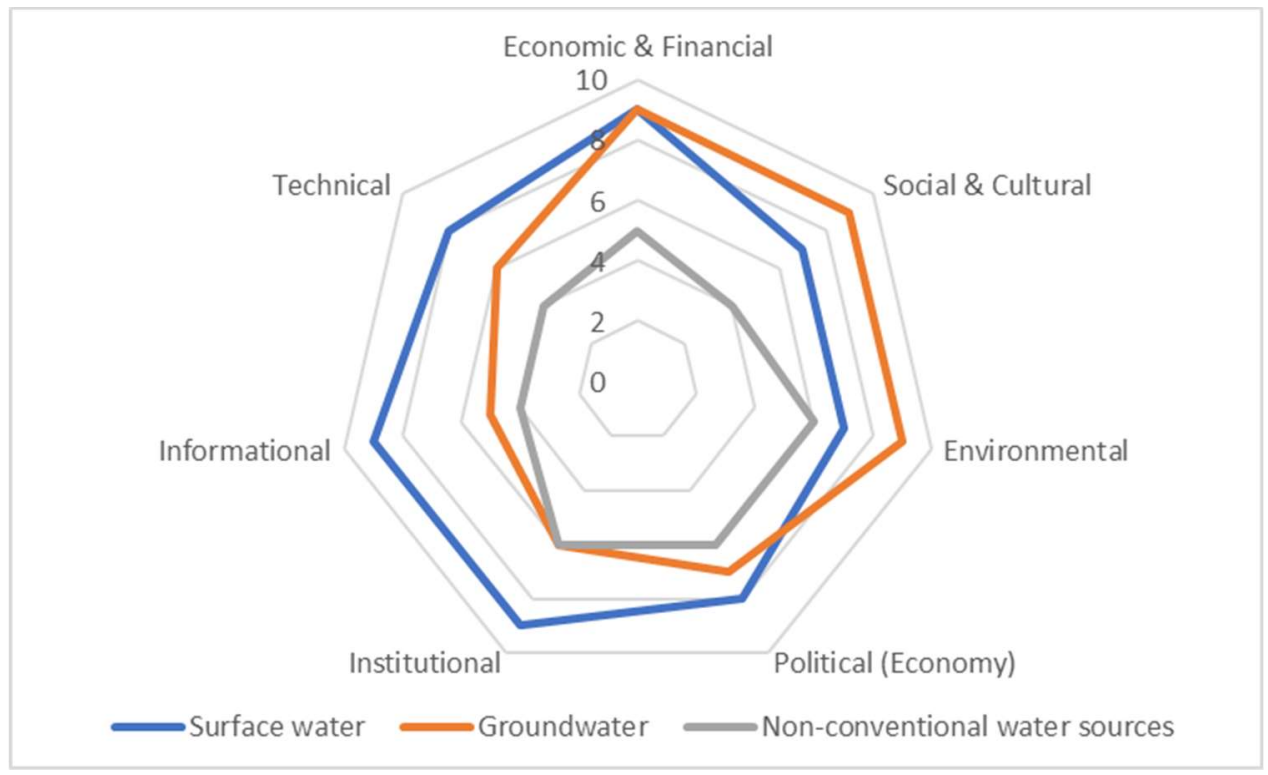

Figure C-Example of holistic water resources assessment at national level

The figure above illustrates that many factors should contribute to decision-making for water resource development - in particular, economic and financial factors should be assessed only in the broader context of other competing factors.

\section{Priority groundwater actions for the World Bank}

\section{Three strategic areas of intervention, where groundwater has the potential to trigger transformational change, have been identified.}

Macroeconomic development through irrigated agriculture

Through IDA18, the World Bank is currently engaging twelve SSA countries on irrigation sector reform and investment (Mauritania, Senegal, Guinea, Mali, Burkina Faso, Niger, Chad, Benin, Nigeria, Cameroon, Ethiopia and Mozambique) and potentially expanding into new countries (Uganda, Kenya and Ghana). Key ASA include the Sahel Initiative, Cameroon (through the Agriculture GP), and planned activities under the GWSP. 
The baseline Bank's annual investment in irrigation in SSA is about one third of lending to the water sector or US\$ 600 million. The rate of growth in irrigated areas in SSA is currently 3 percent $(60,000 \mathrm{ha})$ per annum driven largely by SSA farmers. The World Bank could support expanding irrigation and consider matching this increase over the next 10 years to help SSA countries expand groundwater-based irrigation, currently two million hectares, by 50percent at an annual increase in lending to about US\$ 900 million.

There is opportunity to accelerate and scale up growth in irrigation using groundwater, starting in the SSA countries already being engaged. It is estimated that the costs of developing and expanding groundwater based irrigation schemes in SSA would be similar to other regions (US\$5,000-8,000 per ha). It is desirable to use community based managed investment for small scale irrigation.

Shortlist of potential priority regions / countries for World Bank support: The Sahel region, particularly countries involved in the SIIP (Chad, Mali and Niger) show greatest potential for macro irrigation schemes to promote economic development, supported by groundwater resources. Cameroon (currently engaged by the Agriculture GP) and the other IDA SSA countries could also be considered for support.

Urban and rural water security

Through IDA18, the World Bank is currently engaging 20 SSA to enhance water services for urban and rural population, (Senegal, Guinea Bissau, Guinea, Liberia, Ivory Coast, Ghana, Benin, Nigeria, Mali, Burkina Faso, Niger, Ethiopia, Kenya, Uganda, Tanzania, Mozambique, Zimbabwe, Lesotho, Angola and DRC) and may also engage in 7 other countries (Mauritania, Togo, Cameroon, Congo, Zambia, Malawi and Madagascar) This partnership includes support for improving efficiency of services and enhance and cost recovery of utilities and improving technical performance and financial viability and sustainable services and the provision of Key advisory services and analytics (ASA) include WASH diagnostics and planned activities under the GWSP.

SSA countries are currently achieving 3 percent annual expansion of WSS services, to both urban and rural communities. SSA countries allocate US\$7.5 to 9 billion annually on WSS services. The Bank annual lending to WSS in SSA is about US\$950 million. The Bank should consider matching the publicly funded annual expansion in WSS over the next 10 years at an annual increase in lending to WSS to about US\$ 1.3 billion.

There is opportunity for the World Bank to accelerate the expansion of WSS services using groundwater, starting in the SSA countries already being engaged. This will help SSA countries reach Sustainable Development Goal (SDG) 6 on water. Promoting integrated urban water management (adopting a holistic view of all components of the urban water cycle -water supply, sanitation, storm water management), promises strategic advantages in rapidly growing secondary cities. Managed Aquifer Recharge (MAR) systems can assist in managing drought periods and climate shocks. Groundwater is strategic for rural and small-town WSS and the World Bank could support decentralized community networks. 
Shortlist of potential priority cities for World Bank support: Drought risk exposure in many urban areas is already high and forecast to increase to 2050. The following cities are the largest and most exposed to drought based on current and future population forecasts (Jacobsen, 2013) and hence may be priority cities for groundwater assessment: Kinshasa (Republic of Congo), Khartoum (Sudan), Addis Ababa (Ethiopia), Nairobi (Kenya), Dar Es Salaam (Tanzania), Luanda (Angola), Abidjan (Ivory Coast), Lagos (Nigeria), Abuja (Nigeria), Dakar (Senegal), Kampala (Uganda), Conakry (Guinea) and Mogadishu (Somalia). Furthermore, the number of cities with populations of more than 1 million is projected to almost double from 42 in 2010 to 80 in 2025 and many of today's secondary cities will become tomorrow's megacities, with necessary allocations for IWRM and sustainable WSS services. Shortlisting of priority cities could be coordinated with the Water Scarce Cities Initiative.

\section{Resilience to drought and other shocks}

Through IDA18, the World Bank is currently engaging 24 SSA countries (and potentially engaging 5 more) on water resources management, including strengthening policies and institutions to improve WRM (water allocation mechanisms, infrastructure for managing water extremes, and water quality information). Key ASA include water security diagnostics and analytical activity on groundwater.

An aspirational goal for IDA18 is eleven countries with improved information and institutions for better management of extremes (floods and droughts) benefiting $\mathbf{5 0}$ million people.

There is opportunity for the World Bank to more strategically address recurrent drought and climate shocks through innovative investments, including water supply systems that utilize groundwater's greater storage volumes. Evidence shows that proactive resilience building yields longer lasting economic and humanitarian benefits, relative to emergency response.

Shortlist of potential priority regions / countries for World Bank support: A strategic regional approach to drought resilience investment could be targeted in the Horn of Africa, which experiences recurrent drought events. Some of the countries most vulnerable to drought include Sudan, Somalia, Uganda, Malawi, Zimbabwe and Ethiopia, which could realize socioeconomic, environmental and humanitarian benefits from strategic groundwater development.

Analytical and operational guidance to identify priority countries

Sustainable groundwater development potential is high across SSA countries ${ }^{1}$ and warrants strong integration into broader national water resources strategies. Further to this, a multicriteria analysis of the status of water source and supply in SSA countries - comprising measures of water stress, vulnerability of fresh water supplies to climate change, drought vulnerability; and groundwater potential - suggests that sustainable groundwater development could make the greatest contribution to national water security and resilience in countries across the Greater Horn of Africa (Eritrea, Ethiopia, Somalia, South Sudan, Sudan) and the Sahel (Chad, Mali, Mauritania ${ }^{2}$, Niger, Nigeria). Many of the identified countries have high vulnerability of fresh water supplies to climate change and high vulnerability (and

\footnotetext{
${ }^{1}$ Except Mauritania, where greater than the sustainable yield is already being exploited.

${ }^{2}$ Mauritania warrants support as the only country where groundwater is being exploited at rates beyond the sustainable yield.
} 
exposure) to drought, with low capacities for coping (see Annex 6). Importantly, all the countries have dormant groundwater potential around which to sustainably develop urban water security, irrigated agriculture and drought resilience strategies. While this analysis provides an overview at a national scale, further work will be required to understand potentially large intra-national variability in measures such as degree of water stress and vulnerability to drought, to enable support to be targeted effectively.

\section{Technical Assistance Activities for Immediate Follow-on from this Study}

Based on findings from this assessment, the following are recommended as immediate followon activities:

- Conduct national integrated water resources assessments for priority countries / typologies of countries, including targeted strategies for groundwater development / investment. The economic case for groundwater can be strengthened by engaging Ministries of Finance and incorporating groundwater considerations into public expenditure frameworks.

- Strengthen and expand strategic partnerships with regional and international partners already engaged in groundwater in SSA, with a focus on innovative technology dissemination to help address resource knowledge, development and management deficiencies.

- Help strengthen regional and national institutional capacities- including tertiary institutions and centers of excellence - to build youth capabilities and raise the profile of groundwater development as a potential applied research and career pathway.

- Integrate the water resource management agenda (including groundwater resource development) with the urban WSS agenda. The Water Scarce Cities Initiative provides global examples of this approach which can be shared with clients. 


\section{Report Scope\& Objectives}

\subsection{Scope}

This report focuses on groundwater as an important component of all water resources in SubSaharan Africa (SSA) and as a crucial resource for development across the region. Given the outstanding human and economic development challenges in SSA, and the relatively low level of knowledge and development of aquifer resources, this document catalogues broad resource characteristics and highlights the opportunities (and challenges) presented by groundwater in promoting sustainable and resilient development in the region. The report presents data to confirm that groundwater can play a central role in supporting human and economic development in SSA, as it has done in other global regions, and outlines a framework for groundwater development in SSA at a time when knowledge, policy and governance of resources in the region are at a nascent stage. This document presents a baseline on current knowledge to inform strategic decisions. The major differences in physical characteristics and management approaches for groundwater and surface waters are outlined in Box 1.

\section{Box 1 - Defining water resources and assessing their availabilities}

Water resources are generally divided in 3 different typologies: surface water, groundwater and nonconventional water resources. In a given country or region these resources are available in different quantities, their mobilization / production costs vary and each resource is more or less vulnerable to climate variability or pollution. Figure 1 is a conceptual framework informed by several studies ${ }^{3}$ which illustrates respective costs ranges and available volumes of water from these different sources in a county or region. Surface water is water found in rivers, lakes, ponds and streams and naturally available quantities can often be enhanced by building storage and harvesting infrastructure. Groundwater is water found below the ground surface in interconnected pores, cracks and other openings and can be divided in renewable and non-renewable reserves. Available groundwater volumes can also be enhanced through artificial recharge of aquifers.

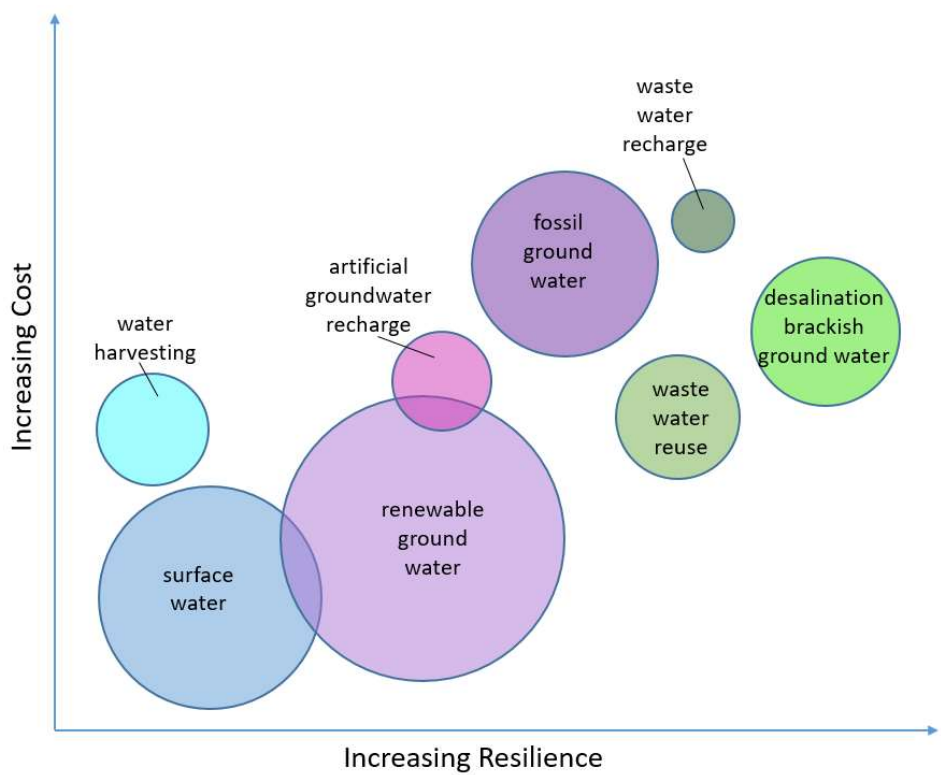

Figure 1 - Conceptual Framework comparing respective cost ranges and available volumes of different water resources typologies in a country or region.

${ }^{3}$ Banerjee \& Morella (2011), World Bank (2011) and World Bank (2015a). 
Non-conventional water sources include a range of potential sources, including desalination of sea water, desalination of brackish groundwater, reuse of treated wastewater and aquifer recharge using treated waste water.

In general, in dryland regions volumes of groundwater are far larger than surface water, but the resource can be difficult to locate and to manage. Both surface water and groundwater have advantages and drawbacks, depending on the circumstances. Water managers and scientists recognize that surface water and groundwater are interrelated parts of the water cycle - for example, groundwater emerges at springs and as baseflow to rivers, whilst surface water percolates downwards to replenish groundwater. This is acknowledged in modern water management approaches such as Integrated Water Resources Management (IWRM).

However, surface water and groundwater can require different management approaches, relying on different procedures and skills sets. The techniques needed to assess and manage a groundwater aquifer are different to those needed for a surface water body, for example. It is therefore often useful to distinguish the two from a management and operational perspective. Groundwater, being physically invisible, is often overlooked or undervalued, making it institutionally invisible too. Funding and policy in Africa remains geared to surface water resources. Non-conventional water sources can be more complex and expensive to develop, but can be useful when used in conjunction with, or as supplements for, surface water or groundwater.

The distinction between groundwater and surface water is similar to that made between shallow and deep groundwater: they are part of the same resource but are recognized separately for operational and practical convenience (see paragraph below).

A technical distinction for this report, is dividing groundwater into shallow and deeper resources. While this is a distinction for economic and management purposes (rather than scientific), it provides a targeted approach for development in SSA. Groundwater occurs at a range of depths, depending on hydrogeological conditions, and there is no common scientific definition of shallow or deeper groundwater. However, a distinction is useful for economic and management purposes. Shallow groundwater (within about $30 \mathrm{~m}$ of the ground surface) can be accessed more easily (often by traditional methods such as dug wells) and requires less energy to pump. Accessing deeper resources requires more complex and expensive drilling technology and pumps. Shallow groundwater may also be more vulnerable to drought, and therefore less reliable. Deeper groundwater is more difficult and expensive to access and pump, but can be less susceptible to drought, to over-extraction and to contamination. Hydrogeological maps often depict depth to groundwater, and sometimes also seasonal depth fluctuations, for these reasons. Some of these features are illustrated in Figure 2, including trade-offs between the generally increasing costs of exploration, exploitation and management / operation of groundwater resources as they become deeper but the increasing scope for large-scale, climate resilient development opportunities. 


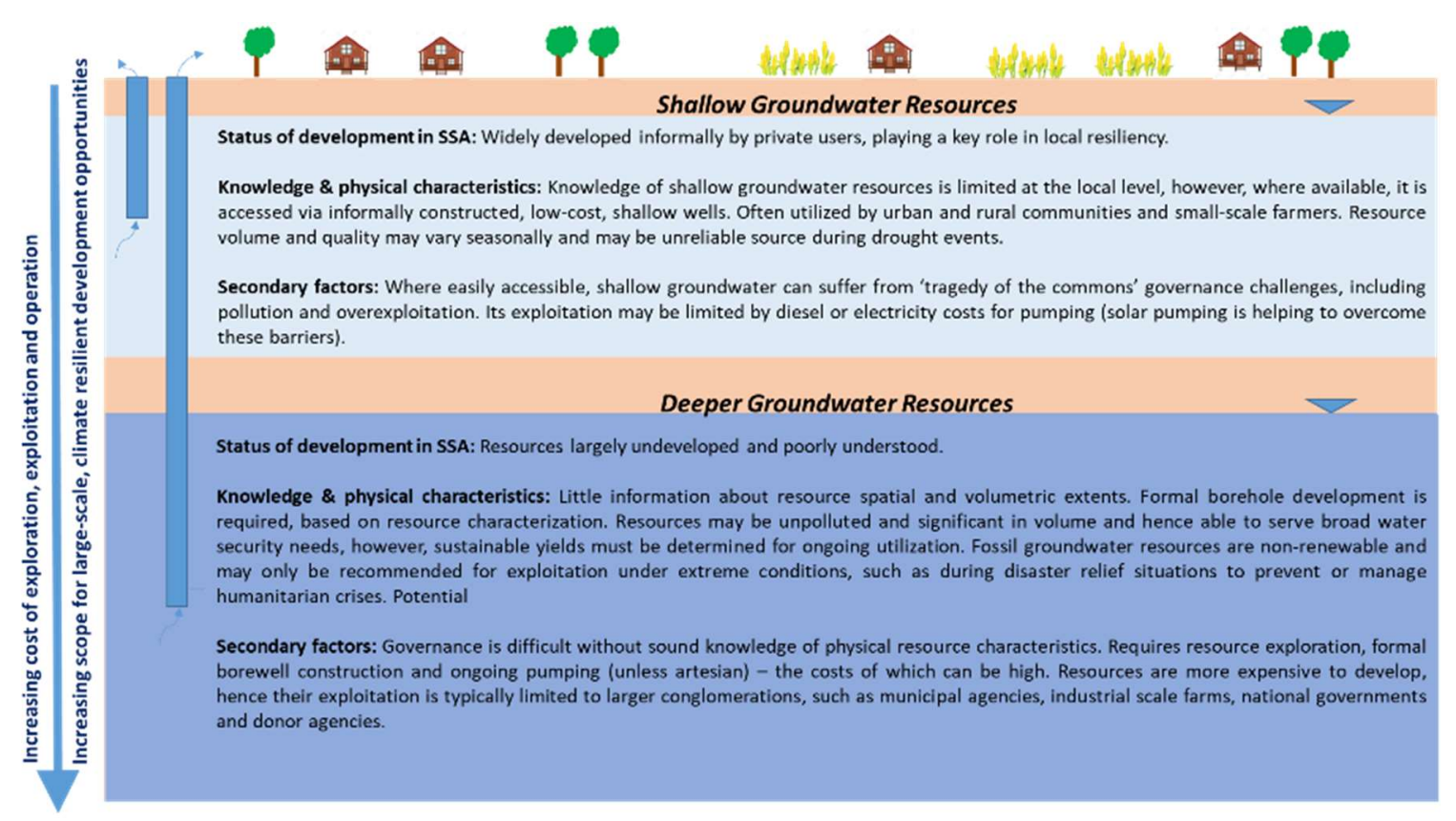

Figure 2 - Distinguishing between shallow and deeper groundwater resources for SSA

To date, the expansion of groundwater development that has occurred in SSA has been largely informal, driven primarily by private well owners exploiting shallow aquifers for drinking water and small-scale irrigation. It is estimated that up to three quarters of people in SSA depend on groundwater for their domestic water supplies. Groundwater also underpins millions of farming and pastoral livelihoods - modest quantities are often found close to where they are needed. Shallow groundwater is also being used by residents in growing urban and peri-urban settlements.

In contrast, most deeper aquifers in SSA remain essentially unutilized. Given the widespread water scarcity across much of the region, this represents a significant dormant economic and human development opportunity. Compared to shallow aquifers, deeper groundwater resources require greater technology and financing for development. Other challenges include limited knowledge of deeper groundwater resources and their potential transboundary nature. However, they are largely climate proof and their spatial extent is believed to be significant, albeit spatially inconsistent. In dryland areas, deeper groundwater resources could represent a significant water source for many communities.

While the scope of the report covers the entire SSA region, it prioritizes the greater than forty percent classified as 'drylands' ${ }^{4}$ (Figure 3), where groundwater has the greatest latent potential for positive development impact. Across the 44 SSA countries, groundwater is by far the largest water resource in dryland areas and could help overcome surface water scarcity and drought-related shocks, both of which compound existing poverty and divert humanitarian resources.

\footnotetext{
${ }^{4}$ Drylands are defined based on an aridity index and include arid, semi-arid and dry sub-humid areas.
} 


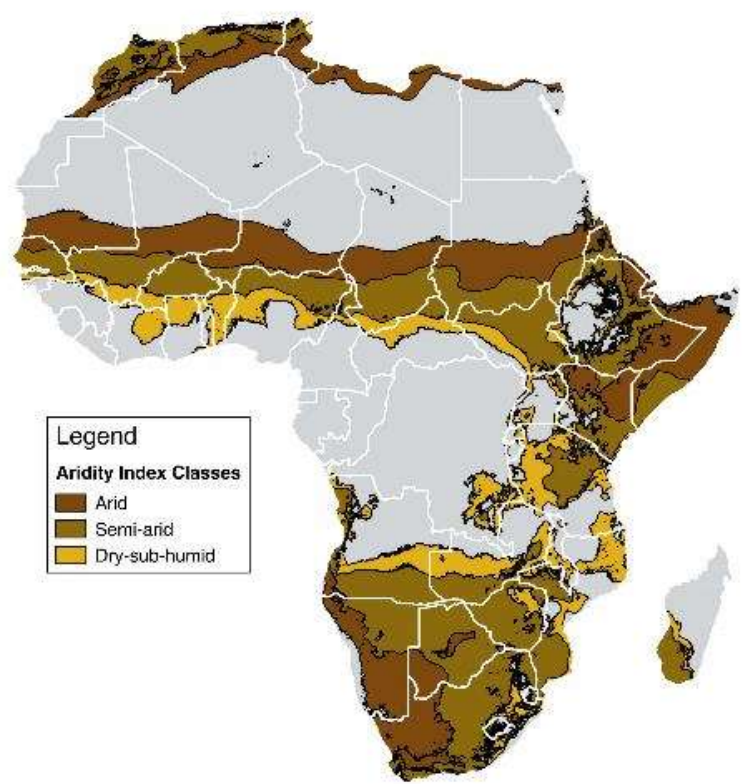

Figure 3 - Drylands comprise arid, semi-arid and dry-sub-humid and occupy more than 40 percent of SSA

The intended audience for this document is Senior Management in the Africa Region and the Water Global Practice. The document provides strategic context for operational guidance, with the goal of supporting groundwater development and management of investments.

\subsection{Objectives}

The objective of this document is to present a framework for the sustainable development and management of groundwater resources in SSA. It is intended that the framework serve to guide investment decisions in groundwater development in line with the World Bank's twin goals to end extreme poverty and promote shared prosperity.

To achieve this objective, the document seeks to:

- Understand and quantify the spatial distribution of groundwater resources (deep and shallow, renewable and non-renewable) across SSA, synthesizing best available existing data;

- Assess opportunities (and risks) of investing in the water sector to increase the utilization of groundwater development in SSA, focusing on macroeconomic development (primarily irrigation) and urban and rural water security (including resilience to acute shock events);

- Present a strategic framework - built around regional, national and local level pillars - for the sustainable development and management of groundwater resources in SSA (to help guide transboundary coordination, country partnership strategies and inform concerned policy makers and practitioners about technical and hydrological dimensions facing the sector); and

- Provide guidance and prioritize investment opportunities for sustainable management of the water sector portfolio.

The methodology for this study is contained in Annex 1. 


\subsection{Report Structure}

This report is structured around the following chapters:

Chapter 2 provides a review of the status of water and development in SSA. It includes a summary of current water sector challenges, predicted climate and non-climate drivers of demand for water, and current utilization of surface and groundwater resources for development.

Chapter 3 provides an assessment of groundwater potential for development in SSA by synthesizing latest information sources. It confirms the availability of reliable and adequate groundwater resources that can be utilized as a foundation to support the advancement of economic and human development in SSA countries.

Chapter 4 identifies strategic areas for intervention where groundwater has the potential to trigger transformational change. Building on the findings from Chapters 2 and 3, this chapter prioritizes groundwater investment which can support the following three strategic challenges: (i) macroeconomic development, chiefly through irrigated agriculture; (ii) urban water security for growing cities; and (iii) rural water security (including disaster risk reduction and climate resilience).

Chapter 5 outlines a strategic framework for the sustainable development and management of shallow and deeper groundwater resources in SSA. The framework is built around the "Four I's" - information, institutions, infrastructure investment, and incentives - for application across regional, national and local scales, with the intention of helping to guide strategic investments in groundwater in SSA.

Chapter 6 outlines the components of an operational investment strategy for groundwater in SSA. It describes criteria for identifying priority activities for national and regional focus, based on the framework derived in Chapter 5. It includes a focus on the Four I's across regional, national and local scales.

Chapter 7 describes an action plan for the World Bank to support sustainable groundwater development in SSA. It also outlines financial resourcing requirements for the components of the strategy. Recommendations for country priorities are made in accordance with IDA18 special themes.

Seven Annexes support the report, with special note given to Annex 5 which outlines the evolving role of investment and development of the nexus of water and development. It includes a preliminary portfolio review of the World Bank's water sector investments in SSA between 1997-2017 and a synopsis of an Independent Evaluation Group (IEG) evaluation of broader World Bank investments in the water sector globally. The reviews find strong justification to increase investment in groundwater development in SSA. 


\section{Status of Water and Development in Sub-Saharan Africa}

Ensuring continuous access to water of sufficient quality and quantity is fundamental for human and economic development. In SSA, as in other global regions, water is an important component in improving the quality of life through the delivery of clean drinking water supply and sanitation (WSS), and in enhancing agricultural production for food security and income generation for rural and urban dwellers. Access to water also enhances resilience to drought and other shock events, thereby helping prevent conflict, famine and forced migration.

Investment in the water sector will play a critical role in SSA eradicating extreme poverty and promoting shared prosperity. Almost half of the SSA population lives below the international poverty line. Investment in the water sector in SSA has been slow, however recent trends indicate more resources are being allocated to expand water development. More targeted resource allocation will be required to realize the economic and social benefits of this sector in SSA.

While groundwater has played a substantial role in contributing to development objectives in many global regions - such as contributing to the Green Revolution in Asia - this has yet to occur in SSA. Hence, there is strong justification to explore reasons for this lag in development and to identify opportunities for sustainable expansion. A synopsis of the current water situation in SSA is provided below.

\subsection{Current water situation in SSA}

Large populations in SSA remain without access to clean water. SSA lags other global regions in expanding the use of water for economic and social development. SSA is constrained by 315 million people remaining without access to improved drinking water (across both rural and urban areas) $)^{5}$. The challenge is most acute in rural areas (Figure 4), where less than half of the regional population use any form of improved water source ${ }^{6}$. There are also strong disparities in access to improved water sources among different wealth levels in both urban and rural areas.

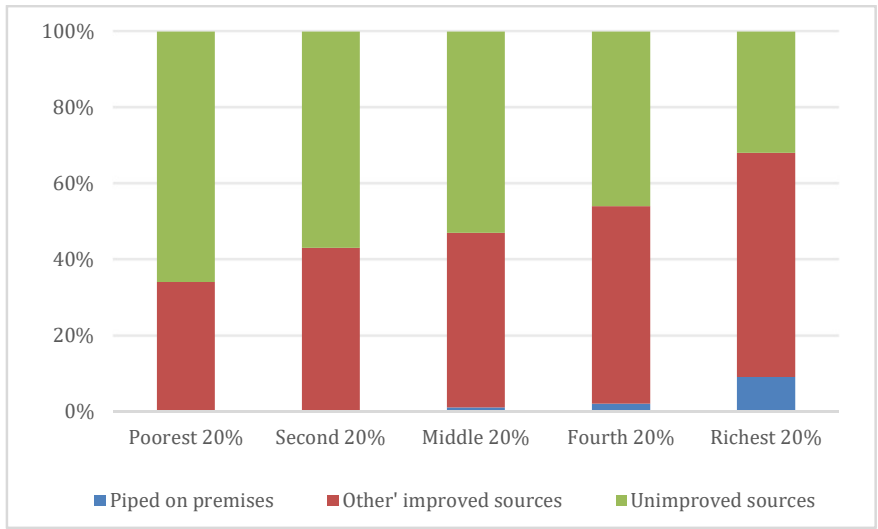

Figure 4-Drinking water coverage by wealth quintiles, rural residence, SSA, based on population-weighted averages from 35 countries (Source: UN 2012)

\footnotetext{
${ }^{5}$ UNDESA 2015.

${ }^{6}$ UNDESA 2015.
} 
SSA contains high proportions of urban dwellers in ever-growing slums, who do not have access to formal water, sanitation and hygiene (WASH) services. SSA has a relatively small share of the global slum population (20 percent in 2005), but this proportion has increased from 14 percent in 1990 and slum populations doubled during those 15 years. The proportion of SSA's urban population living in slums has stayed the same (72 percent) whereas this proportion has dropped from 47 percent to 41 percent on average in other developing regions ${ }^{7}$.

Food production in SSA is almost entirely rain-fed. SSA is the only region globally where chronic food insecurity, including the threat of famine, as well as malnourishment, remain endemic $^{8}$. Rainfall is highly variable in SSA, insufficient for agriculture in many areas. SSA countries exhibit the greatest incidence of undernutrition of any region globally (Figure $5 \mathrm{a}$ ). Rainfall volatility threatens the production of 93 percent of rainfed agriculture in Africa ${ }^{9}$. Irrigated areas make up just 3-5 percent of total cultivated area ${ }^{10}$ (Figure $5 b$ ) - compared to 37 percent in Asia and 14 percent in Latin America - and have the potential to boost agricultural yields by more than 50 percent. Furthermore, two-thirds of SSA's irrigated land is concentrated in just three countries: Madagascar, South Africa, and Sudan.
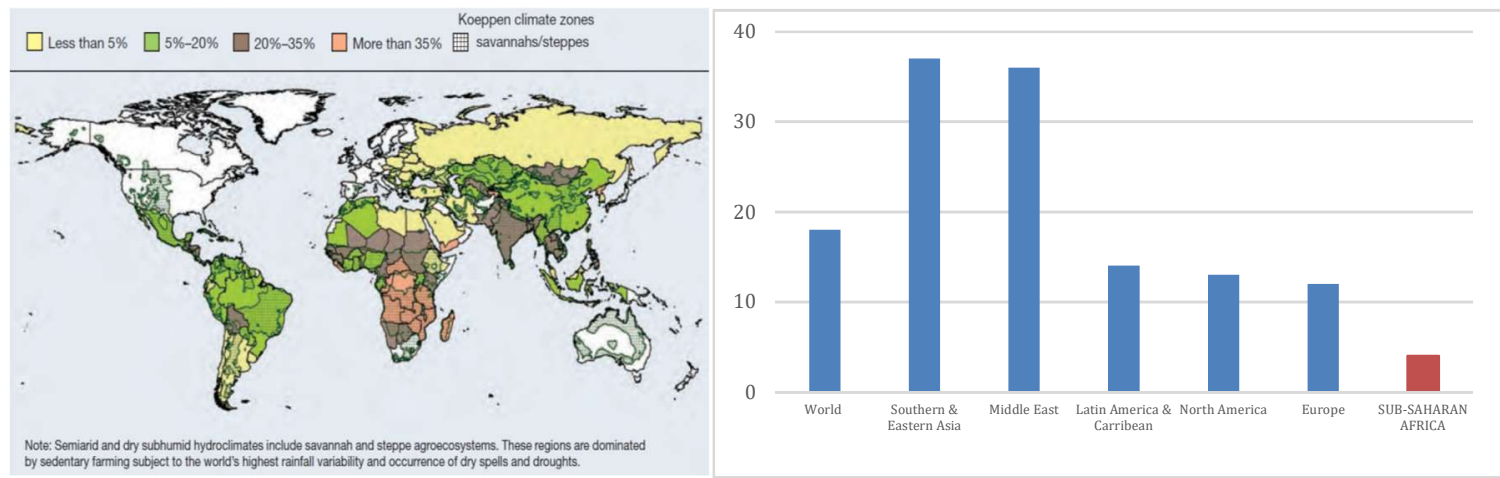

Figure 5 - (a) High levels of undernutrition are concentrated in SSA, undernourished as percentage of total population (Source: UNStat database 2005), (b) Cultivated areas with irrigation, global regions (\%)

Despite most farming being rain-fed, agriculture is the greatest user of water in SSA and the largest contributing sector to regional GDP. Agriculture is the largest contributing sector to SSA's GDP (greater than $1 / 3$ in most individual countries) ${ }^{11}$ and rainfed crops are the main source of incomes for 90percent of the rural population ${ }^{12}$. While agriculture is the largest consumer of water in $\mathrm{SSA}^{13}$, pastoral communities comprise over a quarter of Africa's population ${ }^{14}$ and are also reliant on available water of sufficient quantity and quality for human and livestock consumption.

\footnotetext{
7 Jacobsen et al. 2013.

${ }^{8}$ In 2011, the World Food Program noted that, among the 10 countries worldwide which suffered rates of "acute hunger or starvation" above 35 percent of the population, all 10 were in SSA (Besada \& Werner 2015, Baro \& Deubel 2006).

${ }^{9}$ UNDP 2012.

${ }^{10}$ Siebert et al. 2010, IWMI 2013.

${ }^{11}$ Ludi 2009.

12 UNDP 2012.

13 UNDP 2010.

${ }^{14}$ Department of Rural Economy and Agriculture 2010.
} 
Water scarcity in SSA is high. Water consumption and water availability are often countercyclical, with consumption being highest when availability is lowest. As illustrated in Figure 6, the northern and southern regions of SSA experience multiple months each year when water scarcity is high. The most significant populations in SSA facing severe water scarcity during at least part of the year live in Nigeria (110 million), while countries such as Somalia and Niger have very large fractions of their population (80-90percent and 50-55percent respectively) experiencing severe water scarcity ${ }^{15}$.

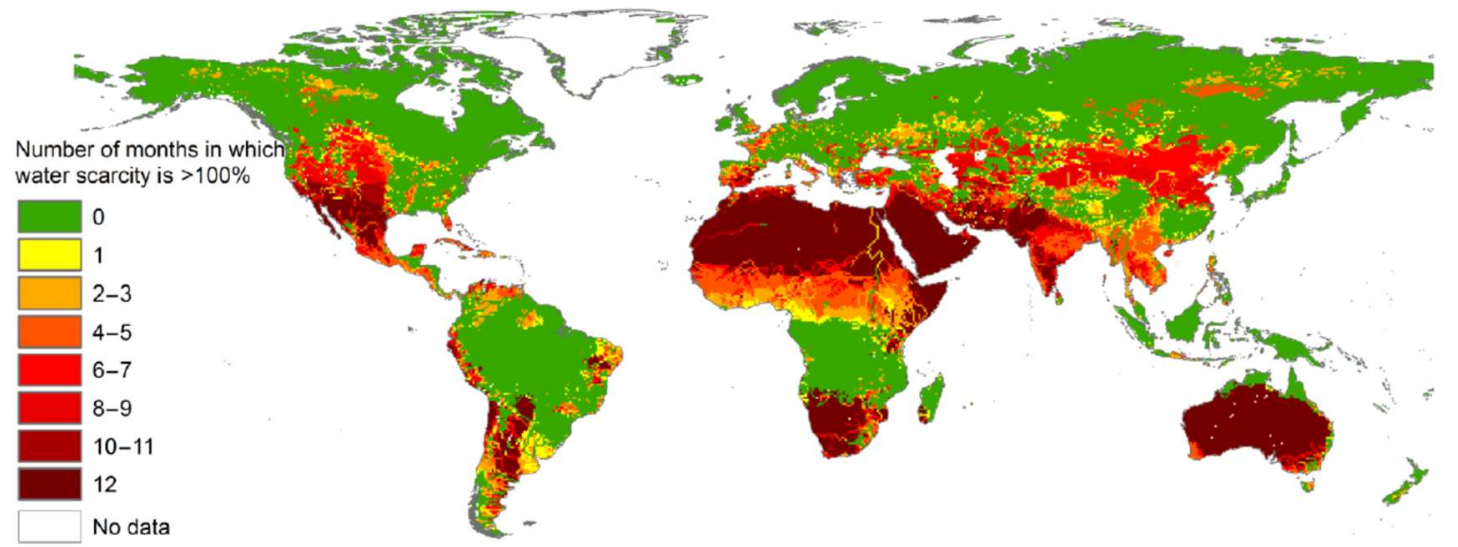

Figure 6 - Northern and southern areas of SSA suffer water scarcity for most, if not all, of the year, number of months per year in which water scarcity is greater than 100 percent (1996-2005) (Source: Mekonnen \& Hoekstra 2016)

Much of the water scarcity in SSA is economic water scarcity - poor management and inequitable distribution - rather than a crisis of absolute scarcity, which means that it can be remedied with targeted investment. Whilst SSA contains regions of absolute physical water scarcity, economic water scarcity is more pervasive (Figure 7). Economic water scarcity occurs when investments on infrastructure development (e.g., water supply pipe networks and reservoirs) needed to cope with the growing water demand are constrained by financial, human or institutional capacity ${ }^{16}$. Water scarcity contributes to chronic food insecurity, environmental migration and civil instability being endemic in some SSA countries.

SSA suffers from recurrent and severe drought events, which have become more frequent and impacting more people. Historical records show that droughts in SSA have already intensified and increased in frequency due to climate change. Africa experienced more than a third of the global share of climatologically driven disasters between 2005 and $2010^{17}$. Droughts can contribute to regional social instability, disasters and forced migration. Figure 8 shows the increasing frequency and human impact of drought in SSA, and Box 2 highlights the ongoing challenge of droughts in SSA.

\footnotetext{
${ }^{15}$ Mekkonen \& Hoekstra 2016.

16 IWMI 2007.

17 UNDP 2012.
} 


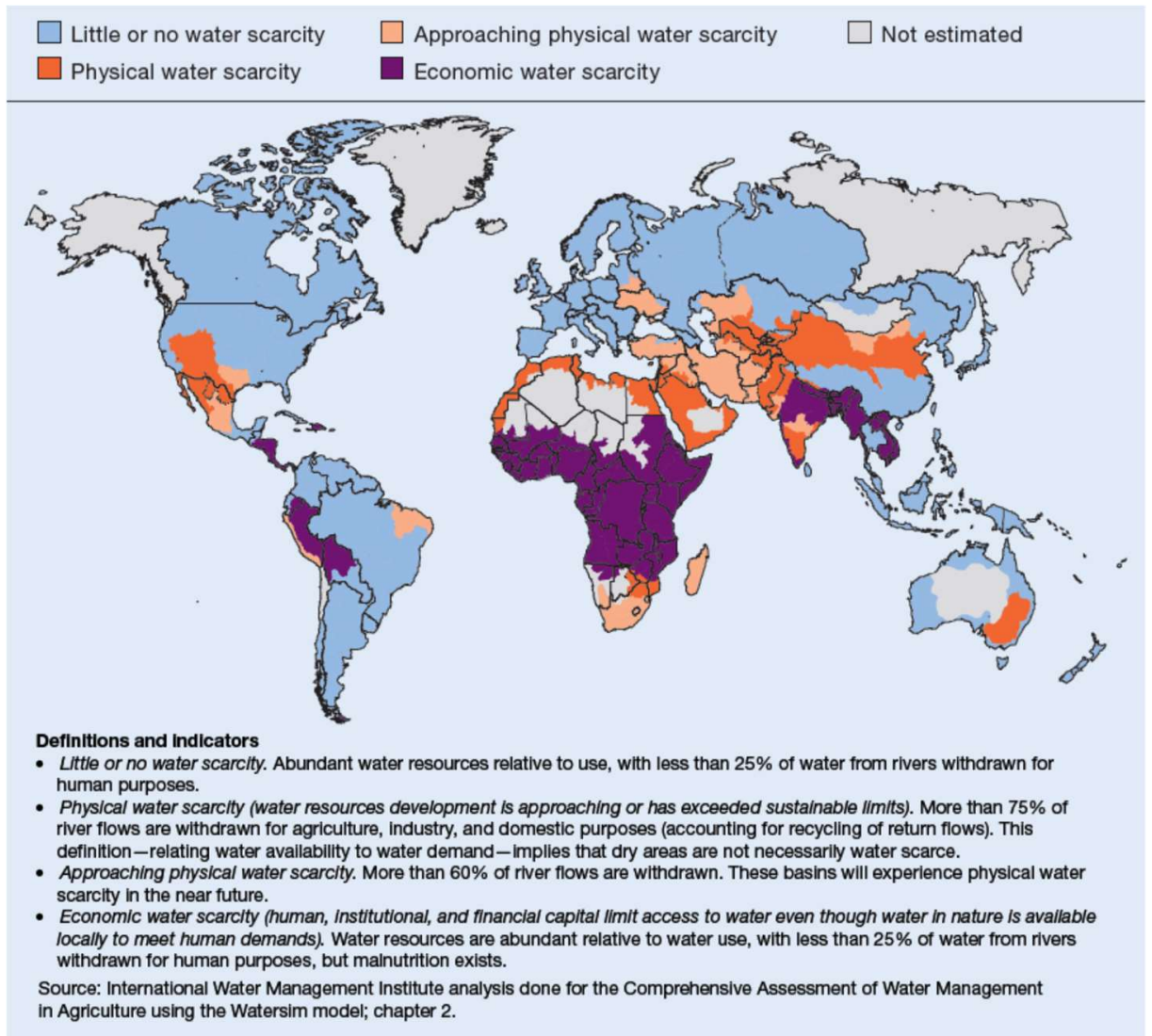

Figure 7 - SSA suffers predominantly from economic water scarcity, indicating that it can be overcome with development intervention, areas of physical and economic water scarcity (Source: IWMI, Mancosu et al. 2015)

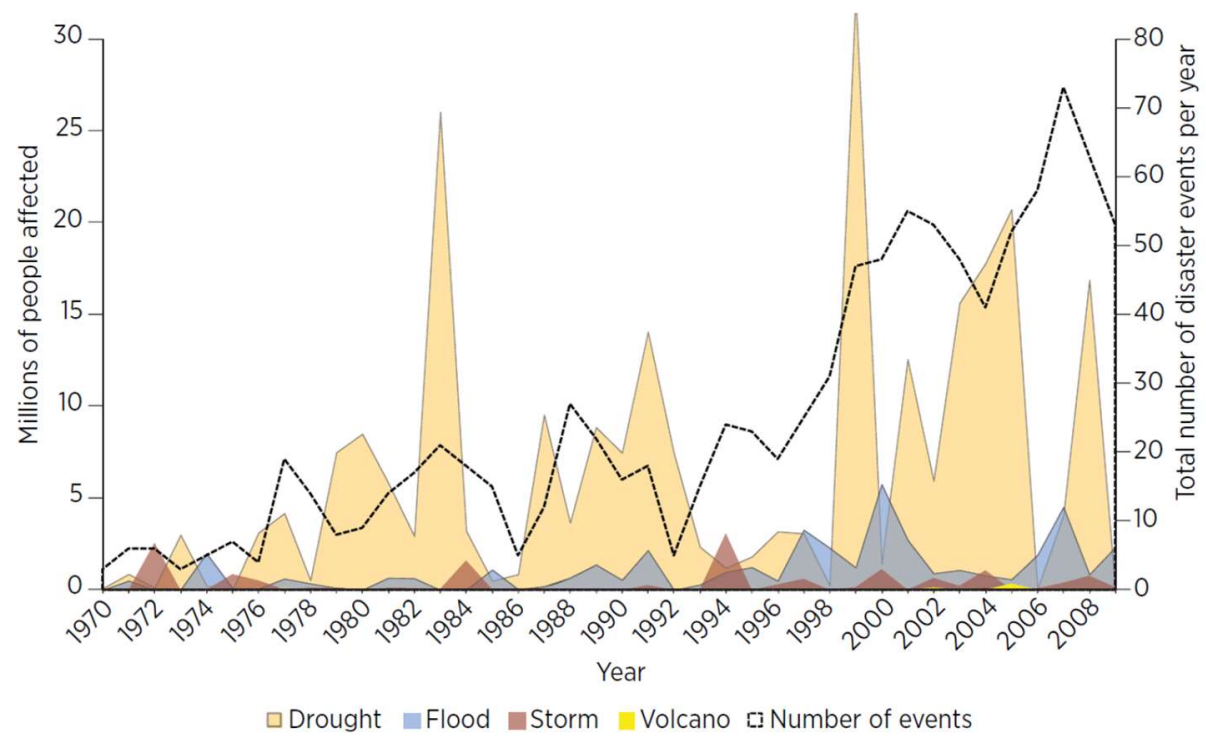

Figure 8 - Increased frequency and impact of reported disasters in SSA (1970-2008), with drought being the most frequent and impactful event type (Source: World Bank, based on EMDAT Emergency Events database 2010) 


\section{Box 2 - Recurrent extreme droughts in SSA}

The United Nations has described recent recurring droughts in southern Africa as "the worst in 35 years" ${ }^{18}$, with more than 38 million people at risk across eastern and southern Africa and famine already being experienced in some countries. At least seventeen countries are struggling to manage the impact ${ }^{19}$, with the highest numbers of at risk populations in Ethiopia (5.7 million), Malawi (6.7 million), Somalia (6.2 million), Sudan (4.6 million) and Zimbabwe (4.1 million) ${ }^{20}$. Additionally, South Sudan and Nigeria are already experiencing famines ${ }^{21}$, a threat which could extend to other countries, such as Somalia. It is estimated that multiple billions of dollars in aid is needed to avert further catastrophe. The current event follows similar humanitarian crises in the region, such as in 2011 when 13 million people were directly affected by drought. Recent research has confirmed that human-induced climate change contributed to recent droughts in Africa (particularly in eastern and southern regions) by increasing El Nino sea surface temperatures and local air temperatures, causing reduced rainfall and runoff, and contributing to severe food insecurity 22 .

In addition to humanitarian costs, drought events cause economic costs via agricultural and pastoralism losses (crop losses, livestock losses), energy generation losses (reduced hydropower generation), industrial production losses, impaired water supply (increased water collection time, time loss due to conflict management meetings, cost of water vendor), forest fires and fishery damage. In some countries, such as Malawi, where recurrent droughts are common, it is estimated that greater than 1 percent is lost annually to drought ${ }^{23}$.

Water scarcity and shocks and poor access to WSS services limit human development, with disproportionate impacts on women and girls. The World Bank (2017) finds that the long-term effects of rainfall shocks can play a role in reducing female agency and empowerment, and increasing fertility rates, perhaps through the effects of lower incomes or education. Furthermore, women and girls often experience underrepresentation in decision making across many levels (lack of voice and participation); traditional roles of water collection come at the expense of education and other economic activities; disproportionate benefits of WSS accrue to men because of the capital-intensive nature of WSS development and management (empowerment and participation); and gender-based biases and violence occurs where there is a lack access to safe sanitation ${ }^{24}$.Gender is an important component of the Sustainable Development Goals (SDGs) - including on issues around access to WSS ${ }^{25}$ - and hence improvements in access to water are required to significantly benefit women and girls ${ }^{26}$.

\footnotetext{
${ }^{18}$ UNOCHA 2016.

${ }^{19}$ Populations currently at risk include: Angola (1.2 million), Burundi (3 million), Djibouti (225,000), Eritrea $(450,000+)$, Ethiopia (5.7million), Kenya (2.6 million), Lesotho (160,000), Madagascar (978,000), Malawi (6.7 million), Mozambique (2 million+), Rwanda (unknown), Somalia (6.2 million), Sudan (4.6 million), Swaziland (638,000), Tanzania (unknown), Uganda (390,000+) and Zimbabwe (4.1 million).

20 IRIN 2017.

21 These famines are related to conflict and drought.

${ }^{22}$ Funk et al. 2016.

${ }^{23}$ Pauw et al. 2010.

24 IEG 2017.

${ }^{25}$ SDG 5 seeks to ensure gender equality and empower all women and girls by 2030 and SDG 6 seeks to ensure availability and sustainable management of water and sanitation for all over the same period.

${ }^{26}$ World Bank 2015.
} 


\subsection{Predicted demand for water in SSA}

Beyond the current water sector challenges in SSA, the region is projected to undergo a globally significant increase in total water demand. The increase in water demand in Africa between 2005 and 2030 is projected to be 283 percent - almost three times higher than any other global region. A significant portion of this new demand (an estimated 92 billion cubic meters, or 20 percent) will come from the municipal and domestic sectors, and competition with other water-using sectors, most notably agriculture (which accounts for 72 percent of this increase), will increase dramatically ${ }^{27}$.

Per-capita water demand will also increase significantly. Per-capita consumption of water (potable and irrigation), food and energy are all predicted to increase in SSA ${ }^{28}$. Increased access to water will help economies develop and move people out of poverty ${ }^{29}$. On one hand, this creates potential threats to water resources, through exposure to quantity and quality issues from lack of management, and opportunities to chart more sustainable water resources development pathways as a driver for socioeconomic development.

While such non-climate drivers will increase demand for water, climate drivers are predicted to alter hydrological cycles. Contributing factors for each are reviewed below.

\subsubsection{Non-climatic drivers of water demand}

The overall impacts of non-climatic drivers - such as population growth, urbanization and changing consumption patterns, increased reliance on irrigation to meet food demand, and land use - on water resources in SSA is expected to be significant on both patterns and magnitudes of water demand ${ }^{30}$. Non-climate stressors are known with high levels of certainty and are predicted to have a far greater influence on groundwater resources than climate stressors in the short-to-medium term. For example, in Ethiopia, the population is expected to increase by 90 percent to 2050 and some authors ${ }^{31}$ predict that the majority (up to 80 percent) of future water shortages (particularly in the short-to-medium term) will be attributed to socioeconomic factors rather than climate change.

Rapid urbanization will arguably be the most important structural transformation to occur in SSA, concentrating demand for water and placing pressure on water resources. SSA is already experiencing some of the world's highest urbanization rates ${ }^{32}$, with the urban population projected to triple (and comprise 60 percent of inhabitants) by $2050^{33}$. This will see an approximate doubling of the current inhabitants in urban areas over that period ${ }^{34}$ (Figure 9). Urbanization will be accompanied by informal settlements (400 million slum dwellers by 2020) and an increase in urban water demands by at least a factor of 4 by $2050^{35}$, which will place pressure on water resources and create wastewater management challenges.

\footnotetext{
27 Jacobsen et al. 2013.

${ }^{28}$ Carter \& Parker 2009.

${ }^{29}$ Hunter et al. 2010 in Macdonald et al 2012.

${ }^{30}$ Calow \& MacDonald 2009, Carter \& Parker 2009, MacDonald et al. 2009, Taylor et al. 2009.

${ }^{31}$ Such as Calow \& MacDonald (2009) and Droogers et al. (2012).

${ }^{32}$ UNHABITAT 2008.

${ }^{33}$ UNDESA Population Division 2010, Collier 2017.

${ }^{34}$ UN Habitat 2010.

${ }^{35}$ Carter \& Parker 2009.
} 


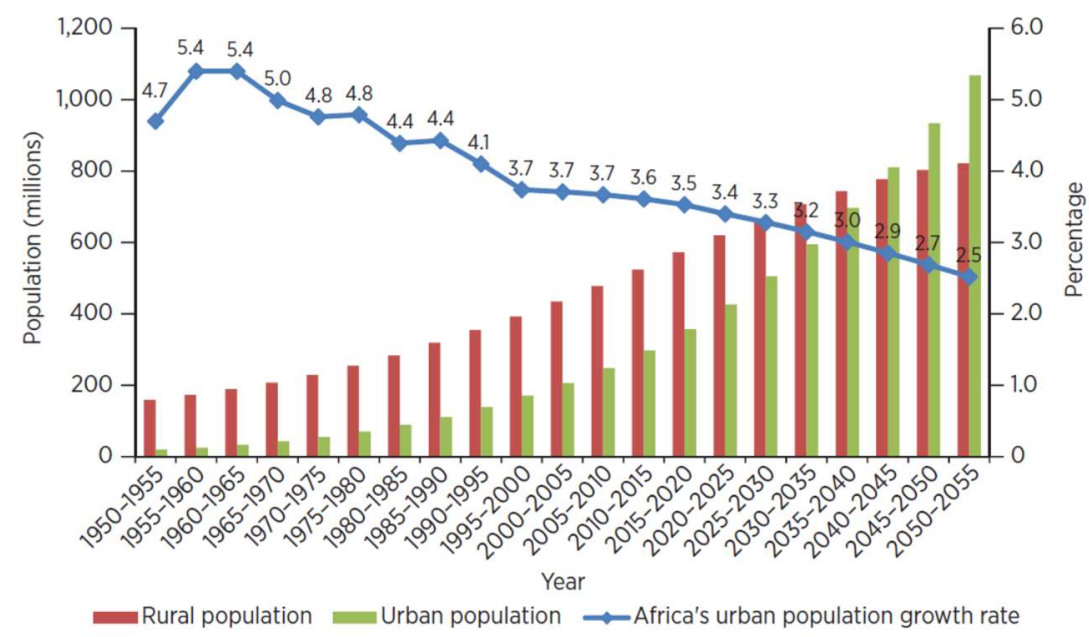

Figure 9 - Trends in urbanization in Africa, showing an approximate doubling by 2050 (Source: UNDESA 2012)

The gap between urban water demand and water supply is growing in SSA. Water demand is increasing at a higher rate than population growth - as income levels of urban dwellers rise and they demand better services - whereas water availability is shrinking due to competing demands from agriculture, mining and industry, and from deteriorating water quality and climate change. SSA cities must 'sprint to stand still' to meet the demands of rapid urban population growth ${ }^{36}$.

Concurrently, absolute rural populations are expected to continue to grow, by approximately 45 percent between 2000 and $2050^{37}$, meaning that rural water security and irrigated agriculture will remain priorities. Livestock production and irrigated agriculture are forecast to grow to support rural population growth, both of which will consume large volumes of water. In other global regions, such as North Africa, the Middle East, the Near East and South Asia, more than 75 percent of food is produced by means of irrigation ${ }^{38}$. Some authors ${ }^{39}$ estimate that the largest relative increase of irrigation requirements globally will occur in Africa (of +300 percent) between 2000 to 2080 .

Population growth and changing consumption patterns will increase demands for energy and industrialization, both of which rely on water as inputs ${ }^{40}$. Surface water resources may experience competition from hydropower for energy generation and industrialization may draw on both surface and ground water resources.

\subsubsection{Climate drivers of water demand}

Further to the primary non-climate stressors outlined above, the effects of climate change on water resources will be spatially variable across SSA and may be felt most severely in the medium-to-longer-term. While spatially variable, generally forecasted accelerated warming in coming decades is likely to increase precipitation in wet months and decrease precipitation in dry months; increase desertification; reduce river flow due to increased evaporation; increase

\footnotetext{
36 Jacobsen et al. 2013.

${ }^{37}$ Carter \& Parker 2009.

${ }^{38}$ Mancosu et al. 2015.

${ }^{39}$ Fischer et al. 2007.

${ }^{40}$ World Bank 2016.
} 
risk of flash flooding; and reduce long-cycle crop production ${ }^{41}$. This will amplify existing stress on water availability in SSA ${ }^{42}$ and ultimately become a key constraint on the region's continued economic development. For example, climate change may cause an estimated 40percent of SSA countries to be "at risk of significant declines in crop and pasture production" ${ }^{43}$, to affect ruralurban migration patterns ${ }^{44}$ and place major stresses on water delivery infrastructures ${ }^{45}$. Climatechange induced water stress is projected to influence $75-250$ million people in SSA by $2020^{46}$ and expose both urban and rural populations to drought.

Climate change may shift the location and extent of drylands. Climate modeling indicates that dryland areas will expand and shift because of climate change. Some zones may become incapable of sustaining livestock production and intensive agriculture (particularly regarding predicted rainfall and surface water scarcity changes). In drier climate scenarios, the extent of SSA dryland may increase up to 20 percent $^{47}$. Figure 10 illustrates possible drylands shift and expansion zones under climate change.

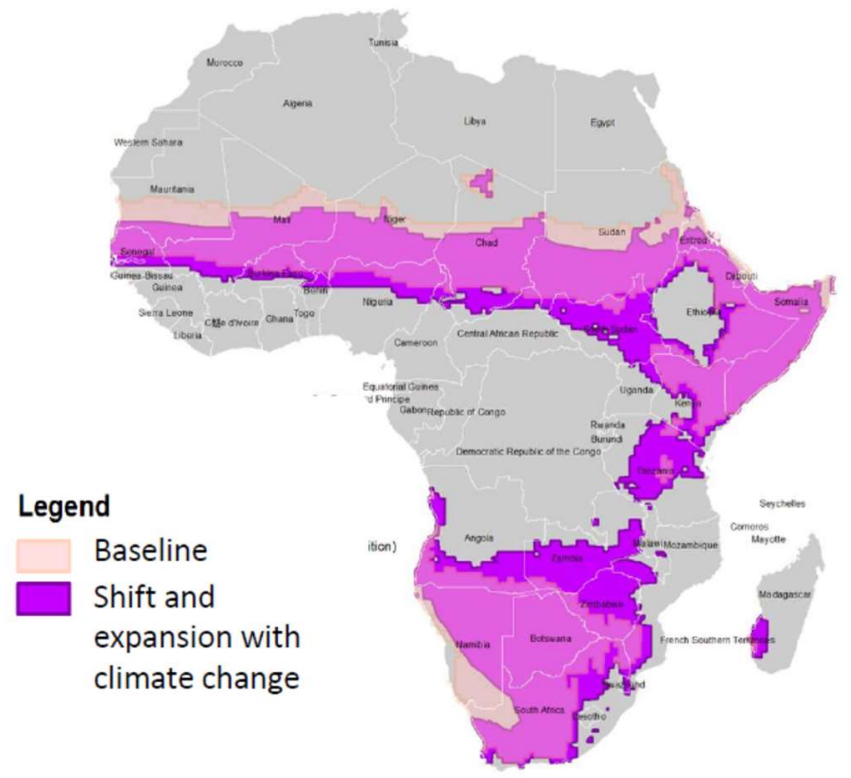

Figure 10 - Expected shift and expansion of dryland areas due to climate change (Source: Saghir 2015)

\subsubsection{Overarching global agreements to help address water-development challenges}

The international community has established several agreements to strategically address both the non-climate and climate drivers of water-development challenges ahead. International agreements, including the SDGs ${ }^{48}$, the Sendai Disaster Risk Framework ${ }^{49}$, and the Paris Climate

\footnotetext{
${ }^{41}$ Besada 2015.

42 IPCC 2012.

${ }^{43}$ Ludi 2009.

44 UN-HABITAT \& UNEP 2010, Yuen \& Kumssa 2011.

45 IPCC 2014.

46 UNDP 2012.

${ }^{47}$ Saghir 2015.

${ }^{48}$ Which build upon the Millennium Development Goals (MDGs).

${ }^{49}$ Which contains four priority areas: (i) understanding disaster risk; (ii) strengthening disaster risk governance to manage disaster risk; (iii) investing in disaster risk reduction for resilience; and (iv)
} 
Accord $^{50}$, have been established to promote sustainable development and poverty reduction, disaster risk reduction and management, and climate resilience, respectively. For each agreement, water is included as a fundamental resource for achieving the desired outcomes.

\subsection{Comparative utilization of surface water and shallow and deep groundwater in SSA}

Given the outstanding demand for water to meet human and economic needs in SSA today coupled with the forecast growth in demand from both non-climate and climate drivers - it is important to understand how surface water and groundwater resources are currently being utilized in SSA ${ }^{51}$.

\subsubsection{Surface water utilization in SSA}

SSA contains significant regional surface water resources. However, availability is unevenly distributed within and between countries, with some blessed with abundance and others scarcity. SSA exhibits a wide range of surface runoff scenarios within and between countries. The high variability of precipitation and temperature across SSA translates into widely varying runoff, with basins such as the Congo displaying extremely high runoff and the arid and semiarid regions of Egypt, the Sahel, Sudan, and southern Africa displaying very low runoff.

Considerable inter- and intra-annual variation in precipitation and surface runoff are common across SSA. Much of Africa exhibits significant changes in runoff and flows within and across years ${ }^{52}$.

There are many transboundary surface water systems in SSA, which require regionally coordinated governance ${ }^{53}$. Africa has 80 transboundary rivers and lake basins and 17 large water catchment areas exceeding $100,000 \mathrm{~km}^{2}$ each $^{54}$.Shared watersheds increase competition between states for limited resources. These transboundary issues may also affect international aquifers associated with these rivers and lakes.

Surface water development is advanced in SSA (relative to groundwater), being the preferred source for uses ranging from urban water supplies to energy generation. Surface water development has been strongly promoted and funded by national and international investors. As an example, most large urban water utilities rely almost exclusively on surface water sources for permanent supply (less than a handful of large urban water utilities use groundwater as a permanent source of supply ${ }^{55}$ ).

enhancing disaster preparedness for effective response and to "Build Back Better" in recovery, rehabilitation and reconstruction (UNISDR 2015).

${ }^{50}$ Which brings all nations into a common cause to undertake ambitious efforts to combat climate change and adapt to its effects, with enhanced support to assist developing countries to do so.

${ }^{51}$ Non-conventional water sources are not considered separately here, but specific cases of desalination, reuse of treated wastewater and rainwater harvesting are outlined in the report.

52 Jacobsen et al. 2013.

${ }^{53}$ Berada 2015.

${ }^{54}$ Ruphael 2004.

${ }^{55}$ Foster et al. 2010. 
As such, it is predicted that to increase production from already developed surface water resources will become increasingly expensive to meet growing demand from non-climate drivers and potentially reduced supply from both climate and non-climate drivers. Many surface water resources have already been influenced by interventions such as upstream diversions, channel re-routing, dams/reservoirs and hydropower installations. Increasingly, large-scale infrastructure projects may cause political tensions and potentially increase the impacts of floods and droughts on downstream and/or neighboring regions ${ }^{56}$.

For those countries without plentiful surface water sources, or those with surface water sources already developed, groundwater may offer one of the only alternatives to match predicted demand increases. Beyond surface waters, and ocean desalination options for countries with coastal access, groundwater resources present the greatest potential for many countries.

\subsubsection{Deep and shallow groundwater: utilization in SSA}

There is currently a high dependence on, particularly shallow, groundwater in SSA, albeit mostly informal development by smallholder farmers. It is estimated that between 50percent ${ }^{57}$ to 75 percent ${ }^{58}$ of SSA's population relies on groundwater, particularly for drinking purposes ${ }^{59}$. A World Bank study of WASH infrastructure in SSA confirms that groundwater plays an important role in many sectors, particularly in arid and semi-arid areas, rural areas ${ }^{60}$ and where rainfall variability is high ${ }^{61}$. Development and management is largely informal and by smallholder farmers.

At the regional scale, groundwater utilization - whilst small relative to its potential (see Chapter 3) - has increased in recent decades. A 2012 study by IWMI confirms that extraction of groundwater for water supply has doubled in the last two decades in three regions: West Africa, Southern Africa and East Africa. More than 60 thousand boreholes were drilled in the 15 countries studied ( 5 countries from each region) to provide drinking water for more than 60 percent of the population of small town and rural areas and to increase groundwater use for small scale irrigation and livestock.

Most development to date has focused on shallow groundwater resources, which are accessible but less resilient than deeper resources. Many communities and private landholders, particularly in drylands, have developed shallow groundwater wells for drinking and agricultural / pastoral purposes. However, such resources can be seasonably variable and limited in their yield and capacity to guard against drought events.

\footnotetext{
${ }^{56}$ WWF International.

${ }^{57}$ Carter \& Parker 2009.

${ }^{58}$ Goulden et al. 2009.

${ }^{59}$ MacDonald et al. 2012.

60 JMP (2008) estimates that up to 80 percent of rural dwellers rely on groundwater-based community or household supplies for domestic and other water needs).

${ }^{61}$ Existing data shows that hydrological variability in Africa is higher than in any other region on the planet. Rainfall is likely to become increasingly unpredictable in terms of both intensity and duration, with increases in the frequency of extreme events (Calow \& MacDonald 2009). Inter-annual and seasonal variability is likely to increase (ibid.).
} 
Although groundwater resources can provide a buffering capacity to climate change, shallow resources are vulnerable to seasonal variations (Figure 11) and even deeper resources will ultimately be influenced by any long-term changes in precipitation patterns. Predicted impacts of climate change on groundwater will vary across climatic zones. Some authors ${ }^{62}$ predict greatest influence in areas receiving between 200 and $500 \mathrm{~mm}$ rainfall per year, where a decline in groundwater recharge could particularly influence shallow aquifers ${ }^{63}$ and coastal aquifers may be vulnerable to saltwater intrusion ${ }^{64}$. Factors such as the timing, intensity and duration of rainfall events in relation to temperature, storage potential of underlying aquifers, soilvegetation conditions and land use could all be significant and altered by climate change ${ }^{65}$. The IPCC's 4th Assessment Report reflects a paucity of information on SSA groundwater resources and uncertainties associated with climate change ${ }^{66}$.

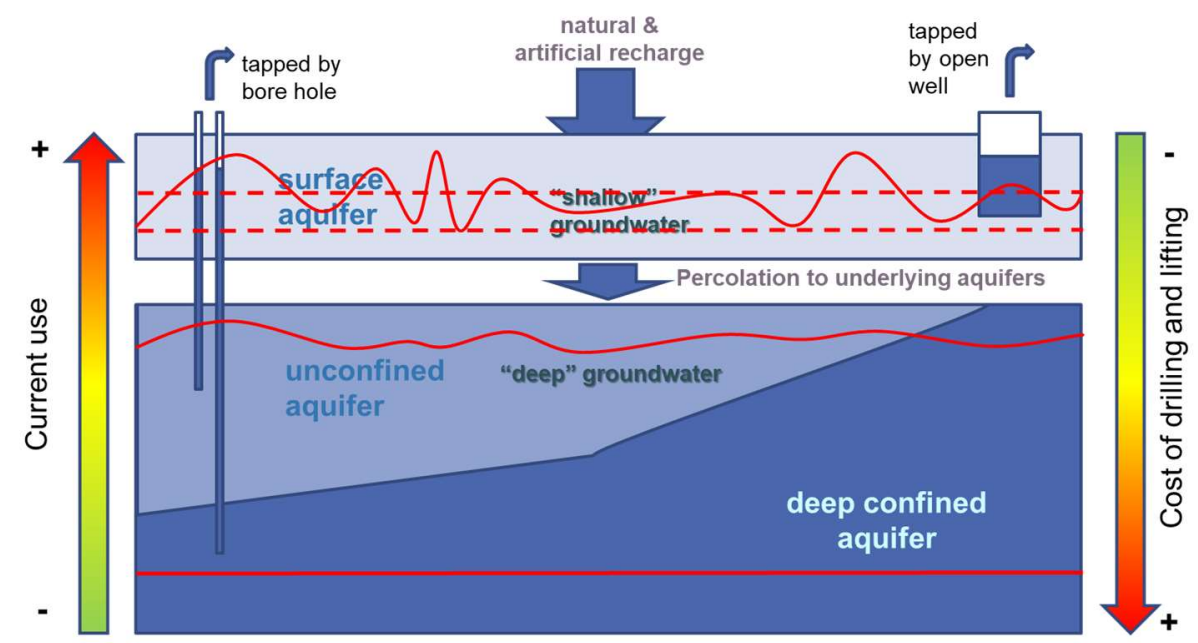

Figure 11 - Shallow groundwater is cheaper and easier to access than deeper resources; but is also more vulnerable to seasonal variation (red lines illustrate seasonal groundwater levels)

Deeper aquifers are generally poorly understood and rarely accessed in SSA (). However, where available and of adequate quality, these resources may hold significant potential in supporting economic and humanitarian development at scale, particularly in the context of climate and non-climate drivers. At present, deep groundwater resources are suspected to be severely underutilized. While only a fraction of SSA's total subsurface potential may be available for extraction through wells, it may likely be enough to satisfy the potable water needs of most of Africa's rural populations ${ }^{67}$. Deep groundwater may be a most reliable source during extended periods of variable rainfall, dry spells, and droughts, however currently they are not being utilized at scale for this purpose (Figure 11). Chapter 3 investigates the location and potential of these deeper groundwater resources.

\footnotetext{
62 Such as MacDonald et al. 2009.

63 Barthel et al. 2009.

${ }^{64}$ Kundzewicz\&Döll 2009.

${ }^{65}$ Calow \& MacDonald 2009.

${ }^{66}$ Bates et al. (2008).

67 Drury 2012.
} 
Despite strong informal development, and a high and increasing dependence on groundwater resources, there are major deficiencies in knowledge and understanding of subsurface systems in SSA. Groundwater systems are complex, with strengths and weaknesses compared to surface water resources ${ }^{68}$. A quantitative understanding of groundwater resources is required ${ }^{69}$, however current knowledge is limited to only a low-resolution understanding. Many authors ${ }^{70}$ note that inadequate or absent observational data in SSA remains a systemic limitation. As a result, the relationship between SSA's highly variable hydro-climatology and groundwater resources is not clear ${ }^{71}$.Key groundwater dynamics are not well understood, particularly in the context of climate change ${ }^{72}$, and groundwater models are limited to specific projects and regions ${ }^{73}$. Some authors ${ }^{74}$ call for quantitative, spatially explicit information on groundwater to characterize resources to usefully inform strategies to adapt to increasing water demand.

Weak data and information systems for groundwater management is a serious challenge. In the absence of reliable data on resource characteristics, sustainable groundwater management is not possible and both shallow and deeper resources may be mismanaged. Renewable and non-renewable resource potential cannot be defined without a thorough understanding of groundwater system dynamics. Evidence-based land-use planning can also not be coordinated to prevent pollution damaging shallow and unconfined aquifers. Information deficiencies also lead to opportunity costs, where resource utilization is well below sustainable potential.

Beyond a paucity of data and information on the physical characteristics of groundwater resources, there is also a deficiency of understanding of 'secondary factors' related to groundwater development. There is a lack of strategic water resources information relevant for economic and sector planning. To make medium and long-term investment plans in critical water dependent sectors like water supply, agriculture or extractives, in addition to an adequate understanding of available water resources, there is a need to understand the comparative costs and benefits of investment in both shallow and deep aquifers and associated secondary factors such as governance arrangements, technological requirements, infrastructure such as energy and transport access, and costs of development, operation and maintenance. An assessment of available and accessible groundwater storage and associated development, operation and

\footnotetext{
${ }^{68}$ Potential benefits associated with groundwater can include lower development costs, less treatment requirements, lower evaporation losses, greater resilience (buffer) to climate variations/change and extreme events, location often able to be close to demand centers, and enhancing reliability of water supply for multiple purposes (Taylor et al. 2009, Calow et al. 2010, MacDonald et al. 2012, CGIAR 2016, Calow \& MacDonald 2009). However, at the same time, groundwater is invisible (Wijnen et al. 2012) and as a result often poorly understood by the public and decision makers, contains limited data on its physical distribution and aquifer characteristics, access is difficult to manage (multiple, uncontrolled users), surface-groundwater interactions are often poorly understood and initial resource evaluations are often high cost and with high uncertainty.

69 Taylor et al. 2009.

${ }^{70}$ Such as Bonsor\& MacDonald 2011, Batisani 2011, Taylor et al. 2009, Neumann et al. 2007.

71 Taylor et al. 2009.

${ }^{72}$ Kundzewiczet al. 2007.

${ }^{73}$ Bonsor \& MacDonald 2011.

${ }^{74}$ Such as MacDonald et al. 2012.
} 
maintenance costs would also allow for a more economic basis for natural resource planning and water allocation.

Overall, shallow groundwater development is proceeding in SSA, particularly in dryland rural areas, albeit in a largely unplanned manner. In contrast, deep groundwater is largely unutilized and is suspected to have significant potential as a strategic development resource. Recent studies estimate that about sixty thousand shallow tube wells are dug annually in SSA, largely by private users. However, knowledge of groundwater and key physical characteristics is low - both for shallow and deeper resources - which has been an obstacle to deeper groundwater development to date. Chapter 3synthesizes the latest information on the state of knowledge on groundwater resources in SSA, with a focus on their spatial distribution, accessibility and consideration of macro trends and secondary factors contributing to their development potential.

\subsubsection{Conjunctive use of surface and groundwater resources in SSA?}

Currently in SSA, there is little consideration of conjunctive use of water resources (surface and ground water interactions), neither at strategic nor operational levels. While there have been many activities in SSA on water scarcity and surface water resource development, much less has been focused on groundwater. Furthermore, surface water development is often pursued without consideration of dependency or interaction on groundwater resources.

There is insufficient attention to groundwater as part of integrated water resources management in SSA. While the decentralized nature of groundwater resources is important to meet local smallholder needs, sustainable investment in groundwater requires careful analysis of local institutional and governance issues, and local hydrological, social, environmental and economic factors which are not as visible as those related to investment in surface water resources. Hence, attention to sustainable management of groundwater resources in SSA should expand the strategic framework of IWRM to address the unique features related to investment in groundwater resource development and management.

\subsection{What potential roles for groundwater development?}

Many aspects of SSA's future development, such as irrigated agriculture, urban and rural water security and drought resilience may become increasingly reliant on groundwater. Hence, demand for resources is expected to increase significantly. Demand for groundwater across SSA is likely to increase as (i) rainfall and surface water sources become less reliable, and (ii) demand from multiple sectors increases. Groundwater may be the only reliable source in many areas during drought events when many surface waters may have reduced or depleted availability. Groundwater is anticipated to be an increasingly critical source as urban centers and irrigated agriculture expand. Some authors ${ }^{75}$ state that increasing reliable water supplies throughout SSA will depend on the development of groundwater, particularly in the face of climate change ${ }^{76}$.

The potential costs of not developing groundwater in SSA may significantly outweigh the costs of its development. The cost of developing the water sector includes diverting public financial

\footnotetext{
75 Such as Giordano 2009 and MacDonald \& Calow 2009.

76 Taylor et al. 2009.
} 
resources for the benefit of select communities with little or no cost recovery creating uneven development favoring landowners in the irrigated areas, depreciation of capital invested in water delivery with limited resources for operations and maintenance, environmental degradation including destruction of natural habitats, depletion of scarce resources especially poorly recharged aquifers, increased salinity, especially in costal zones as a result of over drafting groundwater resources close to the coast, and social cost including waterborne diseases and risks of supplying contaminated water ${ }^{77}$. However, failure to deal with forecast water crises could undermine development progress achieved, and underway, and both cause and exacerbate conflicts, environmental degradation, poverty and food insecurity. The potential costs of no groundwater development seem to significantly outweigh the costs of its development.

Multiple demand- and supply-side factors are converging to make now the opportune time for the World Bank to help drive a sustainable groundwater development agenda forward in SSA. On the demand-side, current and forecast water scarcities will drive the need for alternatives to surface water resources, which are experiencing pressures from climate and non-climate drivers of demand. Additionally, policymakers in SSA are aware that their countries lag other regions, such as in Asia and Latin America, in developing groundwater resources for sustainable economic growth, poverty reduction and for livelihood improvements. On the supply-side, technological advancements in exploring, characterizing, developing and pumping groundwater resources have lowered groundwater development and operational costs. This includes earth observation and global data sets and solar pumping technologies. Synergies with other development sectors, such as energy and transport, present opportunities for enhanced groundwater development. As climate change impacts precipitation patterns, groundwater resources offer buffering capacity against increasing variability and extreme events.

Given that 85 percent of SSA's population lives more than $10 \mathrm{~km}$ from a major river or lake, groundwater has a distinct potential of being developed close to where it is needed. It can also be developed incrementally, in response to demand. This gives groundwater an advantage over surface water, making it ideal for small-scale water supplies and irrigation in rural areas and for smaller municipalities and agro-pastoralist communities. Long pipelines from distant water sources are not required. Groundwater development can be incremental and staged where and when needed - avoiding large upfront investments often associated with many surface water projects (e.g. dams, reservoirs) and conveyance infrastructure. Where sufficient groundwater resources are available, boreholes can be drilled as demand and budgets increase.

While the potential contributions of groundwater are clear, and demand for water is increasing, up until now there has been little certainty in the availability of accessible groundwater resources. Chapter 3 synthesizes available information and presents spatial distribution and volumetric potential of shallow and deep groundwater resources in SSA.

\footnotetext{
${ }^{77} 2007$ World Development Report.
} 


\section{An Assessment of Groundwater Resources in SSA}

\subsection{Overview}

There is significant potential for an increase in groundwater use, including for irrigation, in SSA. The sub-continent uses only around 2 percent of its internally renewable groundwater resource, defined as the total amount of recharge received by its combined aquifers. With its variable rainfall, propensity to drought and vulnerability to climate change, sustainable increases in irrigation are amongst the most effective ways of improving livelihoods, bolstering economic growth and increasing resilience in the region.

Although groundwater resources are significant in SSA, they are also unevenly distributed, and accessibility is highly variable. Rainfall and recharge are highest in the equatorial region of Africa $^{78}$, but groundwater is most needed in drier parts of the continent. Although average annual rainfall is much lower in the semi-arid and arid regions of SSA, the estimated volumes of renewable groundwater available in drylands areas are nevertheless still very significant (less than 5 percent are currently being used). However, even within drylands areas groundwater availability is highly variable.

Relative to the size of the African continent, knowledge of its groundwater resources is poor. Whilst detailed studies have been carried out in many regions over the past decades, a significant share of these studies is not easily accessible because the reports are in paper form or not in the public domain. Groundwater resources in Africa are amongst the least monitored and understood of any continent ${ }^{79}$. Continent-wide datasets on water resources exist, mostly based on remotely sensed data or global model outputs. Groundwater is a resource that depends on local geology, topography and climate, and its potential is highly variable in space. While regional data indicate significant groundwater potential overall, physical resource characteristics need to be confirmed at local levels to determine key parameters such as sustainable yields and water quality.

Groundwater monitoring networks cannot provide even a partial picture of groundwater levels and quality in many places. A few well-monitored aquifers contrast with large areas where little is known apart from regional averages. In some countries (such as Angola, DRC, Equatorial Guinea) routine groundwater monitoring does not take place, and in several others (such as Zimbabwe, Malawi) it is in decline. Recharge rates that are a measure of the renewable groundwater potential are not known for most of the aquifers in SSA. Available estimates of renewable groundwater are based on global hydrological models that provide average values of groundwater recharge for regions (Figure 12).

\footnotetext{
${ }^{78}$ MacDonald et al. 2012, AGW-Net 2014.

${ }^{79}$ See for example Tuinhof et al. 2011 and Vilholth2013.
} 


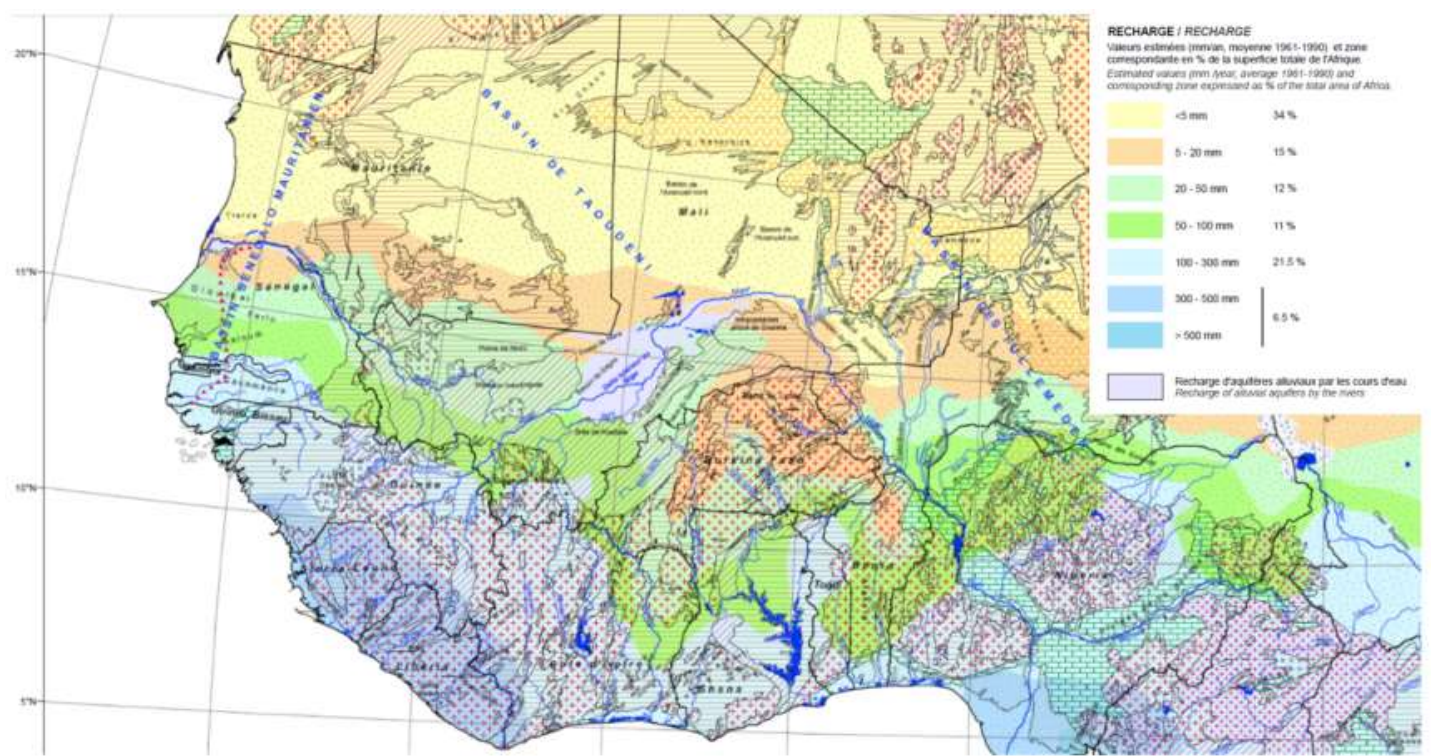

Figure 12 - Detail of the Hydrogeological Map of Africa at 1/10 M Scale (BRGM, 2008) showing parts of West-Africa and the Sahel. Colors indicate estimated values of groundwater recharge (in $\mathrm{mm} / \mathrm{yr}$ ) calculated by Döll et al. (2005) using a global hydrological model.

\subsection{How much groundwater is there in SSA?}

When evaluating the amount of groundwater available, different measures can be used each of which describes another dimension of the groundwater resource. A common indicator of the amount of groundwater that can be used sustainably is the amount of groundwater recharge or the share of rainfall and surface water that infiltrates and percolates down to the groundwater body or aquifer on an annual basis. Annual recharge volumes are often referred to as "renewable groundwater". Another dimension of groundwater is the total volume in storage in the subsoil. These volumes can be significant but are not always relevant as only a small portion of the groundwater stored can be extracted due to technical and economic constraints. Limitations to the amount of water that can be extracted are maximum depth and density of wells and capacity of pumps to lift water to the surface. Box 3 provides further background on limitations to groundwater use.

The total volume of renewable groundwater in Sub Saharan Africa is calculated ${ }^{80}$ to be about 1,400 cubic kilometers per annum $\left(\mathrm{km}^{3} / \mathrm{a}\right)$ - equivalent to 15 years of average total flow of the Nile River. Of this volume, it is estimated that only about $20 \mathrm{~km}^{3} / \mathrm{a}( \pm 0.14$ percent) is being abstracted. The comparable figures for India are an estimated renewable groundwater resource of about $432 \mathrm{~km}^{3} / \mathrm{a}$, with about $251 \mathrm{~km}^{3} / \mathrm{a}$ of this resource being withdrawn (about 58 percent $)^{81}$. In the drylands, only about $15 \mathrm{~km}^{3} / \mathrm{a}$ of the renewable groundwater resource is abstracted from an estimated available renewable volume of $324 \mathrm{~km}^{3} / \mathrm{a}$ (5 percent).

\footnotetext{
${ }^{80}$ Based on FAO Aquastat data, quoted in Margat and van der Gun 2013. This refers to groundwater produced internally in Sub Saharan Africa, including baseflow to rivers, lakes and wetlands. It does not include non-renewable groundwater resources. The total volume of groundwater in storage in Africa, including non-renewable groundwater, is about 0.66 million $\mathrm{km}^{3}$ (MacDonald et al., 2012), making groundwater by far the largest stock of fresh water on the continent.

${ }^{81}$ Based on FAO Aquastat data. Some scholars (e.g. Sekhri 2014) focus on emerging dis-benefits of groundwater abstraction in some parts of India, but in general these are far outweighed by the economic and food security benefits of the South Asian 'Green Revolution' (Shah 2017).
} 
Box 3 - Renewable and non-renewable groundwater, artesian conditions, and groundwater storage

A distinction needs to be made between "renewable" and "non-renewable" groundwater resources. Renewable groundwater is groundwater that is replenished under the current climate, often seasonally or every few years. Non-renewable groundwater, sometimes called "fossil groundwater", is groundwater that receives little or no modern recharge due to changes in the water cycle (e.g. long-term reductions in precipitation and recharge). Both renewable and non-renewable groundwater are vulnerable to unsustainable use. Although non-renewable groundwater cannot be used indefinitely, it can sometimes be used for decades or longer. For example, Libya's "great man-made river" project uses fossil groundwater from the Nubian Sandstone aquifer to provide water to coastal cities, in the knowledge that this resource is finite ${ }^{82}$. This situation is analogous to the mining of a mineral resource.

The volume of groundwater stored in an aquifer is usually many times the volume that it receives as annual recharge. This explains the difference between the figures for total groundwater in storage in SubSaharan Africa, and the volume that is annually replenished. This characteristic can make aquifers useful in drought mitigation, since storage may be depleted in dry years in the expectation of replenishment in years of above-average recharge. This report provides figures for renewable groundwater, rather than total groundwater in storage, unless otherwise specified.

In some cases, it is the depth to groundwater from the surface rather than the volume in storage that defines what is economically exploitable. Groundwater levels deeper than $300 \mathrm{~m}$ below ground level are generally considered a maximum useful depth in terms of pumping costs and technological complexity. Where an aquifer is confined by overlying impermeable strata, the water table often rises above the top of the aquifer when reached by a borehole, known as artesian conditions see diagram below). In these cases, a very deep aquifer can still be economically exploitable if the groundwater table rises close to the surface. These technical issues highlight the need of a sound hydrogeological understanding of any aquifer or groundwater resource that is under consideration as part of a coordinated development strategy.

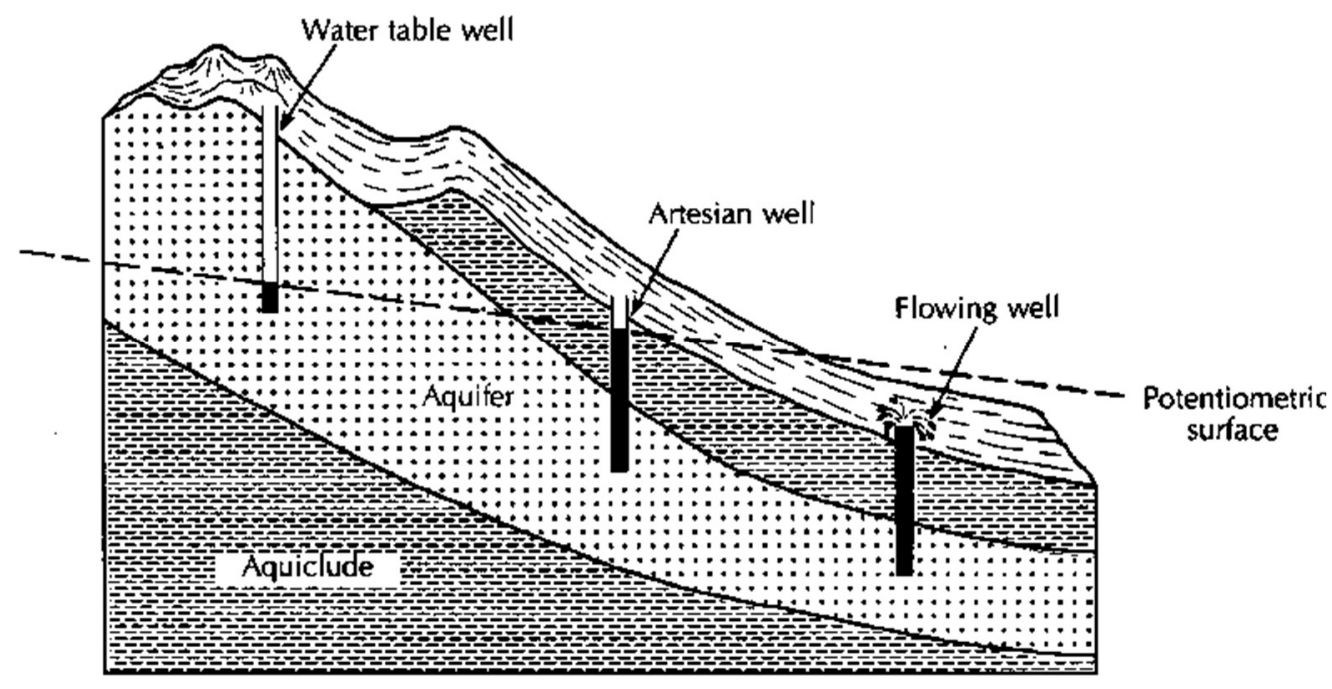

(Diagram after Fetter, 1994)

SSA abstracts, on average, about $28 \mathrm{~m}^{3} / \mathrm{a}$ of groundwater per person (Table 1). The comparable figure for India is about $208 \mathrm{~m}^{3} / \mathrm{a}$. Broken down by country, only Djibouti, Mauritania and South Africa use more than 25 percent of their renewable groundwater resources.

82 Voss and Soliman, 2014 
Table 1 - Comparison between renewable groundwater, and groundwater abstracted, SSA and India

\begin{tabular}{|c|c|c|c|}
\hline & $\begin{array}{c}\text { Total renewable } \\
\text { groundwater }\end{array}$ & $\begin{array}{c}\text { Total groundwater } \\
\text { abstracted }\end{array}$ & $\begin{array}{c}\text { Groundwater abstracted per } \\
\text { capita }\end{array}$ \\
\hline SSA & $1,400 \mathrm{~km}^{3} / \mathrm{a}$ & $20 \mathrm{~km}^{3} / \mathrm{a}$ & $28 \mathrm{~m}^{3} / \mathrm{a}$ \\
\hline Drylands & $324 \mathrm{~km}^{3} / \mathrm{a}$ & $15 \mathrm{~km}^{3} / \mathrm{a}$ & $37 \mathrm{~m}^{3} / \mathrm{a}$ \\
\hline India & $432 \mathrm{~km}^{3} / \mathrm{a}$ & $251 \mathrm{~km}^{3} / \mathrm{a}$ & $208 \mathrm{~m}^{3} / \mathrm{a}$ \\
\hline
\end{tabular}

Source: FAO Aquastat data; " Countries in Sub Saharan Africa with more than 40 percent of their area classified as dry sub-humid or drier.

\subsection{Where is SSA's groundwater found?}

Regional and national groundwater datasets provide a high-level picture of SSA's groundwater resources. For example, continental and regional scale maps ${ }^{83}$ show major aquifers, depth to groundwater, recharge, aquifer productivity, and other important hydrogeological parameters. These maps provide a generalized sense of groundwater potential. More detailed local-level mapping is needed to inform sustainable abstraction and to minimize project risk but is not available for much of the sub-continent.

There are some areas of Sub Saharan Africa where more detailed studies exist. Some of these studies are easily accessible ${ }^{84}$, but others can be difficult to obtain as they are only available in print form or are not in the public domain. Separate hydrogeological maps are also available for many Sub Saharan African countries, but these can be out of date, or in incompatible formats. There remains a need to consolidate and make accessible existing groundwater data and studies in SSA. Increasingly, satellite data and other remotely sensed information adds value to existing information.

Approximately 40 percent of SSA drylands are underlain either by very shallow (depth $<7 \mathrm{~m}$ ) or shallow (depth $\mathbf{7}<\mathbf{2 5} \mathrm{m}$ ) groundwater (Figure 13). This groundwater is more accessible to people with limited resources and/or human powered pumps. Considering population density, the potential of shallow groundwater is even more evident as 64 percent of the population in the drylands lives in areas where groundwater can be found at a depth of less than $25 \mathrm{~m}$. Recharge determines the sustainability of groundwater supplies. It is generally low in semi-arid areas. Nevertheless, nearly half (47 percent) of the drylands population lives in areas where aquifers receive more than $20 \mathrm{~mm}$ of recharge per annum.

\footnotetext{
${ }^{83}$ See MacDonald et al. (2012), and BGR and BRGM (2008), for an overview of hydrogeological maps of Africa produced by the BGS and BGR respectively. See SADC $(2009 ; 2010)$ for information on the hydrogeological map of the SADC region.

${ }^{84}$ For example, the SADC Groundwater Archive, at http://www.bgs.ac.uk/sadc/. There is an opportunity to expand this archive to other regions in SSA.
} 


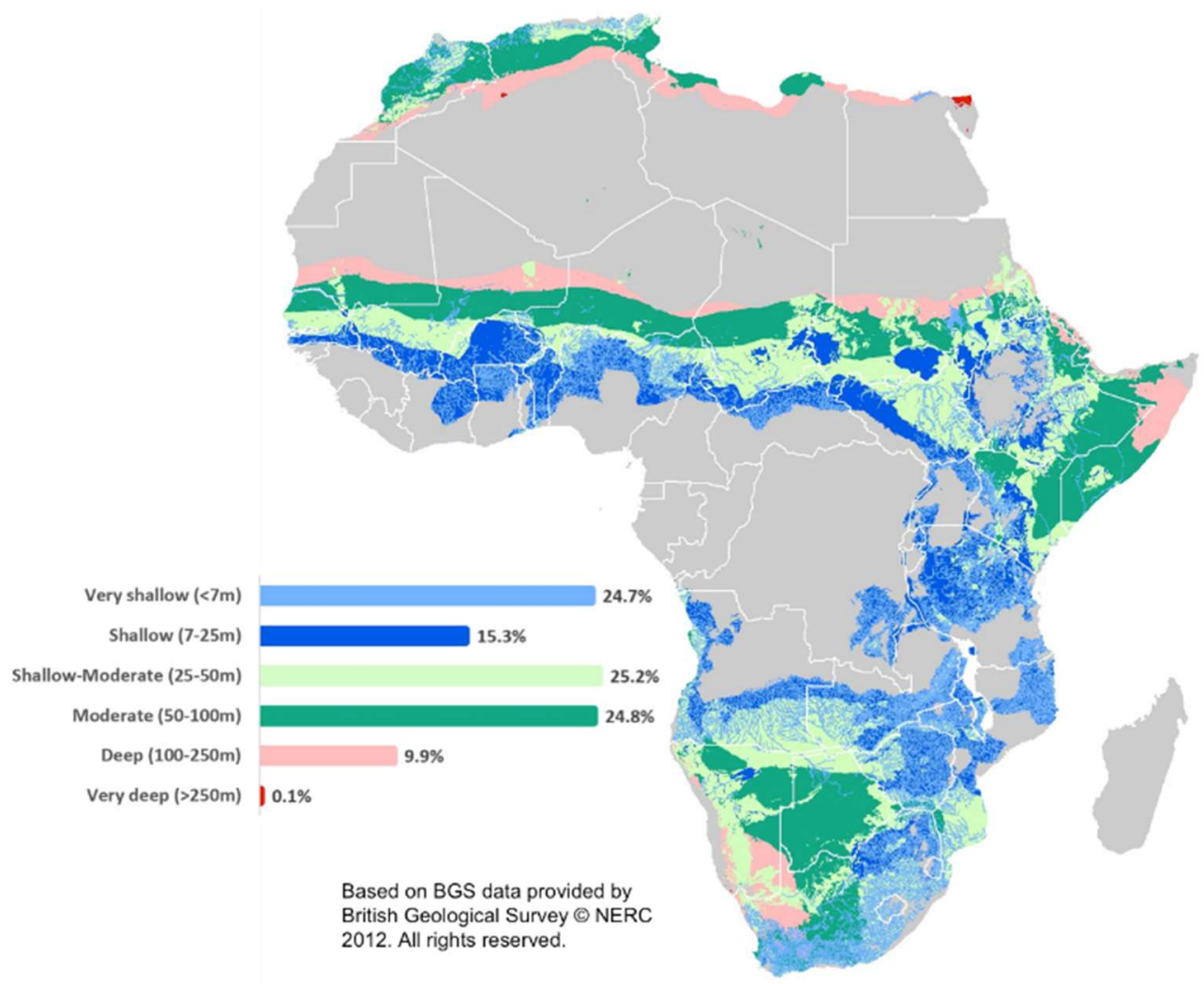

Figure 13 - Areas covered by shallow and very shallow groundwater in the drylands

Although groundwater resource potential is considerable across SSA's drylands current uses depend disproportionally on shallow aquifers with limited capacity. Table 1 indicates that current groundwater abstractions in drylands countries represent only around 5percent of the renewable groundwater resource. However, a significant share of the groundwater used is from shallow local aquifers that often have a limited geographical extent and a limited capacity. These small aquifers, often linked to alluvial deposits or found in hard-rock areas, are more vulnerable to extended periods of drought. Deeper aquifers that are less sensitive to annual fluctuations in rainfall are less utilized because wells require more complex drilling and pump technology and, as a result, are more expensive in construction and operation.

\subsection{How much groundwater is available for irrigation and other socioeconomic development purposes?}

Recent studies confirm that small-scale irrigation by groundwater has tremendous potential in SSA $^{85}$. Table 2 shows that the total area of cultivated land in SSA is about 237 million hectares (Mha), and of this total only about $7 \mathrm{Mha}$ is irrigated. The percentage of cultivated land irrigated by groundwater is lower still - less than 1 percent of cultivated land, or about 2 Mha. Only eleven countries in Sub Saharan African have irrigated areas larger than $0.1 \mathrm{Mha}$, and only two (Madagascar and South Africa) have irrigated areas larger than $1 \mathrm{Mha}^{86}$.

\footnotetext{
${ }^{85}$ For example, Pavelic et al. 2013, Altchenko \& Vilholth2015, Xie et al. 2014.

${ }^{86}$ In comparison, the state of Nebraska alone has about 3.4 MHa under irrigation, about the same as the top three Sub Saharan African countries combined. Data: Nebraska Government Website; http://www.neo.ne.gov/statshtml/73b.html.
} 
Table 2 - Cultivation and irrigation in India and Sub Saharan Africa (SSA)

\begin{tabular}{|c|c|c|c|c|c|c|c|}
\hline & $\begin{array}{c}\text { Pop. } \\
\text { (billions) }\end{array}$ & $\begin{array}{c}\text { Total area } \\
\text { of } \\
\text { cultivable } \\
\text { land (Mha) }\end{array}$ & $\begin{array}{c}\text { Area of } \\
\text { land that is } \\
\text { cultivated } \\
\text { (Mha) }\end{array}$ & $\begin{array}{c}\text { Area of } \\
\text { land that } \\
\text { is irrigated } \\
\text { (Mha) }\end{array}$ & $\begin{array}{c}\text { Cultivated } \\
\text { land that is } \\
\text { irrigated } \\
(\%)\end{array}$ & $\begin{array}{c}\text { Surface } \\
\text { water } \\
\text { irrigation } \\
\text { (Mha) }\end{array}$ & $\begin{array}{c}\text { Ground- } \\
\text { water } \\
\text { irrigation } \\
\text { (Mha) }\end{array}$ \\
\hline SSA & 0.9 & 400 & 237 & 7 & $3 \%$ & 5 & 2 \\
\hline India & 1.3 & 173 & 160 & 66.3 & $39 \%$ & 24.5 & 41.8 \\
\hline
\end{tabular}

Source: FAO Aquastat and World Bank data

Caution is required with respect to the projected availability of groundwater for irrigation development because of spatial and temporal variability. The largest potential benefits from groundwater irrigation exist in the dryland regions of SSA. These dryland regions not only have modest to low average recharge values but the renewable groundwater potential is also unevenly distributed in space and time. Shallow aquifers are sensitive to fluctuations in the amount of direct recharge they receive and during extended periods of drought the available amount of groundwater of shallow aquifers of limited extent will be significantly lower than estimated based on regional long-term recharge values.

Considering existing groundwater uses for water supply and pastoralism (and their projected growth) and minimum (rather than average) groundwater availability, current projections of groundwater potential for irrigation using shallow groundwater resources are likely to be too optimistic and need to be confirmed at the level of individual aquifers. The potential of deeper aquifers in dryland regions is substantial but the higher construction and operating cost of deeper wells makes them less attractive for small-holder irrigation. It is important to evaluate the groundwater irrigation potential based on economic assumptions in line with the shallow and deep groundwater resource availability.

Additionally, SSA's rapidly growing urban populations will require climate resilient water sources, for which groundwater supplies may prove critical. A select number of large cities are already demonstrating that groundwater utilization can be an important part of integrated source planning. To date, only a small number of urban water utilities in SSA - for example, Abidjan, Bamako, Hargeisa, Pretoria, Dodoma, and Lusaka - use groundwater as a permanent source of supply ${ }^{87}$. For growing cities in Africa's dryland regions, groundwater may be the only reliable and substantive future source for water supply (see Figure 14).

Besides quantitative limitations to groundwater use, quality further limits groundwater availability. Groundwater can contain both natural (geogenic) pollutants, arsenic or fluoride (see Figure 15), or anthropogenic pollutants, like fertilizers, pesticides or bacteriological pollution from untreated waste water, that limit its use. The most common quality constraint for groundwater in Africa is high salinity that limits its use for human and livestock consumption but also irrigation. Treatment options exist but are often costly.

\footnotetext{
${ }^{87}$ Foster et al. 2010b.
} 


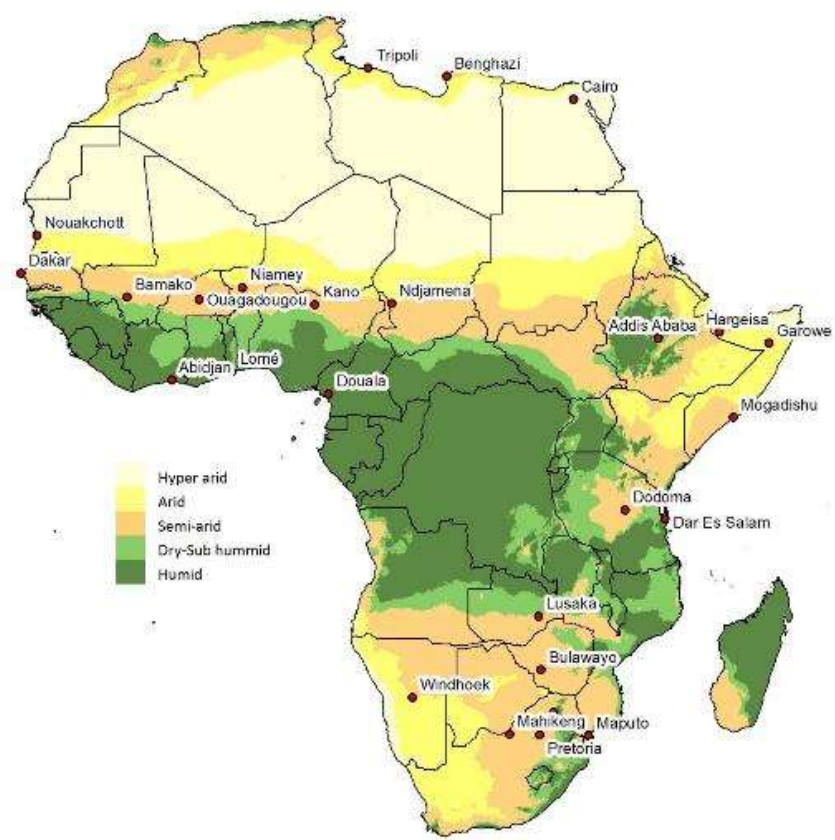

Figure 14 - Large SSA cities where groundwater is a major source for drinking water supply
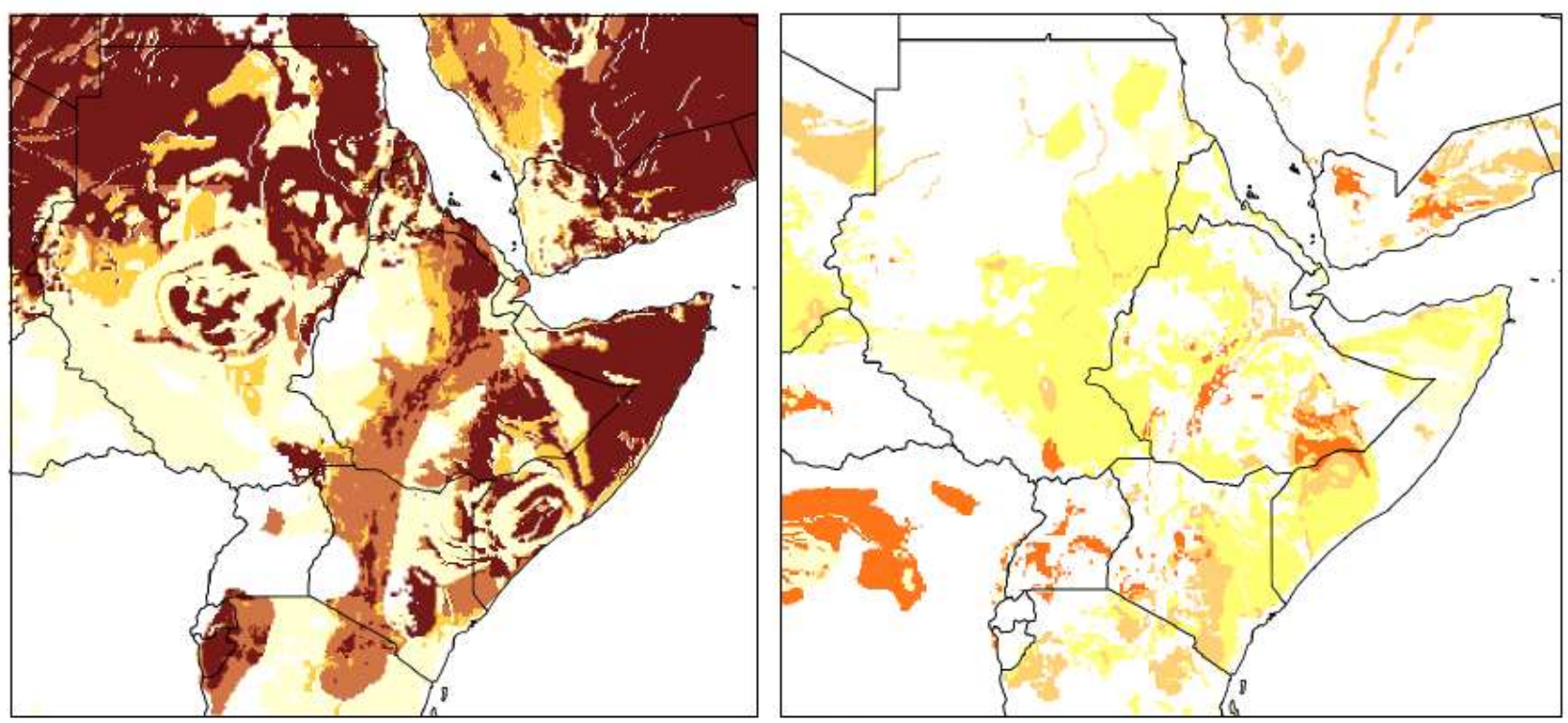

fluoride

arsenic

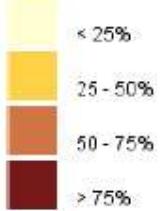

$<25 \%$

$25-50 \%$

$50-75 \%$

$>75 \%$

Figure 15-Modelled groundwater geogenic fluoride and arsenic pollution. The colors show probability of fluoride concentration in groundwater exceeding the WHO guideline of $1.5 \mathrm{mg} / \mathrm{L}$ and of arsenic concentration in groundwater exceeding the WHO guideline of 10 mg/L (Source: EAWAG Aquatic Research Groundwater Assessment Platform maps) 


\subsection{Will groundwater abstraction impact the environment?}

Significant increases in groundwater irrigation are compatible with environmental sustainability. Relatively small volumes of groundwater are abstracted in SSA, and a very small proportion of arable land is under irrigation. Nevertheless, environmental sustainability is often raised as a concern. The challenge is effective assessment at local level. This reinforces the need for better local data, and for local level investigations prior to large-scale groundwater abstraction. Among the potential negative environmental impacts of increased groundwater use are reduced spring flow, lowering water levels in wetlands, reduced baseflow in streams and rivers, increasing groundwater salinity. Intensive groundwater use in certain coastal or other low-lying areas can cause subsidence, altering natural drainage and increasing flood risk.

For nearly all SSA countries, groundwater abstraction could be greatly increased on average, even after making stringent environmental provisions. When environmental functioning is considered, between 44.5 Mha and 105.3 Mha of cropland can be irrigated with groundwater in $\mathrm{SSA}^{88}$. These areas can be compared with the $2 \mathrm{Mha}$ irrigated with groundwater today (Figure 16).

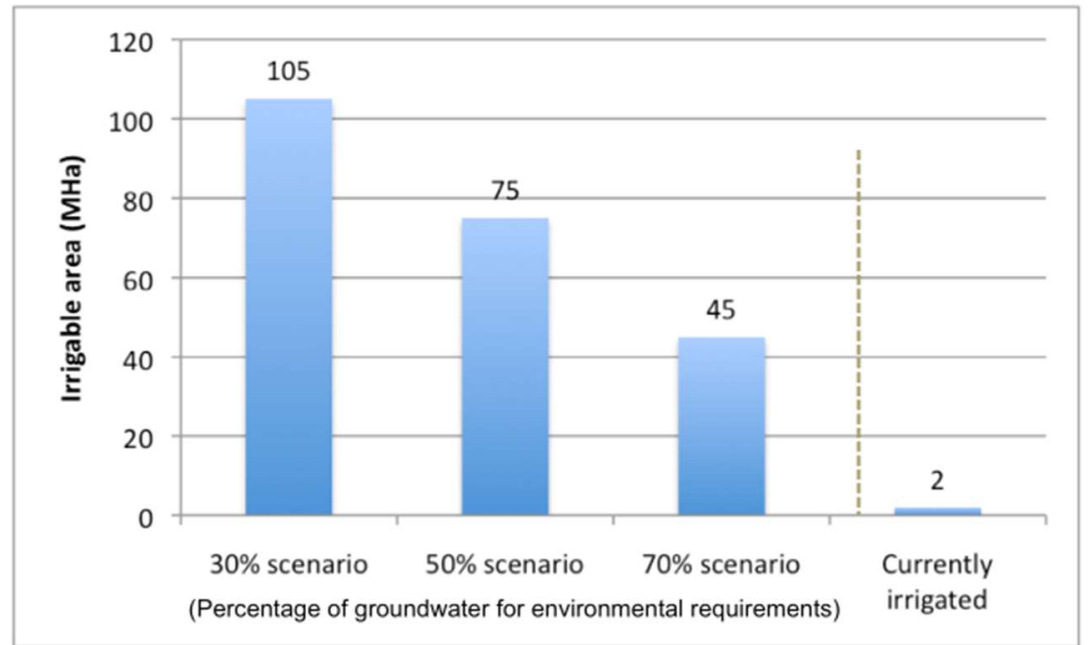

Figure 16 - Potential areas in SSA with irrigable groundwater, whilst reserving groundwater (30\%, 50\% or 70\%) for environmental requirements (Source: Altchenko \& Vilholth 2015)

\subsection{Secondary factors}

Secondary factors greatly affect groundwater use in SSA. These include a diverse range of issues, such as access to electricity, transport networks, availability of credit, national policies and tariff barriers, or land tenure arrangements ${ }^{89}$. These factors can be more important than the physical groundwater availability, when considering overall water supply sustainability. Groundwater physical conditions and secondary factors interact in any groundwater economy to give rise to complex or 'wicked' problems with non-linear components ${ }^{90}$.

\footnotetext{
${ }^{88}$ Altchenko \&Vilholth2015.

89 e.g. Villholth2013, Chokkakula and Giordano 2013, Shah et al. 2013.

${ }^{90}$ De Fries \& Nagendra 2017.
} 
Favorable secondary factors can be key to groundwater viability. For example, cheaper electricity and pumps can allow groundwater to be pumped from deeper levels, effectively changing the level of the (economically exploitable) water table ${ }^{91}$. Complementary investments in secondary factors (e.g. roll-out of renewable energy) can increase groundwater use. Unfortunately, just as primary groundwater data is sparse for many parts of Africa, so information on many secondary factors and how they affect local groundwater economies is also scarce. Proposed groundwater investments require an assessment of primary groundwater availability as well as applicable 'secondary' or political economy factors that together have implications for project risk.

In particular, new technologies, including solar power, may help reduce costs for groundwater development and operation. Lower cost Chinese-made motor pumps, stable energy prices, and lower cost solar energy systems have led to the rapid spread of mechanized pumping for small scale irrigation in parts of Mauritania, Niger, Chad and Senegal ${ }^{92}$. Small pumps can be powered by solar panels where groundwater levels permit, enabling irrigation by electric submersible pumps in areas where electricity grids do not exist. A low cost solar pump for small-scale irrigation, the Sunflower Pump, is currently being tested in Ethiopia, Kenya and Zambia ${ }^{93}$.

Country-level statistics on groundwater resource potential and irrigation area are provided in Annex 2.

\footnotetext{
${ }^{91}$ e.g. Shah \&Das Chowdhury 2017.

92 World Bank 2015a.

${ }^{93}$ According to World Bank (2015), sunflower pumps use a 70/80 W solar panel and can lift $2 \mathrm{~m}^{3} / \mathrm{h}$ at $1 \mathrm{~m}$ groundwater depth, or $0.9 \mathrm{~m}^{3} / \mathrm{h}$ at $6 \mathrm{~m}$ groundwater depth. They can also be locally manufactured and repaired.
} 


\section{Key Benefits and Challenges for Groundwater Investment in SSA}

Based on the strategic challenges and resource characteristics outlined in Chapters2 and 3, key opportunities for groundwater investment in SSA are defined for shallow and deep groundwater resources. As outlined in Figure 17, this chapter identifies three strategic areas where investments in groundwater resources can be transformational: (i) macroeconomic development, chiefly through irrigated agriculture; (ii) urban water security; and (iii) rural water security (including disaster risk reduction and management). Additionally, opportunities to support existing shallow groundwater development to become more resilient and sustainable for all three purposes are outlined.

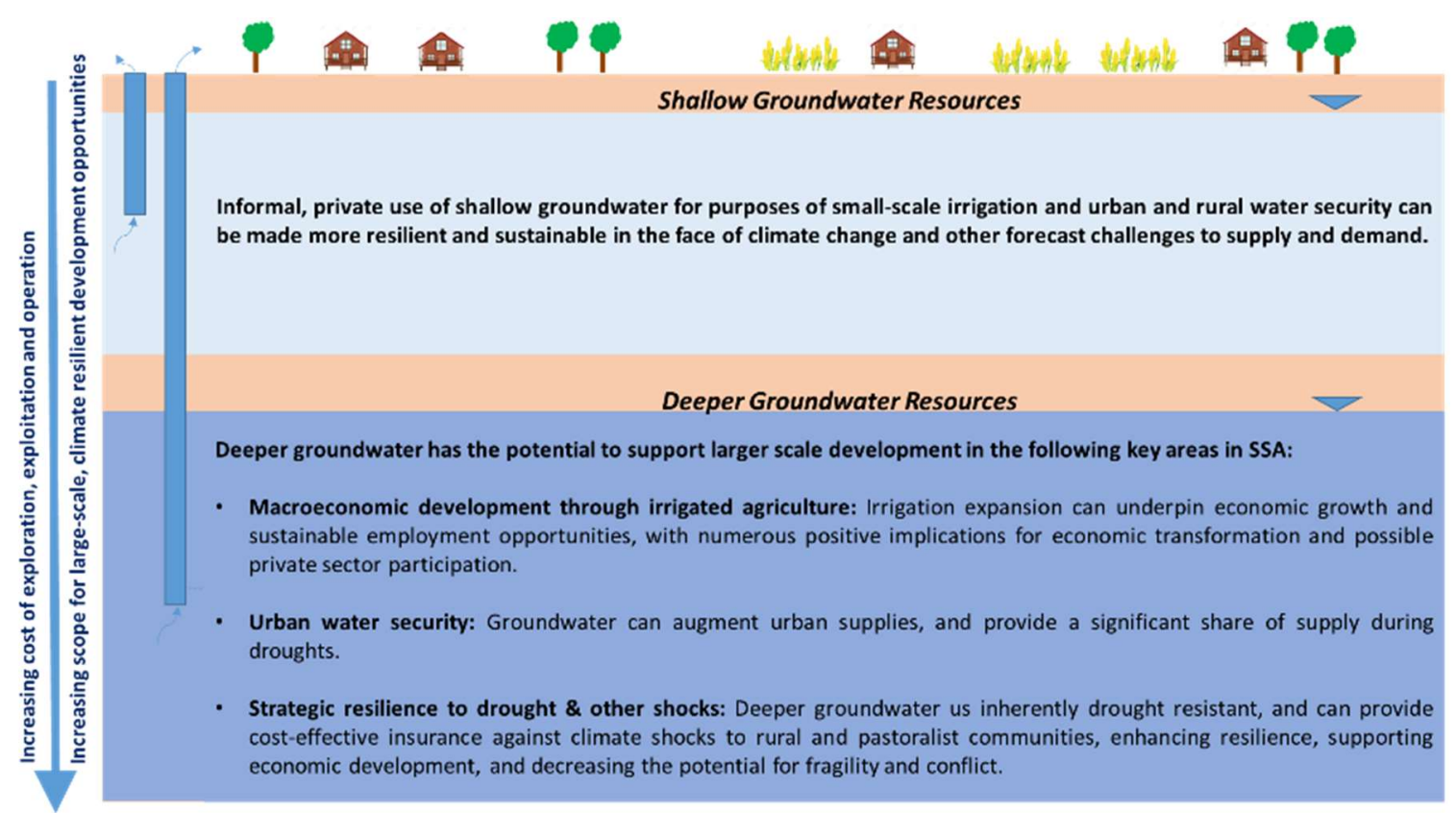

Figure 17 - Key investment opportunities in SSA for shallow and deeper groundwater resources

\subsection{Groundwater development opportunities}

\subsubsection{Macroeconomic development through irrigated agriculture}

Groundwater can be a catalyst for economic opportunity, particularly by enhancing agricultural sector production through irrigation - regarded by some authors ${ }^{94}$ as the single most promising engine of growth in the majority of SSA countries. Given the significant role that agriculture plays in the SSA regional economy, through supporting irrigation, groundwater could help enhance this sector's efficiency, reliability and diversification of outputs. Irrigation has the potential to boost agricultural yields in SSA by at least 50percent. Agriculture accounts for 30 percent of the GDP of SSA, and employs 65 percent of the population, so any improvement in this sector could be potentially transformational and help lift many of the almost 50percent of the regional population currently living below the international poverty line. Irrigation can increase crop yields and agricultural productivity, increase value chain and employment opportunities, enhance land values and increase the assets of rural households ${ }^{95}$.

\footnotetext{
${ }^{94}$ Such as IWMI 2007.

${ }^{95}$ Schoengold \& Zilberman2007.
} 
The potential for irrigation development in SSA is large and could make a significant contribution to economic growth. The potential of irrigated agriculture to impact at the regional macroeconomic scale is illustrated by the fact that it accounts for nearly 38percent of total agricultural output in SSA, despite only occupying 7 million hectares ${ }^{96}$.

Increased agricultural sector production through irrigation could strengthen food security, export commodities and macroeconomic stability. A series of studies conducted by the FAO, IFPRI, IWMI and several regional and national research and development agencies has provided further evidence of the potential of agricultural sector contribution to national and regional economic growth through expansion of export commodities, expanding food production to substitute increasing import of food commodities, and diversifying to higher-value crops. Some estimates suggest that the area irrigated by groundwater in SSA has the potential to increase by a factor of twenty or more, but not everywhere ${ }^{97}$.Groundwater irrigation serves to promote higher value crops (e.g. vegetables) rather than enhance rainfed staple crops (e.g. grains) ${ }^{98}$. Groundwater can also provide important support as livestock drinking water and enhancing fodder production.

The volumes of groundwater resources presented in Chapter 3 suggest that regional irrigation levels could be increased to trigger economic development, along similar pathways as experienced in other global regions. Box 4 illustrates some of the benefits of irrigated agriculture experienced in South and Southeast Asia. Further, Figure 18 illustrates the disparity between irrigated land in SSA (particularly from groundwater) relative to other global regions. SSA is regarded by some authors ${ }^{99}$ as the only global region with scope for significant expansion of irrigated agriculture.

Box 4 - Irrigated agriculture as a basis for macro-economic and household development Irrigated agriculture can intensify land use and permit the planting of more than one crop annually. For example, in many south and south-east Asian countries, groundwater irrigation made possible a new dry season crop, mostly vegetables for the market ${ }^{100}$. Vietnam became the largest exporter of peppers and robusta coffee through irrigation from groundwater ${ }^{101}$. A survey of over 17,000 farmers in India showed that farm households with wells or surface water access (compared to farm households without such access), contained 35 percent higher land use intensity, 35 percent more livestock (cattle and buffaloes), derived 61 percent more income from milk and eggs, and 86 percent more in sales of poultry and livestock.

\footnotetext{
${ }^{96}$ You et al. 2010.

97 CGIAR 2016.

${ }^{98}$ Vilholth 2013.

${ }^{99}$ IWMI 2007.

${ }^{100}$ Molden 2007.

101IWMI 2007.
} 


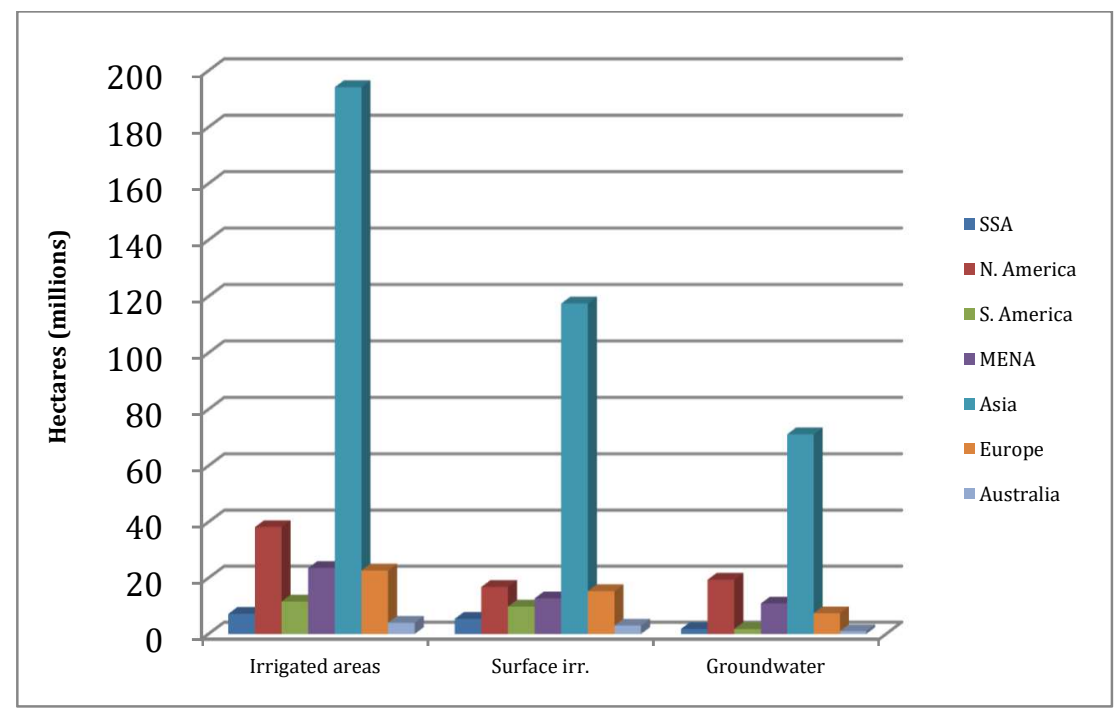

Figure 18 - Surface and groundwater irrigation in world regions (million ha) (Adapted from Siebert et al. 2010)

Evidence from Chapter 3 shows that there is potential to expand groundwater irrigation to multiple countries within SSA. There is potential to expand irrigation from beyond the three countries where it is currently predominant (Madagascar, South Africa and Sudan).

Beyond confirmation of the physical availability of groundwater resources for irrigation, several secondary factors need to be overcome to promote increased investment in irrigation in SSA. Based on some historical irrigation interventions, there is a sense of hesitancy to invest in large-scale irrigation interventions in SSA (see Box 5). Average rates of expansion of irrigated areas in SSA over the past two decades have been only 1percent per year - half the rate recorded in Asia. Outputs from studies commissioned by the World Bank and IFAD identified the following factors to be overcome to promote increased investment in irrigation in SSA:

- Economic factors, such as dispersed populations, small local markets, low levels of transport infrastructure, and limited export possibilities.

- Cultural factors, primarily a lack of familiarity with irrigated agricultural in most SSA countries.

- Financial factors, such as irrigation development costs being relatively high due to remote location of many sites and high irrigation infrastructure construction costs with weak policies for water pricing and cost recovery especially for operation and management

- Fiscal factors, such as many SSA countries having low fiscal capacities to underwrite costly irrigation expansion. Limited allocation in public expenditure and poverty of national budgets earmarked to irrigation.

Given the confirmation of resource availability, the acknowledgement and understanding of reasons for hesitancy in investment, and the renewed momentum for irrigation interventions, there is the opportunity to promote sustainable groundwater development for irrigation in SSA. There may be opportunity to support large-scale irrigation schemes using deeper groundwater resources, as well as providing support for more resilient and sustainable development of already exploited shallow resources. 
Box 5 - Overcoming hesitancy to invest in large-scale irrigation, based on past interventions

SSA must overcome a poor record of irrigation development interventions, and a subsequent hesitancy to invest. Irrigation development during the 1970s and 1980s in SSA delivered low rates of return (between 1975 and 1979, nine major externally financed irrigation projects delivered average rates of return of just 2 percent) and many nationally financed schemes failed (as experienced in countries such as Nigeria). Such poor results deterred governments and donors in financing further irrigation expansion ${ }^{102}$.For example, large-scale irrigation interventions in the Office du Niger in Mali and the Gezira Scheme in Sudan proved challenging in terms of institutional reform, efficient management and rehabilitation, and sustainable crop productivity.

There is some evidence of renewed investor interest in new irrigation development models in SSA, particularly to support small-scale farmers. Lower-cost and more sustainable technological approaches for small-scale irrigation, coupled with participatory, bottom-up governance models, have renewed investor support $^{103}$. Multilateral and bilateral donors, as well as foundations, are starting to re-engage in irrigation interventions.

\subsubsection{Urban and rural water security}

Nations face the dilemma of clean water existing as both a social good / service on one hand and an economic good / service on the other. It is common for public sector utilities manage urban supplies and community-based organizations manage rural water supplies. Governments are generally politically averse to allowing public utilities to pass the full cost of water services to consumers and community-based organizations in rural areas rarely charge adequate tariffs because beneficiaries cannot afford them. This situation poses serious challenge to expanding water services to the growing populations in SSA countries because water providers cannot finance expensive assets and related O\&M expenses without subsidies from their ministries of finance.

Urbanization increases demand for water, generates more wastewater and alters patterns of demand for agricultural products. At its best, urbanization can be the essential motor of economic development, rapidly lifting societies out of mass poverty, while at its worst, it results in concentrations of squalor and disaffection which foment political fragility ${ }^{104}$. While growing cities offer possibilities for employment and income, they can also shift water away from agriculture, put strain on rural communities, and pollute water ${ }^{105}$. Demand for water in cities is growing. This is driven both by population growth and economic growth. Industry requires water and prosperity raises expectation for improved water services. Projected increases in urban and agricultural water demands are expected to quadruple the demand for water in Africa over the next 25 years - the fastest rate of increase than any other region globally ${ }^{106}$. Across SSA, despite successes in increasing access to improved water and sanitation in cities, this has been offset by urban population increases such that the share of the population with access to those services has remained unchanged (at 83 and 43 percent respectively) ${ }^{107}$.

\footnotetext{
102 Ward et al. 2016.

${ }^{103}$ Ward et al. 2016.

104 Collier 2017.

105 IWMI 2007.

1062030 Water Resources Group 2009.

107 Jacobsen et al. 2013.
} 
Increases in access to improved water sources in urban areas in SSA are not keeping pace with population growth. Developing groundwater infrastructure is identified as a source to correct this imbalance. The combined growth rates of the various improved forms of water supply in urban areas (less than 1percent annually) still fall short of population growth (greater than 34percent annually), meaning that greater numbers of people are without access annually. To facilitate the required increase in water service provision, policy and institutional reforms will need to be accompanied by access to finance for infrastructure development. Much of the coverage would have to come from investment in developing groundwater infrastructure ${ }^{108}$.

A recent World Bank report confirms that although water delivery services in several SSA urban centers have improved, the portion of households connected to clean water supplies have declined by more than $\mathbf{1 5}$ percent. Continuing rural-urban migration, mostly to lowincome informal settlements in major cities in SSA translates into growing challenges for extending basic WSS access while overburdening service providers already constrained by insufficient financial and operational autonomy. Despite strong growth in the number of people in urban areas gaining access to improved water supply in these countries, the share with access to improved water sources and household piped connections has declined ${ }^{109}$.

Many settlements, particularly growing urban areas, are outgrowing their traditional surface water sources. Coupled with climate change (and increased frequency of extreme weather events) and increased consumer demand for water, city growth and prosperity may be limited without supplementary sources. Recently, Cape Town, South Africa has captured worldwide attention because of severe city-wide water shortages caused by drought. There is a possibility of the city (home to almost 4 million people) - already under water rationing - to reaching 'Day Zero', when the city's taps run dry (see Box 6). Increased demand and competition for water is happening in many cities throughout SSA, and is expected to continue. Like Cape Town, without exploration of groundwater and unconventional water sources, many other cities may reach Day Zero.

Groundwater can contribute to the diversity of sources needed for cities to be resilient in the face of rapid growth in demand and climate change. An exclusive reliance on surface water can make cities vulnerable (see Box 6). Furthermore, reliance on a limited number of surface water sources to supply centralized systems, may put cities at risk of increased competition for water, climate variability, and political wrangling ${ }^{110}$.

Groundwater is the fastest growing source of urban water supply in SSA, albeit largely informally. Water utility usage of groundwater is increasing across SSA, albeit from a small base (Figure 14). In addition, privately owned boreholes and wells for direct water collection (or reticulation to stand posts) have widely become the fastest growing source of urban water. According to some estimates, 24 percent of urban water supply is collected from wells, which represent the fastest growing source and serve an additional 1.5 percent per year of the urban population ${ }^{111}$.

\footnotetext{
${ }^{108}$ Banerjee 2012.

109 IEG 2017.

${ }^{109}$ Banerjee 2012.

110 Jacobsen et al. 2013.

${ }^{111}$ Tuinhof \&Heederik 2003.
} 
Box 6 - Day Zero and the Cape Town water supply crisis

Cape Town is South Africa's second-largest city (after Johannesburg), with a population of about 3.7 million people. It is the legislative capital of South Africa, and home to the national parliament. Six reservoirs in the mountains around Cape Town supply most of the city's water, storing a combined maximum of about $900 \mathrm{Mm}^{3}$ (i.e. $0.9 \mathrm{~km}^{3}$ ). Beginning in 2015 a severe drought, linked to climate change, has reduced the volumes stored in these reservoirs to critical levels. Without good rains in 2018, there is a real possibility of "Day Zero", when the city's taps run dry. If this happens, emergency water supplies will be delivered by tanker to communal water points around the city.

Cape Town has responded to the crisis in several ways. Leaks in the system have been reduced to about $17 \%$, half of the national average. Campaigns and water restrictions have halved total water used in the city, to about $200 \mathrm{Mm} 3 / \mathrm{a}$ (million cubic meters per year). Even tighter restrictions are now in place. Temporary desalination plants and emergency groundwater supplies will soon bolster supply (about 6 $\mathrm{Mm} 3 / \mathrm{a}$ and $55 \mathrm{Mm} 3 / \mathrm{a}$, respectively). Stand-alone boreholes are being drilled at schools, hospitals and other important locations to reduce their vulnerability to Day Zero.

Like all large South African cities, Cape Town relies mainly on surface water. Growing populations combined with climate change mean that groundwater is increasingly seen as an important auxiliary source. Studies indicate the promise of large aquifers near Cape Town, including the Cape Flats and the Table Mountain Group aquifers. There is also potential for managed aquifer recharge (MAR), like the scheme at Windhoek (see Box 7). The nearby town of Atlantis has long experience of MAR technology - a successful scheme installed in the late 1970 s is capable of meeting Atlantis' water requirements. There is not enough time to develop such integrated groundwater schemes in Cape Town before Day Zero, but they are likely to form a cost-effective part of the climate change mitigation strategies of cities such as Cape Town in the future.

Beyond securing water sources, SSA lags other global regions in provision of modern water services and hence investment is needed to improve potable WSS services. Whilst improved access to water and sanitation services is required across all urban wealth quintiles, there will continue to be a need to improve access in informal urban settlements (urban slums), perhaps through decentralized groundwater-supplied systems. To extend improved water supply to households without access, groundwater could be utilized as a source for decentralized supply systems installed and operated by small-scale independent providers or community cooperatives. Investors could consider such approaches, considering centralized services may be unlikely to reach such customers in many cases.

Mismanagement of sanitation and other pollutants in urban areas can compromise groundwater quality and create health risks. Localized groundwater abstraction in urban areas presents significant groundwater quality challenges that need to be addressed when planning for current and future water supplies. Wastewater infiltration from poorly maintained latrines can pollute aquifers, hence groundwater protection and improved wastewater management and sanitation are connected issues ${ }^{112}$. Additionally, groundwater quality concerns are more acute in coastal areas where the lack of control of aquifer pumping can cause salinity problems due to seawater intrusion ${ }^{113}$.

112 Foster et al. 2006.

113 Jacobsen et al. 2013. 
The rate of urbanization is so rapid across Africa that half of the cities of 2035 have not yet been built. This presents opportunity to integrate new technologies and innovative management systems. In their study of 31 cities across Africa (including SSA), Jacobsen et al. (2013) suggest demonstration projects, transfer of knowledge from other regions, and modification of the way urban water projects are planned, designed, and realized.

Secondary cities (with populations under 1 million) will shoulder much of SSA's urban growth in coming decades, and many will themselves become megacities. Cities under 1 million have borne the bulk of the overall urban growth rate for the past decade (59 percent of growth from 2005 to 2010) and over the next 15 years, 38percent of urban demographic growth is predicted to occur in cities of under 1 million people. Furthermore, today's secondary cities may become tomorrow's megacities: the number of cities with populations of more than 1 million is projected to almost double from 42 in 2010 to 80 in 2025 and thirty-one of Africa's current secondary cities will turn into cities with over 1 million residents over the next 15 years ${ }^{114}$.

Secondary cities will be exposed to similar risks as large cities, but will be less equipped to manage complexities around issues such as sustainable water management. Like megacities, secondary cities will experience rapid population growth, vulnerability to pollution, and increased competition for surface and groundwater sources, however with less financial, managerial and political capital, making them more vulnerable to water-related challenges ${ }^{115}$.

Policy and regulation will need to be developed to keep up with the burgeoning use of wells and boreholes in urban areas for water supply. There may be opportunity to close the water cycle in urban areas by considering wastewater as a resource and exploring artificial recharge opportunities.

A city's water withdrawals and wastewater outputs have a large effect on the catchment from which they draw. Marginal-quality water could help to improve livelihoods, particularly of poor urban and peri-urban farmers ${ }^{116}$.For example, groundwater can be included in a portfolio of water sources, and integrating reuse, recycling and cascading uses, where water quality is matched to its intended function. Aquifers can be used as water storage through groundwater recharge processes and water reuse schemes and provide a buffer to provide water security during prolonged droughts as for example in Windhoek, Namibia (see Box 7).

While drought contingencies are not currently integrated into SSA city water management plans, there is strong support from city leaders for these to be included. Groundwater can be integrated into these plans. Jacobsen et al. (2013) included a knowledge, attitudes, and practices survey for city leaders in Africa and found that leaders overwhelmingly agree that city water management plans should include drought and flooding contingencies, rainwater harvesting, or drainage and solid waste management, even though most typically do not.

\footnotetext{
114 Jacobsen et al. 2013.

115 Jacobsen et al. 2013.

116 IWMI 2007.
} 
Box 7 - Windhoek Managed Aquifer Recharge (MAR) Scheme

The capital of Namibia, Windhoek, receives only $360 \mathrm{~mm}$ of rainfall annually, making it one of the driest capital cities on earth. In the early 1990s, Windhoek's existing water sources (three dams, and a groundwater wellfield) began to struggle to meet growing water demand. Studies showed that new sources of water were far away and very expensive (e.g. desalinating seawater and pumping it from the coast).

City planners responded with an innovative set of solutions: During times of surplus, treated water was stored underground in aquifers, effectively 'banking' this water for use during times of shortage and protecting it from evaporation. This is known as a managed aquifer recharge (MAR) scheme. Windhoek also began to re-use a proportion of its wastewater, treating it to drinking water standards at a new treatment plant. A demand management strategy was aimed at identifying leaks, restricting garden watering and public education. Finally, Windhoek began to operate a 'dual pipe' water supply system in some areas: semi-purified sewage from an old water treatment plant is distributed to sports fields, parks and cemeteries for irrigation, further saving potable water.

Windhoek's MAR scheme and other water management actions have proved far less expensive than other water supply solutions. Windhoek is now a world leader in the sustainable use of reclaimed water, and in MAR. There are considerable opportunities for south-south collaboration and learning based on Windhoek's example, since many other rapidly growing towns in Africa's drylands are beginning to experience similar water supply constraints.

Windhoek's MAR scheme is described in more detail in Annex 3.

There is opportunity for conjunctive use of surface water with groundwater storage and abstraction in urban areas. In rapidly growing cities, such conjunctive use could complement urban water supply and add security and flexibility in case of seasonal resource variation ${ }^{117}$. However, to date there has been little evidence of this in SSA ${ }^{118}$. Box 8 outlines an example where groundwater has been integrated into conjunctive city water supply.

\section{Box 8 - Integrating groundwater into conjunctive city water supply}

The deep Kimbiji Aquifer was discovered in 2006 as a potentially important water source for Dar Es Salaam, Tanzania through to 2030. The aquifer is estimated to cover an area of 10,000 square kilometers and have a storage volume of approximately 1 million megaliters (MI). Average annual recharge rate is estimated to be about 1,000 Ml/year-an enormous potential water source compared to the city's estimated additional 2030 water demand of around $200 \mathrm{Ml} /$ day. Conjunctive use and management of water from the Ruvu River (the existing city water supply) with water from the Kimbiji Aquifer can offer flexibility to effectively respond to hydrological variability during periods of drought. Moreover, the Kimbiji Aquifer (as a naturally buffered system) offers resilience from the impacts of climate change on the city's water supply.

Sources: Hirji 2012, Ruden 2007.

Given the potential scale of groundwater development for urban areas, there may be scope for private-public partnerships / investments. Where investments can serve a large customer base, there may be potential for private sector involvement in WSS service provision.

\footnotetext{
117 Jacobsen et al. 2013.

118 Foster et al. 2006.
} 


\subsubsection{Strategic resilience to drought and other shocks}

Many countries in SSA remain highly vulnerable to recurrent drought events, now and in the future, and which have multiple adverse economic and humanitarian impacts. Between 1970 and 20017, more than 30 countries in SSA experienced at least 8 droughts, and 14 of them experienced at least 10 droughts, precipitating crop damage, livestock death, food crises and destabilization of farming communities. Projected changes in precipitation up to 2075 vary widely for SSA, however nearly all climate change projections signal greater chances of severe drought.

There is a major disparity between disaster response and disaster prevention and preparedness, despite the latter being more cost-effective. Only 4.2percent of total humanitarian aid in 2009 was for disaster prevention and preparedness. For every US\$100 spent on the top twenty humanitarian recipients over the past five years only 62 cents (less than 1 percent) was spent on preparedness ${ }^{119}$. This occurs despite widely held claims that investment in building the resilience of communities to cope with risk in disaster prone regions is more costeffective than the ever-mounting humanitarian response ${ }^{120}$.

There is a somewhat predictable pattern of drought recurrence for some regions, such as the Horn of Africa, meaning that strategically targeted approaches could be effective in reducing adverse impacts. The Horn of Africa experienced severe drought in $2011^{121}$ and is currently amid a two-year drought, which has severely affected crop production, livestock and human wellbeing. While water management cannot prevent drought ${ }^{122}$, it can mitigate or exacerbate the impacts of drought on society and the economy and put in place policies to address longterm water scarcity challenges. There are increasing calls for donors to increase investments that strengthen resilience in contexts experiencing recurrent crises.

There is increasing evidence that investing in resilience can mitigate the worst impacts of recurrent humanitarian crises and can preserve development gains. A recent study ${ }^{123}$ demonstrated that investing in innovative, long-term resilience interventions can help mitigate the worst effects of humanitarian emergencies and protect development gains in vulnerable communities. The results lend support to the efficacy of multi-year, multi-sectoral approaches aimed at strengthening systems (markets, ecological, livelihood) that enable households and communities to respond and adapt to the major shocks and stressors they face. Mercy Corps (2017) recommends increasing investments in strengthening resilience in contexts experiencing recurrent crises, and providing greater support to "systems approaches" to spark transformative changes in systems that underpin people's ability to effectively manage shocks and stresses like drought. Whilst not specifically outlined in the report, groundwater may have potential to contribute to resilience approaches.

An Independent Evaluation Group (IEG) review of the World Bank's water sector portfolio found that lending for droughts tends to be reactive rather than proactive. Furthermore,

\footnotetext{
${ }^{119}$ Kellet\& Sweeney 2011.

${ }^{120}$ Cabot Venton et al. 2012.

${ }^{121}$ Burnlet et al. 2013.

122 Which is a natural hazard caused by large scale climate variability (Van Loon \& Van Lanen 2013, Sadoff 2016).

${ }^{123}$ Mercy Corps 2017.
} 
projects in drought-prone areas often do not anticipate the risk of drought, even though hot spots are well known.

There may be a range of options where deeper groundwater could be used to improve the resilience against drought and water insecurity in SSA. Options could include the development and management of watering points for drinking water for humans and livestock and for smallscale irrigation. Watering points constructed for pastoralist and agro-pastoralist communities in Sudan, Somalia and Ethiopia have helped enhance resilience. A major share of Africa's drylands is underlain by shallow aquifers that can be mobilized to provide water security to rural and pastoralist communities.

There may be merit in investing in resilience measures in areas suffering recurrent drought that focus on early/pre-planned responses and disaster resilience activities which incorporate groundwater, rather than primarily late humanitarian/emergency relief. There is evidence that the comparatively high up-front costs of resilience building are significantly offset by the benefits. In 2015, Mercy Corps undertook an evaluation of the effects of a resilience-focused project in the face of a severe El-Nino shock event in eastern Africa. The results are encouraging, with compelling evidence that supports the efficacy of multi-year, flexibly funded, integrated approaches to building resilience to severe shocks.

The avoided costs of disaster/s and emergency service provision if groundwater sources can maintain base supplies during drought events could be significant. Resilience building should be integrated into areas where recurrent drought occurs. Early response can decrease costs and losses substantially, with very high benefit to cost ratios indicating tremendous potential to improve value for money. While there is a great deal of uncertainty around the cost of building resilience, nonetheless, while the cost of resilience is comparatively high, the wider benefits of building resilience can significantly outweigh the costs, leading to the conclusion that investment in resilience is the best value for money ${ }^{124}$.

\subsection{Support to shallow groundwater development \& integrating non-} conventional water sources

\subsubsection{Securing livelihoods of smallholder farmers and pastoralists}

Millions of small private investments by smallholder farmers and pastoralists have constituted the greatest groundwater development in SSA, albeit largely informal. Many small water management systems, built and operated by communities or individuals - from sources including groundwater - are often not officially recognized, despite their critical and widespread importance. IWMI states that targeting smallholder farmers, particularly in largely rainfed areas, offers the best chance for reducing poverty quickly. Smallholder farmers possess the greatest unexploited potential to directly influence land and water use management. Increased visibility of irrigation and water management of informal systems could influence governments to provide policy and technical support and help to ensure poor farmers' continuing access ${ }^{125}$.

Where available, shallow groundwater resources are valued by smallholder farmers for their general reliability and autonomous accessibility. The expansion of small-scale irrigation in SSA

${ }^{124}$ Cabot Venton et al. 2012.

125 IWMI 2007. 
has been driven by smallholder farmers investing in small-scale, shallow wells ${ }^{126}$. The high availability of shallow groundwater resources (compared to surface sources) and the autonomous control make groundwater development attractive to smallholder farmers. Many smallholder farmers with access to shallow groundwater have already taken the initiative to invest in irrigation to diversify and increase their farming incomes ${ }^{127}$. Such investments are almost exclusively utilized for high-value horticultural production (mostly vegetables, otherwise fruits, flowers, herbs, etc.). They are made in response to factors such as increasing market demand for horticultural crops, higher suitability of smaller irrigated and intensively managed plots, and greater willingness of farmers to diversify their production to higher value crops. This can also enable farmers to plant a second crop, or even year-round production, because crops are not limited by the length of the rainy season. Irrigation can also help guard against the impacts of climate stress associated with drought and extreme heat.

Small-scale shallow groundwater irrigation has helped some smallholder farmers overcome poverty cycles. Irrigation can reduce poverty by increase farmer incomes, provide employment for the landless, reduce staple food prices, and contribute to overall economic growth by inducing secondary benefits, such as boosting agroindustry ${ }^{128}$. Where risks of crop failure (due to enduring periods of variable rainfall, dry spells and droughts) can be overcome, farmers are typically more willing to invest in other farm inputs, such as fertilizers, pesticides, labor, which can help overcome the cycle of risk and poverty. In turn this can facilitate intensification, diversification, higher and more stable productivity / outputs, and net incomes (per unit area under cultivation and per labor unit input) when compared to rainfed and/or surface water farming systems ${ }^{129}$.

The benefit-cost ratio of well drilling interventions is high. The costs, which are often frontloaded, are offset substantially over the lifetime of a well through avoided costs of water aid, time savings, decreased incidence of water borne illness, increased attendance at school, increased productive days, avoided health costs, avoided morbidity and mortality, reduced cost of food and non-food aid, and reduced loss of animals. Even where only some of these benefits are included, the benefit-cost ratio can be high. The challenge for private investors or communities is coming up with the up-front financing.

Groundwater irrigation purportedly has significant benefits for citizens over large surface water irrigation. It can also have gender benefits. IWMI (2007) reports that overwhelming evidence from Asia suggests that groundwater irrigation promotes greater interpersonal, intergender, interclass, and spatial equity than does large surface irrigation. Regarding gender roles, where rainfed cropping coexists with irrigated gardens, men maintain a primary role in cropping while women focus on irrigated gardening. The garden provides a more diversified and nutritious diet for the household and where higher value garden crops are sold, women can play an enhanced role in household income.

Supply-side solutions, such as groundwater development for irrigation, should be accompanied demand-side solutions to optimize the efficiency of water extracted. Low-cost

\footnotetext{
${ }^{126}$ Shah 2010.

${ }^{127}$ Woodhouse et al. 2016.

128 IWMI 2007.

129 IWMI 2007.
} 
measures, such as integrated soil and water conservation technologies, can improve the efficiency and effectiveness of groundwater development. Through empowering beneficiaries, building local ownership, promoting inclusion and sustainability principles ${ }^{130}$, the payoffs can reach 20percent or more ${ }^{131}$. Other demand-side initiatives can increase the productivity of water by gaining more yield and value from less water can reduce future demand for water, limiting environmental degradation and easing competition for water ${ }^{132}$.

With many rural households unlikely to receive centralized WSS services, some use private wells as multi-use systems. Many of SSA's rural population lack any form of utility-provided water, often relying on untreated surface or groundwater. SSA's rural population constitutes 400 million people, most of whom lack any improved or formal water supply. Hence, with piped water almost unseen in rural areas in SSA (among all wealth quintiles) ${ }^{133}$, many smallholders (and/or communities) have developed multi-use systems for purposes ranging from potable supply for humans and livestock to aquaculture or agroforestry ${ }^{134}$. Wells and boreholes serve more than 50percent of households in SSA already, making them the most prevalent form of water supply in the region. Furthermore, wells and boreholes are by far the fastest growing source of improved water in both urban and rural areas, expanding much more quickly than all utility-based alternatives.

Groundwater development for community water supplies could help overcome remaining 'last mile' access and quality of supply issues. Borehole drilling programs could be coupled with new technologies, such as solar pumping and affordable treatment solutions (such as reverse osmosis and/or filtration), for community water supplies. Focusing on livelihood gains by smallscale, individually managed water technologies holds great promise for poverty reduction in the semi-arid and arid tropics. These include small pumps and innovative technologies such as lowcost drip irrigation, small affordable pumps, and small-scale water storage ${ }^{135}$.

\subsubsection{Local resiliency building measures}

The water harvesting/artificial recharge potential in dryland areas is substantial but investments in water security often lack adequate planning. In areas where shallow groundwater resources are not available water harvesting and artificial recharge infrastructure established in favorable locations can provide water security to low intensity uses. Assessments of runoff generated from the arid and semi-arid parts of dryland areas (corresponding to the yellow part in Figure 19a) indicate an average annual volume of $318 \mathrm{~km}^{3}$ (see Figure 19b). A large share of this runoff is already utilized or feeds downstream rivers but if 10percent of the runoff could be harvested this would represent two times the current groundwater abstractions in dryland regions. As runoff is highly variable in space and time building water harvesting structures requires adequate planning. In areas where this harvesting potential is not available, deeper groundwater can be the ultimate strategic water resource to provide water security.

\footnotetext{
${ }^{130}$ Ward et al. 2016.

${ }^{131}$ Sadoff 2016.

132 IWMI 2007.

133 These statistics draw on data analyzed from 35 SSA countries, representing 84 percent of the region's population, UN 2012.

134 IWMI 2007.

135 IWMI 2007.
} 

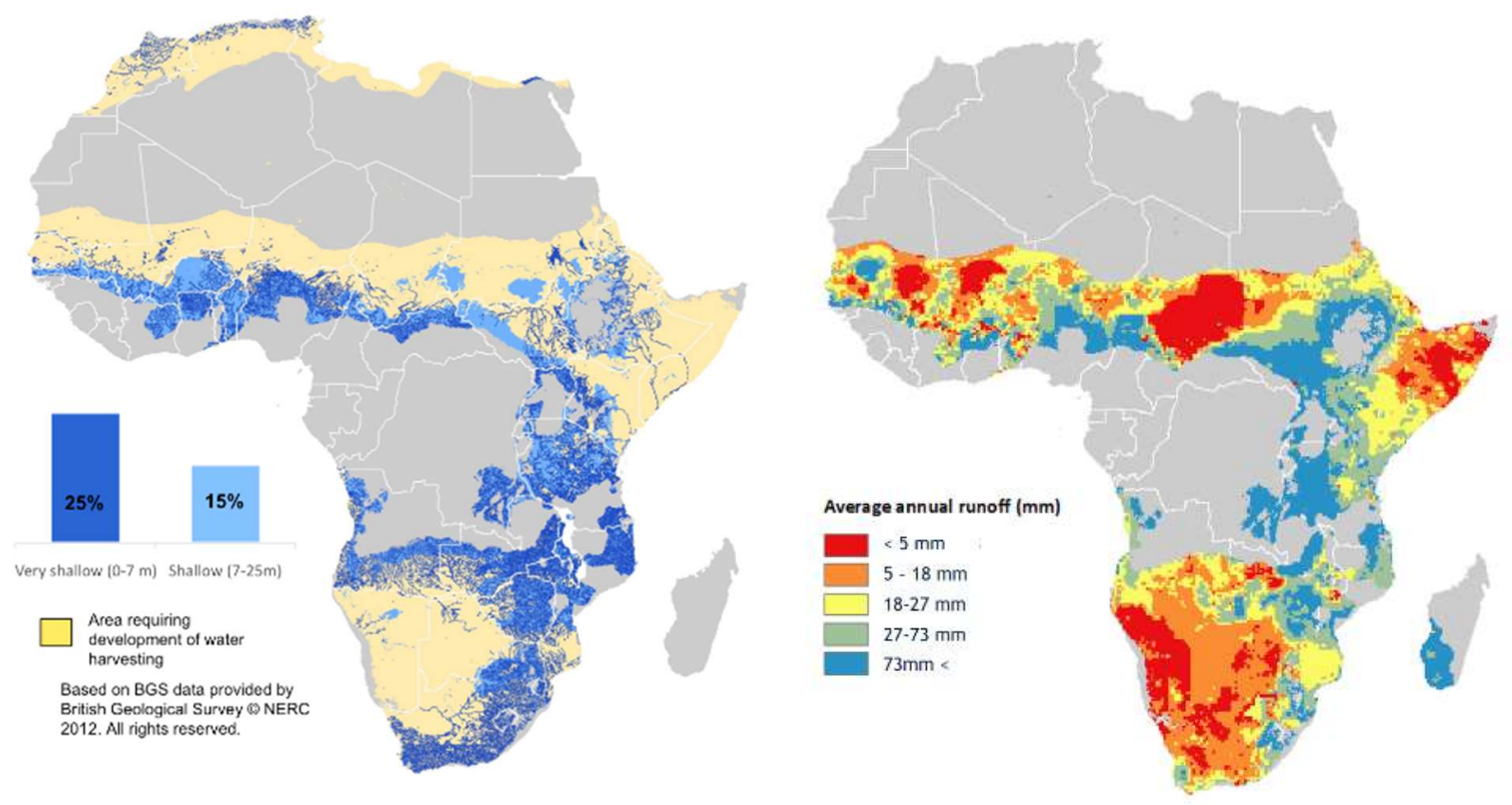

Figure 19 - (a) Presence of shallow groundwater resources below Africa's dryland regions. In areas without shallow groundwater resources water harvesting and artificial recharge in favorable locations can provide water security to low intensity water uses (b) Average annual runoff generated over African dryland regions (average of 19852016 simulated runoff by African Flood and Drought Monitor, Princeton University).

In addition to rainwater harvesting, other non-conventional water sources - such as desalination and reuse of treated wastewater - may be used in conjunction with groundwater development. In cases where groundwater is brackish or saline - such as in some coastal areas there may be opportunity to desalinate groundwater for potable or other (high value) uses. Advances in desalination technologies, for both large- and small-scale instalments, may help lower costs and make the development of some groundwater resources feasible. MAR is discussed in Box 7 and Annex 3.

Investment in the water sector could support community-based water schemes and community capacity building could help to bolster early response and resilience. There is a need to sequence, layer and integrate interventions to build household and community capacity to learn, cope, adapt, and transform in the face of shocks and stresses, rather than a reliance on costly direct emergency assistance after the fact. Inclusive, participatory processes for producing and implementing development plans at community and district levels are key to ensuring solutions fit local contexts and needs, and that benefits are delivered that outweigh costs.

\subsection{Challenges and caveats to groundwater development - potential risks and tradeoffs}

Further to the strong potential offered by deep and shallow groundwater to help address some of the strategic challenges in SSA outlined above, this section outlines some potential risks and tradeoffs to groundwater development.

'Secondary' factors may collectively be the largest obstacle to a groundwater revolution in SSA. Yet, because they are woven into the fabric of the political economy and are obscured, 
they are rarely recognized as combining to form the important constraint that they are. Not enough is known about the collective functioning of these secondary factors: Which ones apply in which countries? How do they combine? What costs do they imply? Are they controlled by national policy, or are they mainly the outcomes of exogenous factors such as climate or population density? Most importantly, how can they best be resolved, and what role can the World Bank play?

Some of these secondary factors are outlined below.

\subsubsection{Governance and institutional challenges}

Groundwater is an open-access resource, which can suffer from tragedy of the commons governance challenges. This is one of the greatest obstacles to optimal and sustainable management. Where property rights to a natural resource are ill-defined, the challenge of open access to many individuals arises. In cases where the resource is limited in supply, users of the resource may not consider the effects of their use on the future availability and cost of the resource to other users. Since groundwater is rarely regulated, anyone can dig a well and pump water for personal use and each user inflicts an externality on others as greater levels of water extracted reduces availability to other users in the future. Once groundwater resources have been accessed, it is often difficult to maintain abstraction levels at sustainable yields. The open access nature of the resource, coupled with its invisibility, makes governance difficult.

Groundwater resources are invisible ${ }^{136}$ and can be fragmented and scattered in different aquifers, all of which makes characterization and understanding of resource dynamics difficult. This leaves many groundwater resources open to potential underutilization or overexploitation. Indeed, there are major deficiencies in knowledge and understanding of groundwater in the three dry regions of SSA: West Africa, Eastern Africa, and Southern Africa. Although several studies seem to agree that in many regions the existing regional groundwater potential is not fully utilized, questions remain about how to quantify the potential and how to mobilize the groundwater resource in a sustainable way.

Whilst groundwater resources can extend across large areas, decisions regarding their development and management are usually local. Strategic and local governance need to be aligned. Inadequate institutional linkages between strategic resource development and local exploitation can lead to the depletion and deterioration of water quality (including salinization and pollution). Furthermore, even when such linkages are present, they need to be enforced through adequate regulations. Often neither the linkages nor the regulations (and their enforcement) are present.

Decentralized development and management of groundwater offers a pathway of empowerment for local stakeholders, but many obstacles must be overcome. Decentralized planning, development and management of groundwater would involve local stakeholders and require them to contribute to policy formulation. Stakeholders could comprise private firms, financially autonomous entities, community organizations, and individual operators through community actions, water associations and cooperatives.

${ }^{136}$ Wijnen et al. 2012. 


\subsubsection{Information and knowledge challenges}

SSA suffers from an acute lack of groundwater data and information ${ }^{137}$. The problem also appears to be worsening ${ }^{138}$, for reasons including lack of hydrogeological capacity, lack of investment, political instability, and the rise of shorter-term and more tangible interventions. In some African countries, groundwater level or quality monitoring are practically non-existent. Knowledge of political economy or "secondary" factors such as energy availability and cost, land tenure arrangements, drilling costs, or availability of spare parts, is also limited ${ }^{139}$.The public sector in Africa struggles to fund and staff long-term hydrogeological data collection, and there are few incentives for private sector engagement. Figure 20 highlights groundwater data deficiencies.

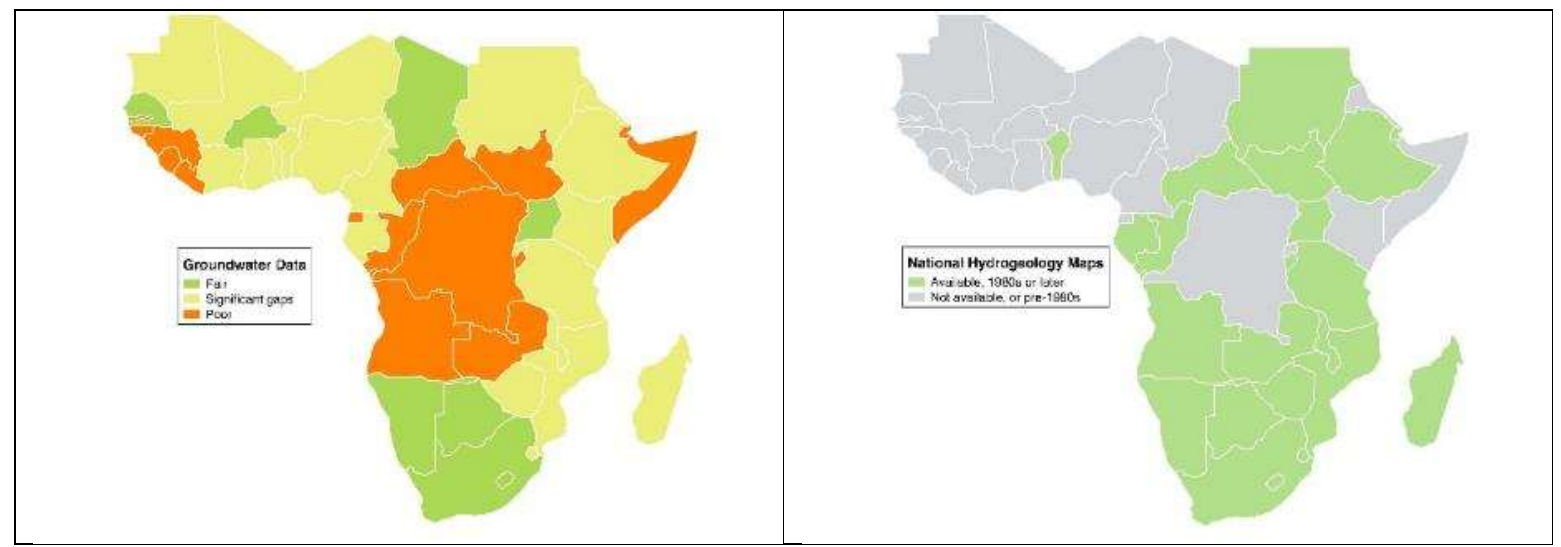

Figure 20 - (a) Estimated groundwater data holdings, and (b) hydrogeology maps in SSA (World Bank 2017a, MacDonald et al. 2012, BGR-WHYMAP 2017, SADC 2010)

Regional or national maps and datasets adequately describe average conditions but lack detail at finer scales. Figure 21 illustrates the decreasing knowledge of groundwater conditions for development in Somaliland as map and database resolutions increase.

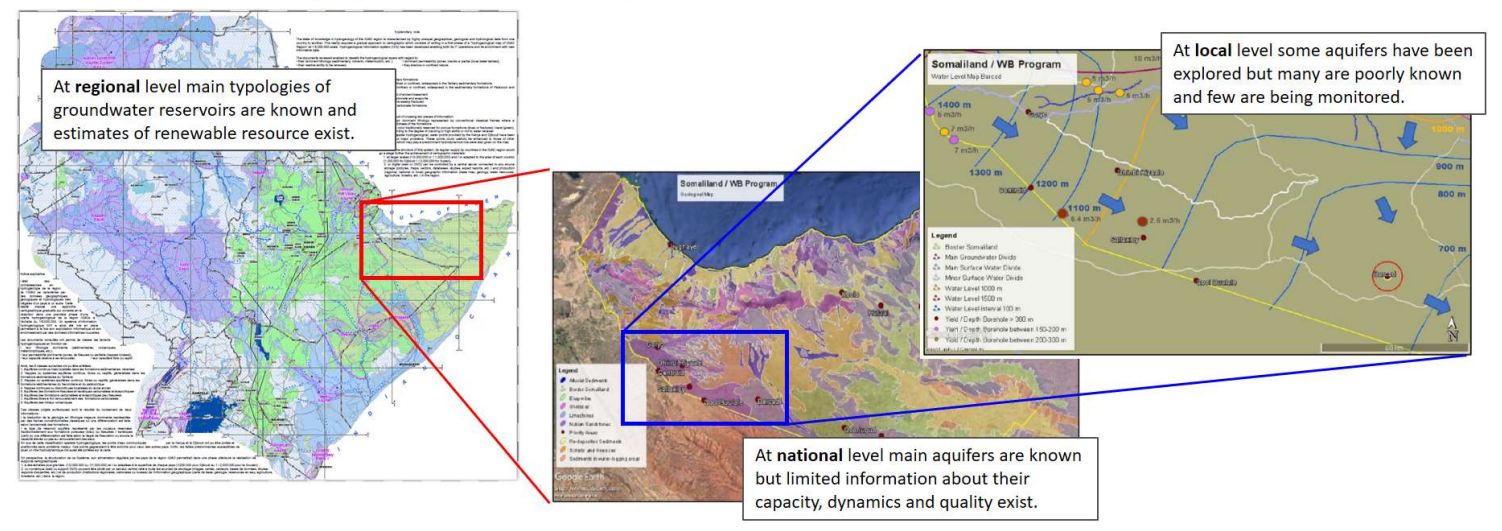

Figure 21 - Example of scale dependency of groundwater knowledge, from Somaliland

\footnotetext{
${ }^{137}$ Adelana 2009, Robins et al. 2002, World Bank 2017a. In this context, groundwater data means parameters such as water levels, borehole yields, or aquifer properties. Groundwater information refers to knowledge products such as reports, maps and guidelines, which interpret groundwater data.

138 Leduc et al. 2017, Robins et al. 2002, Pitman \& Bailey 2015, Lapworth et al. 2017, Foster et al. 2006.

${ }^{139}$ Chokkakula \& Giordano 2013, Villholth et al. 2013.
} 
However, progress on data resolution is nevertheless being made in several areas. For example, a concerted effort in Uganda since the mid-1980s has endowed that country with a groundwater monitoring network, a National Groundwater Database, and a series of local hydrogeological maps ${ }^{140}$. Uganda is dependent on groundwater for both rural and urban water supplies, and these knowledge resources help in planning for future demand in the context of population growth and climate change. In the SADC region, the SADC Groundwater Management Institute ${ }^{141}$ was established in 2016 and is coordinating several regional groundwater initiatives, including the collation of groundwater data and an assessment of institutional groundwater capacity in SADC member states.

Opportunities exist to leverage existing activities in SSA to boost groundwater data collection cost effectively. For example, drilling companies, water utilities, mining companies and nonprofit organizations are at the heart of much local level groundwater development in Africa. There is an opportunity to link these actors to regional or national groundwater data collection initiatives. The standardization and digitization of existing groundwater data held in national databases, or the collation of existing "grey" groundwater literature, also represent clear possibilities.

Information and governance challenges are linked and compounded by an inability to know how to manage a resource discouraging policy development. For example, smallholder irrigation is currently low on the policy agenda because of resource knowledge deficiencies and associated sustainability concerns and lack of clarity on how to balance multiple demands on groundwater resources.

\subsubsection{Economic and financial challenges}

Overcoming up-front groundwater investment costs has proven difficult for development partners. In some cases, the initial costs of groundwater development are not directly recoverable, and in other cases investments may take many years to vest. The distributed, often smaller scale nature of groundwater compared with large surface water schemes can make groundwater projects challenging to identify and manage. Experience in South Asia, China and elsewhere shows that the benefits of improved groundwater use are potentially immense, and a bigger focus on the resource in Africa is warranted.

Compared to surface water development, groundwater can have higher up-front costs for resource confirmation and characterization prior to development - this can prove a major barrier. Figure 22 provides an illustration of the relative indicative costs of groundwater resource confirmation and characterization, and ongoing monitoring, compared to surface water. The plot illustrates the challenge of more significant and enduring up-front costs required to confirm and characterize groundwater resources. For example, while groundwater systems may require both physical monitoring bores and computer modeling for characterization - both of which can be expensive to establish - surface water resources may be characterized with more cost-effective procedures. However, once established, ongoing monitoring costs for both groundwater and surface waters may be similar.

\footnotetext{
140 World Bank, 2017

${ }^{141}$ See the SADC GMI website at sadc-gmi.org
} 


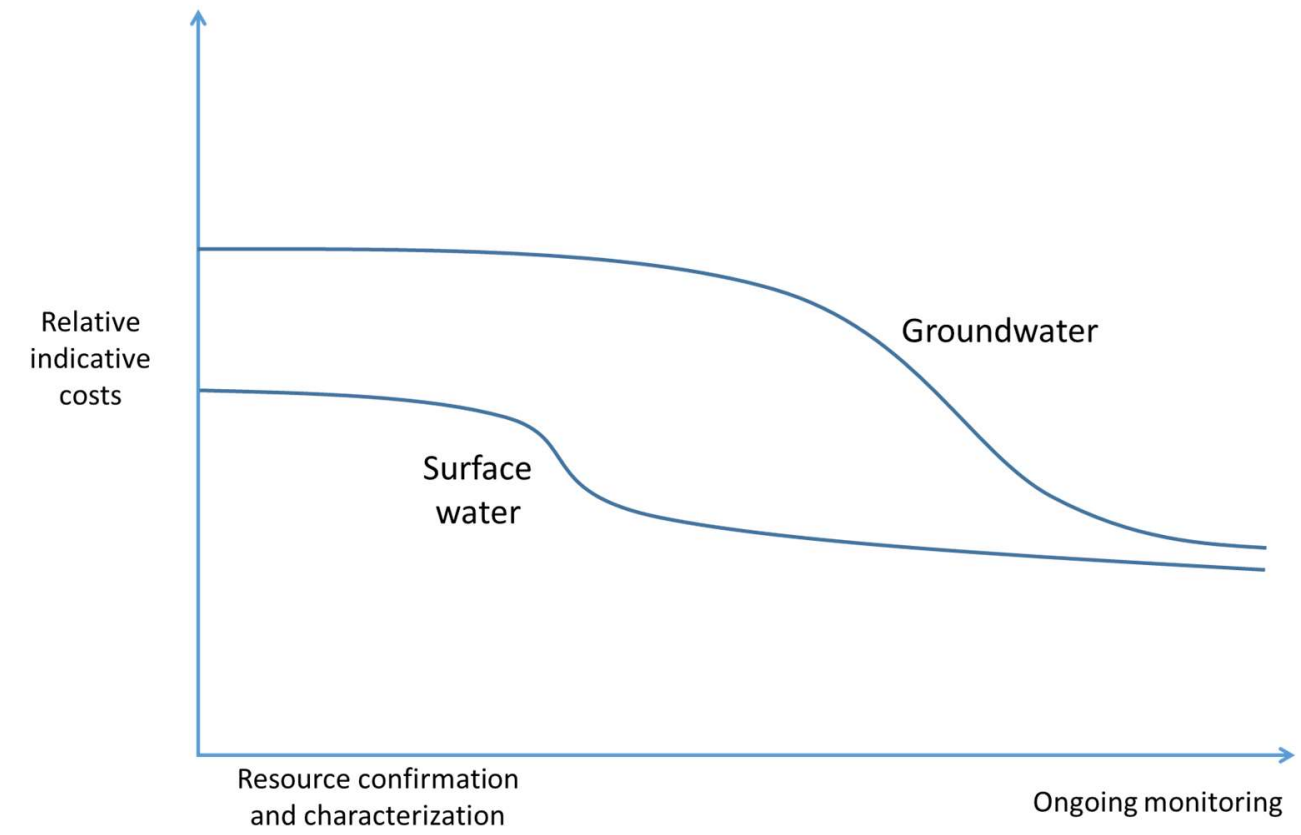

Figure 22 - Indicative costs for resource confirmation and characterization and ongoing monitoring for sustainable groundwater and surface water developments

While dependent on site-specific conditions and other secondary factors (as outlined in Section 4.3), in some cases, groundwater development (both small and large-scale) may have lower capital expenditures and ongoing operational expenditures than equivalent sized surface water development. Figure 23 provides a conceptual illustration of cases where the upfront capital costs for surface water development - primarily reservoirs and conveyance infrastructure - are higher than those for groundwater (primarily well construction). Ongoing operational expenditures may be comparative for surface and groundwater development in many cases, with factors such as pumping and conveyance costs the predominant determining factors. In cases where groundwater resources are more spatially extensive and accessible, ongoing conveyance costs to demand centers may be lower than for more spatially limited surface water resources.

There is a need to estimate the holistic costs of groundwater development by considering expenditures associated with the discrete components of infrastructure investment, operation and maintenance, and secondary factors (Figure 24). Within each of the discrete components are multiple elements which need to be considered, from investigation and exploration costs to energy costs to applicable taxes and subsidies. 


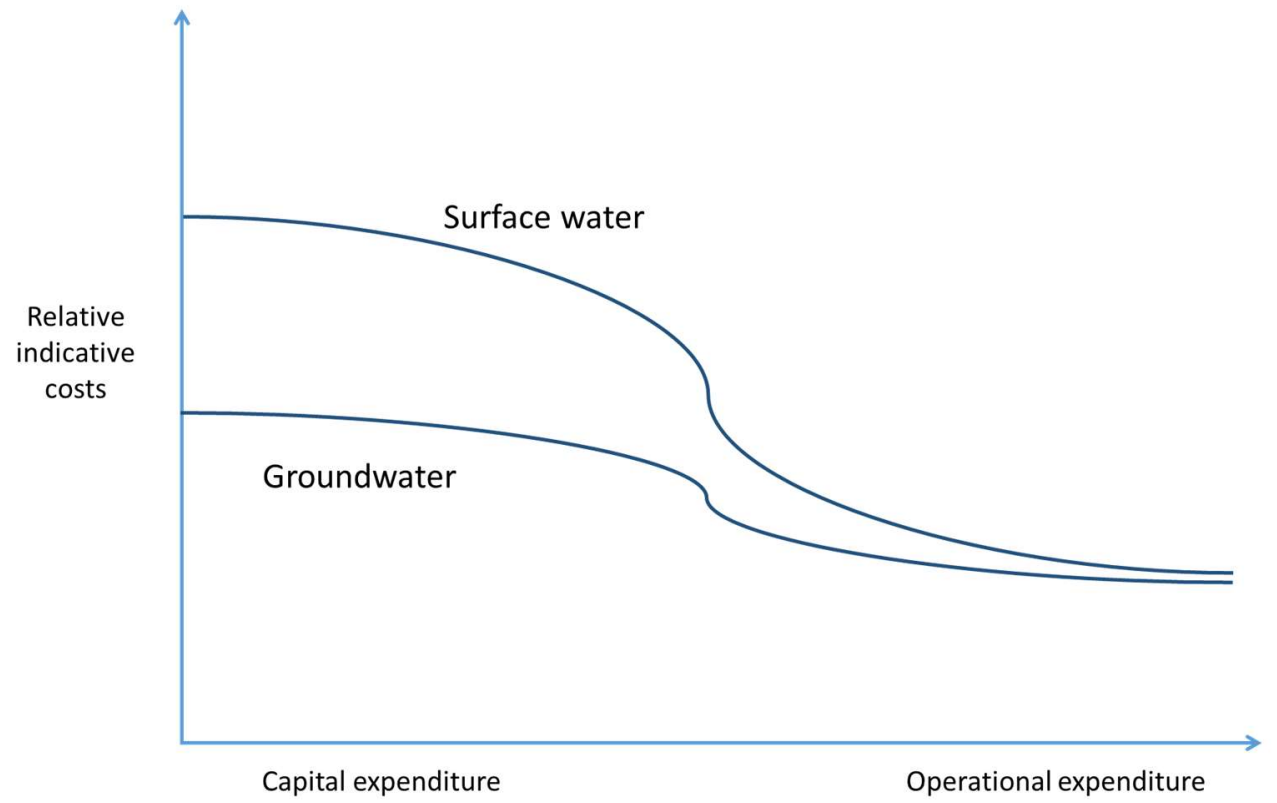

Figure 23 - Indicative capital and operational costs for sustainable groundwater and surface water developments

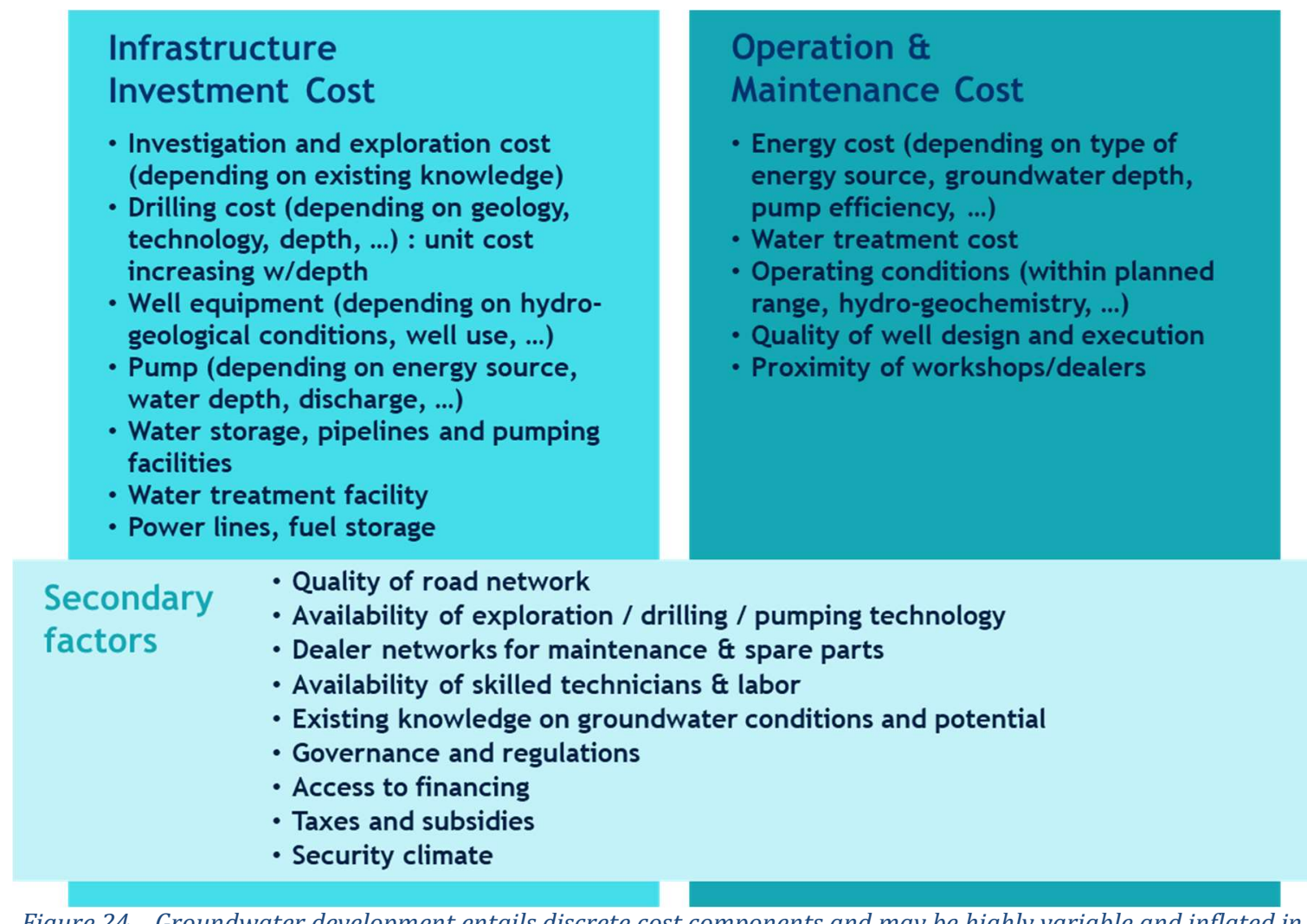

Figure 24 - Groundwater development entails discrete cost components and may be highly variable and inflated in SSA due to secondary factors 
The costs of drilling and pump equipment to extract water from deep or shallow aquifers have a major influence on the viability of small-scale groundwater use. This is known from South Asia, and has been observed in Africa ${ }^{142}$. Anything to make these things cheaper and more widely available will likely have disproportionately large positive impacts. Many factors are at play, such as depth of aquifers and energy cost, economies of scale, African physical conditions, tax regimes, tariff barriers, information asymmetries, and corruption ${ }^{143}$. Little rigorous study has been done of the costs of equipment input factors, and the reasons for these costs. Once understood, policy can be developed to bring these costs into line with those seen in India, China and elsewhere. Available data indicate, that on average, large-scale deep wells could cost up to US\$ 300 thousand and irrigate up to 100 hectares, or US\$3,000 a hectare. Small scale irrigation from shallow aquifers could cost up to US\$1,500.

It is important to establish land tenure security through the various types of social, legal and administrative institutions prevailing in SSA. Security of tenure is associated with four sets of rights, namely: (i) user rights (to grow crops, trees, make permanent improvements including well drilling and water resources development, harvest trees and fruits, etc.); (ii) transfer rights (i.e. rights to sell, give, mortgage, lease, rent or bequeath); (iii) exclusion rights (rights by an individual, group or community to exclude others from the rights granted); and (iv) enforcement rights (legal, institutional and administrative provisions to guarantee rights).For practical purposes, there is a need to define the rules for land and water rights especially in open access lands. Box 9outlines a land tenure reform process in Niger.

\section{Box 9-A guide to securing land tenure in irrigation schemes in Niger}

Niger's National Office for Irrigation Schemes (ONAHA)presented a clear guideline to enhance the land tenure status of the 85 irrigation schemes in Niger, which cover approximately 16,000 hectares and employ more than 40,000 farmers. Under the Kandadji program for ecosystem regeneration and development in the Niger Valley, an additional 45,000 hectares are expected to be developed by 2030.

As demographic pressures increase and available natural resources for agriculture become scarce, the informality of land management in irrigation schemes and of the status of the people who exploit them has become problematic. Former customary land rights holders have challenged State decisions on land allocation or ownership, and have sometimes blocked investments and works. Many of these challenges are brought before the courts, which rulings challenge the public control of irrigation schemes.

To address these challenges, the ONAHA, with the support of Grown Water Institute (GWI), has conducted since 2014 a process of experimenting, formalizing and then generalizing a process to secure land tenure for existing and future irrigation schemes in Niger. This aims not only to preserve and formally recognize the State's rights over irrigation schemes, but also the rights of farmers: the former is achieved by establishing a formal legal status for developed lands through their registration and issuing a land title in the name of the State, and the latter by clarifying and protecting the rights of use of farmers by updating their occupancy contract and registering them on the land title ${ }^{144}$.

Access to credit, banking systems, currency stability and interest rates all impact on groundwater development feasibility, particularly for small farmers. Without access to credit (perhaps secured using land title deeds as collateral) it is impossible for poor farmers to 'bootstrap' themselves into the irrigation economy. The initial investment required is too high,

142 For example, Chokkakula and Giordano 2013.

${ }^{143}$ For example, Colenbrander and van Koppen 2013.

${ }^{144}$ ONAHA 2017. 
even where groundwater is shallow. This is a complex bundle of political, financial and economic issues with both micro- and macro-economic roots. Far too little is understood in terms of their collective impacts on facilitating or retarding an African groundwater revolution.

\subsubsection{Technological and infrastructure challenges}

Improved rural electrification in SSA would greatly enable higher levels of groundwater use. At present, electrical connections are scarce and other energy costs are prohibitively high. Work in India shows the close relationship between electricity pricing and groundwater exploitation ${ }^{145}$. Cheaper energy means that groundwater can be raised from greater depths for the same price, all other things being equal. Put another way, cheaper energy effectively raises the water table to within reach of more poor farmers. Projects to expand rural electrification, or innovate with decentralized and sustainable generation, should ideally take the possibility of groundwater irrigation into account at the planning stage.

Transport infrastructure, border tariffs, fuel prices, regulations, and other costs associated with transporting goods to market also profoundly affect the viability of irrigated agriculture. Not enough is known about the transport 'thresholds' beyond which irrigation becomes viable, and the mix of secondary factors that combine to determine these. Facilities for the storage of produce are also important here. As with many of the secondary factors, small changes (e.g. to the route of a planned road or railway) can have transformative impacts on the viability of groundwater-based irrigation.

\subsubsection{Environmental and social challenges.}

Several factors could cause groundwater development to have adverse social and environment impacts. Where groundwater resources are polluted, they can be slow to recover (decades or centuries) and if utilized in such states, can cause illness or disease for humans and livestock. Over-exploitation of groundwater resources can dry up groundwater dependent surface waters or cause saline intrusion, making water unsuitable for many uses.

Natural (geogenic) and anthropogenic pollution of groundwater can be a development constraint in parts of SSA, just as can be in parts of the rest of the world ${ }^{146}$. High salinity levels can make groundwater unsuitable for certain crops, or for some livestock ${ }^{147}$. Naturally occurring fluoride, arsenic or other dissolved species can render groundwater unfit for human consumption ${ }^{148}$.

Anthropogenic groundwater pollution is also a challenge, particularly in urban areas ${ }^{149}$. Inadequate sewerage, on-site pit latrines, animal feedlots and other sources can give rise to dangerous microbiological contamination, whilst certain industries (petroleum, chemicals, metal fabrication, etc.) can lead to serious groundwater pollution ${ }^{150}$.

\footnotetext{
145 Shah \&Das Chowdhury 2017.

${ }^{146}$ Hynds et al. 2017.

147 World Bank 2017a.

148 Smedley et al. 2002, World Bank 2017a, GAP 2017.

${ }^{149}$ Lapworth et al. 2017.

${ }^{150}$ Lapworth et al. 2017.
} 
Groundwater pumping can alter the dynamics of subterranean systems. Excessive pumping of groundwater can cause saline intrusion, ground subsidence, or both. This is normally only an issue in areas with high rates of groundwater abstraction (e.g. China, California, South Asia), and these problems are thankfully still relatively uncommon in SSA. Nevertheless, monitoring arrangements in SSA should anticipate these problems if groundwater abstractions increase from the present low levels. There is also a need to quantify the impact of local groundwater abstraction on groundwater-dependent ecosystems ${ }^{151}$.

Most potentially adverse environmental and social challenges related to groundwater can be minimized by integrated monitoring systems. Groundwater quality problems, as well as problems consequent on over-use, are made more tractable by adequate groundwater monitoring, and sound hydrogeological knowledge informing effective governance systems ${ }^{152}$.

151 Foster et al. 2006.

152 Ronen et al. 2012,Lapworth et al. 2017, World Bank 2017a, Foster et al. 2006. 


\section{A Strategic Framework for Sustainable Groundwater Development in SSA}

\subsection{A guiding framework built around "four l' $s$ "}

To successfully implement investment projects in SSA using groundwater resources, and to ensure their sustainable use, there is a need to ensure the most critical enabling conditions in terms of knowledge, capacity and economic assessments are in place. These conditions are captured under the key elements of the strategic framework elaborated below. The Bank's efforts to assist SSA countries improve the performance of the water sector with a special emphasis on streamlining the important contribution of groundwater resources should address salient issues at regional, national and local levels for the protection of this important asset, to enhance the welfare of communities, and to advance their economic and social development.

A framework has been established to guide groundwater strategy in SSA (Figure 25). Building upon Figure 2(Chapter 1) and Figure 17 (Chapter 4), Figure 25 outlines a framework to help structure a World Bank approach to support priority shallow and deeper groundwater development in SSA. The framework is built around the "Four I's"153 - Information, Institutions, (Infrastructure)Investment, and Incentives - across regional, national and local scales for sustainable development of shallow and deeper groundwater resources in SSA.

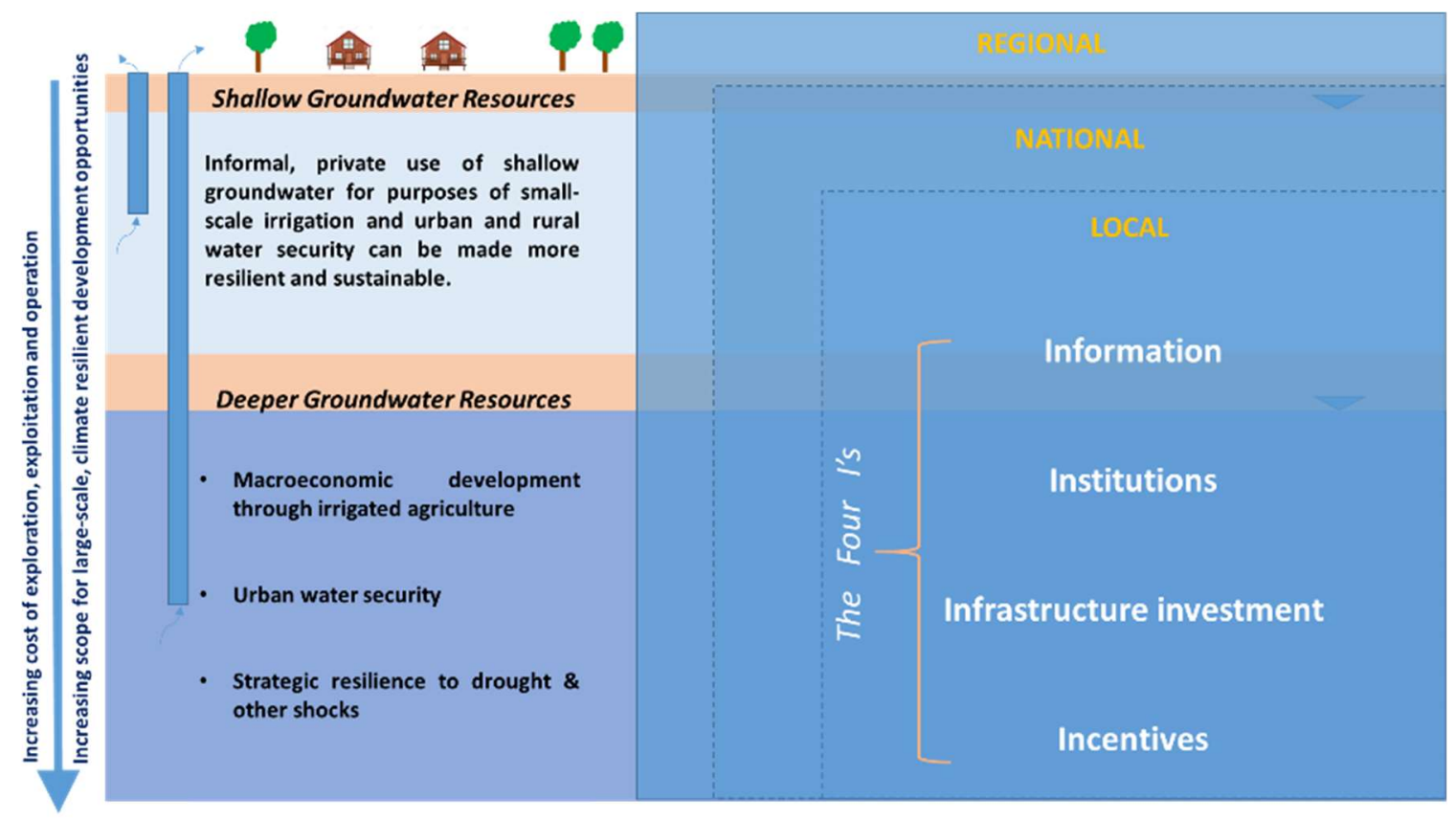

Figure 25 - A framework to guide a World Bank sustainable development strategy for shallow and deeper groundwater resources in SSA

The framework emphasizes groundwater as an important component of SDG 6 on water. SDG 6 focuses on issues such as WASH, water pollution, water use efficiency, integrated water resources management (IWRM), international cooperation and capacity building, and integration of local communities. Groundwater can play an important contributing role to many

${ }^{153}$ As used by authors such as Shome \& Sharma 2015. 
aspects of SDG 6 (see Box 10). A strategy should define responsive policies and actions to enhance the contribution of groundwater to regional, national and local development.

Box 10 - SDG 6 on availability and sustainable management of water and sanitation for all

The SDGs build on the success of the MDGs to address a wider range of challenges related to water. SDG 6 aims to "ensure access to water and sanitation for all", with the following targets:

- Achieve universal and equitable access to safe and affordable drinking water for all (by 2030), - Achieve access to adequate and equitable sanitation and hygiene for all and end open defecation, paying special attention to the needs of women and girls and those in vulnerable situations (by 2030), - Improve water quality by reducing pollution, eliminating dumping and minimizing release of hazardous chemicals and materials, halving the proportion of untreated wastewater and substantially increasing recycling and safe reuse globally (by 2030),

- Substantially increase water-use efficiency across all sectors and ensure sustainable withdrawals and supply of freshwater to address water scarcity and substantially reduce the number of people suffering from water scarcity (by 2030),

- Implement integrated water resources management at all levels, including through transboundary cooperation as appropriate (by 2030),

- Protect and restore water-related ecosystems, including mountains, forests, wetlands, rivers, aquifers and lakes (by 2020),

- Expand international cooperation and capacity-building support to developing countries in water- and sanitation-related activities and programs, including water harvesting, desalination, water efficiency, wastewater treatment, recycling and reuse technologies (by 2030), and

- Support and strengthen the participation of local communities in improving water and sanitation management.

Source: United Nations, 2015

The main elements of the strategic framework are described below.

\subsection{Information}

This element considers the role of information and technology across all scales of the framework, with emphasis on innovations occurring across the value chain from resource characterization, well drilling and construction, water delivery networks, and downstream water productivity.

Advancements in information technology may help improve the knowledge and reduce the cost of groundwater resource characterization and development. In turn, this greater accessibility to information can inform evidence-based policy formulation. Improvements in information technologies to collect and monitor hydrogeological data can provide an evidencebase for policy makers and investors.

The collection, collation and sharing of groundwater data have more potential than ever. There is a need to produce data both at larger and smaller scales. Groundwater data should underpin the production of practical knowledge products that address pressing concerns ${ }^{154}$,

\footnotetext{
${ }^{154} \mathrm{An}$ example of such a knowledge product, distilled from groundwater monitoring data, is the annual 'London Basin Report' produced by the British Geological Survey. Intended for decision makers and planners, the Report shows updated groundwater piezometric contours and rates of change for the London Basin, part of the important Cretaceous Chalk aquifer of South East England. With relatively little
} 
such as helping to provide a basis for supplying water-scarce towns or developing small-scale irrigation. Continent wide groundwater assessments cannot take local variability and exception into account - yet local variability is where many groundwater opportunities are to be found (as examples from southern Africa attest). National hydrogeological surveys or water departments in SSA, and numbers of skilled, trained, motivated groundwater staff, are not keeping up with population growth or increasing climate uncertainty ${ }^{155}$. There is a need to translate data to local levels, where it is needed most.

The outstanding information and knowledge required for groundwater development suggest a role for the World Bank. Improvement of databases, production of better maps, facilitation of sharing of hydrogeological data, capture of out-of-print or 'grey' reports and maps, training of staff, investment in more efficient hydrogeological data collection, and numerous other technical areas suggest opportunities for World Bank support.

Beyond groundwater resource characterization, there is also a need to improve hydrological data collection and processing and weather forecasting. There is a need for greater understanding of rainfall patterns, better surface water monitoring, and increased understanding of environmental functioning in the hydrosphere. In many SSA countries, these systems are in crisis, whilst the need for them has never been higher. Even in South Africa, one of the best resourced countries in the region, there has been a serious decline in hydrological monitoring, particularly the number of rainfall monitoring stations, in the last decade or $\mathrm{so}^{156}$.

Once the information has been collated and processed, there is a need to make it available to guide groundwater investments. The technology of well drilling determines the cost of developing groundwater resources and greater likelihood of successful well drilling can be achieved with better access to information.

Technological development, coupled with secondary (external) factors, such as energy prices and access to markets, also influences groundwater development. For example, the energygroundwater nexus has created a curious political economy paradox: soaring energy prices may help prevent aquifer overexploitation but threaten groundwater-based livelihood systems ${ }^{157}$. Higher energy prices increase the costs of pumping water, applying fertilizers, and transporting products, while improving the energy efficiency of groundwater irrigation may help save aquifers and livelihoods ${ }^{158}$.IWMI has been working with several countries to advance the adoption of solar energy to operate small water pumps to from shallow wells irrigate 1-2 hectares. Investment in this renewable energy will assist small farmers reduce energy cost and increase profitability and reliability of small scale irrigation. However, lower energy costs require the adoption of other mechanisms to control groundwater use. Box 11 outlines advancements in pump technology and opportunities for smallholder farmers.

extra cost, raw hydrogeological data can be turned into a useful product.

155 Robins et al. 2002, Calow et al. 2010.

156 Pitman \&Bailey 2015.

157 IWMI 2007.

158 IWMI 2007. 
Box 11 - Pump technology advancements increasing groundwater development

Adoption of individual pump technology risks rebalancing responsibilities within the household away from women. More broadly, although pumps are relatively affordable, poorer people continue to face barriers to entry. Where water, markets, and functioning value chains are available, farmers find pump technology profitable and the risks manageable. Individual pump irrigation has many advantages. It involves modest levels of investment, requires no communal organization, and needs little government support. Expansion potential is considerable, especially where markets exist. Due to the requirement of cash outlays on a recurrent basis, cash crops must be produced and timely transported to nearby markets.

This is not to say that individual pump irrigation does not face challenges. The biggest negative risk is the impact of unregulated extractions of groundwater on water resources. In many countries of SSA, supply chain inefficiencies reduce or prevent access to adequate equipment at reasonable prices. Commercial crop production is inherently risky, as many of the products are highly perishable. Adoption of individual pump technology risks rebalancing responsibilities within the household away from women. More broadly, although pumps are relatively affordable, poorer people continue to face barriers to entry. Environmental risks also come into play. When farmers pump from groundwater in an unregulated fashion (which is the case everywhere), water tables can drop. The same concern applies to surface water abstractions.

Beyond the exploration and development of groundwater resources, the next link in the value chain is the effectiveness and efficiency of technologies used downstream. For example, technology for irrigation and water delivery affect the efficient use and benefits of groundwater investment. Where farmers rely on simple and low-cost furrow irrigation to deliver water to crops in the field, water use efficiency and water productivity are both low because of substantial losses to evaporation and seepage below the crop root zone. Hence, there are opportunities to link groundwater resource development to efficient downstream utilization.

The final step in the value chain is the choice of end water use. If groundwater development is costly, then, to some extent, water use should reflect that cost by contributing high value returns to society. For example, in irrigated agriculture, adopting high yielding varieties and high value crops coupled with efficient water use. Many of the farming communities in SSA have been irrigating traditional crops which are high in water demand but low in financial returns such basic cereal crops. Irrigation tends to shift farmers to higher value crops as they can receive greater livelihood benefits. A balance needs to be struck, as basic drinking water needs for some should not be superseded by livelihood improvement opportunities for others.

The private sector can play a role in helping to ensure efficient and affordable technology is accessible to groundwater users. The growing needs for long term and reliable water supply for drinking and for irrigation would require adoption of modern technologies across well drilling and construction, pumps size and quality, modern irrigation technologies based on low volume high frequency pressurized network such as drip and sub surface irrigation, and the cultivation of water efficient crops. The private sector is the main source of these technologies and is active in upgrading and marketing new discoveries which are a crucial component in advancing reliable investment in the water sector.

The role of public water agencies is to help individuals and communities to access information and skills needed to adopt technology locally relevant to prevailing hydrological and 
landscape conditions. Partnerships between key stakeholders are required. This process will require financial resources and specialized skills and updated knowledge about operating and maintaining investment packages. Many poor farmers may not be able to afford such investment, which would create inequitable opportunities for income growth and resilience. Partnership between public agencies, the private sector, and local formal and informal institutions at the local level can play import role in addressing these challenges, in providing extension and training and securing finance for small investors and farmers. The World Bank could play a role as a convener of such partnerships.

\subsection{Institutions}

This element considers the role of regional, national and local policies and institutions in governing and managing groundwater, as well as the increased resourcing and capacity requirements to facilitate such change.

Case studies are provided to illustrate the advantages and limitations of selected approaches. Regional considerations include regional cooperation in sharing data, harmonizing rules and regulations, and cooperating on regional-scale challenges (such as transboundary groundwater resources). The strategic plan for groundwater resources by the Southern Africa Development Community (SADC) is a good model to illustrate the main pillars of the strategy and their benefits. National considerations include the costs and benefits of developing a groundwater strategy versus the cost of no action and maintaining business as usual. The case of South Africa is explored. Local considerations include the costs and benefits of investing in small scale irrigation, which has already been undertaken by millions of smallholder farmers in SSA.

\subsubsection{Regional governance}

Some regional and national agencies in SSA have developed strategic and policy frameworks to guide development in the groundwater sub-sector ${ }^{159}$, some of which consider economic and financial considerations. At the national level, countries such as Kenya Tanzania, Mozambique and South Africa have articulated national water strategies to inform their policies and guide investment in the groundwater sub-sector. South Africa went further and detailed a strategy for groundwater management to complement the recommendations for sustainable development of the water sector for enhancing economic growth and social welfare and poverty reduction.

Groundwater governance at the regional level can be complicated by transboundary resources and the need to collaborate across countries. SSA countries often face natural constraints such as a high degree of spatial and temporal variability in the rainfall, and imposed constraints including a lack of basic data and knowledge, fragmented responsibility for management of water resources, lack of community involvement in management, inadequate policies, laws and regulations, and inadequate enforcement of existing regulations. These constraints are particularly apparent in the case of groundwater resources. Regional cooperation and partnerships can enhance the effectiveness of strategic plans at lower levels (e.g. national and local) and help to integrate governance of transboundary resources.

${ }^{159}$ The Alliance includes the World Bank, the African Development Bank, FAO, IFAD, IWMI, and IFPRI with strong support from several bilateral aid agencies. 
A good example of linking between regional and national groundwater strategies has been developed by the Southern Africa Development Community (SADC). The SADC regional strategy aims to provide a framework for governing groundwater resources in arid areas that are under threat from over-exploitation, pollution, sedimentation and introduction of exotic species (see Box 12). These threats arise primarily because of poverty linked to an increase in population pressure, as well as from increasing demand by irrigated agriculture, tourism, mining and pollution from human waste and agricultural chemicals. The threat to the groundwater resources of these vulnerable areas also constitutes a major threat to the related groundwater dependent eco-systems in drought prone areas of the region. Currently, there is very limited groundwater management in the countries of the region with inadequate resources dedicated to the task and a general lack of effective institutions and technical capacity. To date, this regional approach is proving effective in supporting national stakeholders in the community.

Box 12 - SADC Regional groundwater strategy

SADC regional groundwater strategies is based around the following three pillars:

The first pillar is to enhance the institutional capacity for sustainable management of groundwater in SADC countries through: a) Provision of technical assistance and support to modernize and harmonize legal, policy and regulatory frameworks to address gaps in prevailing institutional groundwater management tools at national and transboundary levels. b) developing guidelines, standards and management tools to access and compare up-to-date management tools; c) strengthening groundwater monitoring and data management systems to support member states; and d) facilitating the integration of groundwater in shared watercourse commissions and agreements through transboundary cooperation.

The second pillar is to advance knowledge on transboundary water and national groundwater through: a) assisting member states to identify finance for transboundary aquifer management in member states in through Transboundary Diagnostic Analysis, and Strategic Action plan; b) undertaking demonstration projects on emergent and priority ground water management challenges such as climate change, pollution, etc.; and c) building a knowledge-sharing platform for an integrated data management system interlinked to a GIS platform and website, through information and communication technologies.

The third pillar is to promote groundwater infrastructure management and development through: a) facilitating the development of infrastructure for improved groundwater utilization, management and protection. This will be achieved through assessment, mapping, operation and maintenance of infrastructure at Member States level; b) evaluating impact and learning from groundwater infrastructure investments to help report on results; c) providing operational support for groundwater infrastructure development, including disseminating manuals on infrastructure solutions; and d) providing support to partnership developments and securing funding from among governments, private sector parties and $\mathrm{bi} /$ multilateral partners and others, for scaling- up successful solutions for infrastructure development.

Source: SADC 2016

\subsubsection{National governance}

In preparing a national strategy for groundwater, the government of South Africa presented the financial implications and the cost and benefits of this strategy. The strategy starting point is to answer two main questions: How much groundwater is available? Is it economically viable and financially affordable and cheaper than other sources? To answer these questions the strategy called for investing establishing scientifically based information bank covering main aquifers to avoid the cost of inappropriate development of wells due to lack of information and knowledge specific to groundwater hydrology. 
South Africa's strategy outlines the overall benefits of developing groundwater resources. Benefits include direct contribution to economic growth and social development of the affected communities, ensuring sustainable and equitable water resources management, promoting rural development and enhancing local governments.

The strategy also outlines the overall costs of developing groundwater resources. The primary cost is building the physical and administrative infrastructure needed to develop and manage groundwater resources. Some of this capital is usually provided by the national government but the rest is by local governments and beneficiaries. The cost also includes the establishment of national and local network to monitor and update water quality and quality through observation well designed and located in the aquifer zones. Such service requires specialized agencies with multidisciplinary trained manpower to perform needed services in terms of hydrology, implementation of rules and regulations, and provide information and training to the beneficiaries to conduct needed operation and maintenance ${ }^{160}$. Box 13 outlines the main pillars of South Africa's national groundwater strategy.

\section{Box 13 - National groundwater strategy in South Africa}

The main pillars of the Groundwater Strategy of South Africa are: a) the legislation and regulations which are essential for sustainable management of the important resource and to guide water resource planning, b) institutional capacity building at national and local levels and support groundwater resource governance service, and c) improve information management and support locally relevant field research on groundwater resources. These pillars are designed to address the following issues:

- Increase contribution to economic growth and social development. Investment in groundwater infrastructure to expand provision of safe drinking water supply to many large towns and industrial and farming communities.

- Ensure equitable and sustainable water resources management to address water shortages in drought prone areas and poorly serviced communities.

- Promote rural development, strengthen decentralization for effective drought management: The potential of groundwater for water supply, poverty alleviation, drought planning, and other vital sectors needs to be made more widely known.

- Groundwater must be incorporated into all water plans, and towns that need to augment their water supplies should seriously consider groundwater.

- Groundwater on the other hand is often ideal for rural water supply purposes, for the following reasons: (i) groundwater is a "proximal resource" - it is usually found close to where it is needed, making it ideal for small-scale water supplies in rural areas and for smaller municipalities. Long pipelines from distant surface water sources are not required; (ii) groundwater is resistant to the effects of drought, because very large amounts of water are stored underground, and rates of evaporation are low. This means that boreholes can continue to yield water long after rivers and streams have dried up; and (iii) the natural quality of groundwater is usually good, with little or no treatment needed. This means that expensive treatment plants, with associated operation and maintenance implications, are usually not necessary for small-scale supplies. Some treatment of groundwater is often carried out however (e.g. chlorination), and not all groundwater is safe to drink without treatment.

- Groundwater can also be developed "incrementally". Surface water supplies usually require a large initial investment (e.g. dam and treatment plant) but boreholes can be drilled as demand increases and budgets allows.

Source: Department of Water Affairs, Republic of South Africa 2010.

${ }^{160}$ Department of Water Affairs, Republic of South Africa 2010. 


\subsubsection{Institutional resourcing \& scope of investment}

Priority investment is needed to enhance resourcing (e.g. human and financial) of public interest agencies at both national and local government levels to enable delivery of integrated water programs. These should be informed by well-articulated policies. The programs should inform and shape local projects within sustainable development plans. These programs should shape the institutional structure of these agencies based on bottom up participatory framework with strong involvement of local stakeholders, local government, farmers groups and producer's associations and civil society. Public policy and rules and regulations become effective when designed with participation of the stakeholders. The lessons learned from the experience of the South Africa Ground Water Strategy (see Box 13) is that the rules and regulations of developing and managing groundwater resources were well defined but poorly implemented because of weak participation by local communities.

Public water institutions have a responsibility to provide reliable and timely information to inform evidence-based water sector investment. Public policy should help define special procedures needed to guide the scale intervention and investment in groundwater development and utilization. The main service of the public water agency is the provision of information about three dimensions of investment in the water sector: i)hydrological data about the status of the local aquifers including economic availability and quality of water; ii) enhance joint planning and regulation of water resources and integration within a basin approach to strengthen cooperation amongst communities drawing water from the same aquifer; and iii) provide training and capacity building and extension services to farmers and members of water associations.

The types of groundwater investments currently being undertaken, and needed, should shape the partnership between public institutions and other stakeholders. Groundwater development is SSA currently occurs via two main means: a) individuals or group of investors who drill wells for small-scale irrigation and to provide domestic and livestock water supply, and b) community based and managed irrigation and village or town water supply networks to serve local needs. Strong partnerships with public agencies has improved the profitability and sustainability of small-scale irrigation and has also helped local investors form partnerships with outside agencies that can help finance the development of new sites and support the introduction of management practices to improve water use efficiency. For example, small-scale irrigation schemes have proven popular in most SSA countries, and many "community driven development" (CDD) programs have offered community-based irrigation as one of a range of possible investments.

However, as water resources are increasingly developed and potential conflicts with other water users and environmental needs arise, small-scale irrigation needs to be supported by planning and regulatory frameworks. It will be important to maintain a balance between outside support and local institutions with internal autonomy, to avoid the emergence of a culture of dependence in the face of "top-down" and "engineering-led" approaches. Key factors for success may include: (i) well-functioning water users' associations that have been trained in water management, general management, and administration; and (ii) clustering small schemes together, reducing technology cost uptake by increasing the sales volumes. 


\subsection{Infrastructure Investment}

This element explores the role of public expenditure in groundwater development, and the costs and benefits of groundwater investment at regional, national and local levels.

\subsubsection{Public expenditure}

This element aims to help shift public and private investment in the water sector in SSA toward sustainable groundwater development and management, with balanced attention to expanding water infrastructure and $0 \& M$ expenses based on realistic structure of water pricing and cost recovery.

At the national level, most countries in SSA have increased their scope of focus on waterrelated issues to meet SDG 6. SDG 6 moves beyond basic access targets and calls for the protection of water resources from over-exploitation and pollution ${ }^{161}$. As outlined in Box 10, it includes sub-goals relating to water quality, reuse, scarcity, transboundary cooperation and integrated water resource management.

This shift in focus has been accompanied by an increase in formal and informal investment in the water sector in most SSA countries in the last decade. However, these increases are currently insufficient to meet MDG/SDG targets. Public expenditure on water has been driven by expanding water infrastructure to meet the increasing demand for clean drinking water and for expanding small scale irrigation. According to a World Bank report, the overall price tag for reaching the MDG/SDG target of providing WSS to all in SSA is estimated to require allocations up to US\$21 billion per year, or 2.7 percent of Africa's gross domestic product (GDP) ${ }^{162}$. The cost of new infrastructure is the largest share, requiring allocations of up to 1.5 percent of Africa's GDP every year, or 43 percent of overall spending. O\&M needs are the next largest category, standing at 1.1 percent of Africa's GDP, or 31 percent of overall costs. Rehabilitation of existing assets requires lower yet substantial allocations-up to 0.9 percent of Africa's GDP-accounting for one-fourth of the overall needs. As of 2011, Sub-Saharan Africa spends about US\$7.9 billion a year (1.2 percent of the region's GDP) on WSS-about a third of what is required if the MDG/SDG is to be met $^{163}$.

Low-income and fragile SSA countries will need external support to meet water development goals. The proportion of the population in low income countries without access to WSS services is relatively large. Further, where water infrastructure does exist it may often be aged and/or dysfunctional, requiring financial resources for rehabilitation. It is estimated that, to reach SDG water targets, such countries would have to allocate at least 7 percent of GDP on water supply annually (and almost 12 percent for fragile states), figures which are prohibitively expensive.

Financing gaps for WSS services are persistent in SSA and difficult to recover. A 2017 evaluation of ten years of World Bank support for WSS focused on the financial viability of water utilities in global regions, including SSA $^{164}$. The evaluation found that, generally, public sector

\footnotetext{
${ }^{161}$ World Bank (2016).

${ }^{162}$ Banerjee\& Morella2011.

${ }^{163}$ Middle-income countries spend US\$2.6 billion, followed by low-income countries US\$1.8 billion, resource-rich countries US\$1.7 billion, and fragile states spend about US\$0.5 billion in capital investment and O\&M.

${ }^{164}$ IEG 2017. Assessment of support from 2007-2016.
} 
utilities manage urban water supplies and community-based organizations manage rural supplies. Furthermore, Governments are generally politically averse to allowing public utilities to pass the full cost of service on to consumers, and community-based organizations rarely charge remunerative tariffs because the beneficiaries cannot afford them. Therefore, service providers cannot finance asset rehabilitation and the investments necessary to meet growing consumer demand, or even recover their operation and maintenance (O\&M) costs. Consequently, service providers have little ability and often no incentives to manage their WSS assets efficiently, resulting in progressively deteriorating service quality and rising costs linked to deferred maintenance.

There is scope for supporting public expenditure through efficient cost recovery and realistic policies for water pricing, through improved reliability of water delivery services and strong participation of the beneficiaries. Hence, there is a strong role for national ministries of finance (and donors) to play. Both public and private water utilities in SSA are lacking financial viability because of poor water pricing and tariff regimes associated with poor cost recovery. The financing gap that results from a lack of remunerative tariffs requires donor funding and government subsidies to address it, at least initially. To ensure reliable and sustainable WSS services to urban and rural communities, Ministries of Finance in SSA need to play a greater role ${ }^{165}$

The composition of public spending on the water sector varies substantially across country groups - from capital outlay to operation and maintenance. Middle-income countries allocate 80 percent of spending on the water sector to maintenance, reflecting the fact that they have already built much of the infrastructure needed. By contrast, the other country groups allocate no more than 30 percent to this item. Therefore, resource-rich countries, low-income countries, and fragile states spend 70 to 90 percent of their budgets for water infrastructure on capital investments. Although this reflects their need to build new facilities, a danger looms of neglecting the maintenance needs of the limited network that is available.

Public expenditure estimates do not include the significant informal investment in groundwater development by private stakeholders and smallholder farmers. Groundwater is the main source of drinking water supplies to most of the population in SSA: ranging from 92 percent in Niger, to 56percent in Tanzania. However, investments made by private stakeholders and smallholder farmers (such as drilling wells and delivering water to beneficiaries) are considered 'informal' and are not included in assessments of public expenditures.

The donor community has increased support to the development of water services in SSA, particularly to expand WSS to urban and rural communities. There is opportunity to better integrate sustainable groundwater development into WSS and irrigation lending going forward. Over the last decade, more than 80 percent to the water sector in SSA has been allocated to WSS. Given the ongoing outstanding needs in SSA water sector, there is opportunity to support public expenditure realizing the benefits of sustainable groundwater development.

165 IEG 2017. 


\subsubsection{Costs and benefits of regional and national groundwater strategy for cooperation}

SSA has the lowest level of irrigation development in the world ${ }^{166}$. Yet irrigation can transform the lives of small farmers and pastoralists, increasing resilience and reducing vulnerability ${ }^{167}$. The cost of irrigation is an important factor. Research suggests capital investment costs of USD12, 000/Ha for large-scale irrigation from surface water sources, and USD4,500/Ha for small-scale irrigation from surface and groundwater sources in the African drylands ${ }^{168}$.

Rates of return on irrigation are influenced by infrastructure costs. The return from deep wells is much lower than wells accessing shallow aquifers. The benefits of groundwater-based irrigation can be reduced, as reported by IFPRI, because of the risk of declining operation and maintenance of wells. This problem has impacted the performance of large scale irrigation in SSA where substantial areas equipped for irrigation are left fallow over many years because of poor operation and maintenance and weak partnerships between public institutions and the beneficiaries and farmers organizations. Many donors, including the World Bank, shied away from investing in irrigation because of the poor performance of public agencies responsible for operating and managing large irrigation schemes.

A recent expert study carried out for the World Bank in 2015 focusing on 6 countries in the Sahel found that small-scale irrigation from groundwater has significant economic potential, as well as being technically viable ${ }^{169}$. This study found that costs for small-scale irrigation from groundwater were between USD 1,000/Ha and USD 3,000/Ha. Elsewhere in Africa, irrigation from groundwater has been costed at USD 1,650/Ha for fadama type schemes in Nigeria, USD 4,900/Ha for hard-rock installations in Ethiopia, and USD 10,940/Ha for deep-well systems in Zimbabwe $^{170}$ (Figure 26). In the sedimentary aquifers of the Nile delta, irrigation by groundwater can cost as little as USD 650/ $\mathrm{Ha}^{171}$. These costs depend partly on the depth to groundwater, the equipment installed, and factors such as whether sophisticated systems such as sprinklers or drip irrigation are used.

\footnotetext{
166 Ward et al. 2016.

${ }^{167}$ Cervigni \& Morris 2015.

${ }^{168}$ Ward et al. 2016. Large scale irrigation in this context relies on dams, whilst small scale irrigation relies on a variety of available sources, including groundwater.

${ }^{169}$ World Bank 2015a.

${ }^{170}$ Villholth 2013.

${ }^{171}$ El-Agha et al. 2017.
} 


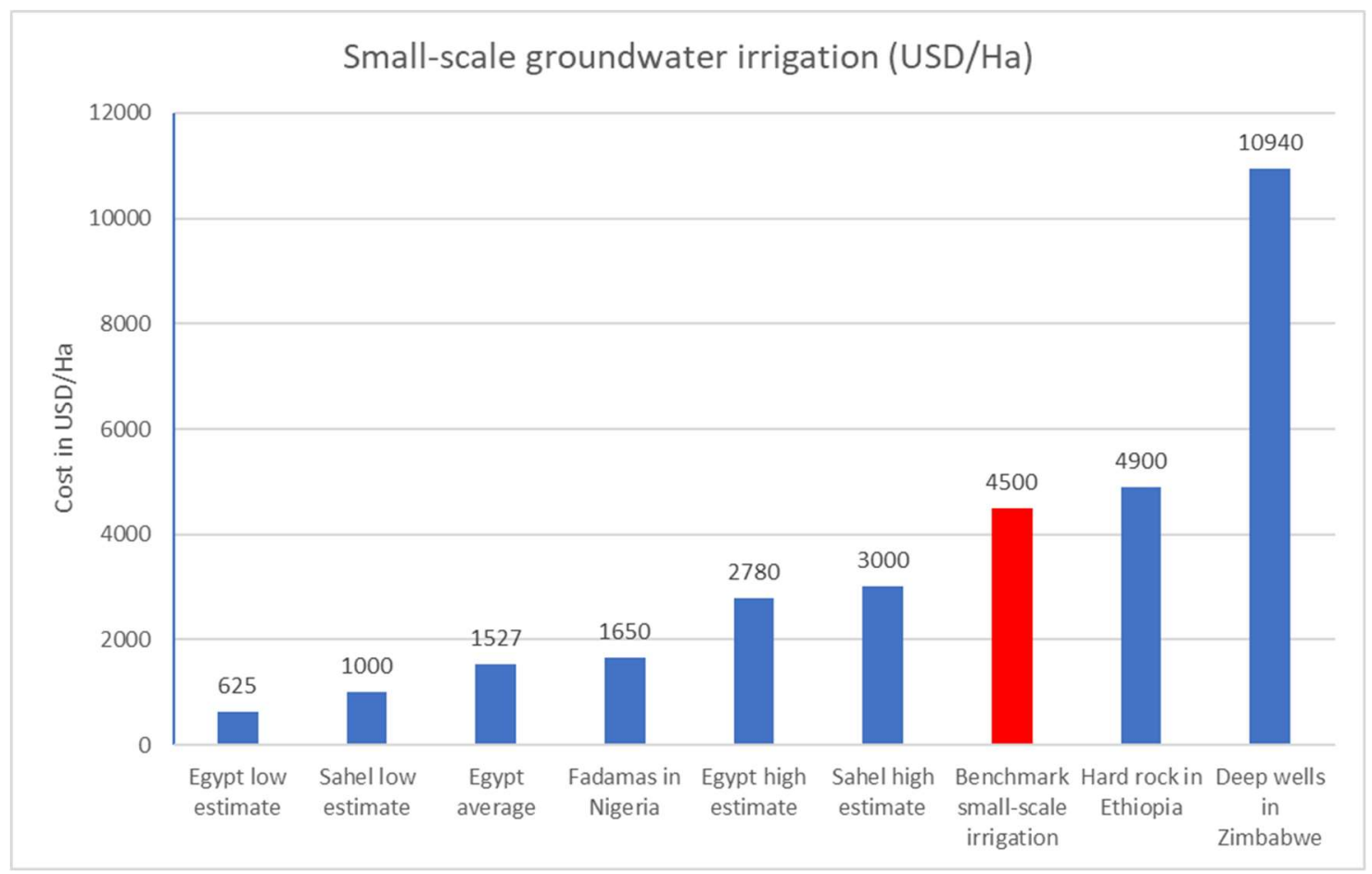

Figure 26 - Small-scale groundwater irrigation costs per hectare

These figures suggest that groundwater-based irrigation in SSA is no more expensive than surface-water irrigation for the small-scale irrigation installations that have the most potential to increase resilience in SSA. In many cases (e.g. where surface water resources are distant or unreliable), irrigation from groundwater is by far the cheaper option. Box 14 provides an example of small scale irrigation in action in SSA.

Box 14 - Economic and financial analysis of investment in groundwater irrigation: Sahel Irrigation Initiative Support Project (SIIP)

A recently World Bank approved investment operation in small scale irrigation in the Sahel indicates that investment in groundwater development is good business. The SIIP identified the main constraints to the productive use of the water is the economic cost of storage and abstraction. Experience shows that the cost can be significantly lowered when appropriate techniques and best design and construction practices are utilized. These techniques include improved rainwater harvesting with partial water control to recharge shallow aquifers including the construction of small sand dams for groundwater recharge in the valleys and flood plains. The operation is financing the development of small-scale private irrigation systems (less than 1 ha up to a few ha) for individuals or small groups of producers, involving pumping equipment, devoted to high value crops such as vegetables and small-scale community-based irrigation schemes of less than 50 ha, usually promoted by nongovernmental organizations (NGO) or Governments, for villages or large groups of producers. The project design emphases investment in small-scale irrigation solutions which are usually less expensive and more cost-effective than large scale irrigation. Substantial benefits of the project will derive from improving the enabling institutional environment as well as the capacity-building and enhancing knowledge systems. The internal rate of return (IRR) ranging from six percent to 64 percent for expansion and from nine percent to 94 percent for rehabilitation. An economic cost-benefit analysis was prepared to reflect the project impact at countries economy level. The cost benefit analysis also includes quantified environmental externalities. The economic IRR of the project is 15.5 percent. 
Groundwater irrigation costs in SSA are also influenced by numerous and interdependent indirect or secondary factors such as energy prices, land tenure, access to markets, transport, storage, and equipment prices ${ }^{172}$ (see Section 4.3, and Annex 4). These costs in SSA are significant. For example, a $40 \mathrm{~m}$ borehole costs between USD 4,000 and USD 10,000 in SSA, but only USD 1,000 in India ${ }^{173}$. Pumps in India cost half of what they do in SSA. Land tenure uncertainty and lack of access to other collateral in SSA hampers borrowing for investment in irrigation equipment ${ }^{174}$. Energy costs in SSA are considerably higher than in India. By addressing excessive costs implied by these secondary factors, the total cost of groundwater irrigation could be further reduced.

\subsubsection{Costs and benefits of groundwater development at the household level}

Several studies have documented that millions of small farmers have been investing in small scale drinking water and irrigation systems in response to opportunities created by market demand and new technology ${ }^{175}$.The important direct benefits accrued to the individual households from water use, include clean drinking water supply on family health, on reducing time wasted and the physical burden of fetching water (largely imposed on women and children who lose thousands of productive hours $)^{176}$. In terms of technology, the introduction of small diesel and electric pumps has led to the rapid growth of individual, low-cost irrigation using pumps drawing water either from local surface water or from wells tapping underground water. The advent of this accessible technology coincided with the growth of domestic and export markets for horticultural products to create a significant new economic opportunity for individual farmers or small farmer groups. Wherever water is available and markets exist, this technology has seen very rapid growth across the SSA countries, particularly in peri-urban areas and where there are export or industrial processing facilities. With relatively low investment costs and individual control over "just-in-time" water, the technology has proved popular. More recently, treadle pumps have proven to be a particularly accessible and low-cost technology that can have a cost-benefit ratio higher than motorized pumps, in addition to being much cheaper to acquire. As solar powered pumps continue to become more affordable, they offer great potential moving forward.

The alliance between the World Bank, IFAD, AfDB, and the CGIAR centers carried out a series of studies, mainly lead by IWMI and IFPRI to assess the economic dimensions of investing in small scale irrigation in SSA, with positive results. IFPRI and IWMI ${ }^{177}$ scientists provided initial estimates of the potential for expanding irrigation in SSA. IFPRI evaluated the potential for irrigation in Africa using existing databases and detailed geographic information systems (GIS) and the detailed information provided by the IWMI study about the future potential of irrigation in SSA. These studies ${ }^{178}$ identified potential areas for irrigation development, using distance to market, existing arable farmland, and distance to water resources. An optimization model calculated the potential for small- and large-scale irrigation for each country. IFPRI studies

\footnotetext{
${ }^{172}$ Lejars et al. 2017, Villholth 2013, Foster et al. 2006.

${ }^{173}$ Chokkukula \& Giordano 2013.

${ }^{174}$ Chokkukula \& Giordano 2013.

175 Especially small pumps and pressurized irrigation systems, Woodhouse et al. 2016.

${ }^{176}$ Banerjee\&Morella 2011.

${ }^{177}$ Xie et al.

178 Ward et al. 2016.
} 
concluded that the internal rate of return (IRR) for small-scale irrigation exceeded 28percent. For large-scale irrigation, the IRR is much lower (less than 10percent).

Most small-scale irrigation expansion by the private sector and individual smallholders has been based on shallow groundwater - it has been a critical resource to support the rapid irrigation growth to date. The availability of low cost pumps drawing water from groundwater has sprung to irrigate small plots up around towns and cities and wherever there is a market for higher-value produce. In Ethiopia, Kenya, and Tanzania, and Niger and Mali, individual irrigators can sell into profitable export markets for fresh fruit, vegetables, and flowers. Private pumps can also provide supplementary irrigation to predominantly rainfed systems to relieve stress at critical points in the growing period and private pumped groundwater can provide "conjunctive use" on irrigation scheme along with canal water. The prospects for this technology are excellent across SSA countries wherever there is perennial groundwater source. The enormous advantages of individual smallholder irrigation are that: (i) it is normally very profitable for farmers, provided the water source is accessible, (groundwater is not too deep) and markets are available; and (ii) it does not usually require public intervention or communal organization.

Cost is a barrier to entry for many - particularly the poor - wanting to develop groundwater for irrigation purposes. IFPRI and IWMI studies assume that the cost of equipping one hectare for pump irrigation from wells up to 50 meters deep is about $\$ 6,000-8,000$, which raises the issue of equity for governments trying to promote pro-poor technologies. At present, poorer people and women generally have limited access to the capital and support needed to invest. Lower-cost technology such as the treadle pump goes someway to addressing this issue.

In some countries, government has taken a very hands-off approach to groundwater development. In Kenya for example, the vibrant market economy has largely eliminated the need for government-supported individual smallholder irrigation. Even in this context, however, governments may provide incentives to irrigators by removing tariffs on imported pumps and design specific incentives to facilitate the export of high value crops.

There may be opportunity for the World Bank to help support some of these technology and entry to (groundwater) market issues at the local level, whilst considering sustainable development of groundwater resources in a strategic context.

\subsection{Incentives}

This element considers the role of incentives in markets and trade policies, private sector engagement and managing adverse environmental impacts.

\subsubsection{Markets and trade policies}

Market factors affecting the water sector rely on both private and public-sector stakeholders. Policies and regulations set the rules of the game for private sector actors. The private sector plays an important role in marketing pumps and related technology to abstract water. This dimension requires careful monitoring to ensure fair competition and provision of reliable service and maintenance. Additionally, supportive public policy is important and includes incentives such as reduced taxes to acquire well designed, environmentally friendly technology suitable for local operating conditions. Policies and regulations to demand safe standards of reasonably priced water equipment and infrastructure are needed to protect consumers and to 
encourage small investors to develop this sector. Although pumps are relatively affordable, poorer people continue to face barriers to entry in this sector. Special lines of credit, along with responsive financial arrangements, could develop functioning markets for advancing small scale irrigation.

Well developed markets and functioning value chains are an important incentive to invest in groundwater irrigation. An important market component is the economic viability of crops grown with groundwater. Horticultural products, often irrigated by groundwater are perishable and requires well developed value chains for grading, storage and timely transport of harvested crops.

Crop diversification can alleviate pressure on water use for traditional food crops, such as cereals which are of low value. SSA countries with limited water resources can produce high value crops or livestock for export that enable them to purchase grains that are water intensive but cheap. Thus, water scientists introduce the notion of virtual water. For example, the volume of water put into vegetables may earn US\$500, while the same volume of water put into sorghum or wheat earns US\$15 or US\$20, thus, the volume used to grow vegetables is worth 25 times in wheat. This could be accomplished if water-scarce SSA countries concentrate on producing high value crops for export (like flowers or vegetables) and then use the revenues to import staple crops like grains. Even though water itself is not tradable across nations, this allows countries to substitute trade in goods produced with the water available to them for direct trade in water. An example of this trade in virtual water is the increasing export of flowers from Kenya and vegetables from Niger to Europe. Policy support to enhance this trend would allow for drastic shift toward high water productivity and improved income for thousands of small producers.

\subsubsection{Support and enhance private sector investment in water services}

Given that small farmers and investors have been the main driver in expanding small scale groundwater development for irrigation and water supply, this trend should help shape public policy and institutional approaches. Specifically, there is a need to (i) enforce and support private initiatives, and (ii) design procedures to protect and sustain equitable development and management of the sector. In this sense, government policy should be demand driven. Elements of successful intervention include policy commitment to long term program for efficient development and management of groundwater resources with strong community participation. Because groundwater resources are found in select locations, it is essential to clarify the roles and responsibilities of national and local government agencies engaged in this water sector.

Policy issues related to securing large and long-term private investments in SSA need urgent attention because they are linked to the agricultural sector and are closely intertwined with the question of land security. Indeed, the fluidity of land access and use rights that characterizes most of rural SSA has long been presented as a reason for the low productivity of African agriculture and a stumbling block for attracting the private investments that would allow breaking the deadlock. It is against this backdrop that many countries have engaged in reforms and policies aiming at securing land through the formalization of rights. Even though customary tenure is generally characterized by a "bundle of rights" whereby different individuals can claim different types of use and access to the same plot of land, formalization has often taken the form of mapping and land titling exercises whereby a single individual is recognized and further granted ownership to any single plot of land. These reforms have raised significant attention 
maybe best epitomized by the worldwide debate on 'land grabbing' whereby outsiders are provided land rights and land titles at the expense of local communities ${ }^{179}$.

Related to the above issues are reforming policies governing water pricing and cost recovery for publicly funded water services with a special framework that articulates challenges to water security at national and local levels.

\subsubsection{Avoiding and minimizing environmental impacts}

Increasing water demands can lead to overexploitation of both groundwater and surface water resources. Trends such as rapid urban and industrial growth and expansion of irrigated land have led to overexploitation of both surface and groundwater resources in some areas. Persistent groundwater overexploitation can result in water-level declines in both shallow and deep aquifers. For example, the Chad Basin (Box 15) suffers an average water-table decline of $0.5 \mathrm{~m} /$ year $^{180}$ and a recently held workshop in Somaliland also warned about declining water tables in the IGAD region because of wells being drilled to meet the growing needs of displaced communities during the drought of 2017. Water table declines are not uniformly distributed and tend to be greatest beneath cities and intensively groundwater-irrigated areas. Water-table declines have also varied over time. With the continued decline of groundwater levels, large depression cones could form both in unconfined and confined aquifers and tracts of land that overlie cones of depression could subside. Abstracting water from coastal aquifers could cause seawater intrusion into previously freshwater aquifers. As water tables decline the withdrawal of water alters the direction of groundwater movement. Some water that flowed to the nearby springs on streams no longer does so and some water may be drawn in from the stream into the groundwater system, thereby reducing the amount of stream flow.

Box 15 - A case of groundwater overexploitation: indicative of future challenges for the SSA region?

A recent study of groundwater resources in the Lake Chad Basin illustrates a case of increasing pressure on an already scarce resource. Excessive groundwater abstraction for domestic, livestock and industrial water supplies in the Nigerian region of the Chad Basin has caused serious declines in the groundwater levels and increases in costs of operation. Data from 1960-2010 indicate that the water levels in the aquifer have declined by about 25-35 meters. The domestic and livestock consumption amounts to over 80 percent of the groundwater use. Over-exploitation has led to economic, social and environmental consequences. Inefficient use and wastage are also issues of concern.

Based on the rate of increase in water demands in the past 10 years, it is expected that almost all countries in SSA will be tapping their precious groundwater resources to meet the growing demand for food and for potable water. Lessons from other global regions, such as Asia, suggest that in addition to realizing the benefits of water sector investments (and their myriad benefits), it is wise to pay attention to potential negative effects (such as environmental degradation) upfront, to promote sustainable development.

The challenges facing the communities living around Lake Chad are mounting as the lake shrinks and its water quality declines. Lake Chad has shrunk by more than 70 percent in the last two decades with serious implications on the availability and quality of aquifers in the Lake region.

\footnotetext{
${ }^{179}$ Venot et al. 2017.

${ }^{180}$ Yusuf 2016.
} 
Groundwater can also be exposed to contamination from waste and wastewater discharges. In many locations, reusing wastewater is becoming an important resource. Common sources of groundwater pollution can be from untreated urban and industrial wastewater discharge and chemical (fertilizer) infiltration from agriculture. Where contaminated, groundwater remediation can be both costly and take considerable time. Furthermore, because of the costs of developing water resources, water recycling is increasingly being implemented. Many countries have adopted advances in wastewater treatment and reuse to augment their scarce water resources. SSA countries would benefit from incorporating all conventional and nonconventional water resources in their national water strategy.

Cross-sectoral efforts are required to minimize and manage environmental disbenefits to groundwater resources. The environmental dimension of developing groundwater resources requires careful assessment of cross-sectoral impacts caused by competing pressures from WSS and other sources (notably agriculture and industry). Progress in developing groundwater resources for both poor and affluent consumers combined with urban growth, will place stress on groundwater quantity and quality. Compounded by unregulated wastewater and sludge disposal could result in serious groundwater and surface water pollution, besides contaminating agricultural land. These environmental stresses would be aggravated by climate variations which give rise to greater uncertainties in water availability. These problems require cross-sectoral efforts to develop a special component of environmental management attached to the groundwater strategy. 


\section{Chapter 6: Implementing the Strategic Framework- Analytical and Operational Guidance}

\subsection{Background and Rationale}

Investing in groundwater in SSA requires a long-term program to enhance the sustainable contribution of the water sector to economic and social development, and to strengthen the resilience of rural communities in SSA. This program should be based on two pillars: (i) analytical dimension to enhance knowledge about the water sector at the national and regional levels in SSA, and (ii) operational dimension to assist member countries design responsive investment opportunities, both of which are outlined in this chapter. The direct objective of this program is to strengthen economic and sector work to include a special focus on the role of water and its three components: surface water, groundwater, and non-conventional water sources in national economic and social development. Because groundwater is an integral component of national water resources, this economic and sector work should guide the development of groundwater resources to complement national efforts to provide clean WSS services to millions of urban and rural poor in the region, to expand the performance of the agriculture sector to reduce poverty, and to increase the income of small farmers and pastoralists by strengthening their resilience against climate shocks.

National and donor supported investment in the water sector in SSA has increased in the last decade but much opportunity in groundwater development can be realized. Currently the World Bank allocates about 30 percent of its global investment in the water sector to SSA. The portfolio does not differentiate among sources of water being developed. The needs for further investment in this sector in SSA are substantial because large segments of the population in the region still do not have access to reliable clean water supplies. Furthermore, the performance of the agricultural sector is below world average in terms of crop yield and productivity of water. Lastly, recurring droughts in some of the region poorest countries disproportionally hit the rural poor whose livelihoods directly suffer from the of lack secure water supply. There are several factors behind the difficulty to overcome some of the key challenges in the water sector in SSA, including poor infrastructure, dispersed populations, distant surface water resources (rivers and lakes) and high cost of building, operating and maintaining infrastructure for water supply and irrigation.

A comprehensive review of the World Bank's water and groundwater portfolio, as well as a list of actors with which the World Bank can collaborate, is provided in Annex 5 (including Annex 5a and 5b).

Support for development of SSA's groundwater resources could help overcome some of the major regional socioeconomic challenges. Due to it being widely available, comparatively cheap and constituting a natural buffer against climate variability in arid and semi-arid regions, groundwater provides clear strategic advantages. At the same time, the successful mobilization and sustainable management of groundwater resources in SSA are hampered by critical deficits in knowledge, capacity and awareness. There is need for a coherent action plan that, in addition to the necessary increase in the level of investments, addresses these critical deficits.

The proposed action plan provides guidance on the identification of priority countries and regions for intervention, identifies necessary preparatory steps at regional, national and local level and includes examples of strategic investment projects World Bank intervention. 


\subsection{Criteria to identify priority countries for intervention}

There is a need to identify priority countries for each of the strategic areas of intervention (urban water security, economic development through irrigation expansion, and drought resilience / water security for rural livelihoods) identified in Chapter 5 . The selection process of priority countries should identify existing demand for Water sector investments as expressed in Country Partnership Strategies or Sector Strategies, aim at maximizing results by considering the urgency to address water security issues in countries and their groundwater potential but should also seek synergies with other WB investment programs, notably under IDA.

The World Bank Water Global Practice has developed a strategy and identified target countries to scale-up reform and investments for IDA 18. The strategy has identified priority countries for engagements in WRM, urban water supply, rural and small-town water supply and in irrigation, based on their traction for reforms, opportunities for reform or because of recent engagement or FCV status (fragility, conflict and violence). Mobilizing Africa's groundwater resources will be key to achieve the IDA goals and to meet rapidly growing water demand. Groundwater is the only widely available water resource to allow rapid small-scale irrigation development and as a decentralized and often relatively easily accessible water resource, groundwater can provide water security in fragile or conflict-ridden regions. To strengthen the coherence of the Water Sector Strategy for Africa, priority countries for groundwater investments should, to the extent possible, be aligned to the IDA target countries.

Investment in groundwater can be prioritized according to a framework balancing the 'need (or demand) for groundwater development' with the 'potential for groundwater development (Figure 27). The highest priority regions / countries will be those with high need and high potential (for macro-economic development and urban and rural water security), while the lowest priority areas will be those with low need and low potential. Where need is high, but potential is low, groundwater may be considered only for emergency relief, whereas where need is currently low but potential is high, there may be opportunity to consider groundwater as a resource around which to trigger sustainable macro-economic development (e.g. irrigation, industrial, urban development). 


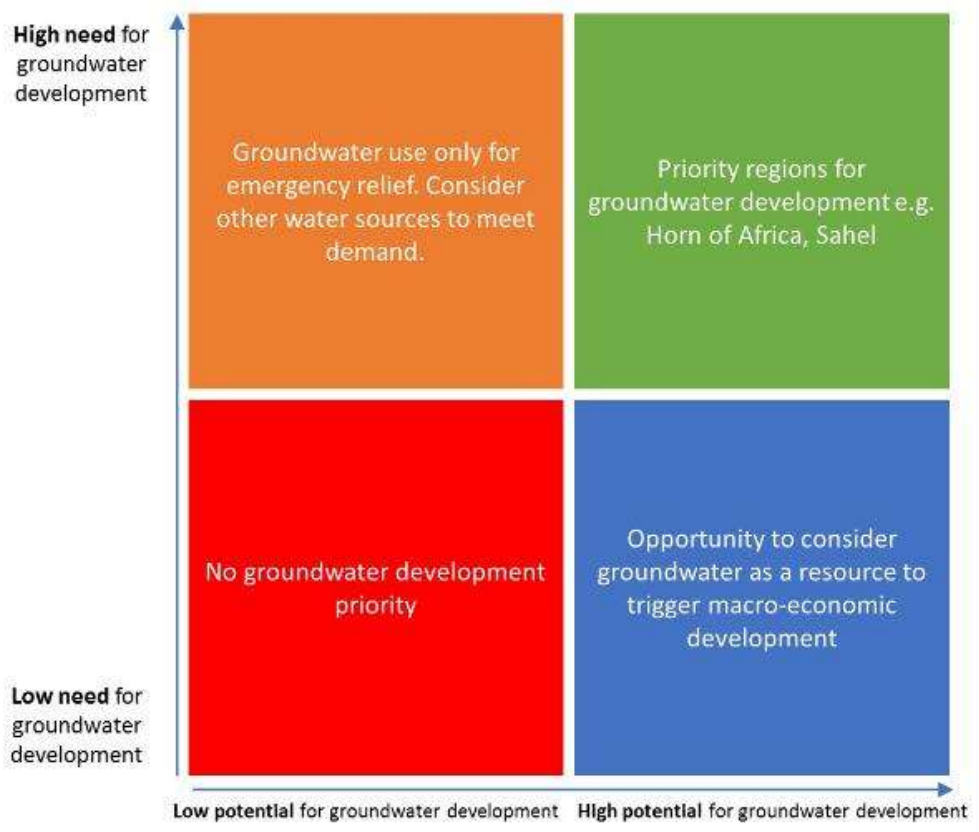

Figure 27 - Framework to guide World Bank prioritization of investment, to match needs with resource potential

Based on the framework outlined in Figure 27, there is opportunity to prioritize countries where investment in groundwater development should be enhanced. While Chapter 3 identified groundwater potential at a macro level, further analysis is required to make recommendations on focus areas due to the significant spatial variability in availability of renewable groundwater resources and in the demands for groundwater at local levels from local communities. More generally, for a groundwater action plan to be successful it will need to cover activities at regional, national and local level. Chapter 7 includes a preliminary list of priority countries for investments in groundwater infrastructure and further analytical and operational guidance to identify priority countries.

\subsection{Framework components to guide implementation}

The Global Framework for Action for Groundwater Governance ${ }^{181}$ identified several critical factors that need to be in place to ensure effective governance of groundwater resources. These key factors include adequate knowledge, capacity, cross-sectoral linkages and financing. To successfully implement investment projects in SSA using groundwater resources, and to ensure their sustainable use, there is a need to ensure the most critical enabling conditions are in place. These conditions are captured under the Four l's in the strategic framework presented in Chapter 5 and re-elaborated in Figure 28.

${ }^{181}$ GEF-FAO-UNESCO-World Bank 2016. 


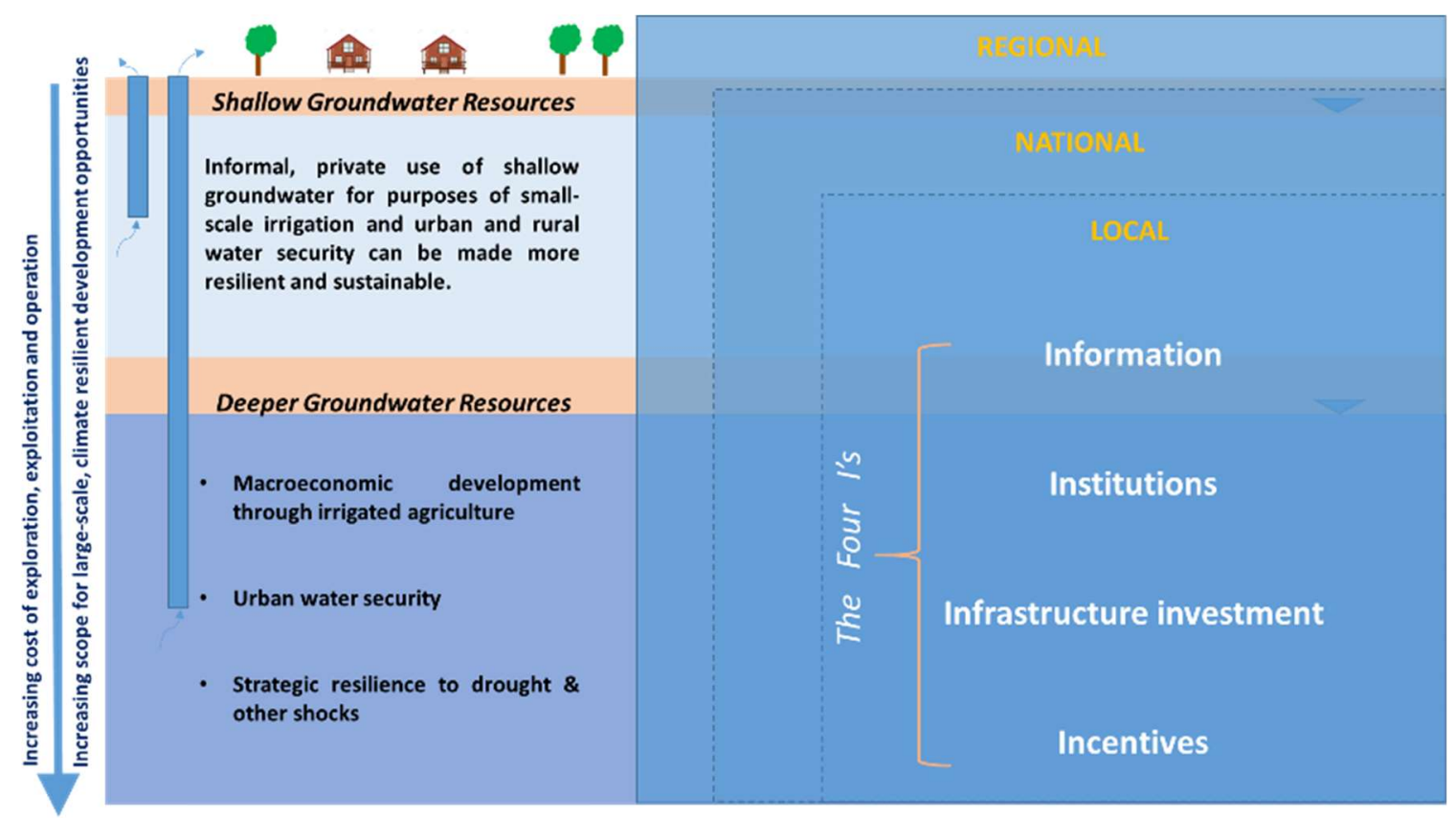

Figure 28- A framework to guide a World Bank sustainable development strategy for shallow and deeper groundwater resources in SSA

National and regional efforts to assist SSA countries improve the performance of the water sector with a special emphasis on streamlining the important contribution of groundwater resources should address salient issues at regional, national and local levels. Hence, the elements of the strategic framework where implementation focus can be made are outlined below.

\subsubsection{Information}

There is opportunity to support the deployment of affordable and reliable technology \& innovations in groundwater. At regional, national and local levels, investments in modern technology, including modern information and knowledge systems, is essential for planning, implementing, monitoring and managing efficient water delivery networks, and to introduce innovative management practices for efficient use of water at the household and farm levels.

There may be opportunity for collective support and investment to help strengthen knowledge in regional and national learning institutions - including tertiary institutions and centers of excellence - to build youth capabilities and raise the profile of groundwater development as a potential applied research and career pathway. Box 16 outlines how the World Bank's existing African Centers of Excellence could better integrate groundwater development issues. 
Box 16 - Opportunity to strengthen regional and national educational institutional capacities

In 2014, the World Bank approved financing for 19 (now 22) university-based African Centers of Excellence (ACEs) in seven countries in West and Central Africa, with the aim of equipping youth with new scientific and technical skills. The competitively selected centers received funding for advanced specialized studies in science, technology, engineering and mathematics (STEM)-related disciplines, as well as in agriculture and health. Facilitated by the Association of African Universities, ACEs offer a regionally integrated way to increase high-quality $R \& D$ services to help find solutions to development challenges facing SSA.

Two examples of institutions promoting innovation in water in education in SSA, and being supported by the World Bank, include:

- 2ie - Institut International D'ingénierie De L'eau Et De L'environnement (in Burkina Faso) is an international institute for higher education and research in the areas of water, sanitation, energy, environment, civil engineering and mining. $2 \mathrm{iE}$ has two join research centers focusing on areas of critical need, the first studying Water and Climate and the second, Energy and Sustainable Habitat. The institute adopts an innovative public-private governance model, involving founding states, private companies and institutional, academic and scientific partners.

- Dakar American University of Science \& Technology (in Senegal) provides instruction and research opportunities for undergraduates and graduates in fields of engineering and technology that are useful in developing technological solutions to address Africa's societal needs and challenges. For example, the College of Civil and Environmental Engineering helps students and graduates learn "to improve sustainability of infrastructure related to water, energy and urban systems with respect to increasing demand from a growing population, climate-related disasters, and deterioration."

There may be opportunity to raise the profile of groundwater across many of the ACEs, many of which focus on cross-cutting issues such as dryland agriculture, maternal and infant health, and environmental sanitation.

Sources: https://ace.aau.org/, http://daust.org/, http://www.2ie-edu.org/

Boosting the capacities of existing centers of excellence (as outlined in Box 16) or establishing a new 'water studies center' could increase regional capacities. Centers of excellence can enhance links between research, education and policy development in the water sector. Support could aim to strengthen interdisciplinary water research and policy development center(s) for teaching and research on critical emerging water development topics (e.g. water resources planning integrating conventional and non-conventional water resources, adaptation to climate change; water scarcity and security for urban and rural communities, and food safety) at selected universities in SSA. These facilities and programs would develop and deliver quality innovative, interdisciplinary research, teaching and extension programs, primarily to audiences in their respective communities (policy makers, small business owners and farmers, and students) would also serve national constituencies and be models for replication in other countries. Such centers would provide a forum for interdisciplinary and comparative research relating to water technology for surface and groundwater resources and their efficient use for water supply and for irrigation. Annex 6 presents a framework for the scope of a water research and development center and its development objectives. 
The World Bank could expand its efforts to (i) act as a convener for increased partnerships between national geological surveys and other knowledge brokers; (ii) build on the example of the SADC groundwater institute, which collects and collates groundwater data and develops groundwater knowledge products; and (iii)strengthen the groundwater capacity of existing river basin organizations in SSA, which builds upon the Bank's track record of transboundary governance initiatives. Current Bank investments in groundwater knowledge production - for example, national hydrogeological mapping in Burkina Faso - suggest a potential for replication in other countries in the region.

\subsubsection{Institutions}

At national and local levels, there is a real need to assist member countries expand knowledge about water policies especially as related to water security and under increasing scarcity and climate risks. Important dimensions of this support include:

- Assessment of public expenditure allocated to the water sector and the financial viability of water agencies and utilities;

- Regulations and water pricing and tariffs regimes;

- Assess policies related to land tenure systems and land titling which affect the investment environment by the private sector; and

- Scope for decentralization and community level engagement in management and related national and local institutions regarding water management.

It is also important helping to strengthen and expand strategic partnerships with regional and international partners already engaged in groundwater in SSA, with a focus on innovative technology dissemination to help address resource knowledge, development and management deficiencies. Table 3 outlines some potential partner institutions already working on groundwater in SSA.

Table 3 - Potential partner institutions already active in (ground)water resource management in SSA

\begin{tabular}{|c|c|}
\hline Institution & Brief description \& status of groundwater integration \\
\hline $\begin{array}{l}\text { Comité Permanent } \\
\text { Inter-Etats de Lutte } \\
\text { contre la } \\
\text { Sécheresse dans le } \\
\text { Sahel (Permanent } \\
\text { Interstate } \\
\text { Committee for } \\
\text { Drought in the } \\
\text { Sahel) (CILSS) }\end{array}$ & $\begin{array}{l}\text { CILLS is the technical arm of the Economic Community of West African States } \\
\text { (ECOWAS) and is responsible for monitoring the food security of } 17 \text { West African } \\
\text { and Sahelian countries, running a large satellite data center, and managing a } \\
\text { protocol that countries follow in collecting their food-security data. CILLS } \\
\text { organizes seasonal regional workshops to ensure modern monitoring and its } \\
\text { training components contribute to regional drought resilience. There may be } \\
\text { opportunity to further increase the tole of groundwater in regional drought } \\
\text { resilience work being undertaken by CILLS. CILLS is currently working with the } \\
\text { World Bank in SSA. }\end{array}$ \\
\hline $\begin{array}{l}\text { International } \\
\text { Groundwater } \\
\text { Resources } \\
\text { Assessment Center } \\
\text { (IGRAC) }\end{array}$ & $\begin{array}{l}\text { IGRAC facilitates and promotes sharing of groundwater information and } \\
\text { knowledge, focusing from early days on aquifer assessment and groundwater } \\
\text { monitoring. Gradually, IGRAC is expanding its interest to other groundwater- } \\
\text { related topics, such as governance, training and climate change adaptation. } \\
\text { Currently, IGRAC is involved in the Groundwater Futures in Sub-Saharan Africa } \\
\text { (GroFutures) project (a 4-year research project that is part of the UPGro } \\
\text { program), which aims to develop the scientific evidence base, tools and } \\
\text { participatory processes by which groundwater resources can be used sustainably } \\
\text { for poverty alleviation in SSA. IGRAC is also investigating the sustainable }\end{array}$ \\
\hline
\end{tabular}




\begin{tabular}{|l|l|}
\hline \multirow{1}{*}{$\begin{array}{l}\text { Japan International } \\
\text { Agency (JICA) }\end{array}$} & $\begin{array}{l}\text { management of transboundary aquifers. In regions such as the Horn of Africa, } \\
\text { which experiences alternating periods of drought and heavy rainfall, Managed } \\
\text { Aquifer Recharge (MAR) is being explored to take advantage of available water } \\
\text { resources. IGRAC is currently working with the World Bank in SSA. }\end{array}$ \\
\hline $\begin{array}{l}\text { groundwater as the water source (boreholes with pumps) through Grant Aid in } \\
\text { Sub-Saharan Africa. In addition, JICA has been providing assistance to enhance } \\
\text { local government's capabilities for implementing their own construction of water } \\
\text { supply facilities, and formulate water supply plans by identifying aquifers and } \\
\text { producing hydrogeological maps, especially for areas where groundwater is } \\
\text { difficult to locate due to the geological structure. JICA activities have also } \\
\text { included the establishment of training centers with courses on topics such as } \\
\text { groundwater investigation, drilling technology, drilling machinery maintenance, } \\
\text { local social development, water supply management and operation and } \\
\text { maintenance of mechanical and electric equipment. }\end{array}$ \\
\hline $\begin{array}{l}\text { Dutch Ministry of } \\
\text { Foreign Affairs }\end{array}$ & $\begin{array}{l}\text { The Dutch Ministry of Foreign Affairs is active in several SSA countries, with a } \\
\text { focus on issues such as improved access to safe drinking water and sanitation; } \\
\text { water management, improved river basin management (including transboundary } \\
\text { basins) and safe deltas; and raising water productivity in farming. The Ministry } \\
\text { has supported innovative groundwater exploration techniques in SSA and has a } \\
\text { record of collaboration with the World Bank on projects. }\end{array}$ \\
\hline
\end{tabular}

Sources: CILLS website, IGRAC website, JICA 2016, Dutch Ministry of Foreign Affairs website.

\subsubsection{Infrastructure Investment}

Integrating groundwater into public expenditure planning. Related to the above point, public expenditure for developing groundwater resources should be an integral component of the national water development strategy. Availability of public funds would be needed to expand and sustain groundwater investment in conjunctive use with surface water resources with special attention to budget allocation for O\&M.

Linking national water resources strategies to investment. Institution building includes detailed reviews of institutional capacities in policy formation and implementation of innovative investment programs in the water sector including integrating groundwater in the national development plan. Investment in the water sector should assist member countries prepare incorporate sustainable water resources strategies within national economic plans. Economic and sector work should include a special chapter on water resources management including surface water, groundwater, and non-conventional water resources including wastewater treatment and desalination. Country economic analysis and country partnership framework should assess the important role of water in addressing crucial dimensions of economic and social development including the importance of clean drinking water for urban and rural populations and the impact of water and irrigation on agricultural growth, employment and environmental management. This assessment requires investment in modern information and data systems.

An important intervention is to help countries undertake and/or compile integrated water resource assessments with Ministries of Finance and water resources and irrigation. The intended audience would be policy makers to address challenges facing the water sector Including the contribution of groundwater in national economic analyses which may help strengthen the case for investment in this component. An integrated assessment of national 
water resource potential - including surface water, groundwater and non-conventional sources - could help be more objective in strategic water resources planning and development. Figure 29 provides a conceptual summary assessment of water resource potential, which could be presented to Ministry of Finance for helping to prioritize public expenditures. In Figure 29, more traditional surface water development benefits from greater informational, institutional and technical experience, while groundwater offers greater potential social and environmental benefits (for equivalent economic outputs).

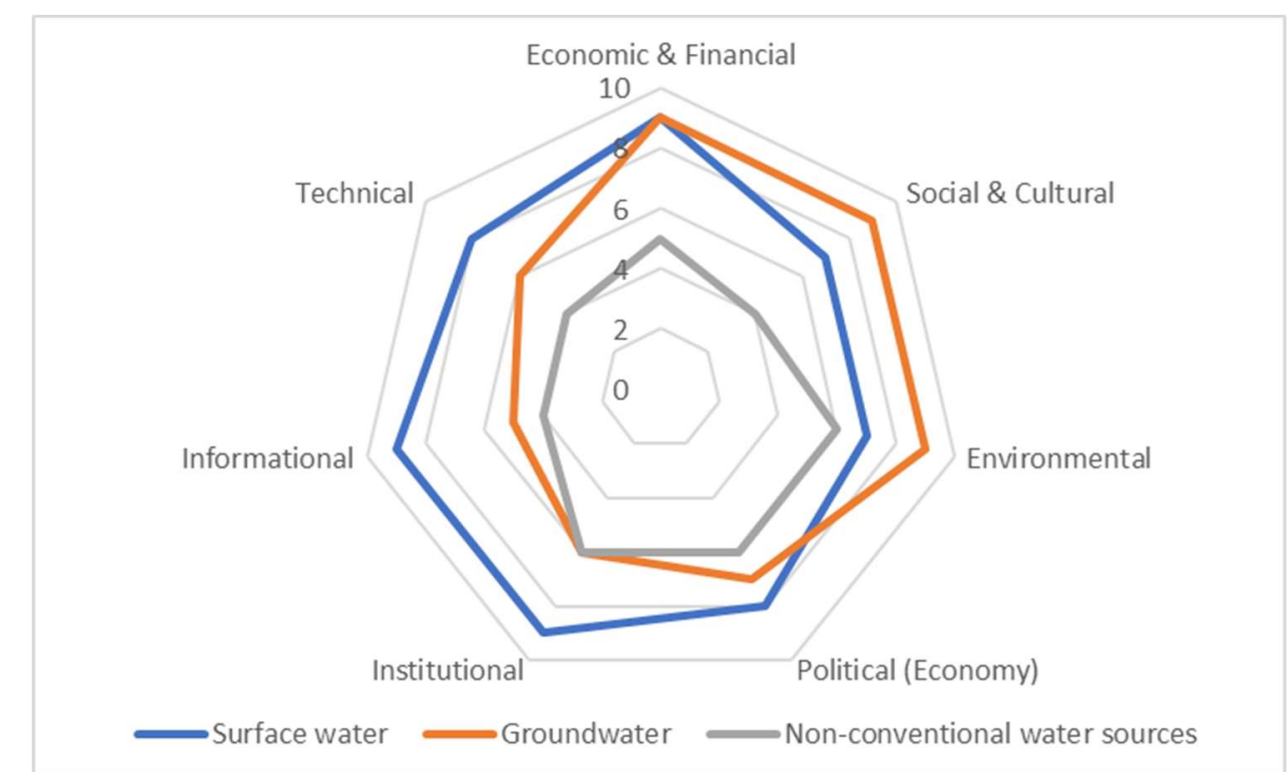

Figure 29 - Theoretical presentation of integrated water resource assessment for prioritizing public expenditure

Linked to the assessment outlined in Figure 29, conducting detailed cost-benefit analyses of shallow and deeper groundwater development, and comparisons to surface water and nonconventional sources. Ensure careful analysis of the holistic costs and benefits of such investments. On the cost side, it is important to analyze non-financial liabilities such as environmental degradation and natural hazards. On the benefits side, non-financial benefits include social and health aspects of improving the quality of life in urban and rural households, in addition to other economic dimensions of proposed interventions. Comparisons of costs and benefits between groundwater investments and surface water investments should also be made.

\subsubsection{Incentives}

Every effort should be made to help SSA countries identify and overcome limiting secondary factors. Investment in groundwater requires supportive and responsive regional marketing and trade activities to confirm demand for end products from groundwater (e.g. potable water, irrigated agricultural products) and water-related technologies. This can also include identifying factors which are limiting groundwater investigation, exploration, development, operations and maintenance at small and larger scales. 
Holistic assessments of groundwater development need to consider environmental and social costs and benefits. Investment in groundwater requires careful assessment across regional, national and local levels for long term impacts of interactions of water resource development on the environment and social stability.

\subsubsection{Regional, national and local considerations}

At the regional level, interventions are needed to enhance the knowledge and capacity of regional institutions and agencies in supporting member countries. A good model is the recently designed regional support projects funded by the Bank and the GEF "Economic growth and water scarcity in the Sahel through groundwater governance" which was designed to enhance the capacity of selected countries in the Sahel in the sustainable management of groundwater resources through improved knowledge, information and data systems and to strengthen regional cooperation (see Box 17).

\section{Box 17: Innovative investment for Sahel Regional groundwater information and knowledge.}

The GEF funded project "Economic growth and water security in the Sahel through groundwater governance" aims at complementing World Bank support to irrigation development in the Sahel to reduce the risks related to groundwater over-abstraction. The proposed project complements the development objective of the Bank-funded "Sahel Irrigation Initiative support project" (SIIP), focusing on three of the six SIIP countries (Chad, Mali, and Niger) because of the priority need for detailed groundwater assessment. The project development objective (PDO) is to improve the knowledge of groundwater potential in the Sahel and to strengthen groundwater governance at local, national, and regional levels, thereby contributing to improved water security in the Sahel. The investment is designed to sustainably manage groundwater through reliable information about the actual availability of the resource. It supports an institutional framework to help avoid overexploitation and manage critical situations through better understanding, and through adapting governance to the local context in participating countries. The project includes governance diagnostics at local, national and transboundary levels to prioritize actions and investment in the face of rising human demand, overall water scarcity, and the anticipated impacts of climate change in the targeted countries.

The focus is on sustainable groundwater development in the Sahel via:

I) Assessment of groundwater resources at national and transboundary levels. This investment is to improve knowledge of groundwater availability in pilot areas and selected aquifers, to ensure the sustainability of uses. It considers the constraints linked to the temporal and spatial variability of the resource, its cost of development and exploitation, and its quality. At regional level, this component will provide regional and national policy makers and institutions with the information and knowledge base needed to support sustainable development of groundwater. The aim is to harmonize the national hydrological databases, add data on quality, record existing uses, and suggest provisions for data, information, and knowledge. These provisions will include tools for: (a) systematic data acquisition (timeindependent data and monitoring); (b) on the basis of acquired data, adequate generation of information and knowledge on groundwater and its context; (c) sharing data, information and knowledge (voluntary and legally binding arrangements, d) collection of new data on groundwater resources to support improved planning and management to better inform decisions on the sustainable development of groundwater and refine the methodology for groundwater resource assessments, considering the economic cost of extraction, the variability, and the quality of the resource .

II) Groundwater governance at local, national, and transboundary levels. This will improve groundwater governance focused on the management of the risks linked to exploiting the resource and includes the installation and capacity building of groundwater monitoring infrastructure based on participatory formulation of groundwater management plans. The project will implement 2-3 pilots per country, at least one of which will be in a transboundary aquifer. 
At the national level, groundwater should be treated as an integral component of national water resources, and should be addressed in the water sector review to define priority areas for investment. The review should describe how groundwater fits into the overall national water balance of supply and demand in the coming decades. This review should address salient issues related to public expenditure, national water policy, and the roles and responsibilities of national and local governments, formal and informal organizations and the private sector in implementing this policy. It is important to support member countries in SSA through technical assistance and capacity building components designed to deliver on this dimension. The objective of the review is to also articulate water policy, legislation and regulations to sustainably manage the sector.

Actions needed at the national level are to enhance the capacity of water institutions and organizations including regional and national water research and development centers. Because water issues are complex and relate to social and financial and environmental challenges the efforts should assist countries to design water sector development and management programs based on strong partnership between policy and research and training based on credible scientific analytical studies. The objective is to modernize water resource assessment systems, including updating national and local data on water resources supply and demand balance and impact on water policies and pricing of water. Groundwater data collection, collation, and data sharing are more important than ever. Such data should underpin the production of practical knowledge products that address real-world problems such as supplies to water-scarce towns or development of small-scale irrigation schemes. Existing regional data related to groundwater assessments in SSA do not reflect local variability - yet local variability is where both opportunities and constraints are found. Knowledge on the temporal variability of groundwater resources is essential to design robust water supply systems capable of bridging dry seasons and extended periods of drought, essential to provide water security to millions of smallholder farmers and pastoralists in the dryland regions of SSA.

The action plan calls for national level support to improve databases, and to apply advanced information technology to produce reliable hydrological maps and data for local and regional aquifers, and to facilitate sharing of hydrogeological data among riparian countries. Also needed are modern systems for the collection and processing of weather forecasting information, improved understanding of rainfall patterns, better surface water monitoring, and increased understanding of environmental functioning in the hydrosphere. In many SSA countries, these systems are in crisis, whilst the need for them has never been higher. Even in South Africa, one of the best-resourced countries in the region, there has been a decline in hydrological monitoring, particularly the number of rainfall monitoring stations, in the last decade or so.

Verification of sustainable use of groundwater resources and assessments of environmental impacts can be done at the individual project level as part of the safeguards review during project preparation. However, limitations in data and understanding of aquifer dynamics complicate this task. Therefore, expanding the knowledge base, possibly by employing innovative methods, is also essential for a robust safeguards process.

At the local level, the action plan calls for the adoption of modern water and irrigation and agricultural production technologies. The performance of the water sector relies on efficient use of modern technology. The action plan should address the needs of the larger community rather than individual households. This requires a special investment in multipurpose 
groundwater schemes designed to deliver drinking water supply to households and their livestock, and for small-scale irrigation. The structure should be demand driven and based on strong partnerships with stakeholders with well-defined cost recovery and responsibilities for O\&M. This component would include four sub components:

- Assist interested communities to acquire the latest technology for water drilling suitable to the needs and their capabilities. As energy is a main factor in the performance of water pumps, it would be desirable to experiment with renewable sources of energy such as solar energy. Pumps operating on solar energy would require special training for efficient operation and maintenance.

- Establish a community-based water supply network to connect individual households at agreed schedules of cost recovery.

- Support small farmers in developing on-farm irrigation networks based on modern technology of low volume but frequent delivery of water on demand to crops such as drip irrigation instead of furrow irrigation. Such designs can reduce the energy used to pump water from the aquifer, whilst allowing for the delivery of irrigation water in time to maintain high quality crops for marketing.

- For urban and peri-urban communities, establish community managed water treatment plants for wastewater treatment and use for irrigation or recharge of local aquifer.

- The benefits of modern irrigation can be augmented through improved transport infrastructure, such as paved local roads to speed product delivery, and modernized market facilities such as cooling, storage and grading. This component could also support partnerships with the private sector to upgrade the value chain to maximize return on investments in irrigation, and would also create jobs for young men and women from the targeted communities. Community based arrangements should be based on a special agreement designed to expand and improve water delivery for drinking, for irrigation and emergency relief. Both components would require special resources for training and capacity building of local institutions and their staff.

- The action plan calls for extensive sharing of knowledge and information with all stakeholders. Sharing knowledge and provide timely and periodic data needed by national and local policy makers and practitioners. It would also assist local investors and farmers to guide their activities and provide early warning signals relevant to their enterprises. Agricultural information and knowledge systems to help farmers acquire the latest information about improved irrigation and cultivation practices, efficient water management, marketing information and other relevant activities.

- Support local communities address challenges related to natural disaster and drought and to guide them toward timely actions to protect their farming and livestock assets.

- Support research and scientific inquiries, updating the water database to guide national and local management, groundwater recharge, energy savings, and interaction between water delivery, crop performance, and efficient use of water to improve water and crop productivity. The research activities would address national and local issues through structures allowing for the establishment of a national research center connected with a network of provincial research satellites for outreach and scientific cooperation with concerned communities. 
Table 4 presents priority actions needed to guide investment in the sustainable development and management of groundwater resources, in the context of the Four l's and across regional, national and local scales.

Table 4 - Priority actions for the sustainable development and management of groundwater resources in Sub Saharan Africa (SSA)

\begin{tabular}{|c|c|c|c|c|}
\hline & Information & Institutions \& policy & Infrastructure Investment & Incentives \\
\hline 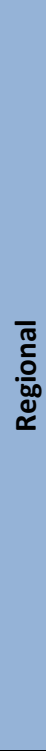 & $\begin{array}{l}\text { - Understand key regional } \\
\text { resource potential (incl. } \\
\text { transboundary), using modern } \\
\text { information technologies (e.g. } \\
\text { remote sensing), \& support } \\
\text { regional gw institutes (e.g. } \\
\text { SADC). } \\
\text { - Facilitate regional cooperation } \\
\text { \& south-south learning by } \\
\text { building on \& promoting } \\
\text { successful African models (e.g. } \\
\text { Managed Aquifer Recharge } \\
\text { Scheme, Namibia). }\end{array}$ & $\begin{array}{l}\text { - Support regional institutions } \\
\text { (e.g. RBOs and IGAD) to } \\
\text { incorporate gw planning \& } \\
\text { policy into regional planning. } \\
\text { - Regional gw capacity } \\
\text { building \& alignment of } \\
\text { policy with multilateral \& } \\
\text { national development } \\
\text { partners on natural resource } \\
\text { stewardship. } \\
\text { - Support regional and } \\
\text { national water research } \\
\text { centers to advance water } \\
\text { studies on water policy and } \\
\text { pricing and to develop and } \\
\text { test scientific models for } \\
\text { sustainable management of } \\
\text { surface and ground water } \\
\text { and non-conventional water } \\
\text { resources including reuse of } \\
\text { treated water and } \\
\text { desalination. }\end{array}$ & $\begin{array}{l}\text { - Support both public and } \\
\text { private sector investment in } \\
\text { gw supplies to growing towns } \\
\text { \& cities, in commercial } \\
\text { irrigation \& resilience } \\
\text { (network of gw wells). } \\
\text { - Investment in other classes of } \\
\text { infrastructure (e.g. energy, } \\
\text { digital infrastructure, } \\
\text { transport) to support gw } \\
\text { development. private sector } \\
\text { - Support in developing } \\
\text { engagement non- } \\
\text { and marketing rater resources } \\
\text { conventional water recling treated } \\
\text { including recyclion. } \\
\text { waste water and desalination. }\end{array}$ & $\begin{array}{l}\text { - Understand regional secondary } \\
\text { factors that limit gw } \\
\text { development (e.g. customs } \\
\text { tariffs on pumps \& equipment, } \\
\text { regional electrification policies, } \\
\text { regional transport corridors \& } \\
\text { links, regional credit, financial } \\
\text { risk \& banking policies). } \\
\text { - Support regional participation in } \\
\text { digital economy (e.g. information } \\
\text { sharing on weather, crop prices, } \\
\text { pump \& energy prices, drilling, } \\
\text { etc.). }\end{array}$ \\
\hline $\begin{array}{l}\bar{\pi} \\
\frac{c}{0} \\
\frac{0}{\pi} \\
z\end{array}$ & 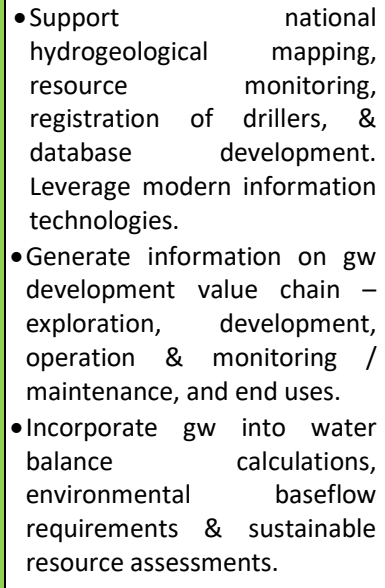 & $\begin{array}{l}\text { - National policy \& institutional } \\
\text { capacity building on gw } \\
\text { regulation \& governance, } \\
\text { with focus on salient policy } \\
\text { issues related to water } \\
\text { security, water pricing, cost } \\
\text { recovery, land tenure \& land } \\
\text { titling. } \\
\text { - National level provision for } \\
\text { decentralized management } \\
\text { of shallow local gw resources. } \\
\text { - Conduct public expenditure } \\
\text { review on gw. }\end{array}$ & $\begin{array}{l}\text { - National level investment for } \\
\text { monitoring of aquifers \& gw } \\
\text { use. } \\
\text { - High investment costs for } \\
\text { larger \& deeper gw supplies } \\
\text { require public \& private sector } \\
\text { contributions. Define roles for } \\
\text { private \& civil society sectors. } \\
\text { - Integrate sustainable gw } \\
\text { development into irrigation, } \\
\text { WSS \& other WB lending. } \\
\text { - Investigate wastewater } \\
\text { treatment \& reuse \& potential } \\
\text { for artificial recharge. }\end{array}$ & $\begin{array}{l}\text { - Supportive national policies for } \\
\text { sustainable gw development e.g. } \\
\text { clear land tenure policies to } \\
\text { improve investment } \\
\text { environment by the private } \\
\text { sector, facilitation of solar } \\
\text { pumps, monitoring of gw } \\
\text { pumping, subsidies, tariff } \\
\text { reductions, etc.). Develop } \\
\text { responsive water pricing policies } \\
\text { - Integration of gw-critical } \\
\text { secondary factors (e.g. road \& } \\
\text { energy access) into national } \\
\text { spatial development planning. }\end{array}$ \\
\hline
\end{tabular}




\begin{tabular}{|c|c|c|c|}
\hline $\begin{array}{l}\text { - High gw resolution at local } \\
\text { scale to understand anomalies } \\
\text { (can differ greatly from } \\
\text { regional averages). } \\
\text { - Local capacity building about } \\
\text { gw knowledge \& management. } \\
\text { - Integrate local information on } \\
\text { pollution sources, gw- } \\
\text { dependent ecosystems, river } \\
\text { baseflow, etc. for better local } \\
\text { gw management. } \\
\text { - Dependence of local } \\
\text { livelihoods on (shallow) gw, \& } \\
\text { impact on drought / shock } \\
\text { resilience. }\end{array}$ & 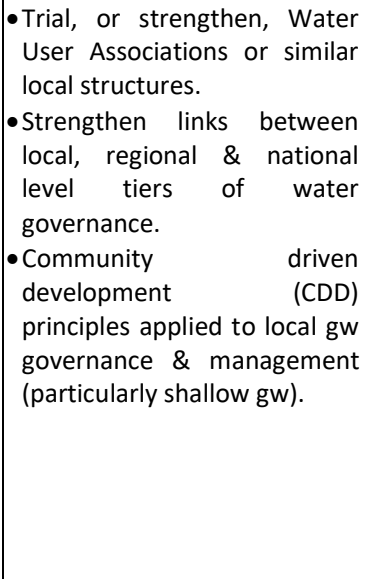 & $\begin{array}{l}\text { - Shallow gw infrastructure } \\
\text { investment occurs largely } \\
\text { independently (private sector). } \\
\text { Larger investments (deeper } \\
\text { gw, higher yielding sources) } \\
\text { require public-private } \\
\text { cooperation. } \\
\text { - Support mechanisms (e.g. } \\
\text { insurance, access to finance) } \\
\text { for local stakeholders to invest } \\
\text { in gw \& gw-related } \\
\text { infrastructure. } \\
\text { - Opportunities to close urban } \\
\text { water cycle (wastewater reuse } \\
\text { \& recharge) \& improve } \\
\text { resiliency of communities } \\
\text { (water harvesting). }\end{array}$ & $\begin{array}{l}\text { - Understanding secondary factors } \\
\text { \& costs specific to local level (e.g. } \\
\text { local energy availability \& price, } \\
\text { pump prices, grain storage } \\
\text { facilities, etc.) \& the role of local } \\
\text { government \& local municipal } \\
\text { policy. } \\
\text { - Combined influence of secondary } \\
\text { factors changes with local gw } \\
\text { depth \& mode of occurrence. } \\
\text { - Incorporation of gw-friendly } \\
\text { policies \& alignment of } \\
\text { secondary factors into local } \\
\text { spatial development planning. }\end{array}$ \\
\hline
\end{tabular}




\section{Chapter 7: An Action Plan for World Bank Groundwater Support}

\subsection{Examples of Investment Projects in 3 Strategic Areas of Intervention}

This chapter outlines opportunities to support sustainable, groundwater development in each of the 3 strategic areas of intervention: economic development through irrigation expansion, urban water security, and drought resilience / water security for rural livelihoods. Examples of investment activities are also given. Such examples are indicative and draw on the principles outlined in the strategic framework in Chapter 5 and the implementation guidance provided in Chapter 6 . The examples below could be built upon and translated into investments and/or other investment projects could be derived from the action plan.

\subsubsection{Macroeconomic development through irrigated agriculture}

Estimated investment of US\$300 million per year in groundwater based irrigation could enhance the baseline rate of growth in irrigated areas in SSA, which is currently 3 percent $(60,000 \mathrm{ha})$ per annum. The World Bank current annual investment in irrigation is SSA is about US\$ 600 million. The Bank should consider matching existing initiatives by SSA farmers to expand irrigation over the next 10 years to help SSA countries expand groundwater-based irrigation. Irrigated area is currently two million hectares, which could be increased by 50 percent by increasing annual investment in the irrigation sub sector to about US\$ 900 million.

Investment rationale: Groundwater can be a catalyst for economic opportunity, particularly by enhancing agricultural sector production through small scale irrigation - it is regarded as one of the largest engines of growth in many SSA countries. Irrigation has the potential to boost agricultural yields in SSA by at least 50percent, thereby strengthening food security, export potential and macroeconomic stability. It is estimated that the costs of developing and expanding groundwater based irrigation schemes in SSA would be similar to other regions. It is desirable to use community based managed investment for small scale irrigation.

Example investment activity: An investment activity could include national or regional support to smallholder groundwater irrigation schemes. IFPRI and IWMI estimate that smallholder irrigation schemes are cost effective to develop (US\$5,000-8,000 per hectare compared to US\$25,000-30,000 for large-scale irrigation schemes). While the development and marketing of individual irrigation technology is and should remain primarily with the private sector through development of dealer networks (an area IFC is currently supporting), such an activity would include components on aspects of inclusion through vouchers and microfinance schemes, as well as ensuring effective groundwater resource assessment, monitoring and governance. There is strong potential to expand groundwater irrigation within SSA from its current concentration in Madagascar, South Africa and Sudan, to multiple other countries within SSA via such an investment activity.

Shortlist of potential priority regions / countries for World Bank support: The Sahel region, particularly countries involved in the SIIP (Chad, Mali and Niger) show greatest potential for macro irrigation schemes to promote economic development, supported by groundwater resources. Cameroon (currently engaged by the Agriculture GP) and the other IDA SSA countries could also be considered for support. 


\subsubsection{Urban water security}

Through IDA18, the World Bank is currently engaging 20 SSA countries (and potentially engaging 6 more) on urban WSS, including efficiency and cost recovery of utilities and improving technical and financial performance. Key advisory services and analytics (ASA) include WASH diagnostics and planned activities under the GWSP.

Through IDA18, the World Bank is currently engaging 4 SSA countries (and potentially engaging 12 more) on rural and small-town WSS, including institutional and financing reforms and appropriate technology solutions. Key ASA include WASH poverty diagnostics and planned activities under GWSP.

There is opportunity for the World Bank to integrate the water resource management agenda (including groundwater resource development) with the urban WSS agenda. This could help accelerate the expansion of WSS services using groundwater, starting in the SSA countries already being engaged. This will help SSA countries reach SDG 6 on water. Promoting integrated urban water management (adopting a holistic view of all components of the urban water cycle water supply, sanitation, storm water management), promises strategic advantages in rapidly growing secondary cities. Managed Aquifer Recharge (MAR) systems can assist in managing drought periods and climate shocks. Groundwater is strategic for rural and small-town WSS and the World Bank could support decentralized community networks. Integration of resource management (including groundwater) and WSS is already being promoted by the Water Scarce Cities Initiative (see Box 18).

\section{Box 18 - The Water Scarce Cities Initiative}

The World Bank's Water Scarce Cities (WSC) Initiative is an innovative undertaking that offers a holistic perspective to urban water security in scarcity conditions. With a host of experiences and extensive global reach, WSC is working towards shifting mindsets across the world, demystifying urban water management, and engaging with water scarce cities to develop concrete solutions.

By serving as a connecting thread between water stressed cities, WSC offers a new avenue for knowledge sharing on water success stories and challenges to spark breakthroughs in best practices. WSC also offers an integrated water approach that encapsulates political, social, and institutional dimensions. The initiative is structured around the following key objectives:

- Providing a toolbox and strategies for cities to support water resilience with knowledge products that highlight integrated water solutions;

- Creating stronger connections between water scarce cities and sharing solutions by providing a platform for practitioners and experts, as well as global thought leaders and institutions; and

- Supporting water scarce cities with concrete engagement, including providing technical assistance for new water management approaches, technological advancements, and political practices.

There may be opportunity to more explicitly integrate water resource management and WSS in the Initiative, as well as further promoting groundwater to help alleviate scarcity (where it is available and accessible).

Source: waterscarcecities@worldbank.org

Investment rationale: Urbanization increases demand for water, generates more wastewater and alters patterns of demand for agriculture (the largest water consuming sector). The demand for water in Africa is expected to quadruple over the next 25 years - the fastest rate of increase than any other region globally, due largely to urbanization and agriculture. Many growing urban 
areas are outgrowing their traditional surface water sources, and groundwater is identified as a source to help address current and future water deficits. Over the next 15 years, 38percent of urban demographic growth in SSA is predicted to occur in cities of under 1 million people, and these so-called 'secondary cities' will be exposed to similar risks as large cities, but are expected to be less equipped to manage complexities around issues such as sustainable water management.

Example investment activity: A bundled investment activity could target multiple secondary cities in SSA, with a focus on integrated urban water management, including principles such as conjunctive surface and groundwater planning, embedding drought contingency into city water management plans, and artificial recharge of treated wastewater into groundwater sources for reuse. Sub-components of such an investment activity could include decentralized groundwatersupplied schemes for informal urban settlements (urban slums) in secondary cities and exploring the role of public-private partnerships in the delivery of urban WSS services. Such an investment activity may be appropriate for many SSA countries where groundwater resources are confirmed near urban centers.

Shortlist of potential priority cities for support: As outlined in Figure 30, drought risk exposure in many urban areas is already high and forecast to increase to 2050. The following cities are the largest and most exposed to drought based on current and future population forecasts (Jacobsen, 2013) and hence may be priority cities for groundwater assessment: Kinshasa (Republic of Congo), Khartoum (Sudan), Addis Ababa (Ethiopia), Nairobi (Kenya), Dar Es Salaam (Tanzania), Luanda (Angola), Abidjan (Ivory Coast), Lagos (Nigeria), Abuja (Nigeria), Dakar (Senegal), Kampala (Uganda), Conakry (Guinea) and Mogadishu (Somalia). Furthermore, the number of cities with populations of more than 1 million is projected to almost double from 42 in 2010 to 80 in $2025^{182}$ and many of today's secondary cities will become tomorrow's megacities, with necessary allocations for IWRM and sustainable WSS services. Shortlisting of priority cities could be coordinated with the Water Scarce Cities Initiative (Box 18).

\subsubsection{Resilience to drought and other shocks}

Through IDA18, the World Bank is currently engaging 24 SSA countries (and potentially engaging 5 more) on water resources management, including strengthening policies and institutions to improve WRM (water allocation mechanisms, infrastructure for managing water extremes, and water quality information). Key ASA include water security diagnostics and analytical activity on groundwater.

An aspirational goal for IDA18 is eleven countries with improved information and institutions for better management of extremes (floods and droughts) benefiting $\mathbf{5 0}$ million people.

There is opportunity to more strategically address recurrent drought and climate shocks through innovative investments, including water supply systems that utilize groundwater's greater storage volumes. Evidence shows that proactive resilience building yields longer lasting economic and humanitarian benefits, relative to emergency response.

182 Jacobsen et al. 2013. 


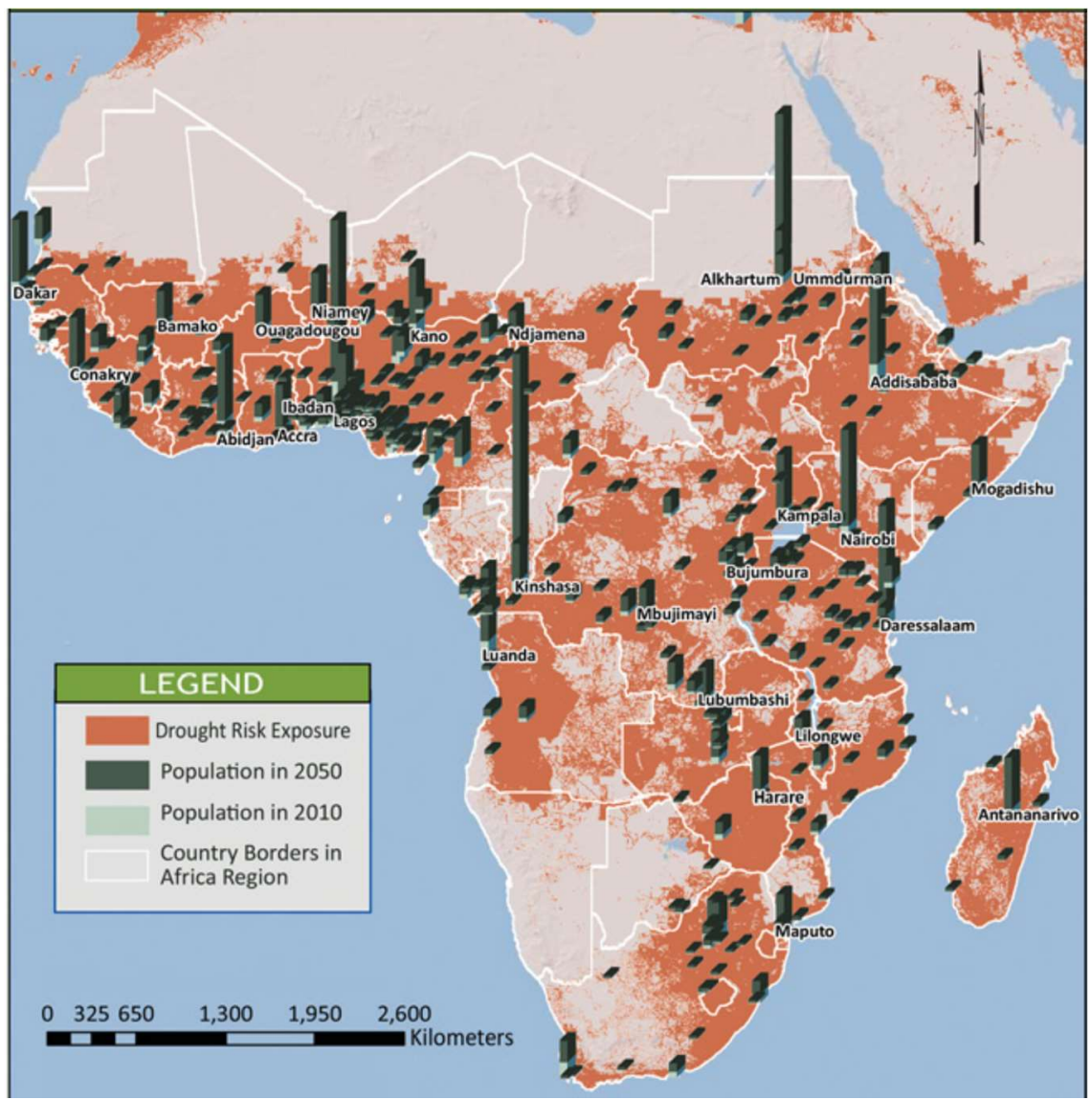

Figure 30 - Current and Future Population in African Cities Exposed to Drought (Source: Jacobsen et al. 2013)

Investment rationale: Although groundwater is generally regarded as a 'drought resistant' resource, many shallow aquifers currently supplying rural populations are vulnerable to annual and longer droughts and, during which, surface water resources often become completely unavailable. Some regions in SSA, such as the Horn of Africa, suffer recurrent severe drought events, with devastating human, livestock and economic consequences, and which may be expected to worsen due to climate change and increasing population pressures. Hence, extending access to weather independent groundwater resources will become increasingly important in guarding against drought events.

Example investment activity: An investment activity could include an investigation into the viability of a strategic network of deep groundwater bores to function during drought events to help protect vulnerable rural populations and reduce environmental migration and minimize related civil instability. Such a network of deep groundwater bores could be coordinated at regional or national scale and be integrated into disaster emergency management plans for contingency use. Such project investment could provide cost-effective insurance against climate shocks to rural and pastoralist communities, enhance resilience, decrease the potential for fragility and conflict, and thereby help to avoid the significant economic and humanitarian consequences of drought events. Sub-components of such an investment activity could include 
water harvesting and efficiency improvements in the use of surface and shallow groundwater resources.

Shortlist of potential priority regions / countries for World Bank support: A strategic regional approach to drought resilience investment could be targeted in the Horn of Africa, which experiences recurrent drought events. Some of the countries most vulnerable to drought include Sudan, Somalia, Uganda, Malawi, Zimbabwe and Ethiopia, which could realize socioeconomic, environmental and humanitarian benefits from strategic groundwater development.

Analytical and operational guidance to identify priority countries

Sustainable groundwater development potential is high across SSA countries ${ }^{183}$ and warrants strong integration into broader national water resources strategies. Further to this, a multicriteria analysis of the status of water source and supply in SSA countries - comprising measures of water stress, vulnerability of fresh water supplies to climate change, drought vulnerability; and groundwater potential - suggests that sustainable groundwater development could make the greatest contribution to national water security and resilience in countries across the Greater Horn of Africa (Eritrea, Ethiopia, Somalia, South Sudan, Sudan) and the Sahel (Chad, Mali, Mauritania ${ }^{184}$, Niger, Nigeria). Many of the identified countries have high vulnerability of fresh water supplies to climate change and high vulnerability (and exposure) to drought, with low capacities for coping (see Annex 6). Importantly, all the countries have dormant groundwater potential around which to sustainably develop urban water security, irrigated agriculture and drought resilience strategies. While this analysis provides an overview at a national scale, further work will be required to understand potentially large intra-national variability in measures such as degree of water stress and vulnerability to drought, to enable support to be targeted effectively.

\subsection{Mobilizing financial resources}

Priority investments should be allocated to members of the $\mathbf{2 0}$ countries identified where there is demand for expanding water services associated with policy and institutional reforms. A 10-year investment program could be scheduled to enhance the sustainable development of groundwater as an integral asset of the national water resources and informed by the following indicators:

- As Chapter 4 indicates, groundwater is the main source of drinking water in SSA. The region spends about US\$7.5-9 billion annually on WSS. The annual expansion of WSS to reach new communities is about 3percent, which translates to about US\$ 350 million annually ${ }^{185}$.

- As paragraph 12 in Chapter 3 indicates, groundwater is the main water source for small-scale irrigation in the region. This has been expanding at 2-3percent annually as reported in the IWMI study ${ }^{186}$, which translates to about 60000 ha annually. Both the IWMI and IFPRI studies assumed that the average cost of equipping one hectare for

\footnotetext{
183 Except Mauritania, where greater than the sustainable yield is already being exploited.

184 Mauritania warrants support as the only country where groundwater is being exploited at rates beyond the sustainable yield.

${ }^{185}$ Banerjee\&Morella 2011.

${ }^{186}$ Pavelic et al. 2012.
} 
small scale irrigation is about US\$ 5000- 8000 , which translate to about US\$ 300 million annually.

- The Bank can assist member countries in SSA by matching their investment in the annual expansion of water services and increase it from 3 percent to 6 percent. This expansion would cover both expanding water supply service, and in expanding areas under small-scale irrigation. The annual incremental cost of this expansion is slightly above half a billion dollars annually. The increase could be gradual and scaled up subject to the performance of the portfolio and the scope of demands of interested member countries. Priority countries could include Nigeria, Mali, Niger, Burkina Faso, Ethiopia and Zambia.

- Although the proposed increase in investment in the water sector may be modest, careful procedures should be established by engaging the beneficiaries, the private sector, and other stakeholders in operational partnerships. This will assist member countries improve their institutional capacity and implementation capabilities in absorbing this expansion. Further scaling up should be based on the performance of the investment at the national and local levels.

\subsection{Priority TAs for World Bank follow-on from this study}

Based on findings from this assessment, coupled with feedback received during the Decision Review meeting ${ }^{187}$, the following are recommended as immediate follow-on activities (perhaps TAs to be initiated) for the World Bank:

- Conduct national integrated water resources assessments for priority countries / typologies of countries, including targeted strategies for groundwater development / investment.

- Strengthen the economic case for investment in groundwater development, by engaging Ministries of Finance and incorporating groundwater considerations into public expenditure frameworks.

- Strengthen and expand strategic partnerships with regional and international partners already engaged in groundwater in SSA, with a focus on innovative technology dissemination to help address resource knowledge, development and management deficiencies.

- Help strengthen regional and national institutional capacities - including tertiary institutions and centers of excellence - to build youth capabilities and raise the profile of groundwater development as a potential applied research and career pathway.

- Integrate the water resource management agenda (including groundwater resource development) with the urban WSS agenda. For example, groundwater can be better integrated into the Water Scarce Cities Initiative.

${ }^{187}$ With joint inputs from the Africa GP and Water GP. 


\section{References}

AfricaNews, March 2017, Reality of the worst drought since 1945 peaking in parts of Africa, Akwei, I., http://www.africanews.com/2017/03/17/depth-of-the-worst-drought-since-1945peaking-in-parts-of-africa//, Accessed August 2017.

Altchenko, Y. \& Vilholth, K.G., 2015, Mapping irrigation potential from renewable groundwater in Africa - a quantitative hydrological approach, Hydrol. Earth Syst. Sci. 19 pp 1055 - 1067.

Ashworth, W. 2006, Ogallala Blue. Water and Life on the High Plains. The Countryman Press, Woodstock, Vermont.

Ayres, A.B., Edwards, E.C.\& Libecap, G.D., 2017, How transaction costs obstruct collective action: evidence from California's groundwater. NBER Working Paper 23382. National Bureau of Economic Research, Cambridge, MA, USA.

Banerjee, S. \& Morella, E., 2011, Africa's Water and Sanitation Infrastructure Access, Affordability, and Alternatives, World Bank Publication.

Besada, H. \& Werner, K., 2015, An assessment of the effects of Africa's water crisis on food security and management, International Journal of Water Resources Development, 31:1, 120133, DOI: 10.1080/07900627.2014.905124.

BGR-WHYMAP, 2017, Website of the World Wide Hydrogeological Mapping and Assessment Programme. Accessed in December 2017 at https://www.whymap.org/whymap/EN/Home/whymap node.html.

Bureau de Recherches Géologiques et Minières (BRGM), 2008, Hydrogeological Map of Africa at 1/10 M Scale published in collaboration with UNESCO-IHP.

Burney, J., Naylor, R.L. \& Postel, S.L., 2013, The case for distributed irrigation as a development priority in Sub Saharan Africa, Proceedings of the National Academy of Sciences, Vol 110, no.31.

Cabot Venton, C., Fitzgibbon, C., Shitarek, T., Coulter, L. \& Dooley, O., 2012, The Economics of Early Response and Disaster Resilience: Lessons from Kenya and Ethiopia, Economics of Resilience, Final Report, DFID, UK.

Calow, R., MacDonald, A.M., Nicol, A.L.\& Robins, N.S., 2010, Ground Water Security and Drought in Africa: Linking Availability, Access and Demand. Ground Water Vol. 48 No. 2 pp $246-256$.

Cervigni, R., \& Morris, M., 2016, Confronting Drought in Africa's Drylands: Opportunities for Enhancing Resilience. Washington, DC: World Bank; and Agence Française de Développement. (C) World Bank. https://openknowledge.worldbank.org/handle/10986/23576, License: CC BY 3.0 IGO.

Chokkakula, S. \& Giordano, M., 2013, Do policy and institutional factors explain the low levels of smallholder groundwater use in Sub-Saharan Africa? Water International, Vol. 38 No. 6 pp $790-$ 808.

Colenbrander, W.\& van Koppen, B., 2013, Improving the supply chain of motor pumps to accelerate mechanized small-scale private irrigation in Zambia. Water International Vol. 38 No. 4, pp $493-503$.

Collier, P., 2017, African urbanization: an analytic policy guide, Oxford Review of Economic Policy, Volume 33, Issue 3, 1 July 2017, Pages 405-437, https://doi.org/10.1093/oxrep/grx031. 
Comité Permanent Inter-Etats de Lutte contre la Sécheresse dans le Sahel (CILLS), 2018, http://www.cilss.int/, accessed January 2018.

DeFries, R.\& Nagendra, H., 2017, Ecosystem management as a wicked problem. Science 356 pp $265-270$.

De Marsily, G.\& Abarca-del-Rio, R., 2016, Water and Food in the Twenty-First Century. Surv. Geophys. 37 pp $503-527$.

Dethier, J.J.\& Effenberger, A., 2012, Agriculture and development: A brief review of the literature. Economic Systems 36:2 pp 175 - 205.

Department of Water Affairs, 2010, Groundwater Strategy, Republic of South Africa.

Döll, P. \& Flörke, M., 2005, Global-Scale Estimation of Diffuse Groundwater Recharge. Frankfurt Hydrology Paper 03. Institute of Physical Geography, Frankfurt University, Frankfurt am Main, Germany.

Döll, P., Kaspar, F.\& Lehner, B., 2003, A global hydrological model for deriving water availability indicators: model tuning and validation. Journal of Hydrology, 270 (1-2).

Du Toit, A.L., 1939, The Geology of South Africa. Second Edition. Oliver and Boyd, Edinburgh.

Dutch Ministry of Foreign Affairs, 2018, Water management, https://www.government.nl/topics/development-cooperation/the-development-policy-of-thenetherlands/water-management, accessed January 2018.

El-Agha, D.E., Closas, A.\& Molle, F., 2017, Below the radar: the boom of groundwater use in the central part of the Nile Delta in Egypt. Hydrogeology Journal 25 pp 1621-1631.

Ellerman, D., 2001, Hirschmanian Themes of Social Learning and Change. World Bank Policy Research Working Paper No. 2591. World Bank, Washington DC.

Fetter, C.W., 1994, Applied Hydrogeology 3rd Ed. Upper Saddle River, New Jersey: Prentice Hall International.

Fischer, G., Tubiello, F.N., Velthuizen, H. \& Wiberg, D.A., 2007, Climate change impacts on irrigation water requirements: Effects of mitigation, 1990-2080, https://doi.org/10.1016/j.techfore.2006.05.021.

Fleck, J., 2016, Water is for Fighting Over and Other Myths about Water in the West. Island Press, Washington DC.

Foster, S.S.D., Tuinhof, A. \& Garduno, H., 2006, Groundwater Development in Sub-Saharan Africa: A Strategic Overview of Key Issues and Major Needs. The World Bank GW-MATE Case Profile Collection No. 15. World Bank, Washington DC.

Foster, S.\& Sage, R., 2017, Groundwater science in water-utility operations: global reflections on current status and future needs. Hydrogeology Journal 25 pp $1233-1236$.

Funk, C., Harrison, L., Shukla, S., Hoell, A., Korecha, D., Magadzire, T., Husak, G. \& Galu, G., December 2016, Assessing the contributions of local and East Pacific warming to the 2015 droughts in Ethiopia and Southern Africa, American Meteorological Society, pp. 75-80.

GAP, 2017, Groundwater Assessment Platform (GAP) of the Swiss Federal Institute of Aquatic Science and Technology. Accessed December 2017 at www.eawag.ch/gap. 
GEF-FAO-UNESCO-World Bank, March 2016, The Global Framework for Action, Global groundwater Governance Project, http://www.groundwatergovernance.org.

Hynds, P., Borchardt, M.A. \& Ibaraki, M., 2017 Preface to Special Edition: Hydrogeology and human health. Hydrogeology Journal 25, pp 897-902.

IGRAC, 2018, International Groundwater Resources Assessment Center, www.un-igrac.org, accessed January 2018.

Independent Evaluation Group (IEG), 2017, A Thirst for Change, The World Bank Group's Support for Water Supply and Sanitation, with Focus on the Poor. An Independent Evaluation. International Bank for Reconstruction and Development / The World Bank.

International Food Policy Research Institute (IFPRI), 2010, What is the Irrigation Potential for Irrigation in Africa: A combined Biophysical and Socioeconomic Approach.

IRIN (formerly Integrated Regional Information Networks), February 2017, How much worse are African droughts because of man-made climate change?, Analysis Article, Lind, P., https://www.irinnews.org/analysis/2017/02/06/how-much-worse-are-african-droughtsbecause-man-made-climate-change, Accessed August 2017.

IRIN, March 2017, Drought in Africa, Feature Article, https://www.irinnews.org/feature/2017/03/17/drought-africa-2017, Accessed August 2017.

International Water Management Institute (IWMI), 2007, Water for Food, Water for Life: A Comprehensive Assessment of Water Management in Agriculture. London: Earthscan, and Colombo: International Water Management Institute.

IWMI, 2012, Groundwater Availability and Use in Sub-Saharan Africa: A review of 15 Countries.

Jacobsen, M., Webster, M. \& Vairavamoorthy, K. (Eds), 2013, The Future of Water in African Cities, Why Waste Water?, Water Partnership Program, The World Bank.

Japan International Cooperation Agency (JICA), June 2016, JICA's Assistance Strategy on Water Supply and Sanitation, Tokyo, Japan.

Kellet, J. \& Sweeney,H., 2011, Analysis of Financing Mechanisms and Funding Streams to Enhance Emergency Preparedness: A synthesis report. Development Initiatives, UK. Funded by the Food and Agriculture Organization (FAO) on behalf of the Inter-Agency Standing Committee (IASC) Task Team on Funding for Preparedness.

Lafforgue, M. \& Lenouvel, V., 2015, Closing the urban water loop: lessons from Singapore and Windhoek. Environ. Sci.: Water Res. Technol., 2015, 1, pp 622-631.

Landefeld, P.\& Sekhri, S., 2014, Agricultural Trade and Depletion of Groundwater. Unpublished conference paper, University of Virginia, Charlottesville.

Lapworth, D., Nkhuwa, D.C.W., Okotto-Okotto, J., Pedley, S., Stuart, M.E., Tijani, M.N.\&Wright, J., 2017, Urban groundwater quality in sub-Saharan Africa: current status and implications for water security and public health. Hydrogeology Journal 25, pp 1093-1116.

Leduc, C., Pulido-Bosch, A.\& Remini, B., 2017, Anthropization of groundwater resources in the Mediterranean region: processes and challenges. Hydrogeology Journal 25 pp 1529-1547.

Lejars, C., Daoudi, A.\& Amichi, H., 2017, The key role of supply chain actors in groundwater development in North Africa. Hydrogeology Journal 25 pp $1593-1606$. 
MacDonald, A.M., Bonsor, H.C., ODochartaigh, B.E., Davies, J.\& Key, R., 2010, Developing Quantitative Aquifer Maps for Africa, British Geological Survey Internal Report IR/10/103 34pp.

MacDonald, A.M., Bonsor, H.C., ODochartaigh, B.E.\& Taylor, R.G., 2012, Quantitative maps of groundwater resources in Africa. Environ. Res. Lett. 7 (2012) 7pp.

Mancosu, N., Snyder, R.L, Kyriakakis, G. \&Spano, D., 2015, Water Scarcity and Future Challenges for Food Production, Review, Water 2015, 7(3), 975-992; doi:10.3390/w7030975.

Manghee, S. \& Poole, A., 2012, Approaches to Conducting Political Economy Analysis in the Urban Water Sector. World Bank Water Paper 74742. World Bank Group, Washington DC, USA.

Margat, J.\& van der Gun, J., 2013, Groundwater around the World, A Geographic Synopsis. Taylor and Francis Group, London.

Mayer-Schönberger, V. \& Cukier, K., 2014, Big Data. Mariner Books, New York.

Mekonnen, M.M. \& Hoekstra, A.Y., 2016, Four billion people facing severe water scarcity, Doi: 10.1126/sciadv.1500323, Sci Adv 2 (2), e1500323.

Mercy Corps, January 2017, Enhancing resilience to severe drought: What works? Evidence from Mercy Corps' PRIME Program in the Somali region of Ethiopia

Molden D., 2007, Water for food, water for life, Earthscan, London and International Water Management Colombo: Institute, 2007.

Murray, E.C., van der Merwe, B., Peters, I. \& Louw, D., 2016, Windhoek, Namibia: From conceptualizing to operating and expanding a MAR scheme in a fractured quartzite aquifer for the city's water security. Proceedings of the ISMAR 9 Symposium. Ninth International Symposium on Managed Aquifer Recharge, Mexico City.

National Office for Irrigation Schemes (ONAHA), 2017, A guide to securing land tenure in irrigation schemes in Niger, GWI West Africa.

Nelson, A., 2004, African Population Database, UNEP GRID Sioux Falls, Retrieved August 2017 from: http://www.arcgis.com/home/item.html?id=9ec46c83ca5c47ebb1a25bd43131b483.

Pahuja, S., Tovey, C., Foster, S.\& Garduno, H., 2010, Deep Wells and Prudence: Towards Pragmatic Action for Addressing Groundwater Overexploitation in India. World Bank, Washington DC.

Pavelic, P., Vilholth, K.G., Shu, Y., Rebelo, L. \& Smakhtin, V., 2013, Smallholder groundwater irrigation in Sub-Saharan Africa: Country-level estimates of development potential. Water International, Vol. 38 No. 4 pp $392-407$.

Peters, I., 2013, Windhoek managed aquifer recharge. Presentation to the 9th IWA water re-use conference, Windhoek, Namibia.

Pitman, B.\& Bailey, A., 2015, A wealth of new freely downloadable information on the water resources of South Africa, Swaziland and Lesotho. Article in Civil Engineering, June 2015, pp 1318.

Robins, N.S., Davies, J., Hankin, P.\& Sauer, D., 2002, Groundwater and data - an African experience. Waterlines Vol 21 No 4 April 2002 pp $19-21$.

Ronen, D., Sorek, S. \& Gilron, J., 2012, Rationales Behind Irrationality of Decision Making in Groundwater Quality Management. Ground Water 2012 Jan-Feb;50(1):27-36. 
Rouse, M., 2013, Institutional Governance and Regulation of Water Services. The Essential Elements. Second Edition. IWA Publishing, London.

Smedley, P.L., Nkotagu, H., Pelig-Ba, K., MacDonald, A.M., Tyler-Whittle, R., Whitehead, E.J. \& Kinniburgh, D.G., 2002, Fluoride in groundwater from high-fluoride areas of Ghana and Tanzania. British Geological Survey Commissioned Report CR/02/316. British Geological Survey, Wallingford.

Southern African Development Community (SADC), 2009, Explanatory Brochure for the Southern African Development Community (SADC) Hydrogeological Map \& Atlas. SADC Infrastructure and Services Directorate - Water Division. Gaborone, Botswana.

SADC, 2010, Hydrogeological Mapping Procedures and Guidelines: SADC Hydrogeological Mapping Project. SADC Infrastructure and Services Directorate - Water Division. Gaborone, Botswana.

SADC, 2016, Regional Strategic Action Plan on integrated water resources development and management.

Sadoff, C., 2016, Dryland water security in the Middle east and North Africa, World Bank draft policy paper.

Saghir, J., October 2015, Confronting Drought in Africa's Drylands, Opportunities for Enhancing Resilience, Findings and recommendations of a major new study, Powerpoint Presentation, The World Bank Group, The Sahel \& West Africa Week, Expo 2015, Milan, Italy; 26-30 October 2015

Schoengold, K. \& Zilberman, D., 2007, The Economics of water, irrigation, and development, Handbook of Agricultural Economics, Vol 3

Sekhri, S., 2014, Wells, Water, and Welfare: The Impact of Access to Groundwater on Rural Poverty and Conflict. American Economic Journal: Applied Economics 6(3) pp 76-102.

Shah, T., 2009, Taming the Anarchy. Groundwater Governance in South Asia. Resources for the Future Press, Washington DC.

Shah, T., 2017, Sustainable Groundwater Governance: India's Challenge and Response. The Journal of Governance Vol. 14 Jan 2017 Special Issue on Water Management.

Shah, T. \& Das Chowdhury, S., 2017, Farm Power Policies and Groundwater Markets: Contrasting Gujarat with West Bengal (1990 - 2015). Economic and Political Weekly Vol. L11 Nos. 25 and 26 pp $39-47$.

Shah, T., Verma, S. \& Durga, N., 2014, Karnataka's Smart, New Solar Pump Policy for Irrigation. Economic and Political Weekly, Vol XLIX No 48 pp $10-14$.

Shah, T., Verma, S. \& Pavelic, P., 2013, Understanding smallholder irrigation in Sub-Saharan Africa: results of a sample survey from nine countries. Water International, Vol. 38 No. 6 pp 809 $-826$.

Shome, P. \& Sharma, P., 2015, Emerging Economies: Food and Energy Security, and Technology and Innovation, Springer.

Siebert, S., Burke, J., Faures, J.M., Frenken, K., Hoogeveen, J., Döll, P. \& Portmann, F.T., 2010, Groundwater use for irrigation - a global inventory, Hydrol. Earth Syst. Sci., 14, pp 1863 - 1880. 
Tredoux, G., van der Merwe, B.\& Peters, I., 2009, Artificial recharge of the Windhoek aquifer, Namibia: Water quality considerations, Boletín Geológico y Minero, 120, 2, pp 269-278.

Tuinhof, A., Foster, S., van Steenbergen, F., Talbi, A.\& Wishart, M., 2011, Appropriate groundwater management policy for Sub-Saharan Africa. GW-MATE Strategic Overview Series No. 5. World Bank Group, Washington DC.

United Nations, 2015, Sustainable Development Goal 6, https://sustainabledevelopment.un.org/sdg6, accessed January 2018.

United Nations Department of Economic \& Social Affairs (UNDESA), 2015, 2005-2015 Decade of Water for Life.

United Nations Economic Commission for Africa (UNECA), 2004, The Africa water vision for 2025: equitable and sustainable use of water for socioeconomic development. United Nations Economic Commission for Africa, Addis Abbaba, Ethiopia.

United Nations Office for Disaster Risk Reduction (UNISDR), 2015, Sendai Framework for Disaster Risk Reduction 2015-2030, Geneva.

United Nations Office for the Coordination of Humanitarian Affairs (UNOCHA), December 2016, Overview of El Nino Response in East and Southern Africa, Briefing Note.

Vahrmeijer, J.T., Annandale, J.G., Bristow, K.L., Steyn, J.M.\& Holland, M., 2013, Drought as a catalyst for change: A Case Study of the Steenkoppies Dolomite Compartment. Chapter 14 in: K Schwabe et al. (eds.), Drought in Arid and Semi-Arid Regions. Springer, Dordrecht.

Van Rensburg, F., 2006, Urban Water Security in the City of Windhoek. Unpublished MSc thesis, University of Stellenbosch, South Africa.

Venot, J P. et. al.,2017, Ideologies development models and irrigated land tenure: the Bagre irrigation project in Burkina Faso. Paper presented at World Bank Conference on Land and Poverty, Washington, 2017.

Vilholth, K.G., 2013, Groundwater irrigation for smallholders in Sub-Saharan Africa - a synthesis of current knowledge to guide sustainable outcomes. Water International, Vol. 38 No. 4 pp 369 $-391$.

Villholth, K.G., Ganeshamoorthy, J., Rundblad, C.M.\& Knudsen, T.S., 2013, Smallholder groundwater irrigation in sub-Saharan Africa: an interdisciplinary framework applied to the Usangu plains, Tanzania. Hydrogeology Journal 21 pp $1481-1495$.

Wada, Y., van Beek, L.P.H., van Kempen, C.M., Reckman, J.W.T.M., Vasak, S. \& Bierkens, M.F.P., 2010, Global depletion of groundwater resources. Geophys. Res. Lett., 37, L20402.

Ward, C., et.al., 2016, Improved agricultural water management for Africa's drylands, World Bank publication.

Wijnen, M., Augeard, B., Hiller, B., Ward, C. \& Huntjens, P., 2012, Managing the invisible: understanding and improving groundwater governance. Water papers. Washington, DC: World Bank, http://documents.worldbank.org/curated/en/450431468157768820/Managing-theinvisible-understanding-and-improving-groundwater-governance, accessed October 2017.

Woodhouse, P., Veldwisch, G.J., Venot, J.P., Brockington, D. , Komakech, H. \& Manjichi, Â., 2016, African farmer-led irrigation development: reframing agricultural policy and investment, The Journal of Peasant Studies, Vol.44, Issue 1. 
World Bank, 2011, Middle-East and Northern Africa Water Outlook, Final Report, World Bank Group, Washington DC.

World Bank, November 2015, The Case of Uzbekistan, Social Impact Analysis of Water Supply and Sanitation Services in Central Asia, Swinkels, R., Mantovani, P., Hiller, B. \& Junge, N.

World Bank, 2015a, Analyse des Opportunités de Développement de l'Irrigation au Sahel à partir des eaux souterraines, Provisional report to the Water Partnership Program - Water Expert Team (Sahel Irrigation Initiative), World Bank Group, Washington DC.

World Bank, October 2017, Uncharted Waters, The New Economics of Water Scarcity and Variability, Damania, R., Desbureaux, S., Hyland, M., Islam, A., Moore, S., Rodella, A.S., Russ, J. \& Zaveri, E.

World Bank, 2017a, World Bank Regional Groundwater Initiative in the Horn of Africa., WPP Case Study on Drought Resilience. World Bank, Washington DC.

Xie, H., You, L., Wielgosz, B. \&Ringler, C., 2014, Estimating the potential for expanding smallholder irrigation in Sub-Saharan Africa. Agricultural Water Management, 131, pp 183 193.

You, L., Ringler, C., Nelson, G.C., Wood-Sichra, U., Robertson, R.D., Wood, S., Guo, Z., Zhu, T. \&Sun, Y., 2010, What is the irrigation potential for Africa, A combined biophysical and socioeconomic approach, IFPRI report for the World Bank.

Yusuf, A.K., 2016, Groundwater Resource Management Strategy in the Nigerian Sector of the Chad Basin, Centre for Arid Zone Studies, University of Maiduguri, Borno State, Nigeria. 


\section{Annexes}

\section{Annex 1 - Study methodology}

This report draws on both primary and secondary quantitative and qualitative data analysis.

Primary data analysis includes a synthesized generation of spatial distribution of groundwater resources in SSA and a preliminary portfolio review of World Bank water sector project investments in SSA. Secondary data analysis comprises a comprehensive literature review of academic and grey literature.

By identifying and prioritizing groundwater development feasibility based on a combination of physical aquifer characteristics, technically and economically exploitable resources, and socioeconomic considerations, this report provides unique guidance on possible groundwater investment opportunities in SSA. It synthesizes information based on multiple data estimates and sources to integrate theoretical physical availability with secondary factors such as depth, difficulty and cost to develop, as well as proximity to dryland areas and population demand centers. The following data sources have contributed to this synthesis:

- Estimates of sustainable groundwater volumes in SSA are based on FAO AQUASTAT data (available at http://www.fao.org/nr/water/aquastat/main/index.stm), and global models of groundwater recharge developed at Frankfurt University ${ }^{188}$ and Utrecht University ${ }^{189}$.

- Estimates of total volumes of groundwater in storage in SSA (i.e. including nonrenewable groundwater), as well as estimates of depth to groundwater, are based on the work of the British Geological Survey $\left.(B G S)^{190}\right)$. Spatial BGS data provided by BGS (C NERC 2012.

- Data for transboundary groundwater basins, and for SSA cities depending partly on groundwater, is derived from the work of the German Federal Institute for Geosciences and Natural Resources (Bundesanstalt für Geowissenschaften und Rohstoffe, BGR). BGR data provided by WHYMAP GWR C BGR \& UNESCO 2015.

- Drylands areas defined according to Aridity Index, based on Cervigni and Morris (2015).

- Estimates of areas irrigable by groundwater in SSA countries are based on Vilholth (2013), Xie et al. (2014) and Siebert et al. (2010). Estimates of areas irrigable by groundwater in SSA countries, taking environmental requirements into account, are based on Altchenko and Vilholth (2015).

- Population data on maps is after Nelson (2004).

To understand the World Bank's evolving role in the water sector - in particular with reference to groundwater and SSA - several internal sources were reviewed:

- Preliminary portfolio review of SSA's World Bank water sector investments between 1997 and 2017;

- Summary of the findings of the Independent Evaluation Group (IEG) 2010 evaluation of the World Bank's global water portfolio, in particular with reference to groundwater. The IEG evaluation is the most recent and comprehensive evaluation of the World Bank's global water sector available. It examined the full scope of the World Bank's lending and grant support for water activities. More than 30 background papers were

\footnotetext{
${ }^{188}$ Döll et al. 2003, Döll \& Flörke 2005.

${ }^{189}$ Wada et al. 2010.

${ }^{190}$ MacDonald et al. 2010, MacDonald et al. 2012.
} 
prepared for the evaluation to analyze Bank lending by thematic area and by activity type; and

- Review of World Bank strategies on water and SSA, namely the World Bank's 2003 Water Resources Strategy (and preceding 1993 Water Resources Management Policy Paper) and the World Bank's current Africa strategy.

The portfolio review evaluated World Bank projects in SSA with relevance to (potential reliance and/or impact on) groundwater. It permitted an assessment of project investments over time and across different World Bank units operating in the Africa region. Projects with relevance to groundwater were selected from a wide range of units across the World Bank (projects without relevance to groundwater were not included for assessment). It is important to state that projects with relevance to groundwater are defined as those which may potentially involve utilization of groundwater resources and/or may impact groundwater resources.

To assess the level of integration of groundwater considerations into project conceptualization, planning and design, 254 Project Appraisal Documents (PADs) were analyzed. PADs form the basis for the financing/loan agreements, Implementation Status and Results Report (ISR), and Implementation Completion Reports. They are approved by the World Bank's Board and are the main project reference for many clients. PADs specify project development objectives and outline investment components, and hence may serve as reliable guides for the degree to which groundwater is integrated into projects in the conceptualization, planning and design phases. A total of 254 projects were activated in the Africa region with relevance to groundwater over a twenty-year period, between 1997 and 2017. PAD abstracts were analyzed for all projects, with more in-depth analysis of some documentation for selected projects.

To assess both the contribution of groundwater to project investments in Africa, and the impacts of projects on groundwater resources in Africa, 85 Implementation Completion \& Results Reports (ICRs) were analyzed. ICRs help to increase the World Bank's development effectiveness, through a continuous process of self-evaluation, lesson learning and application, sharing of knowledge, and being accountable for results. ICRs focus on effectiveness issues and their resolution, factors affecting performance, and the results and outcomes of interventions in the context of objectives. A total of 85 projects were completed in the Africa region with relevance to groundwater over a twenty-year period, between 1997 and 2017. ICR abstracts were analyzed for all projects, with more in-depth analysis of some documentation for selected projects. 
Annex 2 - Country-level groundwater \& irrigation area estimates

Groundwater resources and use in Sub Saharan Africa

(FAO AQUASTAT data, quoted in Margat \& van der Gun 2013).

\begin{tabular}{|c|c|c|c|c|c|}
\hline & $\begin{array}{l}\text { Renewable } \\
\text { groundwater } \\
\left(\mathrm{km}^{3} / \mathrm{a}\right) \\
\end{array}$ & $\begin{array}{l}\text { Groundwater } \\
\text { abstraction } \\
\left(\mathrm{km}^{3} / \mathrm{a}\right)\end{array}$ & $\begin{array}{l}\text { Groundwater } \\
\text { used (\%) }\end{array}$ & $\begin{array}{l}\text { Recharge / } \\
\text { capita }\left(\mathrm{m}^{3} / \mathrm{a}\right)\end{array}$ & $\begin{array}{l}\text { Groundwater abstraction } \\
\text { / capita }\left(\mathrm{m}^{3} / \mathrm{a}\right)\end{array}$ \\
\hline Angola & 58 & 0.41 & 0.7 & 6840 & 21.5 \\
\hline Benin & 1.8 & 0.17 & 9.4 & 1098 & 19.2 \\
\hline Botswana & 1.7 & 0.14 & 8.2 & 5534 & 69.8 \\
\hline Burkina Faso & 9.5 & 0.39 & 4.1 & 648 & 23.7 \\
\hline Burundi & 7.47 & 0.16 & 2.1 & 346 & 19.1 \\
\hline Cameroon & 100 & 0.37 & 0.4 & 5693 & 18.9 \\
\hline $\begin{array}{l}\text { Central } \\
\text { African Rep. }\end{array}$ & 56 & 0.08 & 0.1 & 20964 & 18.2 \\
\hline Chad & 11.5 & 0.45 & 3.9 & 3454 & 40.1 \\
\hline $\begin{array}{l}\text { Congo Dem. } \\
\text { Rep. }\end{array}$ & 421 & 1.22 & 0.3 & 8786 & 18.5 \\
\hline $\begin{array}{l}\text { Congo } \\
\text { Brazzaville }\end{array}$ & 122 & 0.03 & 0.0 & 29522 & 7.4 \\
\hline Cote d'Ivoire & 37.84 & 0.37 & 1.0 & 2228 & 18.7 \\
\hline Djibouti & 0.015 & 0.02 & 133.3 & 85 & 22.5 \\
\hline Eq. Guinea & 10 & 0.01 & 0.1 & 15797 & 14.3 \\
\hline Eritrea & 0.5 & 0.09 & 18.0 & 136 & 17.1 \\
\hline Ethiopia & 20 & 1.49 & 7.5 & 531 & 18.0 \\
\hline Gabon & 62 & 0.03 & 0.0 & 57357 & 19.9 \\
\hline Gambia & 0.5 & 0.03 & 6.0 & 662 & 17.4 \\
\hline Ghana & 26.3 & 0.51 & 1.9 & 1033 & 20.9 \\
\hline Guinea & 38 & 0.09 & 0.2 & 5226 & 9.0 \\
\hline Guinea-Bissau & 14 & 0.03 & 0.2 & 4878 & 19.8 \\
\hline Kenya & 3.5 & 0.62 & 17.7 & 662 & 15.3 \\
\hline Lesotho & 0.5 & 0.02 & 4.0 & 218 & 9.2 \\
\hline Liberia & 45 & 0.07 & 0.2 & 11692 & 17.5 \\
\hline Madagascar & 55 & 0.38 & 0.7 & 6124 & 18.3 \\
\hline Malawi & 2.5 & 0.28 & 11.2 & 1303 & 18.8 \\
\hline Mali & 20 & 0.34 & 1.7 & 1751 & 22.1 \\
\hline Mauritania & 0.3 & 0.76 & 253.3 & 1072 & 219.7 \\
\hline Mozambique & 17 & 0.44 & 2.6 & 3554 & 18.8 \\
\hline Namibia & 2.1 & 0.15 & 7.1 & 3724 & 65.7 \\
\hline Niger & 2.5 & 0.14 & 5.6 & 1013 & 9.0 \\
\hline Nigeria & 87 & 3.44 & 4.0 & 951 & 21.7 \\
\hline Rwanda & 7 & 0.2 & 2.9 & 168 & 18.8 \\
\hline Senegal & 3.5 & 0.74 & 21.1 & 999 & 59.5 \\
\hline Sierra Leone & 25 & 0.11 & 0.4 & 4817 & 18.7 \\
\hline Somalia & 3.3 & 0.28 & 8.5 & 649 & 30.0 \\
\hline South Africa & 4.8 & 3.14 & 65.4 & 348 & 62.6 \\
\hline $\begin{array}{l}\text { Sudan and S. } \\
\text { Sudan }\end{array}$ & 7 & 0.59 & 8.4 & 1260 & 13.3 \\
\hline Swaziland & 0.66 & 0.04 & 6.1 & 550 & 33.7 \\
\hline
\end{tabular}




\begin{tabular}{|l|c|c|c|c|c|}
\hline & $\begin{array}{l}\text { Renewable } \\
\text { groundwater } \\
\left(\mathrm{km}^{3} / \mathrm{a}\right)\end{array}$ & $\begin{array}{l}\text { Groundwater } \\
\text { abstraction } \\
\left(\mathrm{km}^{3} / \mathrm{a}\right)\end{array}$ & $\begin{array}{l}\text { Groundwater } \\
\text { used }(\%)\end{array}$ & $\begin{array}{l}\text { Recharge / } \\
\text { capita }\left(\mathrm{m}^{3} / \mathrm{a}\right)\end{array}$ & $\begin{array}{l}\text { Groundwater abstraction } \\
/ \text { capita }\left(\mathrm{m}^{3} / \mathrm{a}\right)\end{array}$ \\
\hline Tanzania & 30 & 0.98 & 3.3 & 1962 & 21.9 \\
\hline Togo & 5.7 & 0.11 & 1.9 & 1232 & 18.2 \\
\hline Uganda & 29 & 0.62 & 2.1 & 669 & 18.5 \\
\hline Zambia & 47 & 0.3 & 0.6 & 6233 & 22.9 \\
\hline Zimbabwe & 6 & 0.43 & 7.2 & 991 & 34.2 \\
\hline
\end{tabular}

Irrigation in SSA

(Vilholth 2013 Siebert et al. 2010)

\begin{tabular}{|c|c|c|c|c|c|}
\hline & $\begin{array}{l}\text { Area of } \\
\text { cultivated } \\
\text { land }\left(10^{3} \mathrm{Ha}\right)\end{array}$ & $\begin{array}{l}\text { Irrigated area } \\
\left(10^{3} \mathrm{Ha}\right)\end{array}$ & $\begin{array}{l}\text { Proportion of } \\
\text { cultivated land } \\
\text { irrigated }(\%)\end{array}$ & $\begin{array}{l}\text { Area irrigated with } \\
\text { surface water }\left(10^{3} \mathrm{Ha}\right)\end{array}$ & $\begin{array}{l}\text { Area irrigated } \\
\text { with } \\
\text { groundwater } \\
\left(10^{3} \mathrm{Ha}\right)\end{array}$ \\
\hline Angola & 5190 & 35 & 0.7 & 28 & 7 \\
\hline Benin & 3150 & 7.1 & 0.2 & 5.9 & 1.3 \\
\hline Botswana & 287 & 0.62 & 0.2 & 0.33 & 0.29 \\
\hline Burkina Faso & 6070 & 52 & 0.9 & 22 & 30 \\
\hline Burundi & 1450 & 21.4 & 1.5 & 21.4 & 0 \\
\hline Cameroon & 7750 & 25.7 & 0.3 & 24.7 & 1 \\
\hline $\begin{array}{l}\text { Central } \\
\text { African Rep. }\end{array}$ & 1880 & 0.069 & 0.0 & 0.069 & 0 \\
\hline Chad & 4932 & 26.2 & 0.5 & 21 & 5.2 \\
\hline $\begin{array}{l}\text { Congo Dem. } \\
\text { Rep. }\end{array}$ & 7810 & 6.8 & 0.1 & 6.8 & 0 \\
\hline $\begin{array}{l}\text { Congo } \\
\text { Brazzaville }\end{array}$ & 600 & 0.22 & 0.0 & 0.22 & 0 \\
\hline Cote d'Ivoire & 7400 & 66.9 & 0.9 & 66.9 & 0 \\
\hline Djibouti & 2 & 0.39 & 19.5 & 0 & 0.39 \\
\hline Eq. Guinea & 180 & 0 & 0.0 & 0 & 0 \\
\hline Eritrea & 692 & 42.6 & 6.2 & 32.6 & 10.1 \\
\hline Ethiopia & 16488 & 405.3 & 2.5 & 288.1 & 117.2 \\
\hline Gabon & 495 & 4.5 & 0.9 & 4.5 & 0 \\
\hline Gambia & 445 & 1.4 & 0.3 & 1.4 & 0.01 \\
\hline Ghana & 7400 & 228.7 & 3.1 & 42.7 & 186 \\
\hline Guinea & 3700 & 94.9 & 2.6 & 94.5 & 0.46 \\
\hline Guinea-Bissau & 550 & 22.6 & 4.1 & 17.7 & 4.9 \\
\hline Kenya & 6130 & 174.5 & 2.8 & 96 & 78.5 \\
\hline Lesotho & 285 & 0.067 & 0.0 & 0.017 & 0.05 \\
\hline Liberia & 710 & 2.1 & 0.3 & 2.1 & 0.011 \\
\hline Madagascar & 4110 & 1080.7 & 26.3 & 1080.7 & 0 \\
\hline Malawi & 3885 & 74 & 1.9 & 54.1 & 19.9 \\
\hline Mali & 7011 & 181.1 & 2.6 & 176.1 & 5 \\
\hline Mauritania & 411 & 22.8 & 5.5 & 20.4 & 2.4 \\
\hline Mozambique & 5950 & 40.1 & 0.7 & 39.8 & 0.22 \\
\hline Namibia & 809 & 7.6 & 0.9 & 5.9 & 1.6 \\
\hline Niger & 16000 & 80.5 & 0.5 & 64.4 & 16.2 \\
\hline Nigeria & 41700 & 337.8 & 0.8 & 154.8 & 183 \\
\hline
\end{tabular}




\begin{tabular}{|c|c|c|c|c|c|}
\hline & $\begin{array}{l}\text { Area of } \\
\text { cultivated } \\
\text { land }\left(10^{3} \mathrm{Ha}\right)\end{array}$ & $\begin{array}{l}\text { Irrigated area } \\
\left(10^{3} \mathrm{Ha}\right)\end{array}$ & $\begin{array}{l}\text { Proportion of } \\
\text { cultivated land } \\
\text { irrigated (\%) }\end{array}$ & $\begin{array}{l}\text { Area irrigated with } \\
\text { surface water }\left(10^{3} \mathrm{Ha}\right)\end{array}$ & $\begin{array}{l}\text { Area irrigated } \\
\text { with } \\
\text { groundwater } \\
\left(10^{3} \mathrm{Ha}\right)\end{array}$ \\
\hline Rwanda & 1432 & 8.5 & 0.6 & 8.4 & 0.085 \\
\hline Senegal & 3415 & 69 & 2.0 & 62.1 & 6.9 \\
\hline Sierra Leone & 1897 & 10 & 0.5 & 9.9 & 0.15 \\
\hline Somalia & 1129 & ND & ND & ND & ND \\
\hline South Africa & 12413 & 1713.3 & 13.8 & 1370.7 & 342.7 \\
\hline South Sudan & 2760 & ND & ND & ND & ND \\
\hline Sudan & 13893 & 800 & 5.8 & 770.3 & 29.7 \\
\hline Swaziland & 190 & 44.9 & 23.6 & 44 & 0.9 \\
\hline Tanzania & 16650 & 189 & 1.1 & 171.6 & 17.5 \\
\hline Togo & 2850 & 6.3 & 0.2 & 6.2 & 0.046 \\
\hline Uganda & 9150 & 5.9 & 0.1 & 5.8 & 0.059 \\
\hline Zambia & 3836 & 253 & 6.6 & 149.3 & 103.8 \\
\hline Zimbabwe & 4100 & 180.6 & 4.4 & 109.6 & 71 \\
\hline
\end{tabular}

\section{Irrigation potential after making environmental provisions}

(Source: Altchenko \& Vilholth 2015)

\begin{tabular}{|c|c|c|c|c|}
\hline & \multirow{2}{*}{$\begin{array}{c}\text { Area irrigated } \\
\text { with } \\
\text { groundwater } \\
\left(10^{3} \mathrm{Ha}\right)\end{array}$} & \multicolumn{3}{|c|}{$\begin{array}{l}\text { Irrigable area scenario, given percentage of groundwater for environmental } \\
\text { requirements }\end{array}$} \\
\hline & & $30 \%$ & $50 \%$ & $70 \%$ \\
\hline Angola & 7 & 7032 & 5016 & 3001 \\
\hline Benin & 1.3 & 518 & 368 & 218 \\
\hline Botswana & 0.29 & 66 & 46 & 27 \\
\hline Burkina Faso & 30 & 268 & 188 & 108 \\
\hline Burundi & 0 & 214 & 149 & 84 \\
\hline Cameroon & 1 & 7019 & 5005 & 2990 \\
\hline $\begin{array}{l}\text { Central } \\
\text { African Rep. }\end{array}$ & 0 & 6961 & 4969 & 2978 \\
\hline Chad & 5.2 & 566 & 401 & 237 \\
\hline $\begin{array}{l}\text { Congo Dem. } \\
\text { Rep. }\end{array}$ & 0 & 23060 & 16450 & 9840 \\
\hline $\begin{array}{l}\text { Congo } \\
\text { Brazzaville }\end{array}$ & 0 & 7420 & 5295 & 3170 \\
\hline Cote d'Ivoire & 0 & 2920 & 2078 & 1236 \\
\hline Djibouti & 0.39 & 5 & 3 & 2 \\
\hline Eq. Guinea & 0 & 634 & 453 & 271 \\
\hline Eritrea & 10.1 & 10 & 7 & 4 \\
\hline Ethiopia & 117.2 & 4336 & 3064 & 1793 \\
\hline Gabon & 0 & 5884 & 4202 & 2520 \\
\hline Gambia & 0.01 & 24 & 17 & 10 \\
\hline Ghana & 186 & 1426 & 1010 & 594 \\
\hline Guinea & 0.46 & 2751 & 1962 & 1172 \\
\hline $\begin{array}{l}\text { Guinea- } \\
\text { Bissau }\end{array}$ & 4.9 & 176 & 125 & 75 \\
\hline Kenya & 78.5 & 512 & 355 & 199 \\
\hline Lesotho & 0.05 & 21 & 15 & 8 \\
\hline
\end{tabular}




\begin{tabular}{|c|c|c|c|c|}
\hline & \multirow{2}{*}{$\begin{array}{c}\text { Area irrigated } \\
\text { with } \\
\text { groundwater } \\
\left(10^{3} \mathrm{Ha}\right) \\
\end{array}$} & \multicolumn{3}{|c|}{$\begin{array}{l}\text { Irrigable area scenario, given percentage of groundwater for environmental } \\
\text { requirements }\end{array}$} \\
\hline & & $30 \%$ & $50 \%$ & $70 \%$ \\
\hline Liberia & 0.011 & 2238 & 1597 & 956 \\
\hline Madagascar & 0 & 6753 & 4814 & 2875 \\
\hline Malawi & 19.9 & 640 & 454 & 268 \\
\hline Mali & 5 & 787 & 559 & 331 \\
\hline Mauritania & 2.4 & 52 & 37 & 22 \\
\hline Mozambique & 0.22 & 2171 & 1546 & 921 \\
\hline Namibia & 1.6 & 98 & 70 & 41 \\
\hline Niger & 16.2 & 19 & 12 & 6 \\
\hline Nigeria & 183 & 6287 & 4446 & 2606 \\
\hline Rwanda & 0.085 & 148 & 102 & 56 \\
\hline Senegal & 6.9 & 382 & 271 & 160 \\
\hline Sierra Leone & 0.15 & 1551 & 1107 & 662 \\
\hline Somalia & ND & 51 & 35 & 20 \\
\hline South Africa & 342.7 & 270 & 181 & 95 \\
\hline South Sudan & ND & 3042 & 2164 & 1286 \\
\hline Sudan & 29.7 & 429 & 299 & 169 \\
\hline Swaziland & 0.9 & 21 & 15 & 8 \\
\hline Tanzania & 17.5 & 3007 & 2135 & 1263 \\
\hline Togo & 0.046 & 300 & 213 & 126 \\
\hline Uganda & 0.059 & 571 & 399 & 228 \\
\hline Zambia & 103.8 & 3952 & 2818 & 1684 \\
\hline Zimbabwe & 71 & 370 & 259 & 148 \\
\hline
\end{tabular}


Annex 3 - Case study of Managed Aquifer Recharge (MAR) in Windhoek, Namibia

This summary is based on Murray et al. (2016), with contributions from the other references listed.

\section{Introduction}

Windhoek, the capital of Namibia in southern Africa, is one of the driest capital cities on earth. Rainfall is about $360 \mathrm{~mm}$ per annum, whilst potential evaporation is over $2000 \mathrm{~mm}$. The nearest perennial river is the Okavango River, more than $700 \mathrm{~km}$ to the north on the border with Angola. Windhoek's population of 330000 has relied on a combination of groundwater and ephemeral surface water for decades. Whilst the aquifers are close to the city, Windhoek's three main surface water dams are located between 70 and 200 kilometers from the city, and fluctuations in rainfall and natural runoff complicate their operation.

In the 1990s demand for water began to exceed the available supply. Measurements showed that the groundwater was being used unsustainably, and that groundwater levels were slowly falling. Options for augmenting the supply included building a pipeline to the Okavango, pumping from the Tsumeb aquifer $500 \mathrm{~km}$ away, or pumping of desalinated seawater from the coast more than $260 \mathrm{~km}$ away. Studies showed that these options were very expensive, in terms of both money and energy. In the late 1990s Windhoek began to trial a fourth option: the storage of water underground in aquifers during times of higher rainfall, for use during dry periods. This technique is known as managed aquifer recharge, or MAR. The water stored would not only be treated surface water, but would also include a proportion of the city's sewage effluent, treated to drinking water quality in a sophisticated treatment plant.

\section{Windhoek's MAR scheme}

Initial trials showed that the hydrogeological conditions were favorable: the deep, fractured quartzite aquifer near Windhoek easily held the additional water injected via boreholes, and groundwater levels began to rise again. Careful geological and hydrogeological work located the best places for injection - mostly near-vertical fault zones that offered a direct route to the aquifer. Monitoring of both groundwater levels and groundwater quality proved that the system was not only viable, but would work very well indeed. By 2011, six injection boreholes could recharge as much as $420 \mathrm{~m} 3 / \mathrm{hr}$ into the aquifer, more than doubling the natural rate of groundwater recharge for the aquifers. This additional managed recharge is expected to rise to over $900 \mathrm{m3} / \mathrm{hr}$ by 2018. The scheme proved itself in 2014 and 2015, when unusually dry conditions raised water demand and at the same time lowered natural surface runoff and groundwater recharge. The extra water stored in the aquifer was able to compensate for this and cover the shortfall, just as planned.

See Figure 31 and Figure 32 overleaf for operation of Windhoek's MAR scheme during normal and reduced periods of water availability. 


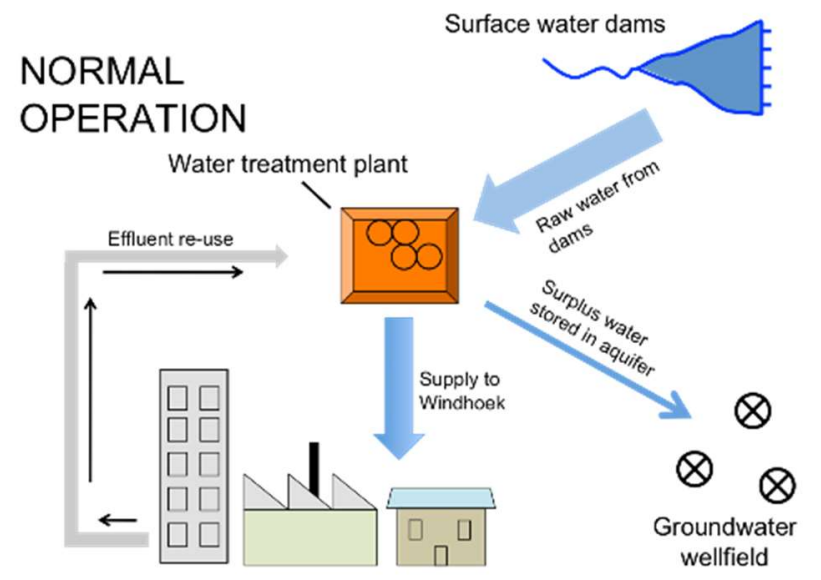

City of Windhoek

Figure 31 - Operation of Windhoek's MAR scheme during normal water availability

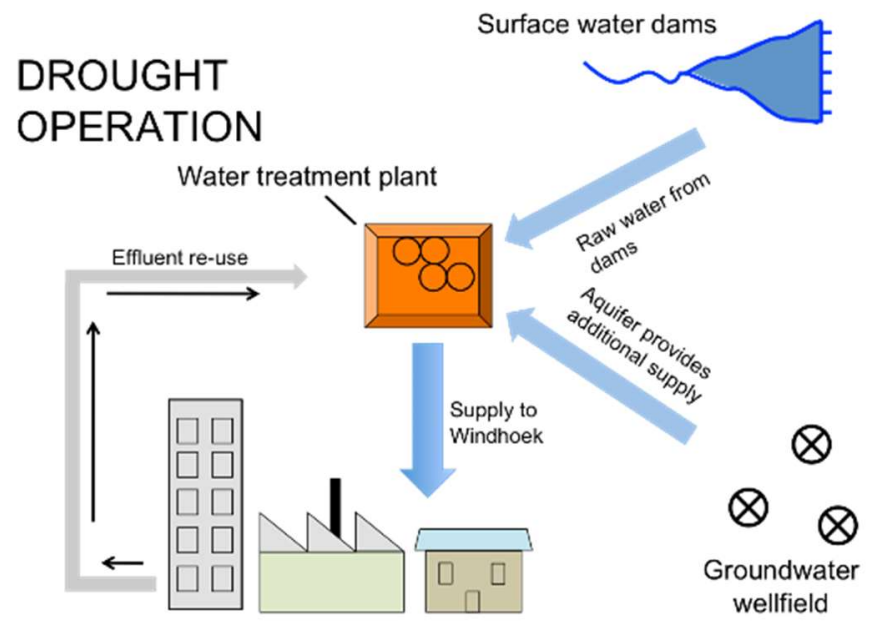

City of Windhoek

Figure 32 - Operation of Windhoek's MAR scheme during reduced water availability

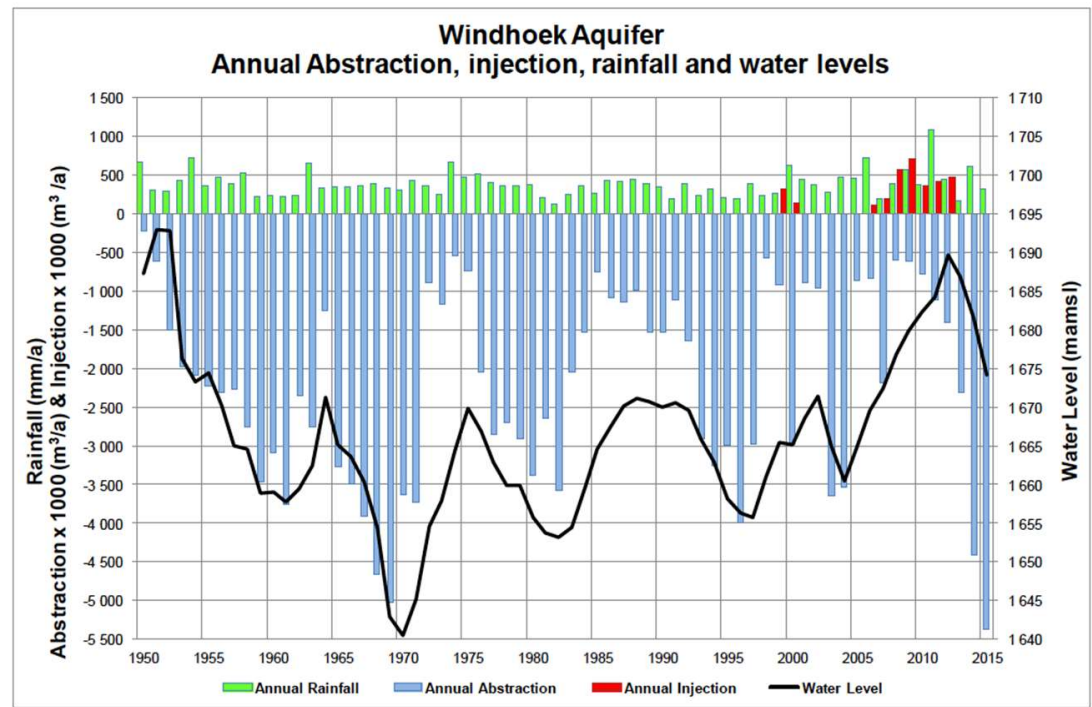

Figure 33 - Rainfall, groundwater levels and abstraction / injection volumes at Windhoek, 1950 to 2015 (after Murray et al., 2016) 
Figure 33 (above) shows that after borehole injection, groundwater levels (and storage) rose to the levels they were in the 1950 s before large-scale abstraction started.

All water injected into the aquifer is treated to drinking water quality, and strict water quality standards are enforced. This is to prevent clogging of the aquifer and injection boreholes as well as long-term deterioration of the groundwater quality, and it enables the municipality to supply treated water directly from the boreholes. Close monitoring of the system shows no serious environmental problems. Furthermore, it has been found that injecting surface water (when available) into the aquifer rather than storing it in the city's dams greatly reduces losses due to evaporation in the hot, dry climate. Further expansion of the system is planned.

\section{Economics of the MAR scheme}

Surface water bulk supply from the dams is managed by a commercial entity, the Namibia Water Corporation (NamWater). NamWater sells surface water during times of surplus to the City of Windhoek, which manages the aquifers and runs the managed aquifer recharge scheme. The City of Windhoek pays NamWater cost price for this water, but an additional payment to NamWater is due whenever the water abstracted from the aquifers exceeds the aquifers' natural recharge rate. In this way, 'low value' excess surface water is stored underground at cost, safe from evaporation. During times of low rainfall or high demand, this water becomes 'high value' water, triggering additional payments to NamWater at a time when their income would otherwise have been low because of surface water scarcity, as well as ensuring water supply security for Windhoek. The Windhoek MAR scheme is thus not only technically innovative, but also affords institutional 'win-win' outcomes even when overall water supply is scarce. It is also the cheapest way to augment the city's water supply. Whilst the MAR scheme is estimated to have required a capital investment of about 575 million Namibian Dollars to date, the losses to industry in Windhoek consequent on lower assurances of water supply are estimated at around 17 million Namibian Dollars per day. The MAR scheme is also much cheaper than pumping water from the Okavango River (even assuming the environmental objections could be overcome) or from a coastal desalination plant - not only are distances vast, but Windhoek lies at an elevation of 1650 meters above sea level.

\section{Other innovative water management measures in Windhoek}

In addition to its MAR scheme, Windhoek implemented a multi-stranded demand management strategy in 1994 that significantly reduced water demand by means of a rising block tariff, leak detection, legislation (e.g. restrictions on garden watering), public campaigns, and other means. The city also operates a 'dual pipe' water supply system, by means of which semi-purified sewage from an old water treatment plant is distributed to sports fields, parks and cemeteries for irrigation, further reducing the use of potable water. This irrigation water is given a lower priority compared with wastewater destined for re-use in the main water supply system. It is reported that the residents of Windhoek take pride in their water management measures, including the re-use of wastewater.

\section{Opportunities for south-south cooperation}

The imperatives of a dry climate and growing water demand led the city of Windhoek to investigate innovative ways of using and conserving its scarce endowment of water. These will only become more important as the population of the city increases in the future, and precipitation becomes more erratic. Sound financial, institutional, and hydrogeological planning 
have meant that the city has become a world leader in the sustainable use of both reclaimed water and managed aquifer recharge (MAR). Amongst the most valuable outcomes of Windhoek's experience is that the city serves as an example of the potential offered by the conjunctive use of surface water and groundwater in Sub Saharan Africa, even in the driest climates and under the harshest conditions. Lessons learned in Windhoek can be transferred elsewhere in Sub Saharan Africa, perhaps piloted by regional bodies such as the SADC Groundwater Institute. Windhoek has also shown how to 'do more with less', making the best use of existing supplies, and avoiding drawing on ever more distant water sources. The water security of Windhoek, the driest capital city in Sub Saharan Africa, proves that great opportunities exist for other cities in Africa with similar challenges to do the same. 


\section{Annex 4 - Economics of groundwater extraction in Sub Saharan Africa}

\section{Introduction}

This annex introduces the diverse input factors to a more comprehensive economic assessment of groundwater extraction in Sub Saharan Africa (SSA). It includes both shallower and deeper groundwater resources with their differing constraints and requirements. This report has focused on 'primary' or hydrogeological factors in SSA, including parameters such as depth to groundwater, recharge, transmissivity, and aquifer type. A broader economic assessment of groundwater in SSA also requires consideration of numerous 'secondary', 'indirect', or political economy factors ${ }^{191}$. There is evidence that it is factors such as energy price and availability, rather than the volume of available groundwater, that primarily determine the level of groundwater development in a region ${ }^{192}$. In rural SSA, access to electricity remains low (Figure $34)$, greatly constraining groundwater irrigation development.

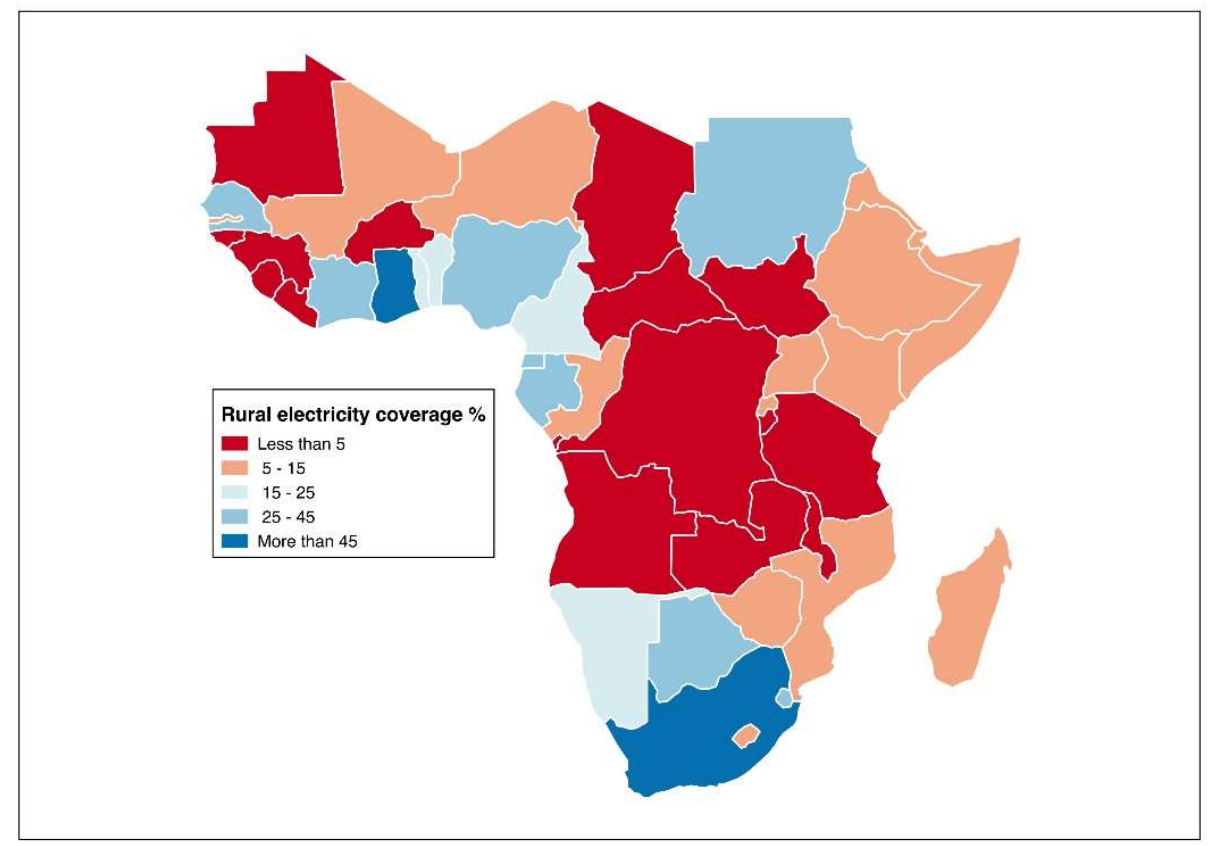

Figure 34 - Percent of rural population in SSA with access to electricity ${ }^{193}$

Step-increases or 'revolutions' in groundwater irrigation - for example in South Asia, China or the American Midwest - have been driven from the bottom up in ways that were largely unplanned and unforeseen, incentivized ultimately by the benefits of increased water for irrigation ${ }^{194}$. Users have tackled primary hydrogeological problems (e.g. locating drilling targets or enhancing recharge) as well as secondary problems such as pumping technology, access to credit, energy costs, or local regulations, in a non-linear learning process involving much trial and error ${ }^{195}$. Shah (2009) memorably described this as similar to 'anarchy'. Empirical observation suggests that hydrogeological data does not automatically lead to better or more widespread

\footnotetext{
191 Villholth 2013, Manghee \& Poole 2012

192 Landefeld \& Sekhri 2014; Shah et al. 2014, Pahuja 2010.

${ }^{193}$ World Bank data: Percent of rural population with access to electricity in 2014.

194 Shah 2009.

195 Fleck 2016.
} 
groundwater development; in fact, it is often widespread groundwater development that leads to better data.

Apart from its huge positive impact on livelihoods, increased groundwater use has helped shape wider political-economy developments, such as subsidy and other policy structures for Midwestern agricultural products dependent on Ogallala Aquifer groundwater ${ }^{196}$, or the nature of electricity pricing in India ${ }^{197}$. These things would have also been hard to foresee prior to widespread groundwater exploitation, since they are the products of iterative political negotiation. These political-economy developments have still wider complex backward and forward linkages with further implications for the pace and characteristics of development. The nature and trajectory of groundwater-based development is therefore a complex system rather than an arrangement of predictable cause-and-effect linkages. Predicting or managing such a system in detail is challenging.

There is a need for knowledge around the 'secondary' or political economy issues that would facilitate a step-change in Sub Saharan African groundwater use, in addition to the requirement for detailed technical knowledge of the resource at local level. In other words, what are the factors - both primary and secondary - that hold back African groundwater development? Even if it were possible to understand the exact nature of groundwater occurrence at any given locality in SSA without a local investigation, this information would only partially resolve the problem. The rest of the problem - involving drilling technology, energy availability, credit availability, management regimes, land tenure, irrigation expertise, and numerous other factors, would remain unaddressed.

The broad hydrogeological overview that can currently be obtained by combining existing regional and continental African groundwater datasets can point towards the kinds of secondary problems that might occur (for example, deeper groundwater requires different pumping and drilling technology, or groundwater quality problems may indicate the need for treatment). But they cannot identify all secondary issues, which in most cases are unrelated to hydrogeology (e.g. energy prices).

Irrigation and drought resilience (deep and shallow groundwater)

SSA has the lowest level of irrigation development in the world ${ }^{198}$. Yet irrigation can transform the lives of small farmers and pastoralists, increasing resilience and reducing vulnerability ${ }^{199}$. The cost of irrigation is an important factor. Research suggests capital investment costs of USD $12,000 / \mathrm{Ha}$ for large-scale irrigation from surface water sources, and USD 4,500/Ha for smallscale irrigation from surface and groundwater sources, in the African drylands ${ }^{200}$.

An expert study carried out for the World Bank in 2015 focusing on 6 countries in the Sahel found that small-scale irrigation from groundwater has significant economic potential, as well

\footnotetext{
196 Ashworth, 2006.

197 Shah 2009, Shah et al. 2014.

198 Ward et al., 2016.

199 Cervigni \& Morris 2015,Dethier \& Ellenberger 2012.

${ }^{200}$ Ward et al. 2016. Large scale irrigation in this context relies on dams, whilst small scale irrigation relies on a variety of available sources, including groundwater.
} 
as being technically viable ${ }^{201}$. This study found that costs for small-scale irrigation from groundwater were between USD 1,000/Ha and USD 3,000/Ha. Work on sedimentary aquifers of the northern Nile delta ${ }^{202}$ shows groundwater irrigation costs from USD 625/Ha to USD $2,780 / \mathrm{Ha}$. Elsewhere in Africa, irrigation from groundwater has been costed at USD 1,650/Ha for fadama type schemes in Nigeria, USD 4,900/Ha for hard-rock installations in Ethiopia, and USD $10,940 / \mathrm{Ha}$ for deep-well systems in Zimbabwe ${ }^{203}$. These costs depend partly on the depth to groundwater, the equipment installed, and factors such as whether sophisticated systems such as sprinklers or drip irrigation are used. These numbers (Figure 35) suggest that groundwaterbased irrigation in SSA is no more expensive than surface-water irrigation for the small-scale irrigation installations that have the most potential to increase resilience in SSA. In many cases (e.g. where surface water resources are distant or unreliable), irrigation from groundwater is the cheaper option.

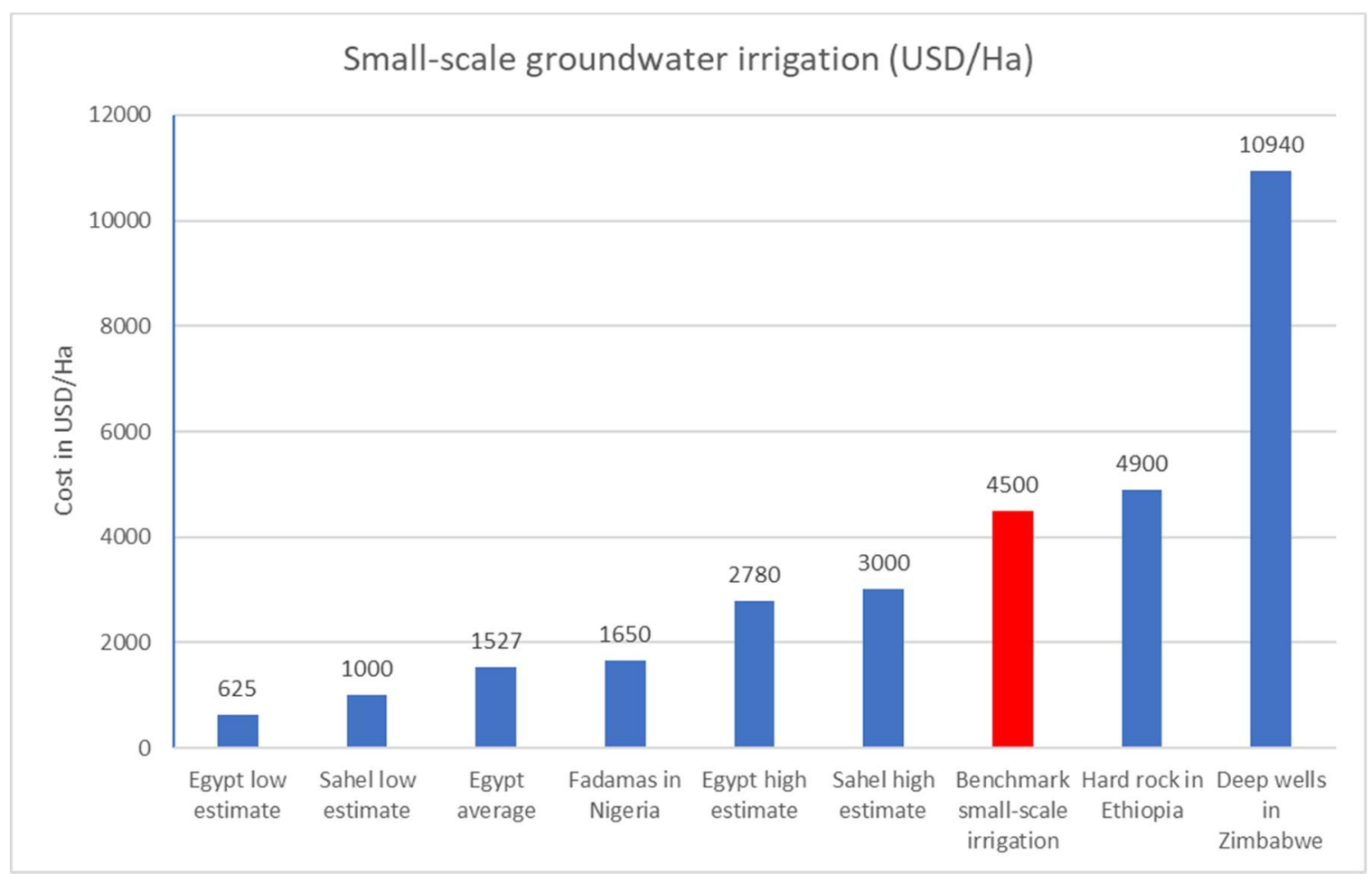

Figure 35-Small-scale groundwater irrigation costs per hectare in Africa

The figures quoted above include both primary and secondary factors (i.e. both hydrogeological and political-economy factors). The impact of these factors, on aggregate, is very significant ${ }^{204}$. For example, a $40 \mathrm{~m}$ deep borehole costing between USD 4,000 and USD 10,000 in SSA, costs only USD 1,000 in India ${ }^{205}$. Pumps in India cost half of what they do in SSA.

Table 5 provides a first-pass disaggregation and explanation of secondary or political economy factors that influence groundwater development in SSA, in particular with regard to small-

\footnotetext{
201 World Bank 2015.

202 El-Agha et al. 2017.

203 Villholth 2013.

204 Lejars et al. 2017, Villholth 2013, Foster et al. 2006.

205 Chokkukula \& Giordano 2013.
} 
scale irrigation development. Any of these factors may function as the determining variable ("gatekeeper") in any given local groundwater political-economy. Current knowledge of these secondary factors is sparse, particularly those specific to groundwater development (e.g. cost of submersible pump spare parts). A key and substantial task for the future is to collate data and develop knowledge relating to these factors.

Table 5 - Some political economy or 'secondary' factors in groundwater development in SSA, with special emphasis on small-scale irrigation development.

\begin{tabular}{|c|c|c|}
\hline Political Economy Factor & Description & Available information in SSA \\
\hline $\begin{array}{l}\text { Energy availability and price } \\
\text { (particularly electricity, but also } \\
\text { including the actual delivered cost of } \\
\text { other energy sources such as diesel } \\
\text { or kerosene) }\end{array}$ & $\begin{array}{l}\text { Energy availability and price has } \\
\text { been shown to be a critical factor in } \\
\text { enabling the boom in groundwater } \\
\text { irrigation in India, more important } \\
\text { than primary availability of } \\
\text { groundwater } 206 \text {. Groundwater } \\
\text { irrigation consumes up to } 31 \text { percent } \\
\text { of India's electricity }{ }^{207} \text {. Advent of } \\
\text { solar pumping systems presents } \\
\text { intriguing possibilities as well as new } \\
\text { challenges }{ }^{208} \text {. }\end{array}$ & $\begin{array}{l}\text { Figures are available for basic } \\
\text { electrical grid coverage in SSA, but } \\
\text { detailed figures for local price and } \\
\text { reliability of electricity and especially } \\
\text { for other energy sources not readily } \\
\text { available. Costs for extending the } \\
\text { electrical grid for even short } \\
\text { distances are prohibitive for farmers, } \\
\text { so resolution of grid spatial coverage } \\
\text { is important. }\end{array}$ \\
\hline $\begin{array}{l}\text { Access to technical expertise, } \\
\text { information, and data }\end{array}$ & $\begin{array}{l}\text { This factor encompasses agricultural } \\
\text { extension, local technical advice, } \\
\text { information on technology } \\
\text { availability and cost, information on } \\
\text { regulatory regimes and incentives, } \\
\text { and peer-to-peer sharing of } \\
\text { agricultural, } \\
\text { hydrogeological, technical, and social } \\
\text { information. }\end{array}$ & $\begin{array}{l}\text { Figures are difficult to obtain. Greatly } \\
\text { facilitated by more sophisticated } \\
\text { 'digital revolution' infrastructure, } \\
\text { which is nascent across much of SSA. } \\
\text { Small improvements in e.g. local } \\
\text { radio programming, cellphone } \\
\text { coverage, or internet access may } \\
\text { have disproportionately large } \\
\text { downstream benefits. }\end{array}$ \\
\hline Access to capital & $\begin{array}{l}\text { Access to capital is critical for even } \\
\text { small groundwater installations, } \\
\text { since local SSA farm incomes do not } \\
\text { normally permit savings } \\
\text { accumulation sufficient for even } \\
\text { basic technology. This factor is more } \\
\text { critical when deeper groundwater } \\
\text { installations are envisaged, implying } \\
\text { multi-year returns on capital } \\
\text { expenditure. For larger installations } \\
\text { (e.g. city supplies), the nature and } \\
\text { structure of available finance is } \\
\text { critical. }\end{array}$ & $\begin{array}{l}\text { Compared with other regions SSA } \\
\text { lacks access to modern banking } \\
\text { facilities. Access to capital is further } \\
\text { constrained by problems of collateral } \\
\text { (see below). Some success has been } \\
\text { achieved with micro-credit loan } \\
\text { facilities, and information on these } \\
\text { (and their latent potential) are likely } \\
\text { to be highly relevant. Information on } \\
\text { currency fluctuations also important, } \\
\text { and widely available (i.e. a useful } \\
\text { proxy factor). }\end{array}$ \\
\hline Land tenure and collateral & $\begin{array}{l}\text { Collateral for loans is essential for } \\
\text { irrigation development - implying a } \\
\text { critical role of land title and land } \\
\text { tenure, since these are the largest } \\
\text { assets available to most small } \\
\text { farmers }{ }^{209} \text {. }\end{array}$ & $\begin{array}{l}\text { Land tenure systems in much of SSA } \\
\text { still tied to structures vested in } \\
\text { traditional leaders or the state, and } \\
\text { lenders are often reluctant to } \\
\text { proceed on this basis. Specific studies } \\
\text { of the impacts of existing land tenure } \\
\text { on capital-raising for agriculture at } \\
\text { local level in SSA are comparatively }\end{array}$ \\
\hline
\end{tabular}

206 Shah et al. 2014.

207 Pahuja 2010.

208 Shah et al. 2014, World Bank 2015.

${ }^{209}$ Chokkukula \& Giordano 2013. 


\begin{tabular}{|c|c|c|}
\hline & & rare. \\
\hline Transport and access to markets & $\begin{array}{l}\text { Irrigation both engenders and } \\
\text { requires higher productivity. Sale of } \\
\text { cash crops to service loans for } \\
\text { irrigation equipment requires } \\
\text { transport / access to markets. } \\
\text { Transport infrastructure (road, rail, } \\
\text { air) is therefore important. }\end{array}$ & $\begin{array}{l}\text { Reasonable information of transport } \\
\text { infrastructure and costs in SSA exists, } \\
\text { but ancillary factors such as food } \\
\text { storage facilities and local tariff } \\
\text { barriers less well understood. Export } \\
\text { of high value crops to the developed } \\
\text { world constrained by tariffs and } \\
\text { other factors }{ }^{210} \text {. }\end{array}$ \\
\hline Rule of law / regional stability & $\begin{array}{l}\text { Fixed groundwater pumping and } \\
\text { irrigation infrastructure and multi- } \\
\text { year secure return on investment } \\
\text { requires a predictable legal regime as } \\
\text { well as physical security. }\end{array}$ & $\begin{array}{l}\text { Poor or deteriorating situation in } \\
\text { several SSA countries, including } \\
\text { Somalia, Mali, South Sudan, DRC, and } \\
\text { others. Can be quantified at national } \\
\text { level, but local resolution } \\
\text { inadequate. }\end{array}$ \\
\hline Institutional and legal landscape & $\begin{array}{l}\text { The nature of the legal and } \\
\text { institutional regulatory and policy } \\
\text { regime regarding groundwater has } \\
\text { an impact on levels of groundwater } \\
\text { development. In some cases, } \\
\text { regulations can be the critical factor } \\
\text { in whether groundwater } \\
\text { development proceeds or not. }\end{array}$ & $\begin{array}{l}\text { There is only limited knowledge of de } \\
\text { facto institutional and policy regimes } \\
\text { for groundwater, and their impact on } \\
\text { African groundwater development. } \\
\text { Evidence suggests that existing } \\
\text { regimes hinder groundwater } \\
\text { development } 211 \text { in SSA. }\end{array}$ \\
\hline $\begin{array}{l}\text { Existing resilience and household } \\
\text { income }\end{array}$ & $\begin{array}{l}\text { Vital to more widespread } \\
\text { groundwater use. Relatively } \\
\text { wealthier and more resilient } \\
\text { households are more likely to be } \\
\text { able to invest in groundwater } \\
\text { extraction technologies, and can } \\
\text { better afford to risk the investment. }\end{array}$ & $\begin{array}{l}\text { Household resilience is known to be } \\
\text { precarious in many parts of SSA, } \\
\text { especially in 'drylands' areas } \\
\text { threatened by climate change and } \\
\text { regional instability, where it may be } \\
\text { deteriorating. Reasonable } \\
\text { information available at national and } \\
\text { regional level. }\end{array}$ \\
\hline Existing local community structures & $\begin{array}{l}\text { Help to embed groundwater use in } \\
\text { practice and tradition, in developing } \\
\text { local solutions to specific } \\
\text { groundwater problems, in } \\
\text { establishing critical mass for repair, } \\
\text { maintenance and drilling services, } \\
\text { and reducing the risk and cost of the } \\
\text { 'first mover' disadvantage in } \\
\text { extracting groundwater. }\end{array}$ & $\begin{array}{l}\text { Likely to be considerable information } \\
\text { on such structures and institutions } \\
\text { arising from numerous NGO-led } \\
\text { community development initiatives. } \\
\text { Infrequently collated, however. }\end{array}$ \\
\hline Cost of drilling equipment & $\begin{array}{l}\text { The cost of drilling equipment is very } \\
\text { important to groundwater } \\
\text { development. The actual cost of } \\
\text { drilling may be higher than } \\
\text { equipment costs imply, due to large } \\
\text { distances, rugged conditions, need } \\
\text { for prompt return on investment, } \\
\text { lack of competition, or poor } \\
\text { regulation. }\end{array}$ & $\begin{array}{l}\text { Actual cost of drilling and equipping a } \\
\text { borehole has been estimated in } \\
\text { several areas, but highly dependent } \\
\text { on geological factors, as well as } \\
\text { numerous subsidiary factors such as } \\
\text { border tariffs and delays. Figures for } \\
\text { small-scale groundwater irrigation } \\
\text { are provided in Figure 35, above. }\end{array}$ \\
\hline $\begin{array}{l}\text { Cost of pumps, spare parts and } \\
\text { ancillary equipment }\end{array}$ & $\begin{array}{l}\text { Similar to cost of drilling equipment, } \\
\text { above. Full benefits of cheaper } \\
\text { Chinese and Indian pumps and } \\
\text { related equipment have yet to be }\end{array}$ & $\begin{array}{l}\text { Similar to above. Little available } \\
\text { specific information, but a study in } \\
\text { Zambia found a lack of information, } \\
\text { lack of spares, and transport costs, }\end{array}$ \\
\hline
\end{tabular}

\footnotetext{
210 Dethier and Effenberger, 2012

${ }^{211}$ Chokkakula and Giordano (2013:796) provide one of the few available analyses, and argue 'Clearly there is limited policy or institutional support for thedevelopment of groundwater irrigation in SSA'.
} 


\begin{tabular}{|c|c|c|}
\hline & $\begin{array}{l}\text { realized in many parts of SSA. } \\
\text { Possibility of emerging solar pumping } \\
\text { solutions (see above). }\end{array}$ & $\begin{array}{l}\text { that can constitute a third of the } \\
\text { delivered pump cost }{ }^{212} \text {. Situation in } \\
\text { other SSA countries may be worse. }\end{array}$ \\
\hline $\begin{array}{l}\text { Fertilizer and appropriate crop } \\
\text { varietal cost and availability }\end{array}$ & $\begin{array}{l}\text { South Asia's 'green revolution' } \\
\text { depended partly on the availability of } \\
\text { cheap fertilizers and high yielding } \\
\text { crop varietals, to support the viability } \\
\text { of groundwater-led irrigation. }\end{array}$ & $\begin{array}{l}\text { Fertilizer costs are known for much } \\
\text { of SSA, but the 'delivered' or local } \\
\text { cost also depends on transport } \\
\text { infrastructure, etc. Modern hybrid or } \\
\text { engineered crop varietals suitable for } \\
\text { African drylands conditions are } \\
\text { under-researched, not widely } \\
\text { available, and unpopular }{ }^{213} \text {. }\end{array}$ \\
\hline
\end{tabular}

\section{Urban water security and water utilities}

The role of groundwater in urban water security similarly relies on a host of political economy factors, as well as hydrogeological issues. Some of these are discussed in the table above. Capital costs of urban water supply schemes tend to be higher than for groundwater-based irrigation, and financing mechanisms and cost recovery modalities are different. In the urban context, the hidden costs of a lack of groundwater development may be unacceptably high (i.e. the opportunity cost of allocating funds to things other than groundwater). This is because groundwater can provide vital continuity of supply during times of drought, even when it is not the primary water source (see the annex to this report on the city of Windhoek in Namibia). Continuity of urban water supply, in turn, underpins business confidence, social stability, public health and a range of other factors usually regarded as necessary for development.

In many cases, an urban water utility (with varying degrees of local government support) is the locus of capital investment in groundwater schemes. In general, more is known about the interplay of political economy factors in urban water security ${ }^{214}$, but much potential in SSA remains unrealized. The case of Windhoek (see annex to this report) shows how MAR systems can improve urban water security (taking into account population growth and climate change), but also that considerable collaboration and technical work is required for these systems to be technically and economically viable long-term.

Water utilities in SSA are often hobbled by inadequate cost recovery, high levels of unaccounted-for water, and inadequate investment. Maintenance costs, low at first, rise as equipment ages. If cost recovery deteriorates, financial sustainability is threatened (Figure 36). Utility operators need to be free of political interference, but are also likely to benefit from an independent regulator who can monitor deliverables according to published targets, and ensure transparency of budget and accounts ${ }^{215}$. Benchmarks such as the number of employees per 1,000 metered consumers, the proportion of unaccounted-for water, or water quality may be used. An analysis of the finances and structure of urban water utilities, in the long and short term, is therefore necessary for a better understanding of the reliability and sustainability of urban water supplies. Intermittent water services do not necessarily save water, and may damage water infrastructure, encourage hoarding of water, and erode confidence in municipal services.

\footnotetext{
212 Colenbrander and van Koppen, 2013

${ }^{213}$ de Marsily \&Abarca-del-Rio 2016, Dethier \& Effenberger 2012.

${ }^{214}$ For example, Rouse 2013.

215 Rouse 2013.
} 


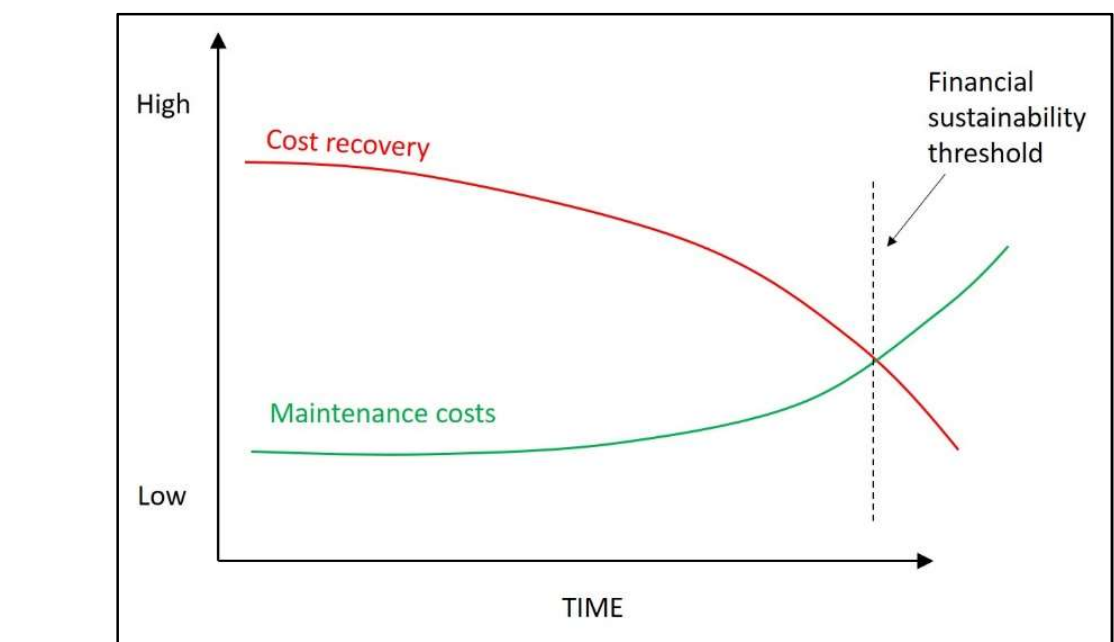

Figure 36 - Maintenance costs rise whilst cost recovery deteriorates in an urban water utility

Any assessment of the potential of groundwater for urban water supply must necessarily consider the existing institutional (regulatory, political, financial, etc.) structures as they relate to existing or envisaged water utilities ${ }^{216}$. These institutional factors can be considered part of the range of secondary factors which greatly influence groundwater use and sustainability. The institutional arrangements for water governance (including operation of utilities) may be considerably more important than the primary characteristics of the groundwater resource, in determining sustainability. Primary groundwater characteristics can, however, provide thresholds or cut-offs beyond or below which a water supply system is not viable. See Box 19 on proxy factors.

\section{Box19 - Proxy Factors}

A third tier of factors related to groundwater in SSA can be identified, in addition to primary (hydrogeological) and secondary (political economy) factors. This third tier can be called "proxy factors". Proxy factors are factors indirectly or loosely related to groundwater use, but which can nevertheless shed light on groundwater use trends. Proxy factors include data on fertilizer sales, time of electricity use, cell-phone coverage, electricity grid coverage, crop export figures, satellite estimates of groundwater irrigation clusters, import enquiries by pump manufacturers, delinquent loan figures from micro-lenders, profitability of drilling contractors, and many others.

Data on proxy factors may be much more widely available (and therefore proportionately more useful) than data on actual groundwater use. Their lower specificity or focus (i.e. they are only indirectly related to groundwater use) is balanced by much better data availability and density ${ }^{217}$. Proxy factors depend partly on the combination of primary and secondary factors operating in a groundwater economy. It can be easier and cheaper to collect proxy factor data, than to collect data on primary hydrogeological conditions, or secondary factors such as submersible pump prices. Analysis of proxy factors is one way in which the large data gaps on African groundwater use and secondary conditions may be bridged.

\section{Quantification of primary and secondary factors}

Once data on hydrogeological conditions (primary data) and on related factor such as pump prices (secondary factors) has been collected, it becomes possible to examine this data empirically. In theory, for any series of primary and secondary factors $(A, B, C)$ controlling

\footnotetext{
216 Manghee and Poole, 2012

217 Mayer-Schönberger and Cukier, 2014
} 
groundwater development at local level in SSA, a non-linear or threshold factor applies $(x, y, z)$, as well as a linear weighting factor $(a, b, c)$ based on local conditions and the interplay of the factors.

Hence the viability of a groundwater scheme or system $V$ can be expressed as:

$$
V=a A^{x}+b B^{y}+c C^{z}+\ldots
$$

A first task is to identify the factors, as well as the non-linear 'thresholds' for each. A weighting factor for each can then be estimated, and through a process of iteration an increasingly accurate value for $\mathrm{V}$ can be defined.

Much depends on precise identification of the factors, and on their respective coefficients. Empirical data is needed both to identify the factors, and to more accurately define their relative weights. At present much of this data is not available at the scale that is required. A further complication is that many factors are likely to remain hidden, and that factors change over time, both absolutely and relative to each other. Nevertheless, this data can allow 'thresholds' to be identified - levels or coefficients (e.g. a particular pump price) beyond which expanding groundwater use becomes viable (Figure 37 ).
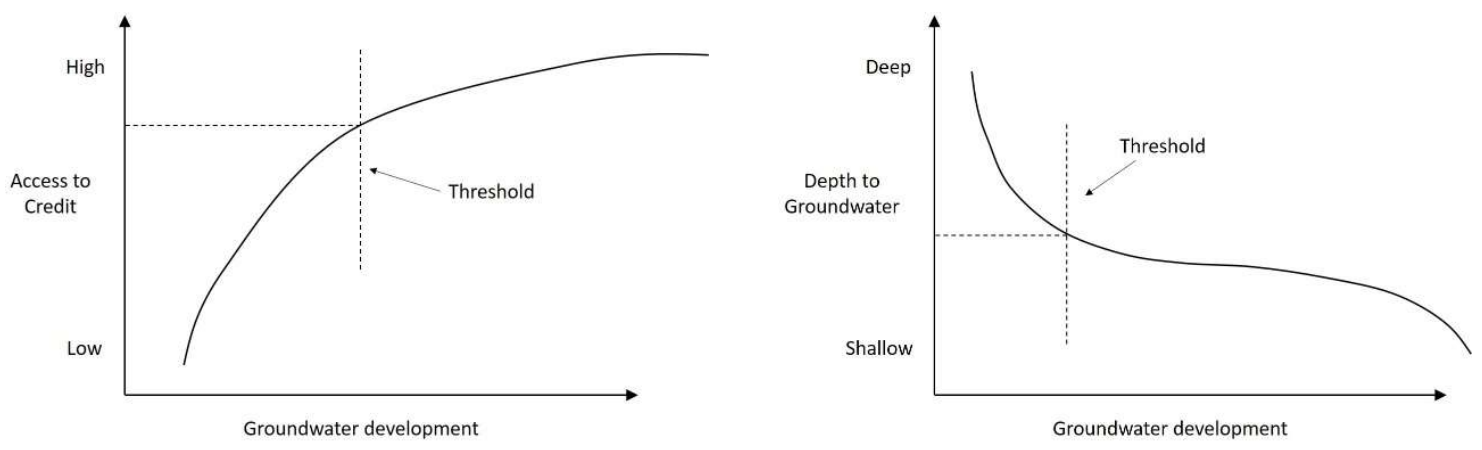

Access to credit

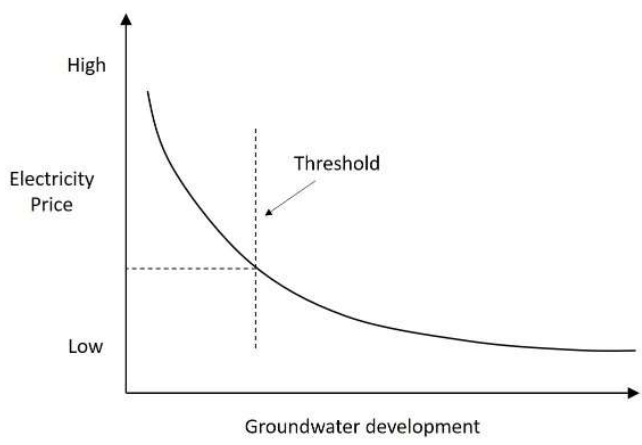

Electricity price

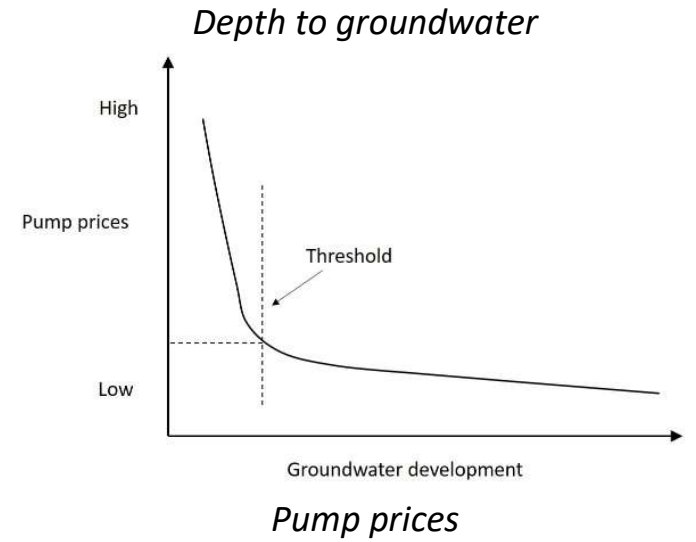

Figure 37 - Indicative impact of non-linear primary and secondary factors on groundwater development

\section{Political economy of groundwater development}

If development is a process of dynamic structural change in society, partly enabled or driven by groundwater use, rather than a series of smaller adjustments to existing (static) activities 
such as small-scale irrigation, then political economy factors will evolve in unpredictable ways as society develops ${ }^{218}$. An assessment of contemporary political economy factors, even if data was available, would necessarily have only a limited shelf-life - once the desired development takes place, these factors change. An ongoing process of data gathering and evolving understanding is required ${ }^{219}$.

The difficulty of trying to understand or control, ex-ante, the characteristics of a step change in African groundwater irrigation is illustrated by the fact that even in California, where extensive irrigation from groundwater takes place in a sophisticated institutional and datarich context, most of the $\mathbf{4 4 5}$ groundwater basins in the state have inadequate management, despite serious overdraft in some of them ${ }^{220}$. The 'anarchy' of groundwater growth in India provides a similar lesson ${ }^{221}$. Nevertheless, enormous and transformative benefits have accrued to both California and India. The harm done by overdraft and other problems linked to overabstraction must be balanced by an awareness and assessment of these benefits. In general, SSA's groundwater resources are greatly underutilized.

In this context it is useful to consider the economist Albert Hirschman's perspective on economic development - one that is incremental, local, and builds on what works ${ }^{222}$. This is opposed to more generic continental overviews and associated more general recommendations. Hirschman's 'Theory of Unbalanced Growth' requires an element of disequilibrium in the pursuit of a step-change in economic development. In the same way, a step-change in SSA groundwater irrigation is unlikely to happen 'naturally', since much of the region is stuck in a cycle of low investment, low returns and low expectations. Such groundwater development is also unlikely to respond well to a predetermined top-down planning or management approach, since so many unknowns exist (mainly secondary factors, but also hydrogeological factors). The most productive intervention therefore may be to work to incrementally remove bottlenecks to groundwater development, likely to be mainly secondary factors (e.g. electricity prices, problems importing pump spare parts, extension of the electricity grid) but also including hydrogeological factors (such as the lack of data on depth to groundwater) where necessary.

\section{Recommendations}

The analysis contained in this annex suggests a series of actions that can be undertaken as part of future work by the World Bank and its multilateral development partners:

- Improve understanding of the extent and availability of secondary or political economy factors influencing groundwater development in the countries of Sub Saharan Africa. Collate available data, and specify key data gaps. Evaluate the extent to which proxy factors on African groundwater can provide important information.

- Using an empirical analysis, rank secondary factors in terms of their influence on groundwater development. Identify thresholds beyond which each secondary factor ceases to be a major constraint on grassroots groundwater development.

\footnotetext{
218 Lejars et al. 2017.

219 Manghee \& Poole 2012.

${ }^{220}$ Ayres et al. 2017.

${ }^{221}$ Shah 2009.

222 Ellerman 2001.
} 
- Collaboratively develop possible interventions for alleviating identified political economy bottlenecks, including the costing of such interventions. Conduct a preliminary ranking of interventions by cost-benefit. Small adjustments to existing policy and practice may have relatively large outcomes in terms of groundwater development (e.g. lowering import taxes on pumps, or changing an onerous / outdated groundwater regulation).

- The steps listed above will make it possible to provide a first-pass quantifiable economic analysis of deep and shallow groundwater development in SSA. This economic analysis can then be incorporated into water projects led by multilateral development partners in SSA.

\section{Annex 5- Expanding role for the World Bank in Water Sector Development in SSA}

The World Bank has contributed significantly to water sector development, including in SSA, and its investment strategy is evolving. As client countries develop and demand for water increases, the World Bank's portfolio will evolve, including a greater emphasis on groundwater.

\section{World Bank guiding policies for water sector development}

The Bank has been playing a leading role in assisting member countries in investing in the water sector. The World Bank supports investment in the water sector to provide clean WSS to improve the quality of life of millions of rural and urban households and to advance irrigation to sustain food security and agricultural productivity. The Bank has also expanded its lending for water to enhance drought management and to strengthen resilience in fragile environments and conflict zones.

To support the contribution of water to enhancing economic and human development, the World Bank has produced two water strategies in the past two decades to inform and guide its investment portfolio:

- The World Bank's 1993 Water Resources Management Policy Paper marked an evolution beyond infrastructure development and towards a multi-sectoral approach, embracing the concept of IWRM. The paper shifted the Bank's planning process away from only discrete investments and promoted IWRM as a coordinated development and management of water, land, and related resources to maximize economic and social welfare in an equitable manner without compromising the sustainability of vital ecosystems ${ }^{223}$.

- The World Bank's 2003 Water Resources Strategy, which remains valid today, is more centered around water management and the connections between resource use and service delivery. It also reintroduced infrastructure investments as an important aspect of Bank support in the sector. The objectives of the strategy are outlined in Box 20.

Box 20 - World Bank 2003 Water Resources Strategy

The objectives of the water strategy are to:

\footnotetext{
${ }^{223}$ Under IWRM, each water-related activity in a project or program is considered carefully considering other competing uses and its social, economic, and environmental consequences.
} 
-Maximize the contribution of water to countries' economic, social, and environmental development
while ensuring that resource and water services are managed sustainably.
- Encourage and help countries establish comprehensive analytical frameworks to foster informed and
transparent decision making, with an emphasis on demand management.
- Promote decentralized implementation processes and market forces to guide the appropriate mix of
public and private sector provision of water services.
The comprehensive analytical frameworks advocated in the Strategy paper are to help guide decisions
about water resources and enable coherent, consistent policies and regulations to be adopted across
sectors in countries where significant problems exist, or are emerging, concerning the scarcity of water,
the efficiency of service, the allocation of water, or environmental damage.

There are strong potential synergies between the World Bank's Africa strategy and water development. The World Bank Africa region comprises low, lower-middle, upper-middle and high-income countries, of which 18 are fragile and conflict-affected states and 13 are small states (characterized by small populations, limited human capital, and confined land area) ${ }^{224}$. The World Bank's strategy in Africa includes the priority areas of agricultural productivity, climate change, regional integration, urbanization, high quality human capital, and knowledge ${ }^{225}$. This includes support to boost agricultural productivity and output via irrigation; help prevent conflicts over water resources; build climate and disaster resilience; improve connectivity and leverage economies of scale; promote integrated urbanization; and manage drylands (particularly in the Sahel and the Horn of Africa) - all of which can be contributed to by surface and groundwater development.

The World Bank has also produced a wealth of knowledge products on water for use by its client countries: both surface and groundwater resources management for urban and rural development, and across multiple global regions. Through the Water Global Practice (GP), and other operational units, the World Bank is a leading source of knowledge contribution on many aspects of water and development. The World Bank also has the capacity to draw on global experiences in water sector development.

\section{World Bank water sector investment}

Overview

Lending in the water sector is an important component of the Bank's global portfolio of projects. Investment in the water sector averages about 10-12 percent of the Bank's annual lending (Figure 38).

\footnotetext{
${ }^{224}$ World Bank 2017a.

${ }^{225}$ World Bank 2017a.
} 


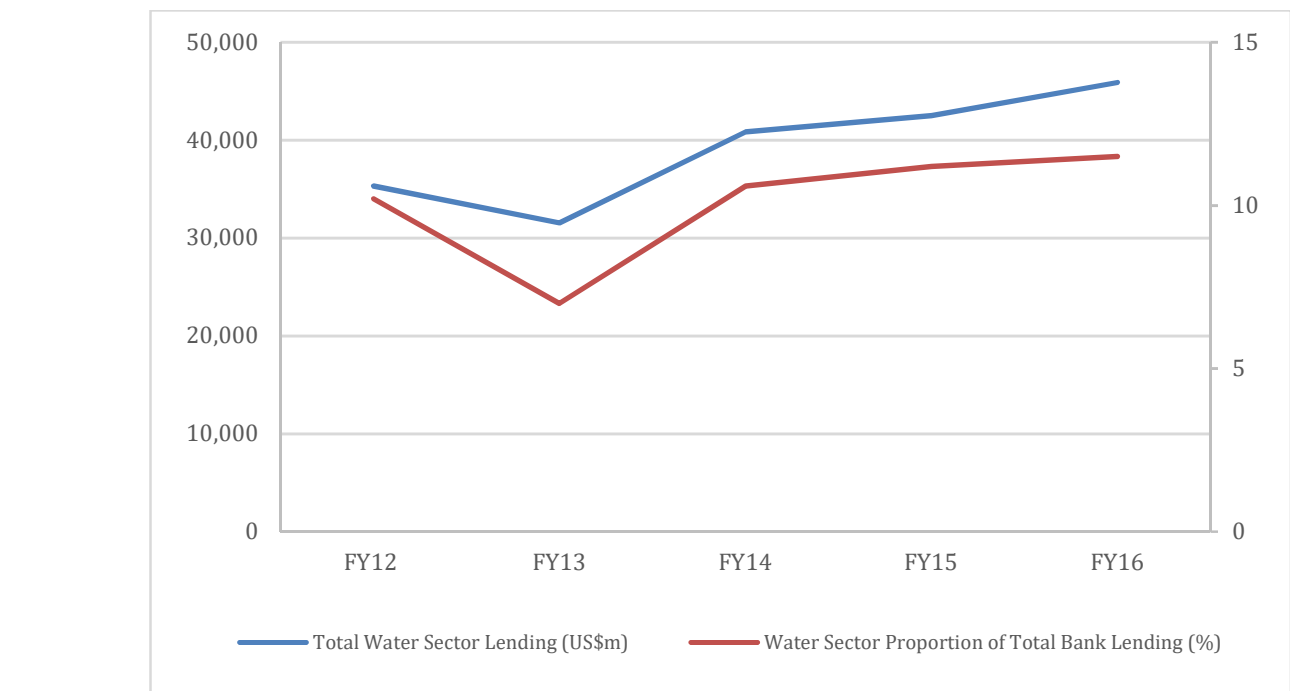

Figure 38 - World Bank lending (IBRD + IDA) for the water sector (US\$ millions) (Source: World Bank Annual Report 2016)

The World Bank's investment in the water sector in the Africa Region averages about 30-35 percent of the Bank's global investment in the sector, and has generally increased over the last decade. Lending for the Africa Region has increased substantially over the last decade (Figure 39) and the World Bank approved lending to more than 94 projects in SSA in the last decade (2007-2017). In 2016, the Bank supported 15 projects in SSA totaling US\$1.9 Billion or 35 percent of lending to the sector. The 2004 World Bank Water Resources Strategy reported that SSA received only eight percent of the allocation to the water sector portfolio in the 1990s. The current active water portfolio includes 52 active projects supporting investment in urban and rural water supply, and 62 projects supporting irrigated agriculture for small and commercial farmers in SSA.

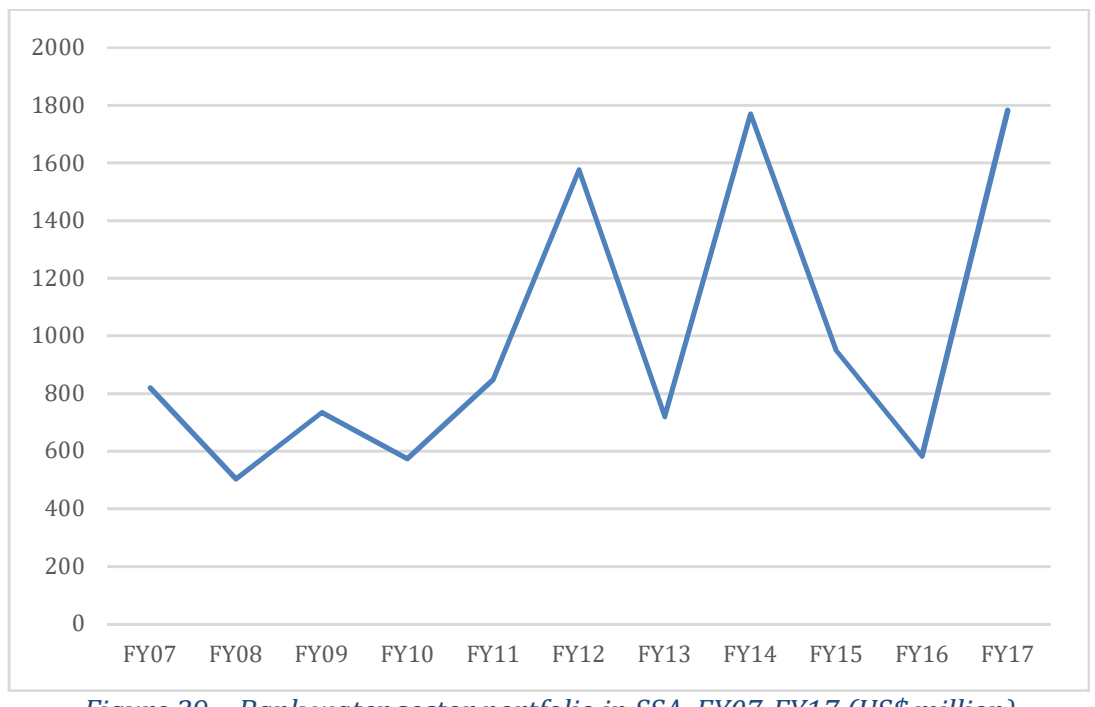

Figure 39 - Bank water sector portfolio in SSA, FY07-FY17 (US\$ million)

Most of investments in the water sector in SSA are mapped to WSS. Most lending for water projects in the Africa region is allocated to WSS, with a steady but lower allocation to the irrigation and drainage sector (Figure 40). 


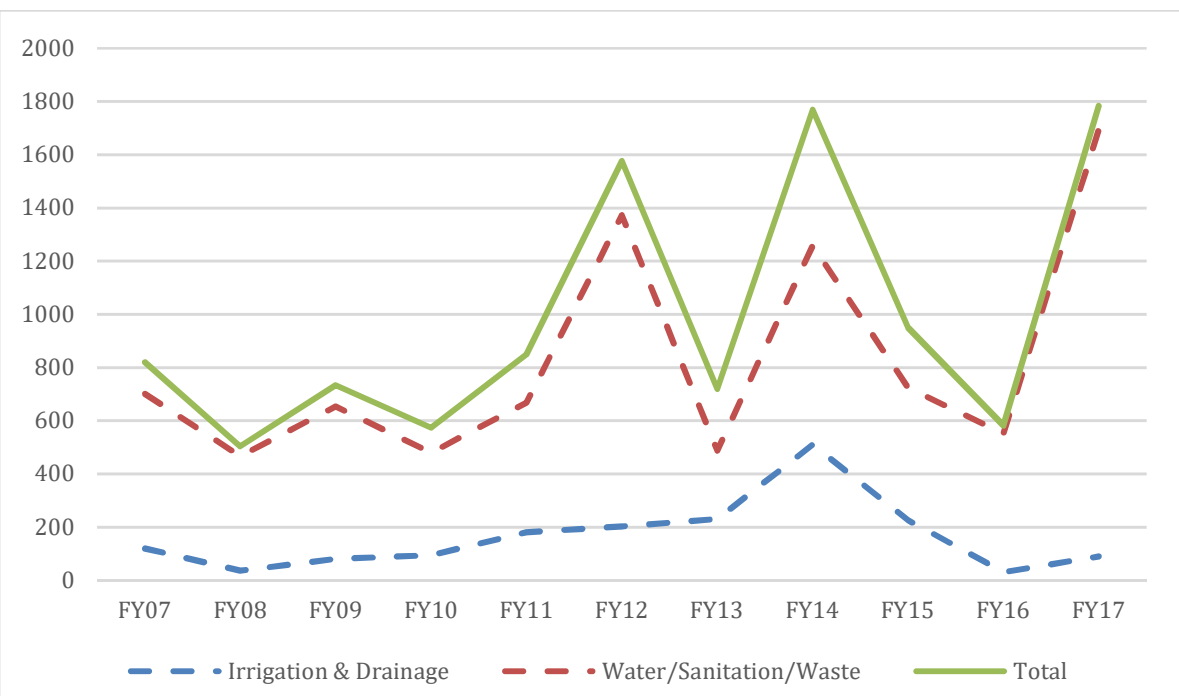

Figure 40 - World Bank lending volumes for water projects in Africa region (FY07-FY17, US\$ millions)

\section{Groundwater}

A detailed assessment of groundwater, both in the World Bank's global water sector portfolio (conducted by IEG 2010), and in the SSA water sector portfolio, is provided in Annex 2 . The major findings of those assessments are summarized below.

While investment in water-related activities is an important component of the World Bank's global portfolio of projects, to date surface water investments have predominated over groundwater investments. Surface water projects (such as watershed management, dams and hydropower, rivers and lakes) have received the greatest investment focus in the Bank's water portfolio. While groundwater has relevance to many water sector projects, it is often not specifically identified and is rarely the primary component of water sector investments, suggesting that there is potential to increase groundwater utilization as a basis for economic development, poverty reduction and disaster resilience.

There is an opportunity to augment the surface water portfolio by treating groundwater as an important strategic component for development. As of 2007, groundwater was the least common theme in the Bank's global water portfolio (Figure 41a). In response, IEG (2010) called for the Bank to be "more ambitious in addressing issues critical to the long-term use of groundwater". These global findings are mirrored in the SSA water sector portfolio (Figure 41b).

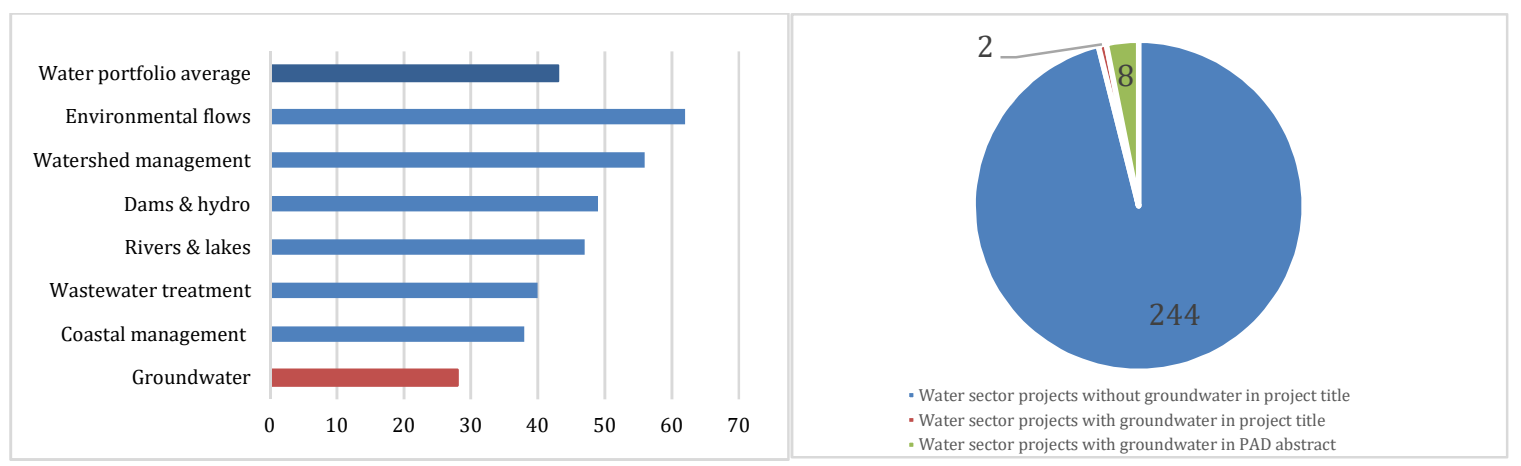

Figure 41 - Groundwater was the least common theme in the Bank's global water portfolio in 2007 (a), and SSA water sector projects predominantly do not contain groundwater in project titles or PAD abstracts 1997-2017 (b) 
There is opportunity to raise the profile of groundwater with clients across the Africa region. The World Bank could invest in more groundwater-focused projects, both at the national and regional scales. Groundwater has been the primary focus of very few investment projects in SSA between 1997-2017. Groundwater can be an option for addressing water stress challenges, increasing climate resilience, promoting economic growth (chiefly irrigation), and helping to secure potable water supplies. If the World Bank invests in more groundwater-focused projects, this could help to serve as examples for clients to increase their awareness of the potential for sustainable groundwater development to contribute to national development goals.

Sustainable groundwater development (extraction) projects have a sound rate of success across the World Bank's global portfolio, which bodes well for future investment in the Africa region. There is opportunity to expand the number of groundwater development projects in the Africa region. Whilst sustainable groundwater development (extraction) projects may be the highest priority for investment in SSA, the portfolio could also grow to include projects dealing with monitoring of groundwater quality, aquifer recharge, and management of leachates and contaminated surface water infiltration.

There is a strong case for a linkage to be made between strategic groundwater development and countries which are water stressed and suffer from recurrent droughts. Currently, there is no evidence in the portfolio of groundwater being used effectively to help water stressed countries, nor to strategically manage recurring droughts. Countries and regions that have suffered repeated droughts (particularly in recent years) have few or no projects where groundwater is used strategically to minimize the impacts of future events. More strategic investment, as opposed to emergency relief, could help break the negative impacts of the cycle of drought. The World Bank could apply a more systematic approach to addressing this significant challenge.

In terms of project processes, there is opportunity to better integrate groundwater into water sector project conceptualization, planning and design, and to bolster monitoring and internal groundwater expertise to achieve this. Increased and specific reporting on groundwater could help realize greater development opportunities from the outset and minimize potential risk associated with mismanagement of resources (e.g. overexploitation and pollution). Given the large variety of units within the World Bank working on projects with relevance to groundwater, and the opportunity to increase the focus on groundwater for many of those projects, it may be warranted to introduce processes (e.g. strategic monitoring) or personnel to become involved in project conceptualization, planning and design to ensure that groundwater is considered to play a greater role in future projects.

Looking forward, a transition towards groundwater resource development will need to help meet the growing gap in demand. The Bank's lending - from irrigated agriculture and WSS to rural development and disaster risk reduction - will become increasingly reliant on groundwater resources, either utilized independently or in conjunction with surface water resources. The current low profile of groundwater in the Bank's investment portfolio in SSA suggests significant opportunity to promote groundwater more explicitly as part of a holistic development approach.

Given the currently low profile of groundwater in the World Bank's investment portfolio in Africa, there appears to be significant opportunity to promote groundwater more explicitly as 
part of a holistic development approach. Chapter 3 provides the basis to inform the World Bank that there is sufficient groundwater to help serve as a foundation for resilient development.

\section{The World Bank as a convener of stakeholders in groundwater}

There is evidence of awareness and momentum building among some client countries and regional stakeholders. The World Bank can use its convening powers to help raise the profile of groundwater and promote its sustainable development. In response to international agreements, such as the SDGs, as well as frustration at seemingly intractable development challenges and recurrent drought events, there has been an increased focus on the role that groundwater can play in addressing these issues. For example, regional intergovernmental actors are forming to contribute to the body of evidence supporting greater action on groundwater knowledge and development. While SSA warrants the defining of a bespoke groundwater development pathway appropriate for its geographical, political and economic setting, the World Bank's investment in the groundwater sector in SSA can draw on lessons learned from global experiences in other regions where groundwater has already played a critical development role.

Despite a historical, and current, lack of focus on the characterization, understanding and management of groundwater resources in Africa, there is recent evidence of increased efforts by multiple stakeholders to address this. The World Bank can build on this emerging momentum, with actors outlined in Annex 3. To overcome the predominant focus on surface water resources over groundwater resources in SSA, recently, there has been an increased emphasis on trying to better understand and manage groundwater resources by a range of international, regional and national stakeholders (see Annex 3 for a comprehensive listing).

\section{Annex 5a- Evaluation of role of groundwater in World Bank water sector portfolio}

Groundwater as a component of the World Bank's global water sector portfolio

This section provides a synopsis of the findings of the Independent Evaluation Group's (IEG) 2010 evaluation of the World Bank's global water sector portfolio, with specific reference to groundwater. It must be stated that the IEG review considered projects between 1997-2007, which is a decade old now. While the review is the most recent available, the findings should be considered with that delay in mind.

At the global scale, IEG (2010) finds that the World Bank's strategic approach to water and development has underemphasized some of the most difficult challenges - including groundwater - which, in turn has left some crucial needs unmet. In response to the reality of growing water scarcity, IEG (2010) reports that the World Bank has not responded at scale to some increasingly pressing water challenges, especially the preservation and restoration of groundwater resources (as well as water quality improvement, coastal vulnerability, and sanitation).

Across the World Bank's global water portfolio, the number of projects dealing with groundwater issues declined between 1997-2007, a trend that IEG (2010) describes as 'problematic' (Figure 42). The number of World Bank-financed projects dealing with groundwater declined during the assessment period (including projects focused on extraction 
and projects focused on sustainability and groundwater conservation). This occurred despite the 2003 Water Resources Sector Strategy forecasting an increase in attention to groundwater.

Groundwater Projects

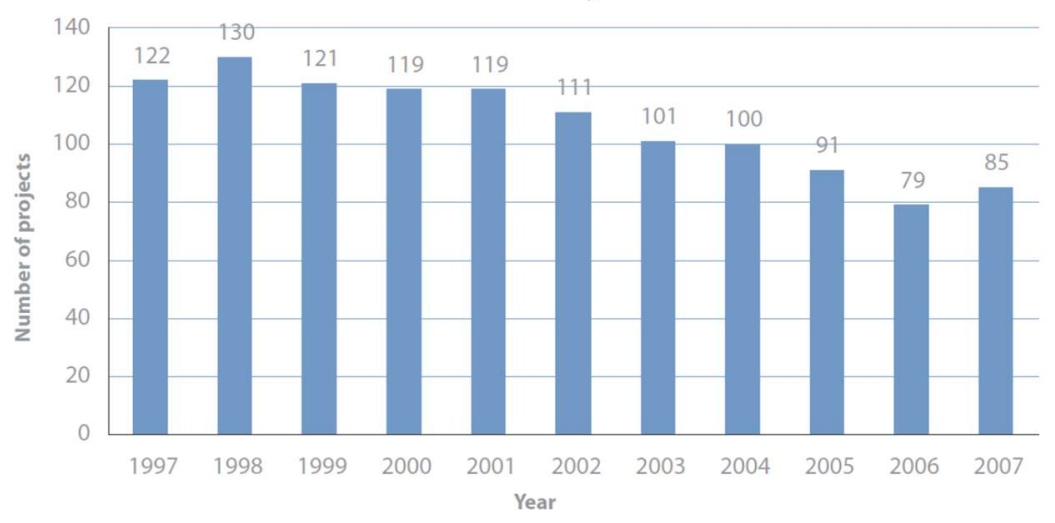

Figure 42 - Number of groundwater projects globally in World Bank (1997-2007)

Given that the Africa region should expand groundwater development as an integral component of investing in the water sector, it is encouraging that the IEG (2010) found the most successful activities in the global groundwater portfolio are those aimed at increasing water supply (Figure 43). Construction of groundwater supply schemes not only was attempted most frequently, but achieved the intended goal most often (IEG 2010). Groundwater monitoring projects were also relatively successful. On the other hand, the least successful activity in the groundwater portfolio was the development of management frameworks or plans, for which only 20 percent of projects successfully completed the task. Other less successful activities related to groundwater recharge and groundwater exploration for water supply and irrigation.
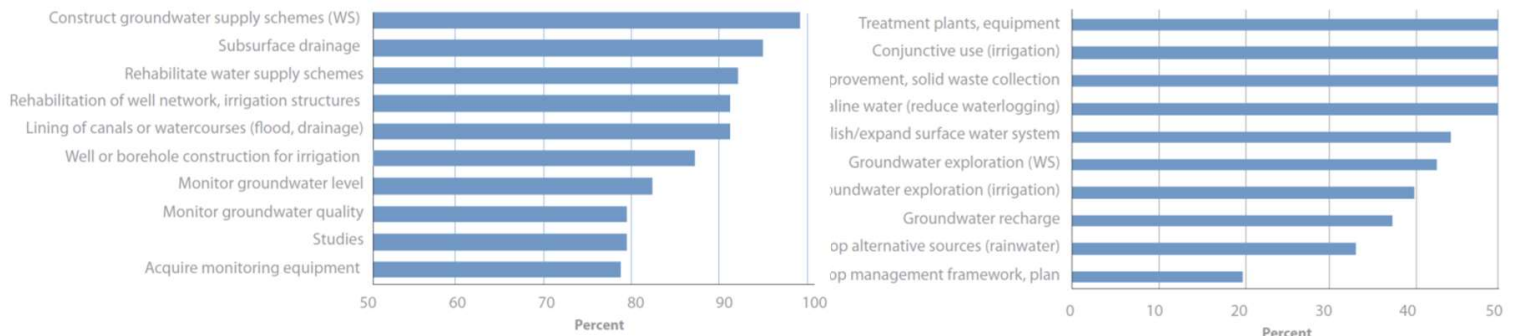

Figure 43 - (a) Ten most successful groundwater activities, and (b) ten least successful groundwater activities (success rate in attaining groundwater-related goals within indicated activity)

IEG (2010) recommends ensuring that projects pay adequate attention to conserving groundwater and ensuring that the quantity extracted is sustainable (Figure 44). Despite the seriousness of groundwater depletion, the extent of the groundwater problem is poorly understood, and few projects protect or restore aquifers. However, as groundwater has become increasingly scarce, ongoing Bank projects have shifted away from investments in extraction towards conservation. 


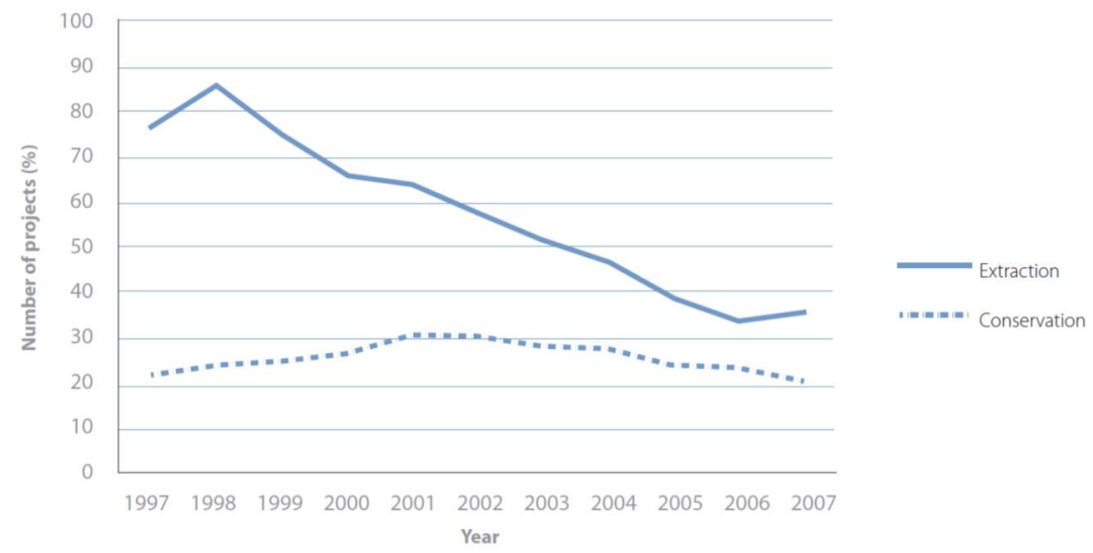

Figure 44 - The focus of groundwater projects across World Bank global portfolio (1997-2007)

As at 2007, groundwater was the least common theme in the World Bank's global water portfolio (Figure 45). While groundwater the least common theme in water projects globally, projects focused on surface water issues received much greater focus (including watershed management, dams and hydro, rivers and lakes, etc.). IEG (2010) stated that themes, such as groundwater, which fall below the water portfolio average, are considered lower or diminishing priorities.

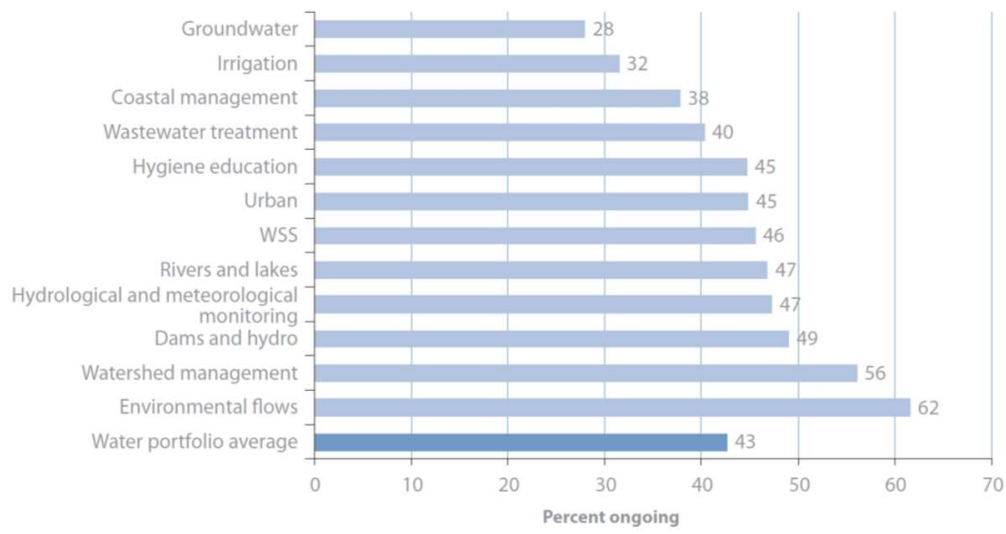

Figure 45- Share of ongoing projects from World Bank global water projects portfolio (as at 2007) addressing selected themes (IEG water database)

The IEG (2010) states that the World Bank needs to be "more ambitious in addressing issues critical to the long-term use of groundwater". The extent of the groundwater problem is poorly understood because data are rarely collected or shared. Project examination by IEG (2010) revealed that while it was quite common for project appraisals to state an intention to monitor groundwater quality and level, those intentions often had not been carried out by the time the loans closed. Data on all aspects of groundwater and relevant socioeconomic conditions need to be more systematically collected and monitored and used better within projects. For example, IEG (2010) states that the collection and analysis of up-to-date groundwater data are more important now than ever and need to be taken on board more commonly than they have been.

The World Bank has not engaged in many transboundary aquifer projects, however IEG (2010) evaluates some of their work as groundbreaking. IEG (2010) draws attention to a 2002 project in Latin America (involving Argentina, Brazil, Paraguay, and Uruguay), which purportedly 
established institutions, supported cross-border subprojects, and effectively reduced the risk of over-extraction and contamination of groundwater resources and other potentially negative transboundary impacts.

Business-as-usual is not an option for water and development and IEG's evaluation suggests that the World Bank should find ways to support systematically the countries that face the most water stress. The World Bank has lent heavily for irrigation and water supply, with a focus on dams and hydropower, but increasingly water stress is related to coastal zone management, pollution control and groundwater.

Up until 2007, there was no relationship between World Bank water lending and country water stress. $\mathbf{3 5}$ of the world's $\mathbf{4 5}$ most water-stressed countries existed in the Africa region. The World Bank can help water stressed countries prioritize water needs as central to national development strategies. In the Africa region, many countries are not only water poor but also economically poor.

IEG (2010) provides the following recommendations, which have relevance to groundwater:

- Work with clients and partners to ensure that critical water issues are adequately addressed, particularly those with the greatest water stress, and pay adequate attention to conserving groundwater and ensuring that the quantity extracted is sustainable.

- Strengthen the supply and use of data on water to promote better understanding of the linkages among water, economic development, and project achievement. More frequent and more thorough monitoring to help ensure data is treated as a public good and widely available.

Groundwater as a component of the World Bank's SSA water sector portfolio

The analysis below summarizes the role that groundwater has played, and is playing, in the World Bank's portfolio of projects in Africa ${ }^{226}$. The primary data analysis draws on projects with relevance to groundwater being activated in Africa over a twenty-year period (1997-2017), as well as those with relevance to groundwater that were closed over the same period. Below is a summary of those findings.

\section{Synopsis of projects with relevance to groundwater in Africa}

Between 1997 and 2017, the World Bank has activated 254 projects in the Africa region with relevance to groundwater. This equates to an average of approximately 13 projects annually across the region with relevance to groundwater. The projects have been drawn from a wide range of units within the Bank.

Across the Africa region, the World Bank's portfolio includes both country-specific and regional projects with relevance to groundwater. While some countries have been engaged in multiple projects over the past twenty years, others have had none (Figure 46). The countries that have been engaged in the most projects with relevance to groundwater are Nigeria (19), Ethiopia (16), Mozambique (15), Kenya (12), Rwanda (11) and Senegal (11). In contrast,

\footnotetext{
${ }^{226}$ The secondary data analysis findings are presented first, as they assess trends and characteristics of the World Bank's water portfolio globally, including groundwater and the Africa region. The primary data analysis findings are presented second, as they focus only on groundwater-related projects and only on the Africa region.
} 
Equatorial Guinea, Eritrea, Liberia, Namibia, and Sao Tome and Principe have had no registered projects with relevance to groundwater (between 1997-2017), while Comoros, Republic of Congo, Gabon, Seychelles, South Sudan, Sudan, Swaziland, and Togo have all only had one registered project over that period. Regional projects (of which 30 projects alone are mapped to Africa region rather than specific country/s) often relate to transboundary management of (surface) water resources.

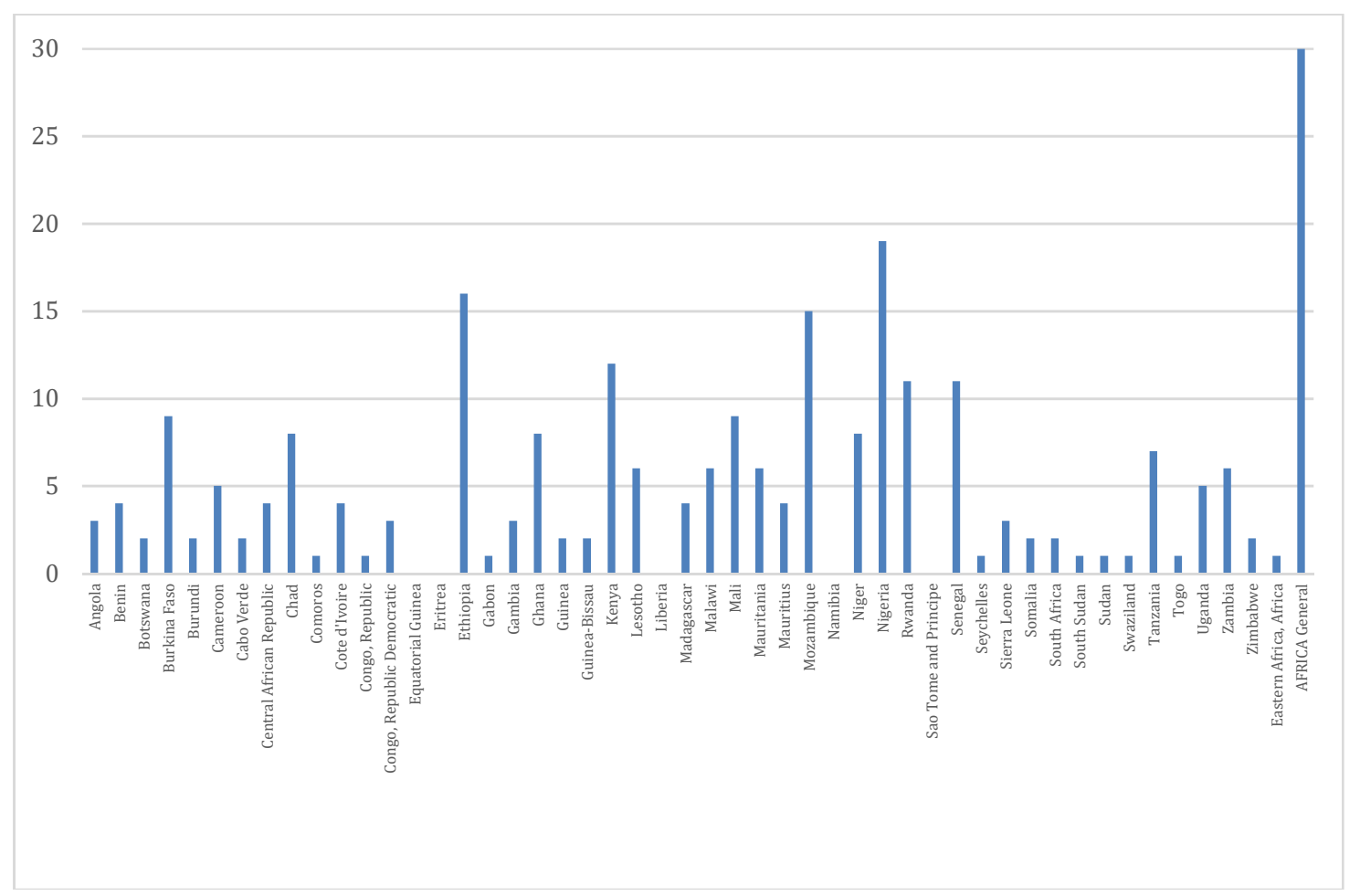

Figure 46 - Number of projects with relevance to groundwater, by country (1997-2017)

Many units across the World Bank own projects with relevance to groundwater: from urban to agriculture, energy to transport, and others (Figure 47). The 254 World Bank projects in Africa with relevance to groundwater (1997-2017) have been drawn from 62 units in the World Bank. The units owning most projects have been: AFT: Urban/Water Anglophone (AFTU1) with 30 projects; AFT: Urban/Water Francophone (AFTU2) with 24 projects; Agric. RD Irrigation Prac 1 (AFTA1) with 19 projects; ENV, NRM, WRM DRM Prac 1 (AFTN1) with 12 projects; and Transport Practice Group (AFTTR) with 11 projects. 


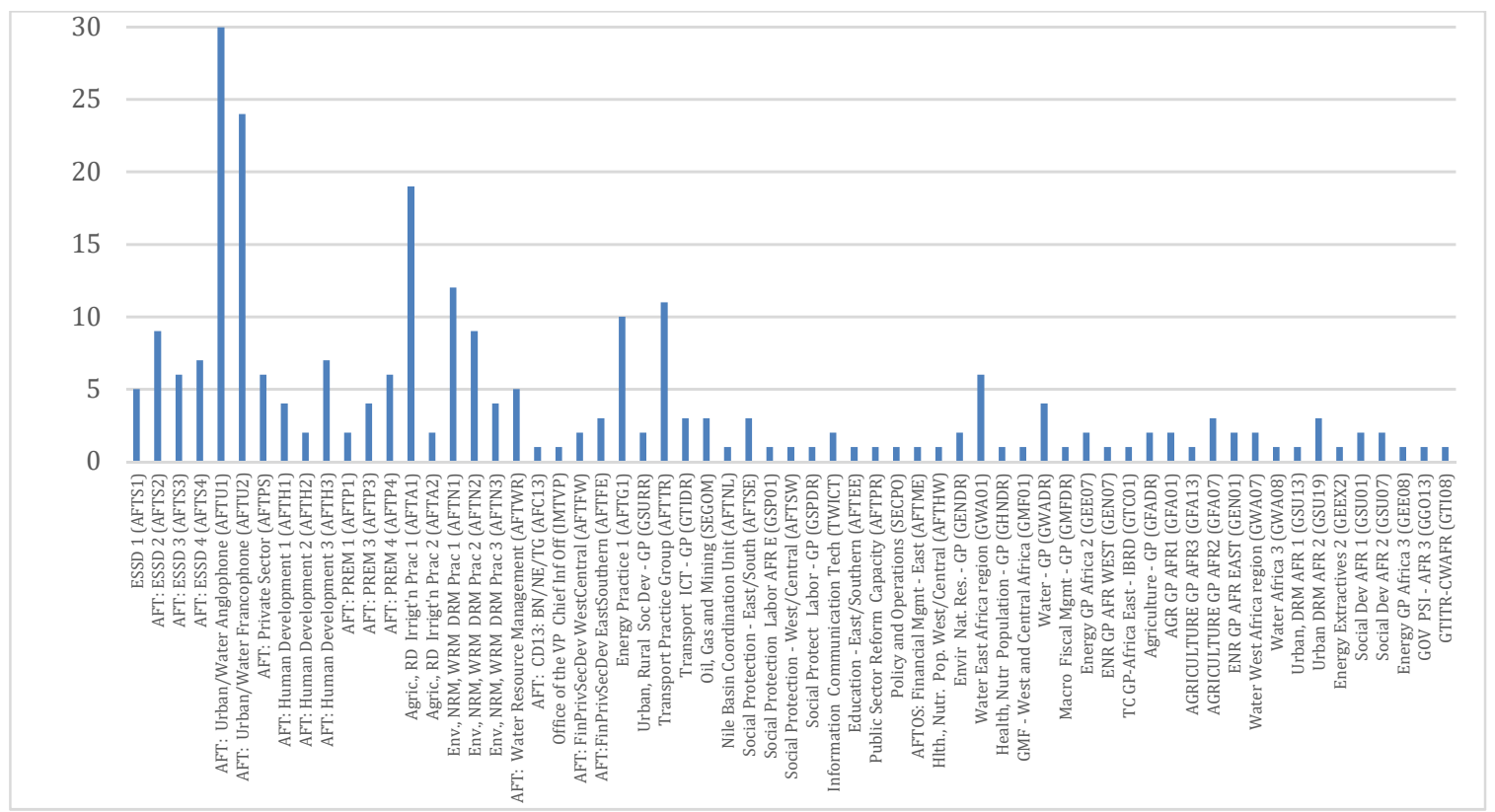

Figure 47 - Number of projects with relevance to groundwater, by Bank Unit (1997-2017)

Up until recently, there has been a generally increasing trend in the number of projects in the World Bank portfolio of projects in Africa with relevance to groundwater over the past twenty years (Figure 48). The calendar year with the most number of projects with PADs was 22 in 2014 , followed by 19 in 2013. The calendar year 2017 may be expected to reach similar total project numbers. This compares with not more than 10 projects per calendar year between 1997-2002 (inclusive).

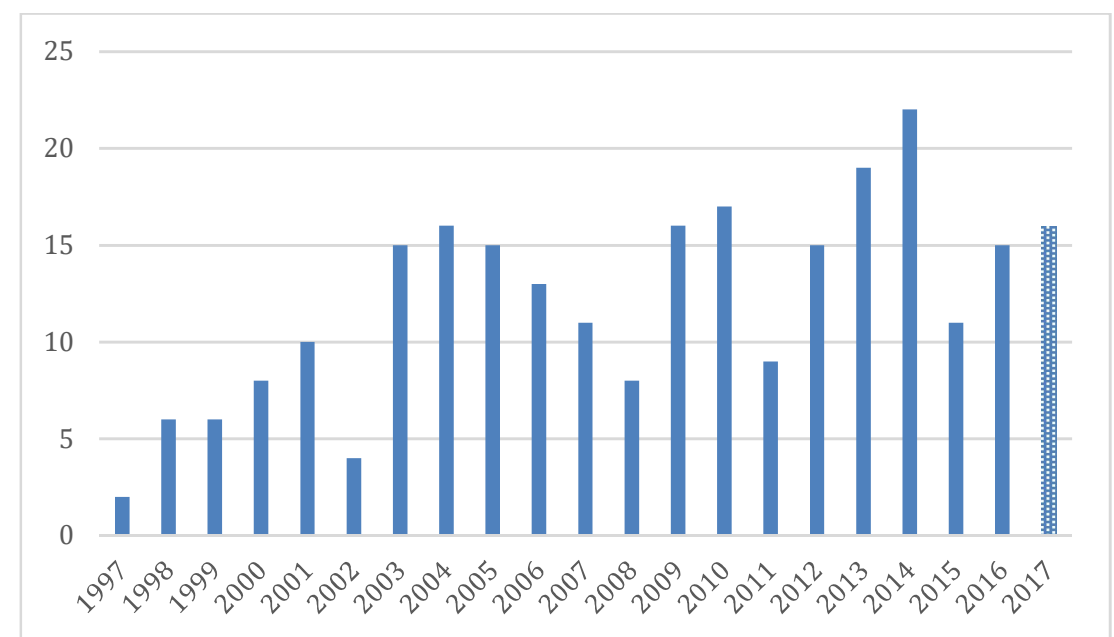

Figure 48 - Number of projects with relevance to groundwater in Africa, by year (1997-2017)

But, how much focus is there on groundwater within projects with relevance to groundwater? However, almost no projects in the portfolio have groundwater as their central focus. Only 2 of the 254 projects with relevance to groundwater contain groundwater in project titles - that is 0.8 percent. Furthermore, only 8 of the 254 projects contain direct reference to groundwater in the abstract of their PAD - that is 3percent. This means that groundwater is likely not being as strongly integrated into project design as it could be. 
The only two predominantly groundwater focused (and titled) projects in the World Bank's Africa portfolio (1997-2017) have been regionally focused, in the Southern African Development Community (SADC) and focused on drought management and sustainable groundwater development. Two projects, both focused in the SADC and offset by almost a decade, show some continuity and evolution on groundwater management: (i) "Groundwater and Drought Management in the SADC" (2005), which aimed to develop a SADC regional strategic approach to support and enhance the capacity of its member states in the definition of drought management policies, specifically in relation to the role, availability, and supply of potential groundwater resources; and (ii) "Sustainable Groundwater Management in SADC Member States" (2014), which aims to support sustainable management of groundwater at national and transboundary levels across SADC Member States.

The other six projects which contain direct reference to groundwater in the abstract of their PADs are nationally focused and have (typically minor) groundwater components as part of a broader scope of work. None of the country-based projects which include groundwater components are large-scale systematic groundwater development interventions. The components of groundwater in those projects range from managing groundwater pollution, developing extraction infrastructure, groundwater storage tanks and protection of resources during emergency relief programs. A synopsis of each of the six projects is outlined:

- The Niger Water Sector Project (P061558) aimed to increase access to WSS services in rural and urban areas, and included integrated monitoring of groundwater pollution in shallow aquifers and an environmental development program to protect against groundwater pollution.

- The Ethiopia Irrigation and Drainage Project (P092353) is an irrigation and drainage project which included the development of 20,000 ha of groundwater and surface water infrastructure (and to ascertain future irrigation potential in 80,000 ha).

- The Bamako Water Supply Project (P122826), in Mali, is a water supply project aimed at increasing access to sustainable water services, including the installation of groundwater storage tanks.

- The Senegal Urban Water and Sanitation Project (P150351), is an urban water and sanitation project to improve access to water and sanitation services, including development of groundwater resources.

- The Botswana Emergency Water Security and Efficiency Project (P160911) is an emergency water security and efficiency project to improve the availability of water supply in drought vulnerable areas, including protection of groundwater resources.

- The Kenya Development Response to Displacement Impacts Project (P161067) aims to improve access to basic social services and enhance environmental management for communities hosting refugees, included reducing uncontrolled abstraction of groundwater for domestic consumption and livestock.

There have been no country-level World Bank projects predominantly focused (and titled) on groundwater in the World Bank's Africa portfolio (1997-2017). This seems to represent a major deficiency in the World Bank's Africa project portfolio.

Furthermore, analysis of 85 project ICRs (between 1997-2017) with relevance to groundwater reveals no major discussions of groundwater. In fact, none of the 85 ICR abstracts analyzed 
contain direct reference to groundwater. This indicates that groundwater is either not being considered in projects, or is being grossly under-reported, or both.

How is drought and disaster resilience integrated into the portfolio?

Further to groundwater not featuring prominently in the World Bank's Africa project portfolio, drought resilience also only receives scant focus. Only 2 of the 254 projects with relevance to groundwater contain 'drought' in the project title, and only 10 of the 254 projects contain 'drought' in the abstract of the PAD. Of the 85 ICR abstracts analyzed, none made direct reference to 'drought'.

Zooming into a known region of repetitive drought conditions - the Horn of Africa - there is not strong evidence of strategic lending to address this problem. The Horn of Africa is currently facing its third consecutive year of drought - three of the four Horn of Africa countries are situated in the Africa region (Eritrea, Ethiopia and Somalia), and only one of those countries has had more than one project relevant to groundwater in the past 20 years. Other countries which have suffered from recent severe drought, and which have had very few (or no) projects with relevance to groundwater, include Namibia (0), South Africa (2), South Sudan (1), Swaziland (1), and Zimbabwe (1).

There is little evidence of World Bank investments related to groundwater development being linked to areas where frequent and repeating drought events are occurring. There is opportunity to better integrate strategic lending for targeted drought resilience into the World Bank's portfolio of projects in Africa with relevance to groundwater. 


\section{Annex 5b - Other actors in groundwater in Africa}

In addition to the World Bank, a range of actors are increasing knowledge and efforts around groundwater development in SSA, albeit from a low baseline. Several regional and national organizations are active in the water sector in SSA. While integrated surface water management SADEC, etc.

International organizations contributing to various aspects of groundwater development The following list is a selection of international organizations contributing to groundwater knowledge and development in SSA:

- Geological surveys outside of Africa. Several of the large geological surveys in Europe, North America, East Asia and elsewhere have track records of hydrogeological work in Africa, sometimes involving extensive and close cooperation with African surveys over many years. This work has often been carried out with support from national or multilateral development organizations. There have been a few initiatives to make groundwater data and information held outside of Africa more widely available. For example, the British Geological Survey (BGS) worked together with SADC, the South African Water Research Commission and other partners to produce the Africa Groundwater Atlas and Literature Archive (http://www.bgs.ac.uk/africagroundwateratlas/) with around 7,000 reports and other items on African groundwater dating from the late nineteenth century onwards (see below). The German Federal Institute for Geosciences and Natural Resources (BGR) has worked with UNESCO and other partners to produce WHYMAP, the World-wide Hydrogeological Mapping and Assessment Programme, an initiative that makes world-wide hydrogeological maps freely available.

- Unlocking the Potential of Groundwater for the Poor (UPGro), adopts a social and natural science approach to enabling sustainable use of groundwater for the benefit of the poor. UPGro is a seven-year international research program (2013-2020), jointly funded by UK's Department for International Development (DFID), Natural Environment Research Council (NERC) and the Economic and Social Research Council (ESRC), focused on improving the evidence base around groundwater availability and management in SSA to enable developing countries and partners in SSA to use groundwater in a sustainable way to benefit the poor. Projects are interdisciplinary, linking the social and natural sciences. Outputs to include a combination of publications and knowledge generation and consortium projects, including the British Geological Survey Africa Groundwater Literature Archive (containing approximately 6,000 reports (in 2015), journal articles, conference papers, maps and other groundwater literature); metadata from long term (>10 year) groundwater datasets (including African Groundwater Atlas); catalyst and consortium grant projects; groundwater risk management for growth and development tool (Gro for GooD); groundwater futures in SSA (Grofutures); building understanding of climate variability into planning of groundwater supplies from low storage aquifers in Africa (BRAVE); experimenting with practical transition groundwater management strategies for the urban poor in SSA (T-GroUP); and unravelling current failures for future success in rural groundwater supply (Hidden Crisis) (UPGro website).

- International Water Management Institute (IWMI), is a non-profit, scientific research organization focusing on the sustainable use of water and land resources in developing countries. IWMI works in partnership with governments, civil society and the private sector to develop scalable agricultural water management solutions that have a real impact on poverty reduction, food security and ecosystem health. IWMI is a member of CGIAR, a 
global research partnership for a food secure future. IWMI works through collaborative research and targets policymakers, development agencies, individual farmers and private sector organizations. The IWMI-Southern Africa (IWMI-SA) regional program was established in 2000, hosted by the South African Government's Department of Agriculture, Forestry, and Fisheries. IWMI-SA's inter-disciplinary research, policy dialogue and capacity building pays attention to niche areas, including sustainable conjunctive use of groundwater and surface water; sustainable and climate-smart intensification of smallholder agriculture; gender and social equity to redress the region's dual economy; transboundary water management, and monitoring and evaluation. IWMI is also engaged in other regional initiatives, such as the Comprehensive Africa Agriculture Development Program (CAADP) and the Regional Indicative Strategic Development Plan (RISDP) of the Southern African Development Community (SADC), which seek to pool knowledge and information for improved agricultural development (IWMI website).

- Stockholm International Water Institute (SIWI), aims to bridge science, policy and practice for a water wise world. SIWI pursues this goal through applied research, policy consultation, capacity-building, and connecting key actors across sectors, thereby stimulating development of innovative policies and scientifically-based solutions to waterrelated challenges. SIWI contains five thematic areas: (i) water governance; (ii) transboundary water management; (iii) water and climate change; (iv) water, food and energy; and (v) water and economics. Recently, SIWI established the Africa Regional Centre, to help in regional and continental efforts to support future-oriented policies, research initiatives and institutional capacity development for more effective water management and development (SIWI website).

- International Groundwater Resources Assessment Center (IGRAC, https://www.unigrac.org/) is funded partly by the United Nations Organization for Education, Science and Culture (UNESCO) and the Government of the Netherlands. It was founded in 1999 by UNESCO and the World Meteorological Association (WMO), and launched in 2003. Initially hosted by the Netherlands Organization for Applied Scientific Research (TNO), IGRAC is today a legally independent organization, and is a UNESCO Centre. IGRAC's stated mission is to 'facilitate and promote international sharing of information and knowledge required for sustainable groundwater resources development and management worldwide'. IGRAC has a global focus, with an emphasis on the developing world. IGRAC collaborates with a variety of partners (e.g. UPGRO, BGS) and acts as a catalyst in groundwater-related projects. IGRAC acts as a broker of information and data on groundwater via its Global Groundwater Information System (GGIS), a modular GIS-enabled web portal that collates and presents global groundwater information (https://www.un-igrac.org/globalgroundwater-information-system-ggis). A component of this is the Africa Groundwater Portal. Meta-information on groundwater reports and publications is also kept, including guidelines and protocols for groundwater development, and many of these are available for download.

- Global Water Partnership (GWP), was founded in 1996 to foster integrated water resource management (IWRM). Its mission is to support the sustainable development and management of water resources at all levels. GWP's strategic goals are to: catalyze change in policies and practice; generate and communicate knowledge; and strengthen partnerships. GWP has regional offices in West, Southern, Central and Eastern Africa (GWP website).

- International Association of Hydrogeologists (IAH), has historically carried out much of its scientific and technical work through its Commissions and Networks. The IAH Burdon 
Network supports hydrogeologists in developing countries who are working to help achieve the SDGs/MDGs and increase access to safe water. The initial focus of the IAH Burdon Network has been SSA (IAH website).

- International Network of River Basin Organizations (INBO), has an objective to promote the exchange of experiences between organizations in charge of river basin management in such areas as institutional and financial management, knowledge of water resources, training different stakeholders involved in water management as well as the staff of basin organizations, and increasing the awareness of the public for water resources management. The INBO contains regional basin organizations, including

- UNESCO International Hydrological Programme (UNESCO-IHP), is the only intergovernmental program of the UN system devoted to water research, water resources management, and education and capacity building. IHP has evolved from an internationally coordinated hydrological research program into an encompassing, holistic program to facilitate education and capacity building, and enhance water resources management and governance. IHP facilitates an interdisciplinary and integrated approach to watershed and aquifer management, which incorporates the social dimension of water resources, and promotes and develops international research in hydrological and freshwater sciences. Specifically, for groundwater, IHP objectives include promoting measures addressing the principles of sustainable management of groundwater resources, addressing methods for the sound development, exploitation and protection of groundwater resources, developing new groundwater resource maps, and strengthening groundwater governance policy and water user rights in emergency situations. These challenges call for comprehensive research, implementation of new science-based methodologies and the endorsement of principles of integrated management, and environmentally-sound protection of groundwater resources. The five focus areas for groundwater are: (i) enhancing sustainable groundwater resources management; (ii) addressing strategies for management of aquifers recharge; (iii) adapting to the impacts of climate change on aquifer systems; (iv) promoting groundwater quality protection; and (v) promoting management of transboundary aquifers. In 2006, IHP established the GRAPHIC (Groundwater Resources Assessment under the Pressures of Humanity and Climate Change) project in Africa to improve understanding of how groundwater contributes to the global water cycle and thus how it supports ecosystems and humankind (UNESCO website \& UNESCO-IHP 2006).

- FAO (Food \& Agriculture Organization), focuses on more efficient, equitable and environmentally friendly use of water in agriculture. Water-related issues identified by FAO include (i) producing more food while using less water; (ii) building resilience of farming communities to cope with floods and droughts; and (iii) applying clean water technologies that protect the environment. FAO works to modernize irrigation systems and is supporting intensification models that are clean and resource-efficient, raising the productivity of water across the domestic, industrial and agricultural uses. FAO programming includes groundwater governance efforts to deliver policy and institutional guidelines designed at local, national and transboundary levels. FAO promotes best practices in groundwater governance to achieve sustainable management of groundwater resources, including (i) promotion of pro-active drought and flood risk management policies; (ii) capacity building on early warning and regular information on threats; and (iii) support to increased water storage to buffer climate variability and change. FAO operates and maintains AQUASTAT, a global water information system, which is purportedly the most comprehensive and quoted source on global water statistics. It contains data and information by country on water resources, water uses, agricultural water management (FAO website). 
- UN-Water, is the United Nations inter-agency coordination mechanism for all freshwater related issues. It provides a platform to address the cross-cutting nature of water and maximize system-wide coordinated action and coherence. UN-Water promotes coherence in, and coordination of, UN system actions aimed at the implementation of the agenda defined by the SDGs. The scope of UN-Water's work encompasses all aspects of freshwater, including surface and groundwater resources, with a purpose to maximize system-wide coordinated action and coherence as well as effectiveness of the support provided to Member States in their efforts towards achieving time-bound goals, targets and actions related to its scope of work as agreed by the international community, particularly those contained in the SDGs. In 2014, the Integrated Monitoring initiative GEMI was established as an inter-agency initiative composed of United Nations Environment Programme (UNEP), the United Nations Human Settlements Programme (UN-Habitat), the United Nations Children's Fund (UNICEF), the Food and Agriculture Organization of the United Nations (FAO), the United Nations Educational, Scientific and Cultural Organization (UNESCO), the World Health Organization (WHO) and the World Meteorological Organization (WMO), operating under the UN-Water umbrella and complementing JMP and GLAAS. The longterm goal is to establish and manage, by 2030 , a coherent monitoring framework for water and sanitation to inform the post-2015 period, and contribute to country progress through well-informed decision-making on water, based on harmonized, comprehensive, timely and accurate information.

- Global Environment Facility - Transboundary Water Assessment Programme (GEFTWAP), provides the first global-scale assessment of transboundary waters and aims to provide improved knowledge for informed decision-making, raising awareness and fostering cooperation among all stakeholders about transboundary water issues. UNESCOIHP has been entrusted with the execution of the global Assessment of Transboundary Aquifers and Small Island Developing States (SIDS) Groundwater Systems. The TWAP Groundwater Assessment will be carried out jointly with a network of partners at national, regional and international level. The assessment strives to involve directly all countries sharing aquifers. Country involvement is considered an essential element of the TBA methodology, given the need to improve data availability, and to achieve mutual recognition of their shared nature (GEF-TWAP website).

- United Nations Environment Programme (UNEP), coordinates the Network On Urban Groundwater Vulnerability In Africa initiative through UNESCO-IHP, under the leadership of the UNEP Division of Early Warning and Assessment (DEWA). The project focuses on urban pollution of surficial and groundwater aquifers in Africa. The project was realized, in collaboration with UNCHS/Habitat (UNCHS/Habitat is implementing a project on Water for African cities which includes six African cities) and ECA who have been involved as regional and political partners. UNEP also coordinates the GEMStat program, the objective of which is to support global, regional, and national environmental assessment and reporting processes on the state and trends of water resources by providing access to quality-assured data and information on water quality in freshwater ecosystems worldwide. GEMStat is designed to share surface and ground water quality data sets collected from the GEMS/Water Global Network, including more than 3,700 stations, close to 4.3 million records, and over 100 parameters (UNEP website).

- UNDP Transboundary Water Program, is supporting over 100 countries in the preparation of cooperative governance / management frameworks for international basins, including major water bodies in Africa, such as the Nile, Okavango, Orange/Sengu, Senegal and Niger river basins (UNDP website). 
- International Atomic Energy Agency (IAEA), helps tackle some of the earth's most pressing water challenges by applying nuclear techniques in the fields of water resource assessment, agricultural water management and marine pollution control. IAEA engages in cooperative activities with major international and national partners, including the World Bank, Global Environmental Facility (GEF), UNESCO, World Meteorological Organization (WMO), the U.S. Geological Survey (USGS) and the French Research Institute for Development (IRD). The IAEA is sponsoring regional technical co-operation projects addressing practical issues related to water resources assessment and development in some parts of Africa. For example, one project seeks to strengthen isotope hydrology capacity to determine fast-moving (recent) groundwater and slow-moving (ancient) groundwater. Such projects aim to develop regional isotope hydrology expertise and facilities to provide data which in combination with those derived from conventional techniques will assist in guarding against economic and social disasters from groundwater mismanagement, particularly during extreme events (IAEA website).

Continental / regional organizations contributing to various aspects of groundwater development

The following list is a selection of continental / regional organizations are contributing to groundwater knowledge and development in SSA:

- Africa Groundwater Network (AGW-Net), was established to increase awareness of the potential and value of groundwater across Africa and to contribute to capacity building in the groundwater sector. AGW-Net objectives are to: (i) build capacity for improved groundwater management at all levels; (ii) promote IWRM practice in the groundwater sector; (iii) improve awareness of groundwater resources; (iv) foster groundwater research and academic cooperation; ( $v$ ) enhance the sharing of information; (vi) improve the level of integration between surface and groundwater practitioners; and (vii) provide a positive contribution to the realization of regional and continental development goals with regard to groundwater. The AGW-Net also acts as a meeting place for the African groundwater community and functions under the Cap-Net umbrella, cooperating with other networks within the Cap-Net affiliation (AGW-Net website).

- African Ministers' Council on Water (AMCOW) (\& Africa Groundwater Commission), was formed in 2002 in Abuja Nigeria, to promote cooperation, security, social and economic development, and poverty eradication among member states through the effective management of Africa's water resources and provision of water supply services in a bid to realize the 2025 Africa Water Vision. AMCOW has also being accorded the status of a Specialized Committee for Water and Sanitation in the African Union. The vision of AMCOW is to promote cooperation, security, social and economic development, and poverty eradication among member states through the effective management of Africa's water resources and provision of water supply services in a bid to realize the 2025 Africa Water Vision. The mission of AMCOW is to provide political leadership, policy direction and advocacy in the provision, use and management of water resources for sustainable social and economic development and maintenance of African ecosystems. As part of AMCOW, an Africa Groundwater Commission (AGWC) is also being operationalized.

- Southern African Development Community (Groundwater Management Institute (SADCGMI), has an objective to achieve development, peace and security, and economic growth, to alleviate poverty, enhance the standard and quality of life of the peoples of Southern Africa, and support the socially disadvantaged through regional integration, built on democratic principles and equitable and sustainable development. As an institute of SADC, 
SADC-GMI has an objective to support the sustainable management of groundwater at national and transboundary levels across SADC member states. SADC-GMI is intended to be a center of excellence for the region, with an initial focus on operationalizing objectives, strengthening institutional capacity; advancing knowledge on transboundary and national groundwater; and promoting groundwater infrastructure management and development. SADC partners include the World Bank, GEF, SADC Secretariat, Cooperation in International Waters in Africa (CIWA), University of the Free State, and Institute for Groundwater Studies (SADC website).

- The Intergovernmental Authority on Development (IGAD), in Eastern Africa was created in 1996 (superseding IGADD, founded in 1986) to address the recurring and severe droughts and other natural disasters in the region which were causing widespread famine, ecological degradation and economic hardship. This regional approach supplemented national efforts. The mission of IGAD is to assist and complement the efforts of the Member States to achieve, through increased cooperation on (i) food security and environmental protection; (ii) promotion and maintenance of peace and security and humanitarian affairs; and (iii) economic cooperation and integration. Its objectives are to: (i) promote joint development strategies and gradually harmonize macro-economic policies and programs in the social, technological and scientific fields; (ii) harmonize policies with regard to trade, customs, transport, communications, agriculture, and natural resources, and promote free movement of goods, services, and people within the region; (iii) create an enabling environment for foreign, cross-border and domestic trade and investment; (iv) achieve regional food security and encourage and assist efforts of Member States to collectively combat drought and other natural and man-made disasters and their natural consequences; $(\mathrm{v})$ initiate and promote programs and projects to achieve regional food security and sustainable development of natural resources and environment protection, and encourage and assist efforts of Member States to collectively combat drought and other natural and man-made disasters and their consequences; (vi) develop and improve a coordinated and complementary infrastructure, in the areas of transport, telecommunications and energy in the region; (vii) promote peace and stability in the region and create mechanisms within the region for the prevention, management and resolution of inter-State and intra-State conflicts through dialogue; (viii) mobilize resources for the implementation of emergency, short-term, medium-term and long-term programs within the framework of regional cooperation; (ix) promote and realize the objectives of the Common Market for Eastern and Southern Africa (COMESA) and the African Economic Community; and $(x)$ facilitate, promote and strengthen cooperation in research development and application in science and technology (IGAD website).

- The African Network of Basin Organizations (ANBO) (a regional basin organization of INBO), promotes communication and exchange of experiences, expertise and know-how, between its members, related to IWRM per basin. The ANBO endeavors to: (i) develop cooperation between the organizations in charge of IWRM and to favor exchange of experiences and expertise among them; (ii) participate actively in policy formulation and implementation, bringing in experience of practice, as well as to carry out diagnostics, analysis enabling the harmonization of policy, strategies and practices at national level, as well as the level of basins and sub-basins; (iii) promote and strengthen existing organizations and to encourage the creation of new basin organizations; (iv) facilitate development of tools suitable for institutional and financial management, for knowledge and monitoring of water resources, for the organization of data bases, for the concerted preparation of master plans and action programs in the medium and long term; (v) 
strengthen and network the existing documentation and information centers of the member organizations, to produce, exchange, synthesize and disseminate knowledge and know-how of IWRM, in collaboration with their regional and international partners and to support the creation of new water-related documentation and information systems in the organizations which have none; (vi) develop information and train personnel, to carry out studies and to prepare educational material; (vii) promote IWRM principles per basin in international co-operation programs; (viii) evaluate actions initiated by the member organizations and disseminate their results; (ix) organize joint activities of regional interest between its members and to support their actions in obtaining finance, in particular; $(x)$ support the African Ministers Council on Water (AMCOW), to meet its specific requests on management per basin and implement its orientations in this field (International Network of River Basins Organizations website).

- The Cooperation in International Waters in Africa (CIWA) program, assists riparian governments in SSA in unlocking the potential for sustainable, climate-resilient growth by addressing constraints to cooperative water resources management and development. CIWA funds a variety of organizations - governments, river basin organizations, regional economic communities, civil society organizations, and African regional or national organizations - to address the constraints of cooperative transboundary water management. Managed by the World Bank, CIWA is uniquely poised to provide neutral third-party facilitation, technical support, and critical analysis to better understand transboundary water issues and inform decisions. CIWA supported activities - which cut across sectors including energy, agriculture, transportation, social issues, and the environment - assist the World Bank's clients to utilize transboundary resources productively and equitably, protecting people and property from water-related shocks, and ensuring the sustainability of the resource base (World Bank website).

- University of the Free State, Institute for Groundwater Studies (IGS), is one of the leading groundwater research groups in Africa on aspects related to fractured rock aquifers, industrial and mining contamination, groundwater governance and groundwater resources. The IGS has expertise in the following fields of geohydrology: groundwater research; laboratory services; groundwater in a mining environment; development of groundwater monitoring programs; hydrogeological and contaminant investigations; reserve determinations; geochemical assessments; groundwater software development; acid-mine drainage prediction and management; assessment of groundwater pollution; groundwater risk assessments; groundwater resource development and management; environmental management program reports for the mining industry; geohydrological impact assessments at industries and landfills; project management for groundwaterrelated projects; geophysical investigation; and manipulation and integration of GIS data.

- The Alliance for a Green Revolution in Africa (AGRA), is an alliance led by Africans with roots in farming communities across the continent. AGRA's vision is that Africa can feed itself and the world by changing agriculture in Africa from farming as a solitary struggle to survive, to farming as a business that thrives. AGRA is collaborating with groups such as IWMI to enhance the role of groundwater in providing improved food security and livelihoods in AGRA-targeted countries. Objectives include assessing groundwater availability and sustainability, including the impacts associated with its use and role in adapting to climate change; identifying opportunities and constraints in using groundwater, and provide advice to investors in groundwater interventions; and developing a groundwater strategy for the region (AGRA website \& IWMI). 


\section{National organizations contributing to various aspects of groundwater development}

Some national-level organizations are also contributing to groundwater development. Notable progress on groundwater development is being made by some national ministries (typically Water ministries) with leading examples coming from countries such as South Africa.

Most notable of these are African geological surveys and public-sector water departments. African geological surveys, water departments and allied public sector organizations and authorities are mandated to collect and store data and information on groundwater occurrence and use, and to make it available for legitimate use. In many cases, capacity and funding constraints limit the extent to which this task can be fulfilled. Decentralization initiatives in some countries (e.g. Zimbabwe) have devolved groundwater data collection and storage to regional or basin level, and this can make accessing information by parties outside of the region or basin more difficult. Collaboration between African geological surveys and other partners underpinned the 2010 publication of the first hydrogeological map of the SADC region. 
Annex 6 - Matrix of national-level water assessments, with special attention to vulnerability and to potential for sustainable groundwater resource development

\begin{tabular}{|c|c|c|c|c|c|c|c|}
\hline \multirow[t]{2}{*}{ SSA Country } & \multirow{2}{*}{$\begin{array}{c}\text { IDA } \\
\text { Eligibility }\end{array}$} & \multicolumn{2}{|c|}{ Water Stress } & \multirow{2}{*}{$\begin{array}{l}\text { Vulnerability of } \\
\text { national fresh water } \\
\text { supplies to climate } \\
\text { change }\end{array}$} & \multirow{2}{*}{$\begin{array}{l}\text { Drought } \\
\text { Vulnerability } \\
\text { Indicator }\end{array}$} & \multirow{2}{*}{$\begin{array}{c}\text { Percentage } \\
\text { Groundwater Used }\end{array}$} & \multirow[t]{2}{*}{ National Synopsis } \\
\hline & & Present & Future & & & & \\
\hline Angola & & Low-Moderate & Low-Moderate & $\begin{array}{c}\text { Moderate-High } \\
(0.381)\end{array}$ & Moderate & $\begin{array}{l}\text { Low } \\
(0.7)\end{array}$ & $\begin{array}{l}\text { Not IDA eligible; low-moderate water stress; } \\
\text { moderate-high / moderate vulnerability } \\
\text { measures; virtually no groundwater } \\
\text { potential being utilized. }\end{array}$ \\
\hline Benin & $\mathrm{v}$ & Low & Low & $\begin{array}{l}\text { High } \\
(0.417)\end{array}$ & Moderate & $\begin{array}{l}\text { Low } \\
(9.4)\end{array}$ & $\begin{array}{c}\text { IDA eligible; low water stress; high / } \\
\text { moderate vulnerability measures; low } \\
\text { proportion of groundwater potential being } \\
\text { utilized. }\end{array}$ \\
\hline Botswana & & Low-Moderate & High & $\begin{array}{l}\text { Moderate } \\
(0.304)\end{array}$ & Low & $\begin{array}{l}\text { Low } \\
(8.2)\end{array}$ & $\begin{array}{l}\text { Not IDA eligible; high future water stress; } \\
\text { moderate / low vulnerability measures; low } \\
\text { proportion of groundwater potential being } \\
\text { utilized. }\end{array}$ \\
\hline Burkina Faso & 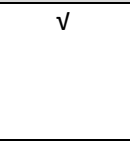 & Low & Low & $\begin{array}{c}\text { Moderate-High } \\
(0.398)\end{array}$ & Moderate & $\begin{array}{l}\text { Low } \\
(4.1)\end{array}$ & $\begin{array}{l}\text { IDA eligible; low water stress; moderate-high } \\
\text { / moderate vulnerability measures; low } \\
\text { proportion of groundwater potential being } \\
\text { utilized. }\end{array}$ \\
\hline Burundi & $\mathrm{v}$ & Low & Low & $\begin{array}{l}\text { Low } \\
(0.198)\end{array}$ & High & $\begin{array}{l}\text { Low } \\
(2.1)\end{array}$ & $\begin{array}{l}\text { IDA eligible; low water stress; low / high } \\
\text { vulnerability measures; small proportion of } \\
\text { groundwater potential being utilized. }\end{array}$ \\
\hline Cabo Verde & $\mathrm{v}$ & & & $\begin{array}{l}\text { Low-Moderate } \\
(0.274)\end{array}$ & & & $\begin{array}{l}\text { IDA eligible; low-moderate vulnerability of } \\
\text { national fresh water supplies to climate } \\
\text { change. Otherwise, assessment information } \\
\text { limited. }\end{array}$ \\
\hline Cameroon & $\mathrm{v}$ & Low & Low & $\begin{array}{l}\text { Moderate } \\
(0.334)\end{array}$ & Low-Moderate & $\begin{array}{l}\text { Low } \\
(0.4)\end{array}$ & $\begin{array}{c}\text { IDA eligible; low water stress; moderate / } \\
\text { low-moderate vulnerability measures; } \\
\text { virtually no groundwater potential being } \\
\text { utilized. }\end{array}$ \\
\hline $\begin{array}{l}\text { Central African } \\
\text { Republic }\end{array}$ & $\mathrm{V}$ & Low & Low & $\begin{array}{l}\text { Low-Moderate } \\
(0.228)\end{array}$ & Moderate-High & $\begin{array}{l}\text { Low } \\
(0.1)\end{array}$ & $\begin{array}{l}\text { IDA eligible; low water stress; low-moderate } \\
\text { / moderate-high vulnerability measures; } \\
\text { virtually no groundwater potential being } \\
\text { utilized. }\end{array}$ \\
\hline Chad & $\mathrm{v}$ & Low & Low & $\begin{array}{l}\text { High } \\
(0.440)\end{array}$ & High & $\begin{array}{l}\text { Low } \\
\text { (3.9) }\end{array}$ & $\begin{array}{l}\text { IDA eligible; low water stress; high } \\
\text { vulnerability measures; small proportion of } \\
\text { groundwater potential being utilized. }\end{array}$ \\
\hline
\end{tabular}




\begin{tabular}{|c|c|c|c|c|c|c|c|}
\hline SSA Country & IDA & \multicolumn{2}{|c|}{ Water Stress } & Vulnerability of & Drought & Percentage & National Synopsis \\
\hline Comoros & $\mathrm{v}$ & & & $\begin{array}{l}\text { Low } \\
(0.115)\end{array}$ & & & $\begin{array}{l}\text { IDA eligible; low vulnerability of national } \\
\text { fresh water supplies to climate change. } \\
\text { Otherwise, assessment information limited. }\end{array}$ \\
\hline $\begin{array}{l}\text { Congo, } \\
\text { Democratic } \\
\text { Republic }\end{array}$ & v & Low & Low & $\begin{array}{l}\text { High } \\
(0.455)\end{array}$ & Moderate-High & $\begin{array}{l}\text { Low } \\
(0.3)\end{array}$ & $\begin{array}{c}\text { IDA eligible; low water stress; high / } \\
\text { moderate-high vulnerability measures; } \\
\text { virtually no groundwater potential being } \\
\text { utilized. }\end{array}$ \\
\hline $\begin{array}{l}\text { Congo, Republic } \\
\text { of }\end{array}$ & $\mathrm{v}$ & Low & Low & $\begin{array}{l}\text { High } \\
(0.442)\end{array}$ & Moderate & $\begin{array}{l}\text { Low } \\
(0.0)\end{array}$ & $\begin{array}{l}\text { IDA eligible; low water stress; high / } \\
\text { moderate vulnerability measures; no } \\
\text { groundwater potential being utilized. }\end{array}$ \\
\hline Cote D'Ivoire & $\mathrm{v}$ & Low & Low & $\begin{array}{c}\text { Low-Moderate } \\
(0.291)\end{array}$ & Moderate & $\begin{array}{l}\text { Low } \\
\text { (1.0) }\end{array}$ & $\begin{array}{l}\text { IDA eligible; low water stress; low-moderate } \\
\text { / moderate vulnerability measures; virtually } \\
\text { no groundwater potential being utilized. }\end{array}$ \\
\hline $\begin{array}{l}\text { Equatorial } \\
\text { Guinea }\end{array}$ & & Low & Low & $\begin{array}{c}\text { Low-Moderate } \\
(0.244)\end{array}$ & Low-Moderate & $\begin{array}{l}\text { Low } \\
(0.1)\end{array}$ & $\begin{array}{l}\text { Not IDA eligible; low water stress; low- } \\
\text { moderate vulnerability measures; virtually } \\
\text { no groundwater potential being utilized. }\end{array}$ \\
\hline Eritrea & v & High & High & $\begin{array}{l}\text { High } \\
(0.464)\end{array}$ & Moderate & $\begin{array}{l}\text { Low } \\
(18.0)\end{array}$ & $\begin{array}{l}\text { IDA eligible; high water stress; high / } \\
\text { moderate vulnerability measures; low but } \\
\text { noteworthy groundwater potential being } \\
\text { utilized. }\end{array}$ \\
\hline Ethiopia & v & Low & Low & $\begin{array}{l}\text { High } \\
(0.447)\end{array}$ & High & $\begin{array}{l}\text { Low } \\
(7.5)\end{array}$ & $\begin{array}{l}\text { IDA eligible; low water stress; high } \\
\text { vulnerability measures; low groundwater } \\
\text { potential being utilized. }\end{array}$ \\
\hline Gabon & & Low-Moderate & Low & $\begin{array}{l}\text { Low-Moderate } \\
(0.300)\end{array}$ & Low & $\begin{array}{l}\text { Low } \\
(0.0)\end{array}$ & $\begin{array}{l}\text { Not IDA eligible; low-moderate water stress; } \\
\text { low-moderate / low vulnerability measures; } \\
\text { no groundwater potential being utilized. }\end{array}$ \\
\hline Gambia, The & v & Low & Low & $\begin{array}{c}\text { Low-Moderate } \\
(0.276)\end{array}$ & Low-Moderate & $\begin{array}{l}\text { Low } \\
(6.0)\end{array}$ & $\begin{array}{l}\text { IDA eligible; low water stress; low-moderate } \\
\text { vulnerability measures; low groundwater } \\
\text { potential being utilized. }\end{array}$ \\
\hline Ghana & v & Low & Low & $\begin{array}{l}\text { Low } \\
(0.219)\end{array}$ & Low & $\begin{array}{l}\text { Low } \\
(1.9)\end{array}$ & $\begin{array}{c}\text { IDA eligible; low water stress; low } \\
\text { vulnerability measures; low groundwater } \\
\text { potential being utilized. }\end{array}$ \\
\hline Guinea & $\mathrm{v}$ & Low & Low & $\begin{array}{l}\text { Moderate } \\
(0.319)\end{array}$ & Moderate & $\begin{array}{l}\text { Low } \\
(0.2)\end{array}$ & $\begin{array}{l}\text { IDA eligible; low water stress; moderate } \\
\text { vulnerability measures; virtually no } \\
\text { groundwater potential being utilized. }\end{array}$ \\
\hline Guinea-Bissau & $\mathrm{v}$ & Low & Low & $\begin{array}{c}\text { Low-Moderate } \\
(0.282)\end{array}$ & High & $\begin{array}{l}\text { Low } \\
(0.2)\end{array}$ & $\begin{array}{l}\text { IDA eligible; low water stress; low-moderate } \\
\text { / high vulnerability measures; virtually no } \\
\text { groundwater potential being utilized. }\end{array}$ \\
\hline Kenya & $\mathrm{v}$ & Low & Low & $\begin{array}{l}\text { High } \\
(0.501)\end{array}$ & Low-Moderate & $\begin{array}{l}\text { Low } \\
(17.7)\end{array}$ & $\begin{array}{l}\text { IDA eligible; low water stress; high / low- } \\
\text { moderate vulnerability measures; low but } \\
\text { noteworthy groundwater potential being } \\
\text { utilized. }\end{array}$ \\
\hline
\end{tabular}




\begin{tabular}{|c|c|c|c|c|c|c|c|}
\hline SSA Country & IDA & \multicolumn{2}{|c|}{ Water Stress } & Vulnerability of & Drought & Percentage & National Synopsis \\
\hline Lesotho & $\mathrm{v}$ & High & Low-Moderate & $\begin{array}{c}\text { Low } \\
(0.203)\end{array}$ & Low & $\begin{array}{l}\text { Low } \\
(4.0)\end{array}$ & $\begin{array}{l}\text { IDA eligible; high current water stress; low } \\
\text { vulnerability measures; low groundwater } \\
\text { potential being utilized. }\end{array}$ \\
\hline Liberia & $\mathrm{V}$ & Low & Low & $\begin{array}{l}\text { Moderate-High } \\
(0.383)\end{array}$ & Moderate-High & $\begin{array}{l}\text { Low } \\
(0.2)\end{array}$ & $\begin{array}{l}\text { IDA eligible; low water stress; moderate-high } \\
\text { vulnerability measures; virtually no } \\
\text { groundwater potential being utilized. }\end{array}$ \\
\hline Madagascar & $\mathrm{V}$ & Low-Moderate & Low & $\begin{array}{l}\text { High } \\
(0.455)\end{array}$ & Moderate & $\begin{array}{l}\text { Low } \\
(0.7)\end{array}$ & $\begin{array}{l}\text { IDA eligible; generally low water stress; high } \\
\text { / moderate vulnerability measures; virtually } \\
\text { no groundwater potential being utilized. }\end{array}$ \\
\hline Malawi & $\sqrt{ }$ & Low & Low & $\begin{array}{l}\text { Low-Moderate } \\
(0.291)\end{array}$ & Moderate-High & $\begin{array}{l}\text { Low } \\
(11.2)\end{array}$ & $\begin{array}{c}\text { IDA eligible; low water stress; moderate / } \\
\text { moderate-high vulnerability measures; low } \\
\text { but noteworthy groundwater potential being } \\
\text { utilized. }\end{array}$ \\
\hline Mali & $\mathrm{V}$ & Low & Low & $\begin{array}{l}\text { High } \\
(0.439)\end{array}$ & High & $\begin{array}{l}\text { Low } \\
(1.7)\end{array}$ & $\begin{array}{l}\text { IDA eligible; low water stress; high } \\
\text { vulnerability measures; low groundwater } \\
\text { potential being utilized. }\end{array}$ \\
\hline Mauritania & $\mathrm{v}$ & Low & Low & $\begin{array}{l}\text { High } \\
(0.438)\end{array}$ & Moderate-High & $\begin{array}{l}\text { High } \\
(253.3)\end{array}$ & $\begin{array}{c}\text { IDA eligible; low water stress; high / } \\
\text { moderate-high vulnerability measures; } \\
\text { unsustainably high groundwater potential } \\
\text { being utilized. }\end{array}$ \\
\hline Mauritius & & & & $\begin{array}{l}\text { Moderate } \\
(0.313)\end{array}$ & & & $\begin{array}{c}\text { IDA ineligible; moderate vulnerability of } \\
\text { national fresh water supplies to climate } \\
\text { change. Otherwise, assessment information } \\
\text { limited }\end{array}$ \\
\hline Mozambique & $\mathrm{v}$ & Low & Low & $\begin{array}{l}\text { Moderate-High } \\
(0.398)\end{array}$ & Moderate-High & $\begin{array}{l}\text { Low } \\
(2.6)\end{array}$ & $\begin{array}{l}\text { IDA eligible; low water stress; moderate-high } \\
\text { vulnerability measures; low groundwater } \\
\text { potential being utilized. }\end{array}$ \\
\hline Namibia & & Low-Moderate & High & $\begin{array}{l}\text { Moderate } \\
(0.317)\end{array}$ & Low-Moderate & $\begin{array}{l}\text { Low } \\
(7.1)\end{array}$ & $\begin{array}{l}\text { IDA ineligible; high future water stress; } \\
\text { moderate / low-moderate vulnerability } \\
\text { measures; low groundwater potential being } \\
\text { utilized. }\end{array}$ \\
\hline Niger & $\mathrm{V}$ & Low & Low & $\begin{array}{l}\text { High } \\
(0.673)\end{array}$ & High & $\begin{array}{l}\text { Low } \\
(5.6)\end{array}$ & $\begin{array}{l}\text { IDA eligible; low water stress; high } \\
\text { vulnerability measures; low groundwater } \\
\text { potential being utilized. }\end{array}$ \\
\hline Nigeria & $\mathrm{v}$ & Low & Low & $\begin{array}{l}\text { High } \\
(0.422)\end{array}$ & High & $\begin{array}{l}\text { Low } \\
(4.0)\end{array}$ & $\begin{array}{l}\text { IDA eligible; low water stress; high } \\
\text { vulnerability measures; low groundwater } \\
\text { potential being utilized. }\end{array}$ \\
\hline Rwanda & $\mathrm{v}$ & Low & Low & $\begin{array}{l}\text { Low } \\
(0.216)\end{array}$ & Moderate-High & $\begin{array}{l}\text { Low } \\
(2.9)\end{array}$ & $\begin{array}{l}\text { IDA eligible; low water stress; low / } \\
\text { moderate-high vulnerability measures; low } \\
\text { groundwater potential being utilized. }\end{array}$ \\
\hline $\begin{array}{l}\text { Sao Tome and } \\
\text { Principe }\end{array}$ & $\mathrm{v}$ & & & $\begin{array}{l}\text { Low } \\
(0.141)\end{array}$ & & & $\begin{array}{l}\text { IDA ineligible; low vulnerability of national } \\
\text { fresh water supplies to climate change. }\end{array}$ \\
\hline
\end{tabular}




\begin{tabular}{|c|c|c|c|c|c|c|c|}
\hline SSA Country & IDA & \multicolumn{2}{|c|}{ Water Stress } & Vulnerability of & Drought & Percentage & National Synopsis \\
\hline & & & & & & & Otherwise, assessment information limited. \\
\hline Senegal & $\mathrm{v}$ & Low & Low & $\begin{array}{l}\text { High } \\
(0.424)\end{array}$ & Moderate & $\begin{array}{l}\text { Low } \\
(21.1)\end{array}$ & $\begin{array}{c}\text { IDA eligible; low water stress; high / } \\
\text { moderate vulnerability measures; low but } \\
\text { noteworthy groundwater potential being } \\
\text { utilized. }\end{array}$ \\
\hline Seychelles & & & & & & & $\begin{array}{l}\text { IDA ineligible; assessment information } \\
\text { limited. }\end{array}$ \\
\hline Sierra Leone & $\mathrm{v}$ & Low & Low & $\begin{array}{l}\text { Moderate-High } \\
\quad(0.385)\end{array}$ & High & $\begin{array}{l}\text { Low } \\
(0.4)\end{array}$ & $\begin{array}{l}\text { IDA eligible; low water stress; moderate-high } \\
\text { / high vulnerability measures; virtually no } \\
\text { groundwater potential being utilized. }\end{array}$ \\
\hline Somalia & $\mathrm{v}$ & Low & Low-Moderate & $\begin{array}{l}\text { High } \\
(0.542)\end{array}$ & High & $\begin{array}{l}\text { Low } \\
(8.5)\end{array}$ & $\begin{array}{l}\text { IDA eligible; generally low water stress; high } \\
\text { vulnerability measures; low groundwater } \\
\text { potential being utilized. }\end{array}$ \\
\hline South Africa & & High & High & $\begin{array}{l}\text { Moderate } \\
(0.300)\end{array}$ & Low & $\begin{array}{l}\text { Moderate } \\
(65.4)\end{array}$ & $\begin{array}{l}\text { IDA ineligible; high water stress; moderate / } \\
\text { low vulnerability measures; moderate } \\
\text { groundwater potential being utilized. }\end{array}$ \\
\hline South Sudan & $\mathrm{v}$ & Low & Low & & Moderate-High & Low & $\begin{array}{l}\text { IDA eligible; low water stress; moderate-high } \\
\text { drought vulnerability measure; low but } \\
\text { noteworthy groundwater potential being } \\
\text { utilized. }\end{array}$ \\
\hline Sudan & $\mathrm{v}$ & Low & Low-Moderate & $\begin{array}{l}\text { High } \\
(0.692)\end{array}$ & Moderate-High & (8.4) & $\begin{array}{l}\text { IDA eligible; generally low water stress; high } \\
\text { / moderate-high vulnerability measures; low } \\
\text { but noteworthy groundwater potential being } \\
\text { utilized. }\end{array}$ \\
\hline Swaziland & & High & Moderate-High & $\begin{array}{l}\text { High } \\
(0.425)\end{array}$ & Low-Moderate & $\begin{array}{l}\text { Low } \\
(6.1)\end{array}$ & $\begin{array}{l}\text { IDA ineligible; high / moderate-high water } \\
\text { stress; high / low-moderate vulnerability } \\
\text { measures; low groundwater potential being } \\
\text { utilized. }\end{array}$ \\
\hline Tanzania & $\mathrm{v}$ & Low-Moderate & Low-Moderate & $\begin{array}{l}\text { Moderate-High } \\
\quad(0.366)\end{array}$ & Low-Moderate & $\begin{array}{l}\text { Low } \\
(3.3)\end{array}$ & $\begin{array}{l}\text { IDA eligible; low-moderate water stress; } \\
\text { moderate-high / low-moderate vulnerability } \\
\text { measures; low groundwater potential being } \\
\text { utilized. }\end{array}$ \\
\hline Togo & $\mathrm{v}$ & Low & Low & $\begin{array}{l}\text { Moderate-High } \\
\quad(0.354)\end{array}$ & Moderate-High & $\begin{array}{l}\text { Low } \\
(1.9)\end{array}$ & $\begin{array}{c}\text { IDA eligible; low water stress; moderate-high } \\
\text { vulnerability measures; low groundwater } \\
\text { potential being utilized. }\end{array}$ \\
\hline Uganda & $\mathrm{V}$ & Low & Low & $\begin{array}{l}\text { Moderate } \\
(0.328)\end{array}$ & Low & $\begin{array}{l}\text { Low } \\
(2.1)\end{array}$ & $\begin{array}{l}\text { IDA eligible; low water stress; moderate / } \\
\text { low vulnerability measures; low } \\
\text { groundwater potential being utilized. }\end{array}$ \\
\hline Zambia & $\mathrm{v}$ & Low & Low & $\begin{array}{l}\text { Low } \\
(0.230)\end{array}$ & Low-Moderate & $\begin{array}{l}\text { Low } \\
(0.6)\end{array}$ & $\begin{array}{l}\text { IDA eligible; low water stress; low / low- } \\
\text { moderate vulnerability measures; virtually } \\
\text { no groundwater potential being utilized. }\end{array}$ \\
\hline Zimbabwe & $\mathrm{v}$ & Low & Low-Moderate & Moderate & Low-Moderate & Low & IDA eligible; generally low water stress; \\
\hline
\end{tabular}




\begin{tabular}{|c|c|c|c|c|c|c|}
\hline SSA Country & IDA & Water Stress & Vulnerability of & Drought & Percentage & $\begin{array}{c}\text { National Synopsis } \\
\text { moderate / low-moderate vulnerability } \\
\end{array}$ \\
& & & & $(0.300)$ & & $\begin{array}{c}\text { measures; low but noteworthy groundwater } \\
\text { potential being utilized. }\end{array}$ \\
\hline
\end{tabular}

Caveats to the analysis in the matrix above include: (i) the indicators come from different sources, and hence methodologies and consideration of groundwater resources are not consistent; (ii) national-level assessments do not capture the variability across regions within countries (for example, a country assessment may reveal low overall water stress or vulnerability, but have select areas where water stress is high); and (iii) sustainable groundwater resource development potential is high across all countries (except Mauritania), meaning groundwater development should be considered as part of an integrated water resources strategy for all SSA countries.

\section{Description of matrix indicators}

\begin{tabular}{|c|c|c|}
\hline Indicator & Indicator Description / Calculation & Source \\
\hline IDA eligibility & $\begin{array}{l}\text { Eligibility for IDA support depends first and foremost on a country's relative poverty, defined as GNI per capita } \\
\text { below an established threshold and updated annually ( } \$ 1,165 \text { in fiscal year 2018). Some countries (such as Nigeria) } \\
\text { are IDA-eligible based on per capita income levels and are also creditworthy for some IBRD borrowing. They are } \\
\text { referred to as "blend" countries. } \\
\text { In the matrix, countries in SSA eligible for IDA support are identified. }\end{array}$ & World Bank. \\
\hline Water stress & $\begin{array}{l}\text { Water stress is defined as the ratio between total water withdrawals and available renewable (surface water, } \\
\text { including shallow groundwater) water at a sub-catchment level. Higher levels of water stress correspond to greater } \\
\text { competition among water users relative to available water resources. The model used in the paper models } \\
\text { precipitation being made available for consumption in the form of surface and shallow groundwater. } \\
\text { Present: Baseline water stress measures total annual water withdrawals expressed as a percentage of the total } \\
\text { annual available blue water. Baseline water stress is a particularly important indicator to understand when } \\
\text { evaluating water-related risks. It measures the ratio of total water withdrawals (by industry, agriculture, and } \\
\text { domestic users) to the available supply, considering upstream uses and depletion of water. A global ranking of } \\
\text { baseline water stress for all countries is provided in the paper. } \\
\text { Future: The rankings provided in the matrix draw from a global analysis of Aqueduct projected country water stress } \\
\text { ranking for } 2040 \text { under business-as-usual scenario. } \\
\text { Rankings for present and future water stress are extracted from the papers (see sources in column adjacent) and } \\
\text { rated as low, low-medium, medium, medium-high, and high. }\end{array}$ & 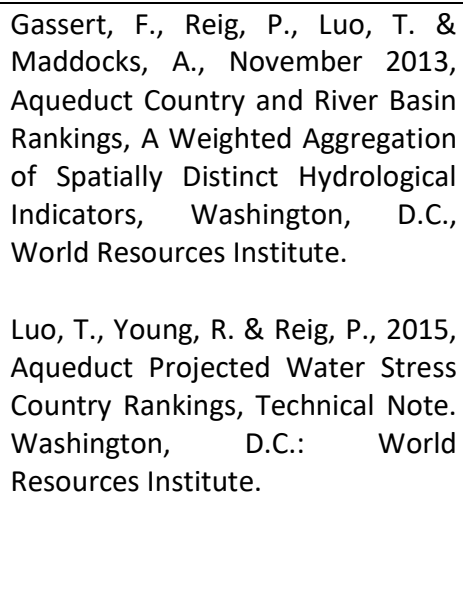 \\
\hline
\end{tabular}




\begin{tabular}{|c|c|c|}
\hline $\begin{array}{l}\text { Vulnerability of } \\
\text { national fresh } \\
\text { water supplies } \\
\text { to climate } \\
\text { change }\end{array}$ & $\begin{array}{l}\text { The ND-GAIN Country Index is a measurement tool that helps governments, businesses and communities examine } \\
\text { risks exacerbated by climate change. A Country Index uses } 20 \text { years of data across } 45 \text { indicators to rank } 181 \\
\text { countries annually based on their level of vulnerability (and their readiness to successfully implement adaptation } \\
\text { solutions). Vulnerability measures a country's exposure, sensitivity and ability to adapt to the negative impact of } \\
\text { climate change. ND-GAIN measures the overall vulnerability by considering vulnerability in six life-supporting } \\
\text { sectors, including water. } \\
\text { The Water score captures a country's vulnerability of fresh water supplies to climate change. Indicators include: } \\
\text { projected change of annual runoff, projected change of annual groundwater recharge, fresh water withdrawal rate, } \\
\text { water dependency ratio, dam capacity, and access to reliable drinking water. } \\
\text { Of } 177 \text { countries ranked globally for vulnerability of fresh water supplies to climate change, the following } \\
\text { categorizations are made for low, low-moderate, moderate, moderate-high and high vulnerability. } \\
1^{\text {st }}-35^{\text {th }} \\
36^{\text {th }}-70^{\text {th }} \quad \text { Low ranking } \\
71^{\text {st }}-105^{\text {th }} \quad \text { Moderate ranking } \\
105^{\text {th }}-140^{\text {th }} \text { Moderate-High ranking } \\
141^{\text {st }}-177^{\text {th }} \quad \text { High ranking } \\
\text { Three of the four most vulnerable countries in the world are in SSA (Sudan (most vulnerable), Niger (2 } \\
\text { vulnerable) and Somalia } 4^{\text {th }} \text { most vulnerable). }\end{array}$ & $\begin{array}{l}\text { ND-GAIN (www.gain.nd.edu }) \\
\text { Notre Dame Global Adaptation } \\
\text { Initiative }\end{array}$ \\
\hline $\begin{array}{l}\text { Drought } \\
\text { vulnerability } \\
\text { indicator }\end{array}$ & $\begin{array}{l}\text { A composite drought vulnerability indicator (DVI) reflects different aspects of drought vulnerability for four } \\
\text { components: the renewable natural capital, the economic capacity, the human and civic resources, and the } \\
\text { infrastructure and technology. The selection of DVI variables and weights reflects the assumption that a society with } \\
\text { institutional capacity and coordination, as well as with mechanisms for public participation, is less vulnerable to } \\
\text { drought. } \\
\text { SSA countries classified with higher relative drought vulnerability are Somalia, Burundi, Niger, Ethiopia, Mali and } \\
\text { Chad. The analysis of the renewable natural capital component at sub-basin level shows that the basins with high to } \\
\text { moderate drought vulnerability can be subdivided into the following geographical regions: the Mediterranean coast } \\
\text { of Africa; the Sahel region and the Horn of Africa; the Serengeti and the Eastern Miombo woodlands in eastern } \\
\text { Africa; the western part of the Zambezi Basin, the southeastern border of the Congo Basin, and the belt of Fynbos in } \\
\text { the Western Cape province of South Africa. } \\
\text { Comparison of the DVI at the country level with drought disaster information from the EM-DAT disaster database } \\
\text { produced a good agreement between the drought vulnerability maps and the number of persons affected by } \\
\text { droughts. }\end{array}$ & $\begin{array}{l}\text { Naumann, G., Barbosa, P., Garrote, } \\
\text { L., Iglesias, A. \& Vogt, J., May 2014, } \\
\text { Exploring drought vulnerability in } \\
\text { Africa: an indicator based analysis } \\
\text { to be used in early warning } \\
\text { systems, Hydrology and Earth } \\
\text { System Sciences, 18(5):1591-1604. }\end{array}$ \\
\hline
\end{tabular}




\begin{tabular}{|l|l|l|}
\hline & DVI map published in the journal article. & \\
\hline $\begin{array}{l}\text { Percentage } \\
\text { groundwater } \\
\text { used }\end{array}$ & $\begin{array}{l}\text { Percentage groundwater used is the average annual renewable groundwater volume available for each country, } \\
\text { divided by the estimated groundwater withdrawals. Aggregation of this data to national level can obscure over- } \\
\text { abstraction "hotspots", but it does provide a general indication of groundwater availability. Fossil groundwater } \\
\text { resources, which are substantial in some countries, are not included. }\end{array}$ \\
$\begin{array}{l}\text { The rankings of low, low-moderate, moderate, moderate-high and high in the matrix have been calculated } \\
\text { according to the \% of groundwater potential currently being used: } \\
0-25 \% \quad \text { Low ranking } \\
25-50 \% \quad \text { Low-Moderate ranking } \\
50-75 \% \quad \text { Moderate ranking } \\
75-100 \% \quad \text { Moderate-High ranking } \\
>100 \% \quad \text { High ranking }\end{array}$ \\
$\begin{array}{ll}\text { Of all the SSA countries, only Mauritania is over-exploiting its national groundwater resources. The vast majority of } \\
\text { countries are ranked as low, with significant potential for sustainable groundwater resources development. }\end{array}$ \\
\hline $\begin{array}{l}\text { National } \\
\text { Synopsis }\end{array}$ & $\begin{array}{l}\text { Provides a brief overview of each country's national water resources and supply assessment, with countries } \\
\text { highlighted red where sustainable groundwater development may have high potential to contribute to urban water } \\
\text { security, irrigated agriculture and drought resilience. }\end{array}$ & N/A \\
\hline
\end{tabular}


Annex 7-A guide for developing a specialized center for Advanced Water Studies with special focus on the impact of climate change on water resources

A: Development Objectives: A specialized center for Water Studies would provide a forum for interdisciplinary and comparative research relating to water policy and assessment of technology for water supply and irrigation, water resources management, water governance and water institutions both formal and water users. An important dimension of the development objective is to enhance understanding of increasing water scarcity in the country and the need to develop scientific tools for water policy including allocation to competing sectors at national and local levels. The Center would establish a knowledge base for water resources management to help policy makers and practitioners to design responsive and effective policy and development agenda for the efficient use of water for WSS, agriculture and use of non-conventional water resources and other development activities.

B: Research and Education Framework: The center would conduct:

- Research: collaborative, interdisciplinary research on water policy and economics of water management, water technologies, water resources and development within national and regional issues.

- Education: strengthen and expand water related education at the university, including distance learning and applied field studies.

- Partnerships and capacity building: undertake joint projects with academic and NGO partners at regional and national levels and where possible international partners, and develop proposals in response to expressed needs of practitioners/water professionals.

- Public debate and Extension and Training: enhance informed, critical debate on water resources and development and prepare training programs for field practitioners and water users and NGOs concerned with water services and quality enhancement of water systems.

- Areas of research and education could include interdisciplinary research and education on the following issues:

- Update data and information systems on water resources studies of national and regional water supply and demand and water balance in the country. Studies of the dynamic relationship between surface and ground water and advances in water resources management through advances in information technologies and GPS and satellite surveys and data gathering.

- Delivery of water services including advances in technologies for irrigation, for water supply and the environmental management of water resources.

- The interaction between advances of irrigation technologies and improvements in crop productivity and field management of agronomy and irrigation delivery systems.

- Water policies and institutions and water laws and regulations.

- Water Quality and utilization. Special attention is needed on water reuse and utilization of waste water in agriculture.

- Water economics and water productivity.

- Water security and the links between water security and food security.

- Water and catchment ecosystems and implications of climate change.

- Water security and management of risks and scarcity of water resources. 
- Impact of climate Change on water and related irrigation systems. Establish operational partnership with interdisciplinary centers for the study of climate change and impact on water and agriculture. The partnership should emphasize the main linkages between climate change, water resources, and agriculture, and the impact of climate change on natural resources and crop productivity. The research and education activities of the Center would provide a forum for interdisciplinary and comparative research and education to better focus on the scientific tools needed to identify and discuss adaptation and mitigation strategies for better management of agriculture including crops and livestock and water natural resources to meet increasing variations in climate patterns related to rainfall and temperature.

- Based on this partnership, the center's research and teaching activities should provide guidance to the policy makers in the finance departments and in the water and agricultural policy makers and other partners locally relevant scientific information needed to improve the understanding of appropriate mix of agricultural practices, policies and market approaches to address the interaction between agriculture and water systems under increasing patterns of climate change in the State.

- Climate variability and water resources and associated hydrology and groundwater recharge and crop productivity: The center would establish a research and education program on the interaction between climate variables and water security and scarcity and impact on agriculture and options for adaptation and mitigation to climate change. Agricultural production depends critically on how climatic variables such as precipitation and temperatures vary across the region and the country over time and space. The effects of climate change on surface and ground water resources and drought occurrence and associated agricultural and pastoral practices occur through changes in water requirements, availability and quality of water for human and livestock and crop production which are affected by both long-term gradual change and extreme events, and across a range of scales from local to regional to continental. Moreover, climate is not only changing but is becoming non-stationary, meaning that expectations can no longer be based only on past observations.

- Mitigation of Green House Gas Emissions: The center would also establish lines of investigation and teaching assessing how SSA agriculture can not only reduce its contribution to greenhouse gases, but serve as a sink that would further mitigate atmospheric accumulations. These types of studies would include process level evaluation of Carbon sequester by different land use patterns and Nitrous oxide by optimized fertilizer management.

- Education: Study and teach the impact of Climate Change on water resources and Farm Level Activities: The Specialized Center would develop research and education programs to help farmers develop strategies and practices to manage the effects of climate change in the short to medium term. These activities would include research and field studies into alternative management and the development of adaptation management practices and techniques to be transferred to the farming communities through extension and training projects.

- Study Sustainable resilient pastoral and farming practices under increasing risks to water security and scarcity: The outcomes of these activities would focus on: 
Measure to adapt to the unavoidable impacts of climate change, field studies of potential opportunities to promote the development of sustainable and resilient production systems such as adaptation actions such as increasing soil moisture and fertility or genetic improvement of crops and livestock. Other adaptation actions may only become applicable in the future, depending on the degree of climate change. For example, changing cereal varieties and planting windows could be effective adaptation strategies.

- Capacity building and training: Improve data knowledge of climate change in local communities: The center would also develop research and training programs to study local climate projections across the State to support production systems models. These models could increase understanding of risks associated with the projected impacts of climate change and can be used to help farmers and other land managers make more informed decisions to better manage these risks. 
